\title{
Ground-notations Estrategias de enraizamiento en la obra de Alison y Peter Smithson
}

\section{David Casino}

Tesis doctoral. 2017

ETSAM Universidad Politécnica de Madrid 



\section{Ground-notations Estrategias de enraizamiento en la obra de Alison y Peter Smithson}

\section{David Casino}

\section{Arquitecto}

Directoras: $\quad$ Tesis Doctoral, 2017

Ma José Aranguren | Emilia Hernández-Pezzi

Departamento de Proyectos Arquitectónicos de la Escuela Técnica Superior de Arquitectura ETSAM. Universidad Politécnica de Madrid 

Tribunal nombrado por el Mgfco. Y Excmo. Sr. Rector de la Universidad Politécnica de Madrid, el día

Presidente D.

Vocal D.

Vocal D.

Vocal D.

Secretario D.

Realizado el acto de defensa y lectura de Tesis el día en la Escuela Técnica Superior de Arquitectura de Madrid

Calificación:

EL PRESIDENTE

LOS VOCALES

EL SECRETARIO 

a Vanesa, Emma y Adriana 



\section{Agradecimientos}

A mis dos directoras: a Milla Hernández-Pezzi, con quien inicié este recorrido por la obra de los Smithson, por su apoyo en todo momento, su rigor intelectual y sus consejos siempre acertados; y a María José Aranguren, por la confianza plena en este trabajo, su empuje para llevarlo a cabo y por descubrir junto a ella el paisaje de Inglaterra.

Max Risselada merece un agradecimiento especial por la ilusión mostrada en esta investigación desde los inicios, sus agudas observaciones y todo el conocimiento que me trasmitió durante mi estancia en la $T U$ Delft. Simon y Soraya Smithson han sido claves para esta tesis: a ellos les agradezco su enorme generosidad por haberme abierto, además de los archivos familiares, su casa.

A Alejandro Klimowitz y a Francisco López por la colaboración en los los dibujos; y a Luisa Rodríguez-Gimeno Wiggin por las traducciones.

A mi socio y amigo Bernardo Angelini, por su complicidad y su ayuda incondicional; a Juan, Óscar, Jorge y Mónica por estar siempre ahí; a mi madre y hermanos por su gran apoyo, y en especial a Gonzalo, por su comentarios críticos y valiosos consejos. Y por último, a Vanesa, Emma y Adriana, porque sin ellas esto no hubiera sido posible. 



\section{Resumen}

Esta investigación pone en valor el trabajo con el plano del suelo como un tema esencial en la arquitectura de Alison y Peter Smithson. El estudio de este aspecto concreto de su obra revela que los Smithson desarrollaron un "pensamiento topográfico" propio, consistente en una particular destreza para definir la implantación de sus edificios mediante la manipulación de la sección del terreno. A través de una intensa experimentación con el territorio, este instinto operativo que subyace latente en el conjunto de sus proyectos, da lugar a un entendimiento personal del suelo, como un soporte configurable topográficamente, susceptible de ser modelado mediante marcas e incisiones y capaz de definir un estrato de mediación entre la arquitectura y el contexto.

La atracción de los Smithson por la configuración artificial del territorio impulsaría el desarrollo de sus estrategias de enraizamiento: aquellas que desde la apropiación de ciertas huellas del paisaje autóctono alentaron todo un conjunto de formas de articulación y contacto con el suelo, favoreciendo, a través de la consideración del contexto y la disposición de los espacios exteriores, la creación de una intencionada conexión con el emplazamiento. Las operaciones fundamentales de estas estrategias — las ground-notations — constituyen el objeto principal este trabajo, desplegado a partir del análisis de una extensa documentación inédita, procedente de los archivos de la familia Smithson; un material de carácter personal que aporta datos reveladores de los intereses y las fuentes de inspiración de estos arquitectos. El "libro de recortes" de Alison Smithson - The Big Scrapbook - constituye un hallazgo esencial en esta investigación, no sólo por su valor documental intrínseco, sino también, por la relación que establece esta técnica de montaje con las estrategias de enraizamiento llevadas a cabo mediante acciones de yuxtaposición.

La tesis se estructura en dos partes. La primera, compuesta por los tres primeros capítulos Exploraciones, Apropiaciones e Incursiones - analiza el alcance del territorio en la formación de las estrategias de enraizamiento, mostrando cómo éstas se originan mediante singulares procesos de apropiación: fragmentos del paisaje capturados, transformados y despojados de su función original son la génesis de las ground-notations. Esta primera parte del trabajo incluye el estudio de los viajes de los Smithson realizados, durante más de 25 años, por diferentes lugares del clasicismo griego y romano: una profunda incursión en el mundo antiguo que fortaleció su convicción en una arquitectura íntimamente ligada a las condiciones específicas del paisaje y su topografía. The Antholoy of Classical Sites — un trabajo no publicado, realizado por Alison Smithson en los años finales de su trayectoria- contiene las conclusiones de aquellas exploraciones por el Mediterráneo, reflejando, de manera explícita, su fascinación por el "sentido del emplazamiento topográfico".

La segunda parte de la tesis comprende el estudio específico de las ground-notations en el conjunto de la obra de los Smithson. A través de 6 capítulos, estas tácticas proyectuales son analizadas atendiendo a los movimientos de tierra que las originan y los efectos de enraizamiento que desencadenan. Su investigación revela cómo trabajan desde una noción contemporánea de "lo pintoresco" que retoma las técnicas y principios enunciados en la segunda mitad del siglo XVIII, demostrando la decisiva influencia que ejerció la tradición inglesa trabajo con el territorio en la obra de los Smithson. 



\section{Abstract}

This research work claims for the use of the ground plane level as an essential topic in the architecture of Alison and Peter Smithson. The specific study of this concrete aspect of their work reveals that the Smithson's developed a topographical thinking of their own, which consists of a particular ability to define the allocation of their buildings by altering the terrain section. Thanks to an intense experimentation of the territory, this operative instinct that underlays latent throughout all their projects gives rise to a personal understanding of the ground as a support topographically configurable and subject to be shaped by notches and incisions with the aim of defining a mediating layer between the architecture and its context.

The attraction of the Smithson's by the processes of artificial configuration of the territory would boost the development of their grounding strategies: those that from the appropriation of certain artificial shapes of the local landscape, encouraged a whole set of means of contacting and articulating the ground while they stimulated the appearance of an intentional connectivity with the site by considering the context and the configuration of outdoor spaces. The fundamental operations of these strategies - the ground notations - constitute the main subject of this work that has been developed on the basis of the analysis of extensive unpublished documentation from the archives of the Smithson family. Such a personal material provides revealing information of their interests and their sources of inspiration. The discovery of The Big Scrapbook by Alison Smithson constitutes an essential finding for this research work, not only because of its documentary value but above all for its capacity to establish relationships with the grounding processes, through the techniques of assembly and juxtaposition of fragments.

The thesis is structured in two parts. The first one, consisting of the three first chapters Explorations, Appropriations and Incursions - analyses the influence of the territory in the development of the ground strategies. Those are originated through appropriation processes: fragments of the landscape that are captured, transformed and stripped of their original function are on the genesis of ground-notations. This first part of the work includes the Smithson's searches in the Ancient World, an exploration carried out for more than 25 years in different places of the Mediterranean that strengthened its conviction in an architecture closely linked to the specific conditions of the topography, by considering the ground as an a stratum of opportunity, capable of provoking the rise of precise links between the buildings and the place where they are located. The Anthology of Classical Sites, an unpublished work of Alison Smithson found within her personal files, confirms the influence of, as well as explicitly disclosures their fascination for, the "instinctive sense of placement".

The second part of this Thesis, formed by six chapters, comprises the study of groundnotations through the recognition and analysis of these project tools in the whole set of projects of Alison and Peter Smithson. These operations are analyzed in their projects, being classified according to the type of earth moving that causes them and interpreted as the result of a concrete operation of appropriation of the landscape. The grounding effects that those operations trigger are analysed, as are the mechanisms of contact between buildings and soil and between the topographical setting limits and the surface of the site. These analysis reveal how the ground-notations work from a contemporary notion of "the picturesque" that returns to its techniques and principles and which demonstrates the decisive influence of the English tradition of working with the territory in the architecture of Alison and Peter Smithson. 

Índice 



\section{Índice general}

Introducción La recuperación del suelo

Primera Parte. La formación de un "pensamiento topográfico"

1. Exploraciones. El conocimiento del territorio: colecciones, fotografías aéreas y montajes.

2. Apropiaciones. La interiorización del paisaje autóctono.

3. Incursiones. La asimilación del mundo antiguo: viajes al Mediterráneo, 1951-1979

Segunda Parte. Ground-notations: tácticas de configuración del plano del suelo

4. Ha-has

5. Moats and ditches

6. Earthwork terraces

7. Bunds

8. Mounds and bumps

9. Trees and hedgerows

Conclusiones Conclusions

Bibliografía

Anexo 1: textos inéditos

Anexo 2: Smithsons' Territory (*) 



\section{Índice desglosado}

Introducción. La recuperación del suelo $\quad 13$

Objetivo de estudio y justificación.

Estado de la cuestión. Fuentes directas.

Estado de la cuestión. Fuentes indirectas.

Objetivos e hipótesis.

Método.

The Hutte: los archivos de la familia Smithson

Entrevistas.

Viajes y visitas

Revisión teórica y bibliográfica.

Análisis gráfico.

Estructura.

Primera Parte. La formación de un "pensamiento topográfico"

Experiencias previas.

Principios pintorescos.

Topografías de posguerra.

1. Exploraciones. El conocimiento del territorio: colecciones, fotografías aéreas y montajes

1.1. Mapas, fotografías y trabajo de campo.

Diapositivas y álbumes fotográficos.

Mapas y trabajo de campo.

Folletos, guías. y otros recortes.

1.2. Imágenes aéreas: la incorporación de un nuevo punto de vista.

Archivos y fuentes de imágenes aéreas.

1.3.Técnicas de montaje. The Big Scrapbook.

El "libro de recortes"de Alison Smithson.

Imágenes yuxtapuestas.

2. Apropiaciones. La interiorización del paisaje autóctono

2.1 Huellas y topografías defensivas del Limes

Enraizamiento y topografía en Robin Hood Gardens.

La huella de los milecastles.

2.2 Patrones de muros primitivos en Yorkshire Dales.

La exploración de los field walls.

La huella de Steilshoop.

Los pasajes de Worcester. 
2.3 Asentamientos vernáculos en la costa de North Yorkshire Moors

Riding the landscape.

Los miradores de Whitby.

2.4 Ruinas medievales en North Yorkshire

Ocupación del territorio.

Enmarcar el paisaje.

El vacío de Mount Grace Priory.

Fortificaciones.

3. Incursiones. La asimilación del mundo antiguo: viajes al Mediterráneo, 1951-1979

3.1 Primeros viajes. Grecia, 1951 y 1958.

There is no Greek Space. Vacío e intervalo.

Interacción con el paisaje. La interpretación de Scully.

3.2 The Siting of Buildings: una investigación sobre el emplazamiento topográfico.

La exposición de fotografías.

The Anthology of Classical Sites.

\section{Segunda Parte. Ground-notations: tácticas de configuración del plano del suelo}

4.1 La experiencia de Seaton Delaval.

4.2 Transposición de la tradición inglesa.

4.3 Límite defensivo.

\section{Moats and ditches}

5.1 El vacío de Gray's Inn

5.2 Robin Hood Gardens: una interpretación desde los Limites Romani

\section{Earthwork terraces}

6.1 Un suelo de color herrumbre

6.2 Paseo Pintoresco en Brasilia

6.3 Basamento vegetal en el Garden Building

\section{Bunds}

7.1 Topografías primitivas en Golden Lane

7.2 Enraizamiento en la casa Bates

$7.3 \mathrm{El}$ anillo de Figsbury

7.4 El bund de Upper Lawn

\section{Mounds and bumps}

8.1 La apropiación de Silbury Hill.

8.2 Efectos de paralaje.

8.3 Estrategias de recuperación del paisaje. $\quad 339$ 
9.1 Dibujando árboles. Reelaboraciones de proyectos a partir de la década de 1970.

9.2 Pantallas verdes en Ringolds Way.

9.3 La configuración del límite en el concurso de Hunstanton. 355

9.4 "Cinturones" de setos.

Conclusiones Conclusions $\quad 358$

$\begin{array}{ll}\text { Bibliografía } & 376\end{array}$

$\begin{array}{ll}\text { Bibliografía general } & 378\end{array}$

Bibliografía específica $\quad 384$

Libros y artículos de A\&P Smithson

Textos críticos sobre A\&P Smithson

Bibliografía sobre Paisaje y territorio

$\begin{array}{ll}\text { Bibliografía. Otros } & 403\end{array}$

Tesis doctorales

Documentos no publicados/inéditos

Entrevistas realizadas

Archivos y fuentes documentales

$\begin{array}{ll}\text { Anexo 1: textos inéditos } & 407\end{array}$

The Siting of Buildings 408

Propectus (1977)

The Wit's Anthology of Classical Sites (1990)

Speaking to the Sky (1987)

Collective Design Sensibility Primers

Collective Design Sensibility Primers (Fragmentos)

Interpretations of Q.F.K. (Fragmentos)

1916 A.S.O. (Fragmentos de textos)

A.S, in D.S. (Fragmentos de textos)

Anexo 2: Smithsons' Territory $\left(^{*}\right)$ 
La recuperación del plano del suelo 


\section{Introducción}




\section{La recuperación del suelo}

En 1993, Alison y Peter Smithson publicaban Shifting the Track ${ }^{1}$, un revelador artículo acerca de uno de los temas clave en su obra: el vínculo entre la arquitectura y el territorio. El texto comenzaba con una rotunda afirmación: "Las condiciones topográficas de un territorio tienen el poder de dar sentido a lo que se coloca encima"2; un argumento apoyado en una serie de ejemplos conocidos en los que fácilmente podía percibirse cómo la singularidad del relieve del suelo determinaba la implantación de los edificios. El trazado de las calles de Siena, siguiendo la topografía de la ciudad, o las casas de Simla, estratégicamente ancladas a la pendiente, eran, sin duda, demostraciones de una intencionada respuesta a las condiciones específicas del lugar.

Esta convicción en la capacidad del plano del suelo de estructurar los asentamientos humanos, con la que Alison y Peter Smithson iniciaban este artículo, estaba apoyaba en su propia experiencia, en una aguda percepción del territorio del norte de Inglaterra, de donde ambos procedían ${ }^{3}$. Las numerosas marcas topográficas - huellas de civilizaciones pasadas - que configuraban aquel paisaje fueron entendidas por los Smithson desde su condición más operativa, asimilándolas como instrumentos capaces de ordenar el territorio:

"(...) en la parte de Inglaterra donde crecimos, los patrones formados en la tierra por las vallas de piedra, junto con los hitos que delimitan el territorio y las fortificaciones de tiempos pretéritos, nos sobrecogen...Es la capacidad de estas formaciones de tierra hechas por el hombre, de ejercer su influencia a lo largo del tiempo, de persistir en la tierra e influenciar lo que en ella se coloca... lo que hace que sea tan irresistible la idea de usar estas 'notaciones de suelo' como dispositivos estructuradores".4

1. SMITHSON, Alison and Peter. "Shifting the Track", en Italian Thoughts, Stockholm, 1993, p.86-91. Este texto fue realizado en 1989 con motivo de los talleres ILA\&UD (Laboratorio Internacional de Arquitectura y Urbanismo, fundado en Urbino por Giancarlo De Carlo en la década de 1970) e incluido en su anuario.

2. Ibid., p.86

3. Peter Smithson nació en 1923 en Stockton-on-Tess (Newcastle upon Tyne). Alison Gill nació en 1928 en Sheffield, y estuvo viviendo en South Shields, una población costera de Newcastle, también cercana a Stockton-on-Tess. Ambos estudiaron en la Escuela de Arquitectura de la Universidad de Durham, ubicada en Newcastle hasta principios de 1960. Tras la finalización de sus estudios, los Smithson se trasladaron a vivir a Londres, en donde establecieron su despacho profesional en 1949. Véase, entre otros: COLOMINA, Beatriz. "Amigos del Futuro: una conversación con Peter Smithson", en Doble Exposición. Arquitectura a través del arte. Akal, Madrid, 2006.

4. SMITHSON, Alison and Peter, op. cit. p. 86,87

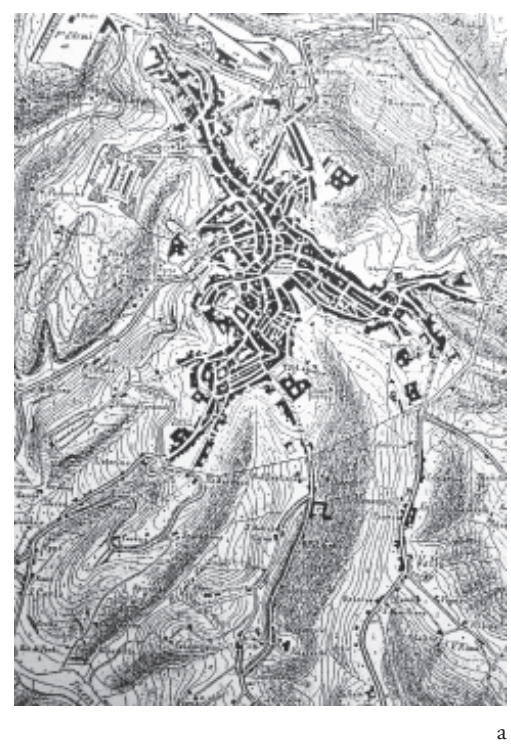

a. Siena: “(..) houses strung along ridgetop streets making a seemingly large city of thin threads". A\&PS: Italian Thoughts. 


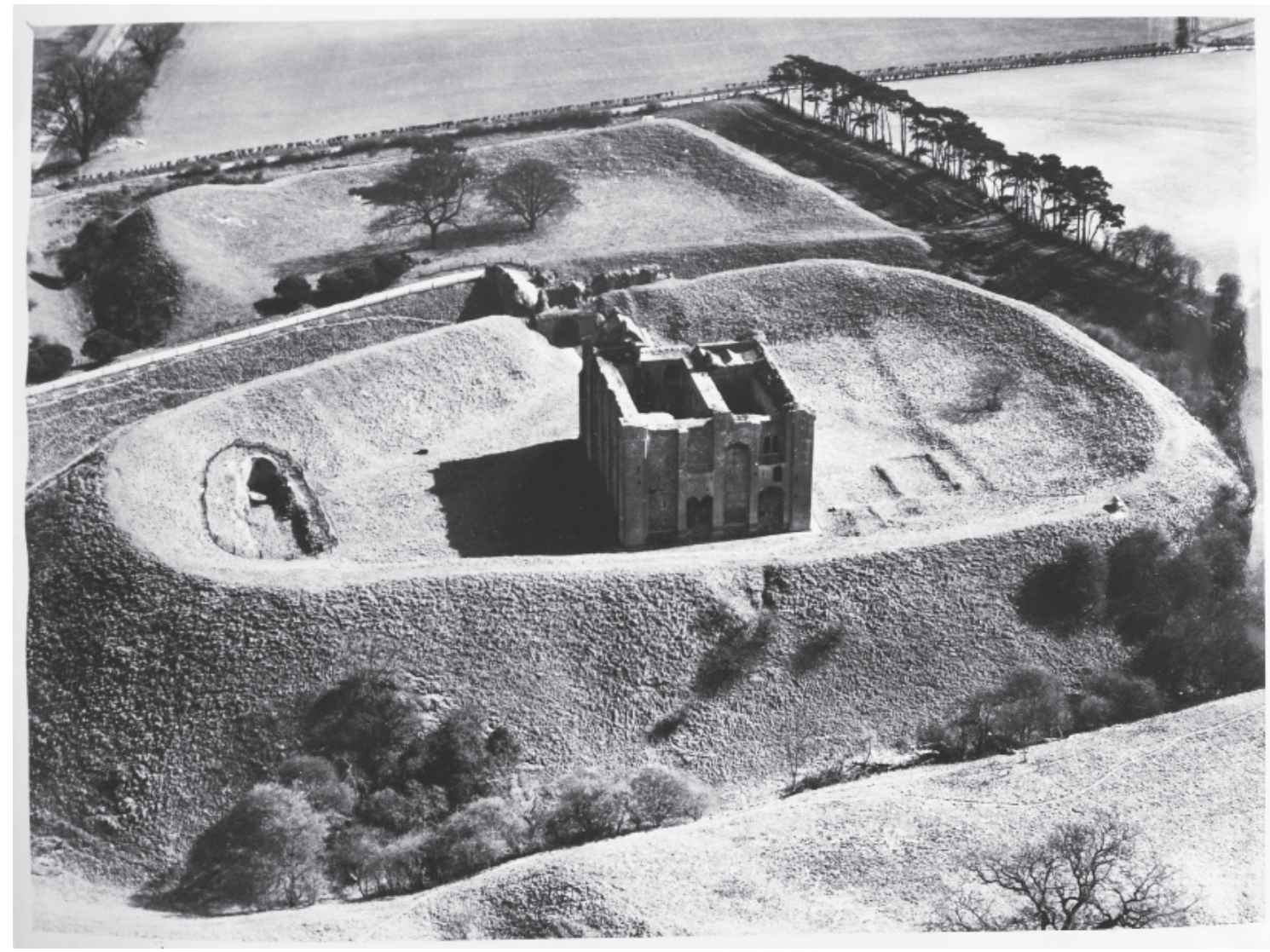

Castle Rising, Norfolk. Man-made ground forms Aerofilms Limited

Smithson Family Collection 
Para ilustrar estos recuerdos, los Smithson incluyeron junto al texto tres evocadoras imágenes: la primera de ellas era una fotografía aérea de Maiden Castle, una fortificación de origen neolítico cuyo perímetro se configuraba mediante alteraciones del terreno, generando tres anillos defensivos de profundos fosos y terraplenes; la segunda, una imagen de Castle Rising, un castillo del siglo XII erigido sobre un singular movimiento de tierras que protegía mediante su forma envolvente los restos de aquella construcción medieval; y, la tercera, una fotografía tomada por el propio Peter Smithson de uno de los valles Yorkshire Dales, completamente cubierto de nieve y del que sobresalía un sorprendente patrón de líneas negras: la coronación de los muros de piedra a junta seca que, desde épocas primitivas, habían servido para delimitar aquellos terrenos en pendiente.

Los Smithson, fascinados por estos vestigios de épocas remotas, cuyas formas depuradas por el paso del tiempo y su admirable entendimiento de la topografía los convertían en artificios que formaban parte indisoluble del paisaje, plantearon la posibilidad de tomarlos como referencia, apropiándose de su habilidad para dialogar con el territorio. Así, con la intención de hacer de la manipulación de la tierra una poderosa herramienta, capaz de configurar una arquitectura igualmente integrada en su emplazamiento, formulaban la siguiente pregunta:

"¿Podría ser que, actuando del mismo modo que las enérgicas formaciones de tierra existentes en el paisaje, nos inventáramos y construyéramos 'notaciones de suelo' para poder, de un modo análogo, dar sentido a los asentamientos humanos desestructurados y sin intención?"5

Fijándose en las numerosas trazas que desde tiempos remotos habían estructurado el territorio ${ }^{6}$, los Smithson propusieron a continuación una serie de acciones con las que intervenir en la tierra. Peter Smithson las plasmó gráficamente en un pequeño dibujo: un croquis realizado en un trozo de papel del estudio en el que esbozó, mediante trazos muy sencillos, un conjunto de operaciones esenciales; ${ }^{7}$ una serie de ideogramas que acompañados de una palabra clave conformaban un valioso catálogo de herramientas proyectuales: "el léxico de las ground-notations".

Los Smithson, en los numerosos artículos que escribieron, pocas veces incluyeron una explicación detallada de sus obras. Sus textos constituían una sugerente exposición de sus ideas o conceptos,

5. Ibid., p.87

6. En Shifting the Track, Alison y Peter Smithson incluyen un listado de 'marcas' del territorio que estructuran su superficie: mounds, terracing, bunds, earth boundaries, ditches, earth fortifications; rides, clearings, tree screens, field hedges, field walls; tracks, roads, canals, railways, motorways, landing strips.

7. En este dibujo de Peter Smithson podemos leer el nombre de las siguientes 'notaciones': Bumps, waves, water sytems, grooves, bunds, walls, bushes, hedges, screes.

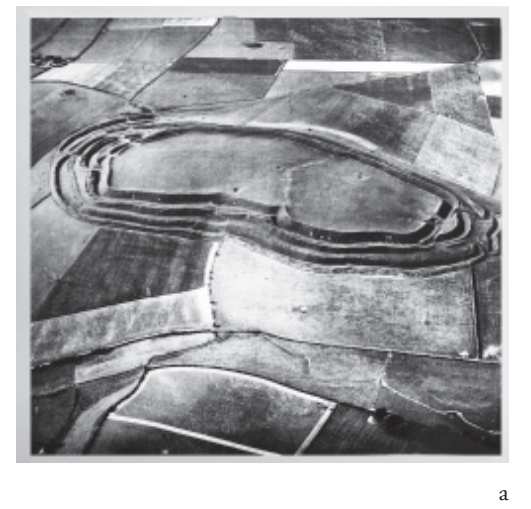

a 


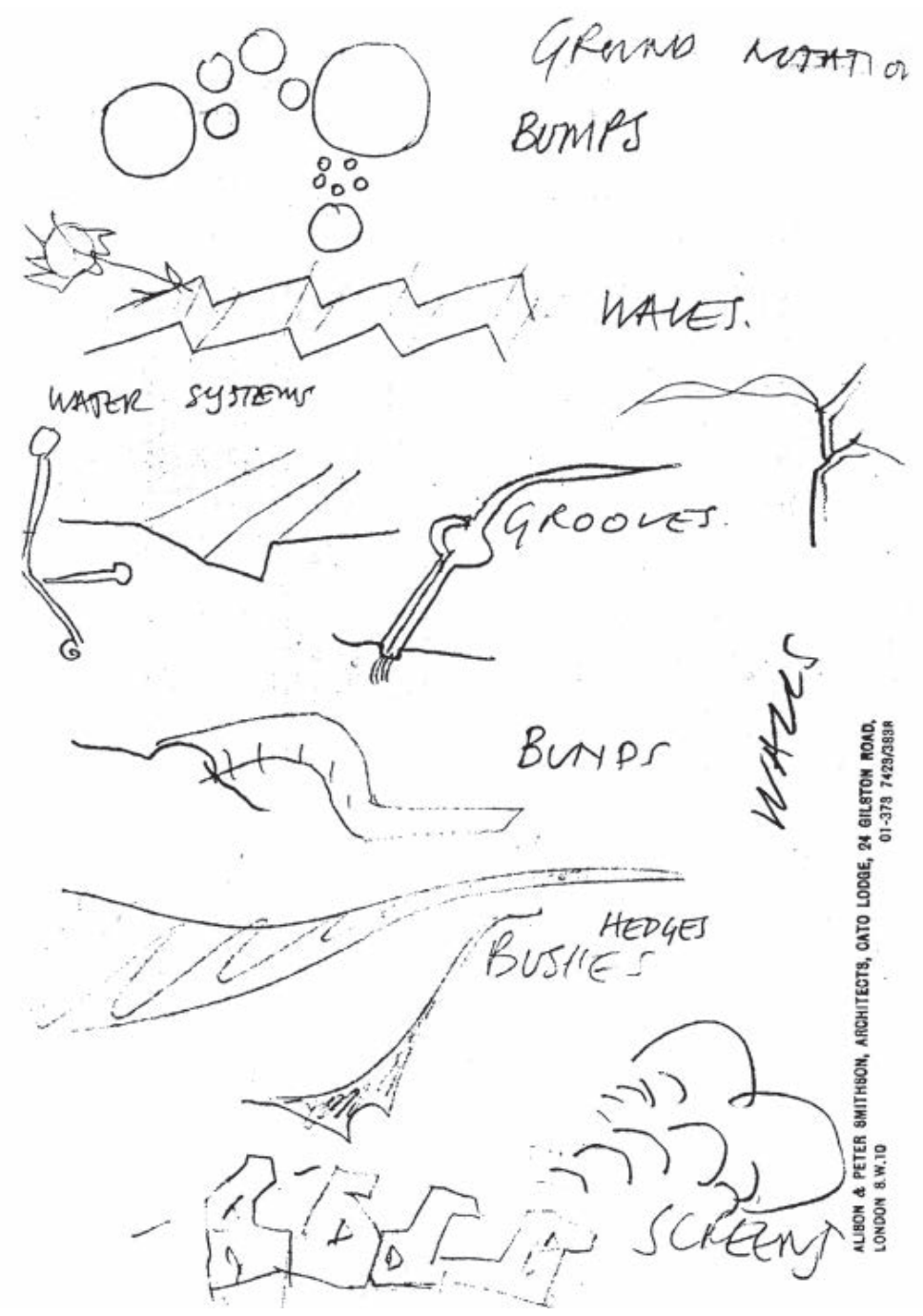


tratados de manera independiente a los proyectos; los escritos discurrían, por tanto, de manera paralela a sus edificios, dejando un intencionado vacío - un espacio intermedio- que, como afirmaba Max Risselada, suscitaba la aparición de múltiples interpretaciones e hipótesis sobre su obra ${ }^{8}$. En este sentido, Shifting the Track no resultaba una excepción. La respuesta a la excitante propuesta de los Smithson de intervenir en los proyectos manipulando el suelo no se encontraba en el posterior desarrollo del artículo. Apenas la muestra de dos de los últimos proyectos realizados por los Smithson, "San Miniato Park" y "Ansty Plum Ramp" -ambos de finales de la década de 1980 y no demasiado significativos en el conjunto de su obra- arrojaba algo de luz sobre del verdadero alcance de las groundnotations.

Sin embargo, a pesar de la ausencia de otros ejemplos más relevantes, capaces de explicar mejor estos instrumentos proyectuales, Shifting the Track poseía una enorme relevancia. En contra de lo que parecía adelantarnos el significado de su insinuante título -cambio de pista o cambio de trayectoria-, el artículo no planteaba ningún giro drástico en el pensamiento de los Smithson, sino más bien, la revelación de una 'vieja táctica' de estos arquitectos para configurar la implantación de los edificios, basada en la utilización de formas del paisaje; una estrategia que, pese a haber sido desvelada en uno de sus últimos artículos publicados, ya formaba parte sustancial de su pensamiento en su primera obra, la Escuela Secundaria de Hunstanton (1949-54), en la que los Smithson se apropiaron de una huella del paisaje autóctono para configurar el límite del proyecto. La verdadera importancia de Shifting the Track estaba, por tanto, en su carácter revelador, en mostrar por primera vez de manera evidente esta estrategia, una de las más significativas y menos analizada de Alison y Peter Smithson, que denominaremos enraizamiento: aquella que desde la apropiación de ciertas formas artificiales del paisaje autóctono alentó todo un conjunto de formas de contacto y articulación con el suelo, favoreciendo, a través de la consideración del contexto y la configuración de los espacios exteriores, la aparición de una conexión intencionada con el emplazamiento.

Para los Smithson, la búsqueda de una arquitectura enraizada, capaz de radicar' (del latín radicare: echar raíces, enraizar) en el lugar fue un asunto crucial a lo largo de su obra. En sus inicios, en la década de 1950, emplearon el término "enraizamiento" para alertar del carácter autónomo y desconectado del suelo que poseía la arquitectura

8. RISSELADA, Max. "The Space Between-Re-arrangements. A Smithsons Celebration». OASE, junio de 1999

9. "La arquitectura está marcada por su radicación a un lugar y su definitiva pertenencia a él". MARTI ARIS, Carlos. Las variaciones de la identidad. Barcelona, Colegio de Arquitectos de Cataluña, 1993.
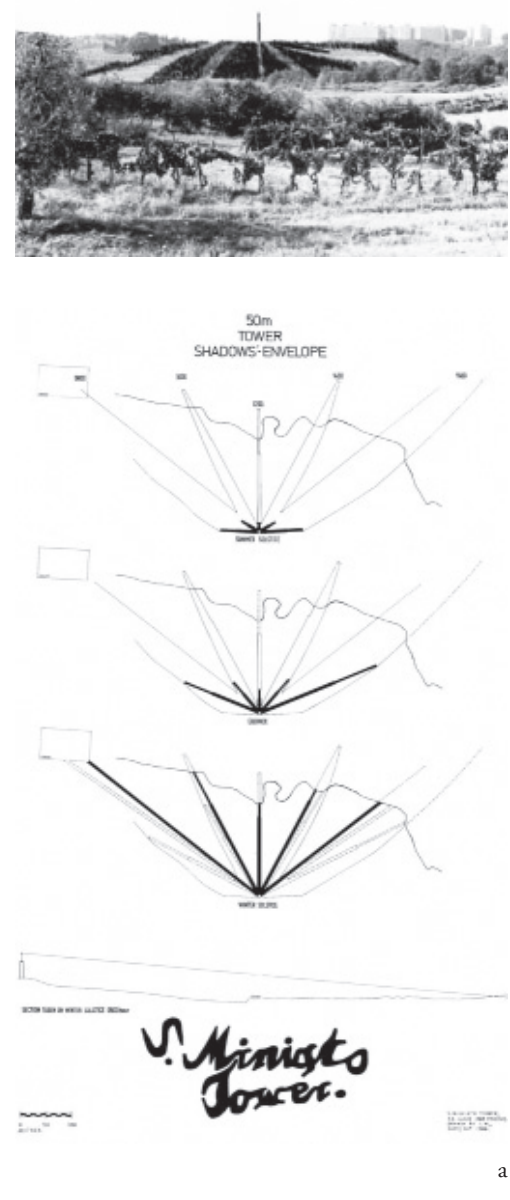

a. San Miniato: gnomon casting morning shadow into a 'shadow envelope' on the billside opposite the suburb of $S$. Miniato, Siena. Photomontage: L.W. and P.S. November 1988 | Shadow envelopes diagram. Study of 'shadow envelopes' in a tree plantation to contain the shadow of a tower acting as a gnomon. Drawing: L.W. 1988. 

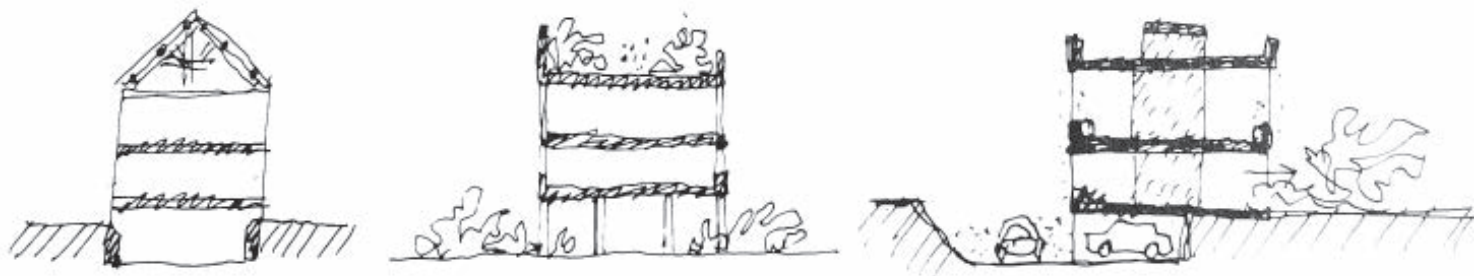

Place-connected; place establishing

Peter Smithson, 1974 
moderna, su herencia directa ${ }^{10}$. Los Smithson la calificaron como "altamente abstracta en su interpretación de las actividades humanas, completa en sí misma, suspendida en el aire y no enraizada a su emplazamiento": ${ }^{11}$ una afilada crítica del mecanicismo moderno que apuntaba su condición objetual ${ }^{12}$ y su ausencia de contacto con el suelo como causas principales de su desconexión con el lugar y las actividades humanas. Los Smithson consideraron que esta falta de cohesión con la tierra lastraba definitivamente ciertas propuestas modernas convirtiéndolas en máquinas para habitar flotando sobre un suelo olvidado: "No hay razones humanas para estar elevado en el aire, ni hay ninguna ventaja para permanecer despegado del suelo (como el extrańo concepto "flotando en un mar de verdor", de la Ville Radieuse de Le Corbusier)"13, argumentaron los Smithson en una radical defensa del enraizamiento. ${ }^{14}$

Superar esa dicotomía entre lo construido y el lugar, ${ }^{15}$ tan explícita en los pilotis lecorbuserianos, suponía para los Smithson modificar sustancialmente el esquema estratificado impuesto por sus maestros y la radical separación moderna entre objeto y paisaje ${ }^{16}$ : el edificio elevado debía volver a descansar sobre el suelo, y el jardín moderno, que hasta entonces reposaba autista sobre las cubiertas, descender hasta tocar la tierra, situándose en contacto directo con los espacios habitables del edificio. Mediante esta nueva adherencia al terreno, ${ }^{17}$ el plano del suelo se convertía en un elemento clave del proyecto: su superficie, ocupada estratégicamente, se configuraba a través de huellas quebradas, retorcidas, dobladas o fragmentadas, capaces

10. "This Heroic Period of Modern Architecture is the rock on which stand. Through it we feel the continuity of history and the necessity of achieving our own idea of order" SMITHSON Alison and Peter. The Heroic Period of Modern Architecture. Rizzoli, Nueva York,1981.p.5.

11. "Essentially a 'Modern Architecture' (...) was posied, not rooted to its site"A\&PS: SMITHSON, Peter, "Talks to Young Architects", published in the Architects' Journal, may 21st, 1959; incluido en el artículo "On Modern Architecture", publicado en: Ibid.,p.9

12. Rafael Moneo reflexionaba el carácter autónomo y "la condición objetual que reclamaba para sí la arquitectura moderna", que "ve lo que se construye con una autonomía que permite hablar de los edificios como entes con vida propia”. MONEO, Rafael. «La otra modernidad». Revista de Arquitectura y ciudad. Ediciones del Círculo de Bellas Artes, Madrid, 2007.

13. "Sources of anxiety in flat dwellings". SMITHSON, Alison and Peter. "Criteria for Mass Housing». Architectural Design, septiembre de 1967.

14. "La arquitectura del 'primer Le Corbusier', a pesar de su creatividad indiscutible, y de su asimilación positiva de la herencia del pasado, no cumple con una condición imprescindible: la construcción del lugar -con los sacrificios que ello conlleva-, lo que proporciona a sus casas un carácter de objeto, de artefacto alejado en el fondo de lo estrictamente arquitectónico" LINAZASORO, José Ignacio, La memoria del orden. Paradojas del sentido de la arquitectura moderna, Adaba, Madrid, 2013, p.90.

15. MONEO, Rafael. Inquietud teórica y estrategia proyectual en la obra de ocho arquitectos contemporáneos. Actar: Barcelona, 2004, p.15.

16. MONEO, Rafael. «La otra modernidad». Op.cit. p.48

17. Sedlmyr señalaba la ausencia de relación entre la arquitectura moderna y el plano del suelo, aludiendo a una falta de posición y contacto con el terreno: "la falta de todo intercambio orgánico entre la arquitectura y el paisaje, de modo que las arquitecturas 'puras' parecen caídas del cielo en medio de la 'pura' naturaleza”. SEDLMYR, Hans. El arte descentrado. Las artes plásticas de los siglos XIX y XX como sintoma y simbolo de la época. Labor, 1958.
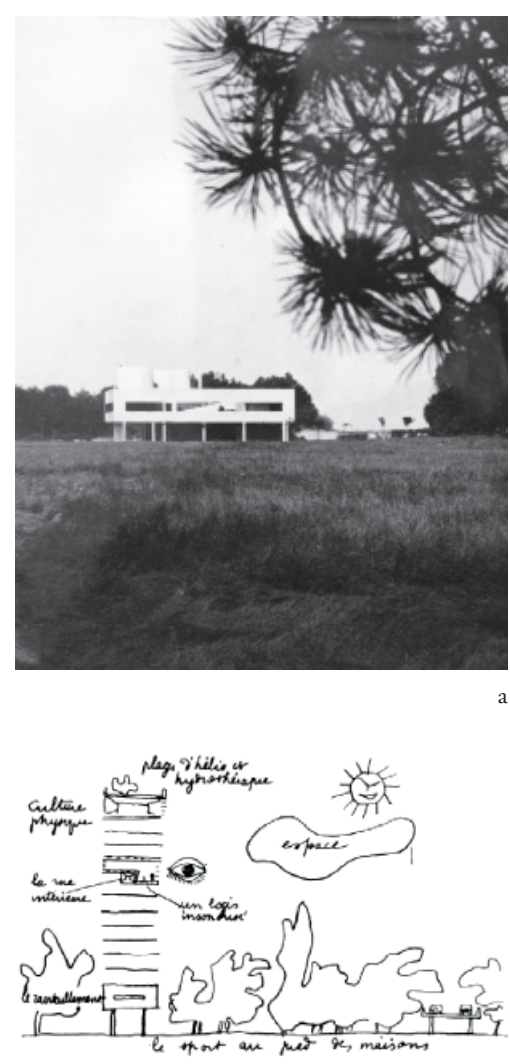

imagen izqda:"The now-accepted genaral base of the architecture at the present time contrasted with that of the Heroic Period: Place-connected; place establishing; Separate domain for vehicular movement, parking \& vehicular servicing (to separate out 'noisy for quiet); garden as quiet place immediately accesible from living space, fragment of a collective structure." PS, Lightness of Touch, 1974

a. Villa Savoye a Poissy, le Corbusier, 1929-1931: "La maison ast un objet posé au-dessus du sol, au milieu du paysage". Photograph: Courtesy Oeuvre Complete 1929-34. Smithson Family Collection.

b. Unidad de Habitación de Marsella, Le Corbusier, 1952. the dwelling". 

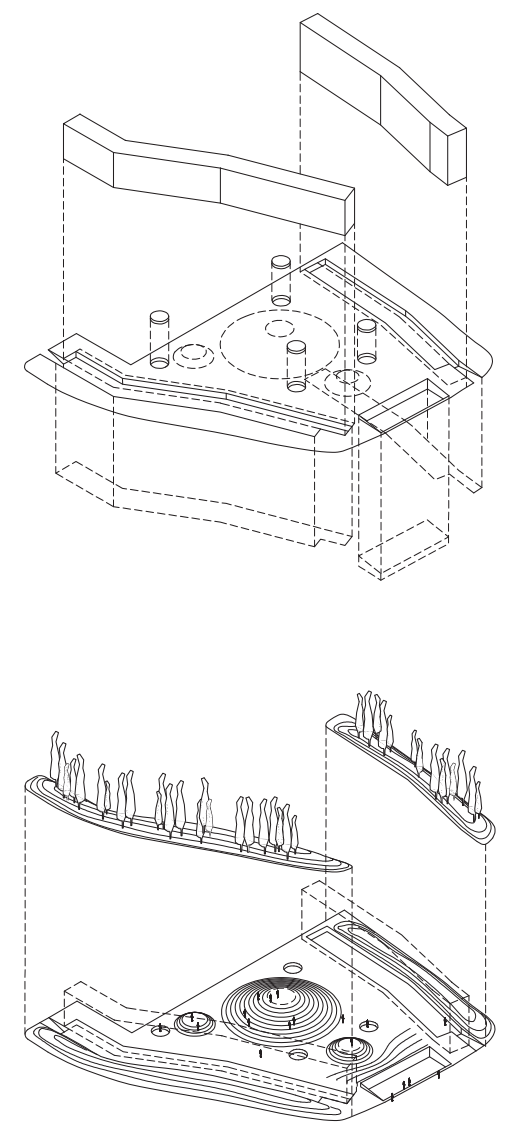

A\&PS. Robin Hood Gardens, 1966-72

Ocupación del suelo y ground-notations Moats, mounds, holes, earthboundaries, tree screens Dibujo del autor 
de atrapar mediante su forma el espacio exterior del proyecto; y su sección se modelaba mediante precisos movimientos de tierra, generando un conjunto de alteraciones topográficas, como zanjas, fosos, hoyos, diques, plataformas, terrazas y montículos. ${ }^{18}$ Estas nuevas configuraciones del suelo que surgían de manipular su propia materia -cavando, amontonando, removiendo o desplazando la tierra- no eran otras que las ground notations: adaptaciones de aquel catálogo de "notaciones del suelo" recuperado por los Smithson al final de su trayectoria, tal vez en un intento personal por no dejar olvidada una de sus estrategias más decisivas.

Las ground-notations, combinadas entre sí y actuando de manera complementaria, son las operaciones clave del enraizamiento: responsables de gestionar la relación entre la arquitectura y el territorio $^{19}$, definiendo una morfología del suelo capaz de responder, tanto a las necesidades programáticas como a la intención de fortalecer y reprogramar el lugar en donde se inserta. Estas tácticas proyectuales surgen -como insinuaban los Smithson en Shifting the Track- de la apropiación del paisaje autóctono, de la captura de sus marcas prehistóricas o medievales, como huellas de asentamientos o límites primitivos; pero también, de otros mecanismos relevantes de transformación del paisaje, como algunas de las técnicas topográficas empleadas por primera vez por los jardineros ingleses del siglo XVIII. ${ }^{20}$

Los Smithson se fijaron en estos artificios del paisaje por su destacada capacidad para configurar el territorio sin necesidad de recurrir a la "construcción". Aprovechar las huellas del paisaje autóctono como modelos reales de los que extraer su esencia topográfica suponía un intento de rescatar valores de la tradición y la cultura popular inglesa, así como de revitalizar el vínculo con la naturaleza. Además, su condición primitiva y vernácula encajaban a la perfección dentro del clima cultural y artístico de posguerra. La atracción que sentían los Smithson por estas manipulaciones del suelo estaba motivada no sólo por sus relevantes valores intrínsecos, como operaciones capaces de estructurar y dar sentido a al territorio, sino también por el vínculo particular con sus propias biografías, lo que las convertía en

18. En "Lightness of Touch" (1974) Peter Smithson proponía nuevas condiciones de la arquitectura en contraposición con las establecidas en la arquitectura 'moderna' del Periodo Heroico. Entre ellas, el contacto con el suelo quedaba reflejado mediante una serie de dibujos en los que comparaba los "cinco puntos" de Le Corbusier con "la base de la arquitectura del tiempo presente", y en los que se podía apreciar una renovada atención al plano del suelo ("place-connected"; "place-establishing") y a los espacios exteriores: "garden as quiet place immediately accesible from living spaces". SMITHSON, Peter. "Collective Design : Lightness of Touch». Architectural design v. 44, n. 6, p. 377-378, junio de 1974.

19. "(...) durante el segundo periodo, ha ido en aumento la conciencia de que la intervención del edificio en la configuración del territorio y la configuración espacial de éste deben ocupar el centro de nuestra obra". SMITHSON, Peter, Introducción, en: VIDOTTO, Marco, $A+P$ Smithson. Obras y Proyectos.

20. "Usar las formas existentes, he aquí una actividad que no es ninguna novedad (...) es evidente que usar las formas equivale a recurrir a la Historia, volver a darle vida, trazar una línea desde el 'producto' obtenido hasta su o sus modelos históricos". BOURRIAUD, Nicolas, Radicante, Adriana Hidalgo editora, 2009, p.170.
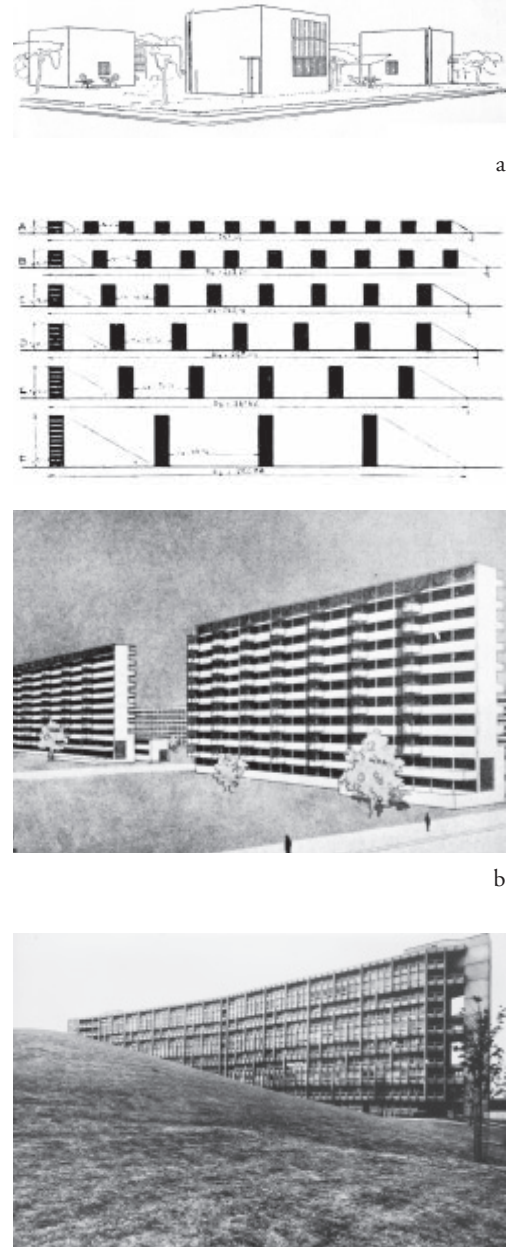

a. Houses in series for workers (Le Corbusier, 1924) muestra una serie de volúmenes cúbicos y abstractos "arrojados" sobre el plano del suelo: máquinas dispuestas en una estricta ordenación funcional sobre un terreno neutro; el contacto con el suelo es directo, sin elementos de transición entre la tierra y el edificio

b. Slab block studies (Gropious, 1931) propone la ocupación del suelo mediante un sistema. El espacio entre los bloques surge de la aplicación de instrucciones. El resultado es la absoluta disociación entre el suelo y los edificio.

c. A\&PS. Robin Hood Gardens (196672). "we felt that the sense of beloging could be helped by giving to the dwelling a piece of inviolate territory: a yard, a garden contained by the dwelling, a compound that contained the dwelling". 


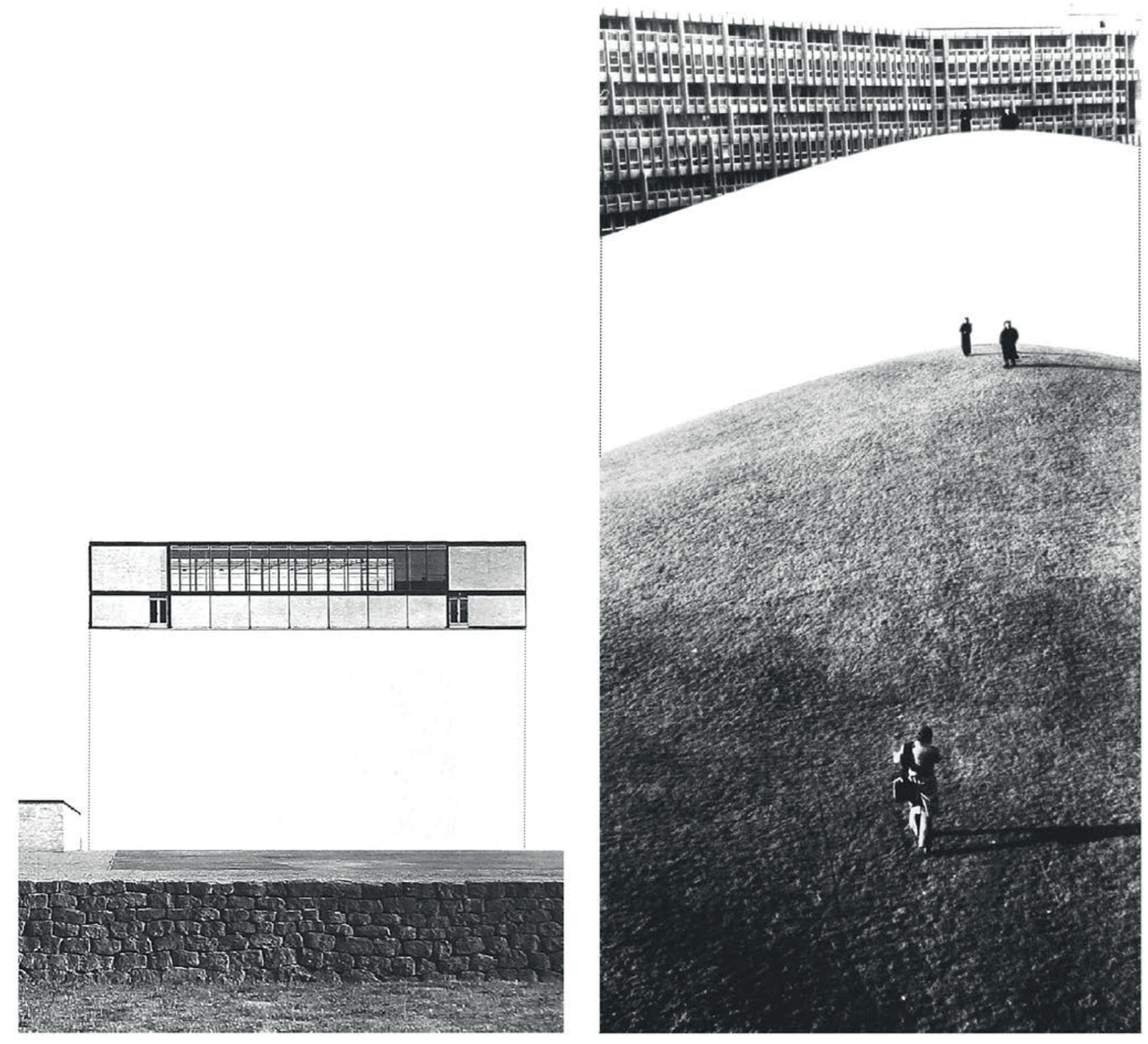

Estrategias de enraizamiento mediante ground-notations Montaje del autor 
fragmentos de paisaje cercanos a sus vidas dotados de un significado especial.

Las marcas del territorio formaban, por tanto, parte de sus recuerdos, y recuperarlas como impulsoras de estrategias proyectuales consistía, básicamente, en rescatarlas de la memoria y la experiencia para introducirlas en sus proyectos, transformadas y despojadas de su función original, como un estrato modelado topográficamente sobre el que implantar los edificios. Así, los movimientos de tierra defensivos de Castle Rising resurgirían en la casa Bates en un singular abombamiento del terreno para aproximar la tierra al edificio; las marcas de asentamientos celtas en Fyfield Down, muy cerca de su casa de vacaciones de Fonthill, servirían para reordenar los caminos en el exterior de Mehringplatz o en el jardín de la escuela infantil de Wokingham; los taludes de los jardines paisajistas reaparecerían convertidos en un basamento verde sobre el que se alzaría el Garden Building; y las imágenes de Silbury Hill y de los yacimientos neolíticos de Avebury, capturadas por los Smithson en sus frecuentes viajes desde Londres a Upper Lawn, serían recuerdos a los que, sin duda, estos arquitectos recurrirían para proyectar las colinas de Robin Hood Gardens o las topografías de Art into Lanscape.

A través de estos procedimientos de apropiación, los Smithson supieron encontrar soluciones no sólo al problema de la implantación del edificio, sino también, incorporar a su arquitectura uno de los ingredientes fundamentales que dotaban de radicalidad y carácter diferenciador a su postura crítica con los postulados funcionalistas modernos. En su arquitectura, los Smithson pusieron en contacto dos realidades diferentes. Por un lado, la herencia de la abstracción geométrica de sus maestros; $y$, por otro, sus propias raíces: fragmentos del paisaje inglés, atrapados, descontextualizados y manipulados en un intencionado acercamiento que convergía en el plano del suelo, y que originaban en cada proyecto una estudiada implantación, impulsando un nuevo sentido de identificación y pertenencia al sitio, un vínculo indisoluble con el lugar, el "enraizamiento". 


\section{Objeto de estudio y justificación}

Esta tesis tiene por objeto estudiar las estrategias de enraizamiento de Alison y Peter Smithson. Para ello, se centra en la investigación de sus operaciones fundamentales: las ground-notations. El análisis de estas herramientas proyectuales comprende dos aspectos esenciales. El primero, explicar la apropiación del paisaje de la que surgen, rastreando su origen en ciertas experiencias de los Smithson en el territorio. Y el segundo, analizar su papel en la implantación de los proyectos. Para ello, las ground-notations se definen y se clasifican según el tipo de movimiento de tierra que producen; se reconocen en cada uno de los proyectos y se explican desde sus efectos en la articulación del edificio con el plano del suelo y en la configuración de la morfología del conjunto del emplazamiento.

La elección de este tema de tesis tiene, en primer lugar, una motivación personal, surgida durante la experiencia propia de algunas obras de los Smithson, como The Economist y Robin Hood Gardens, que pude visitar durante el tiempo en el que estuve trabajando en Londres como arquitecto, en los años 2004 y 2005. El conocimiento directo de la plataforma de The Economist y la topografía artificial de los jardines Robin Hood fueron experiencias que contribuyeron a despertar mi interés por el plano del suelo, alimentadas, al mismo tiempo, por mi trabajo en Foreign Office Architects ${ }^{1}$.

Al cabo de unos años, coincidiendo con la publicación de Robin Hood Gardens: Re-visions ${ }^{2}$ y la controversia en torno a su posible demolición, resurgió mi interés por este proyecto e inicié su estudio. Mis trabajos de investigación, realizados en el Máster de Proyectos Arquitectónicos Avanzados en la ETSAM en el periodo 20102012, centrados en el análisis de los Robin Hood, me permitieron profundizar en el conocimiento del suelo en este proyecto, y finalmente, mi Tesis Fin de Máster, titulada Robin Hood Gardens: la recuperación del plano del suelo en Alison y Peter Smithson, terminó por definir esta idea, al reparar en que las colinas, los fosos y los recintos hundidos que configuraban aquella evocadora topografía escondida en el este de Londres no eran un hecho aislado en la obra de los Smithson, sino parte de un poderoso hilo conductor que hilvanaba toda su obra y cuyo alcance estaba todavía por descubrir.

1. Varios proyectos de Foreign Office Architects (Alejandro Zaera-Farshid Moussavi) en aquellos ańos planteaban topografías artificiales a partir de movimientos de tierra: Downsview Park, Toronto (2000); Parque de la Gavia, Madrid (2003) o el Parque litoral y auditorio del sudoeste de Barcelona (2002-2004), entre otros

2. POWERS, Alan, ed. Robin Hood Gardens. Re-Visions. London: The Twentieth

Century Society, 2010. 
Pero la elección de este tema de investigación obedece también, obviamente, a razones objetivas. A pesar de que los estudios sobre la obra de Alison y Peter Smithson son numerosos, existe un vacío en torno al tema que propone esta tesis doctoral. La manera en que la arquitectura de los Smithson convive y dialoga con el territorio no ha sido suficientemente tratada: ${ }^{3}$ sus estrategias de enraizamiento permanecen aún sin investigar. El estudio de las ground-notations se ha limitado al análisis concreto de alguna de estas operaciones, y siempre de una manera breve y sin profundizar más allá de lo expresado por los propios arquitectos. Faltan, por tanto, trabajos que estudien estas intervenciones topográficas de una manera global, entendiéndolas como parte de una estrategia de mayor alcance, capaces de precisar el verdadera dimensión del suelo en la obra de Alison y Peter Smithson.

Este vacío en las investigaciones acerca de las estrategias de enraizamiento de los Smithson ha podido estar motivada por varias causas. Por una parte, el papel relevante de los Smithson en temas tan estudiados en los últimos años, como el Team 10, The Independent Group o el Nuevo Brutalismo, ha podido eclipsar otros asuntos de interés en su obra, como las ground-notations. Y, por otra parte, las escasas explicaciones de los propios Smithson sobre estas herramientas proyectuales ha contribuido a mantenerlas en cierto modo "ocultas", ya que entre las numerosas publicaciones que realizaron —-más de 260, entre 1952 y $2002^{4}$ —, ninguno de sus artículos ha tratado de manera específica este tema, salvo Shifting the Track.

Para los Smithson, cuyas experiencias personales alimentaban sus proyectos y viceversa, la apropiación del paisaje era algo inherente a su forma de proyectar, una acción interiorizada de tal modo que no sentían la necesidad de exponerla en cada proyecto. Sin embargo, el permanente interés de los Smithson por el territorio ${ }^{5}$, generó un buen número de escritos que, si bien no analizaban de un modo específico las ground-notations, gravitaban en torno a la relación entre los edificios y su emplazamiento. Estos escritos, en general breves,

3. Otras estrategias desarrolladas por los Smithson para conectar los edificios con el lugar, diferentes a la basada en el contacto con el plano del suelo — la utilización de imágenes encontradas en el contexto del proyecto, la captura del paisaje a través de celosías o la adecuación a las condiciones climáticas a través de la forma y la orientación del edificio-, han sido explicadas por los Smithson y por otros autores en diversas publicaciones. Véase, entre otros: WONG, L., P. SALTER, and Alison and Peter SMITHSON. Climate Register: Four Works by Alison \& Peter Smithson. v. 6. Architectural Association, 1994.

4. Entre los años 1952 y 2002, Alison y Peter Smithson realizaron — conjuntamente o por separado- 268 publicaciones, incluyendo artículos y libros. Véase bibliografía en HEUVEL, Dirk van den, and Max RISSELADA, eds. From the House of the Future to a House of Today. Rotterdam: 010 Publishers, 2004

5. "La búsqueda de una arquitectura adherida íntimamente al emplazamiento del proyecto es donde se encuentra el hilo que une todos los proyectos de los Smithson". VIDOTTO, Marco. Alison + Peter Smithson. Obras y Proyectos, Barcelona: Gustavo Gili, 1997. 
constituyen el material con el que adentrarse en la investigación de las estrategias de enraizamiento, desde el conocimiento generado por sus autores.

\section{Estado de la cuestión: fuentes directas}

Entre los textos de los Smithson más relevantes para esta investigación se encuentran los realizados por Peter Smithson con motivo de los talleres de verano en ILA\&UD, entre los ańos 1976 y 2003, y que fueron publicados, al menos un parte importante de ellos, en Italian Thoughts. Algunos de estos breves textos - entre los que se encontraba Shifting the Track- abordaban diferentes cuestiones acerca de la relación de la arquitectura con el territorio, generalmente, a través de la explicación de los proyectos de pequeña escala que Peter Smithson planteó en los talleres IL\&UD: Territory ${ }^{7}$; To Establish a Territory ${ }^{8}$; A Notations of Trees'; Markers on the Line ${ }^{10}$; o Tracks for the Territory ${ }^{11}$. En algunos de ellos, Peter Smithson continuó desarrollando aspectos ya tratados anteriormente en Shifting the Track, como en Markers on the Land, ${ }^{12}$ en donde recuperaba parte de aquel vocabulario de marcas sobre el suelo explicando algunos de sus efectos sobre el paisaje; o en Notation in the Suburbs, ${ }^{13}$ en donde analizaba una intervención en un paisaje de carreteras realizada mediante "cinturones de árboles".

En The Shift ${ }^{14}$ los Smithson trataron de explicar algunas de las intervenciones realizadas en el suelo de sus proyectos, aunque de manera muy breve y sin emplear el término ground-notations para referirse a ellas. En su lugar, utilizaron la expresión "connective landscape forms", con la que denominaron algunas de esas operaciones realizadas hasta la década de 1980, como el ha-ha y las superficies de grava de los espacios exteriores de Hunstanton; las pantallas de vegetación del Churchill Collage; y las intervenciones en la

6. SMITHSON, Alison and Peter. Italian Thoughts. Stockholm: Royal Academy of Fine Arts, 1993.

7. SMITHSON, Alison and Peter. "Territory", en: Italian Thoughts. Op.Cit.

8. SMITHSON, Peter.“To Establish a Territory”. en: ILA \&UD Annual Report 198586, Siena 1986.

9. SMITHSON, Peter. "A Notations of Trees", en: ILA\&UD Annual Report, 1990-91, Urbino 1991.

10.SMITHSON, Peter. "Markers on the Line" en: ILA\&UD Annual Report 1991-92,Urbino 1992.

11.SMITHSON, Peter. “Tracks for the Territory", en: ILA\&UD Annual Report 1992-93,Urbino 1993.

12. SMITHSON, Peter. "Markers on the land" in: ILA\&UD Annual Report 1992-93, Urbino 1993.

13. SMITHSON, Peter. "Notation in the Suburbs", in: ILA\&UD Annual Report 1994 95, San Marino 1995.

14. SMITHSON, Alison and Peter, Alison and Peter Smithson. The Shift, Architectural Monographs, edited by David Dunster, Vol. nr. 7. London: Academy Editions, 1982. 
Embajada Británica de Brasilia. En The Shift, los Smithson dejaron entrever la existencia de una línea evolutiva que conectaba a todas estas intervenciones, aludiendo a un proceso de maduración que comenzaba en Hunstanton y concluía en las topografías artificiales de los Robin Hood Gardens y Art into Landscape, estas dos últimas explicadas como operaciones "as found", basadas en la reutilización de los escombros hallados en el lugar.

Without Rhetoric. An architectural aesthetic ${ }^{15}$, contenía algunos temas recurrentes de los Smithson que manifiestan el aumento de la sensibilidad hacia el contexto natural que experimentó su trabajo a partir de la década de $1970^{16}$. Los Smithson explicaron el plano del suelo como un estrato en el que poder absorber el movimiento de los vehículos, liberando el espacio exterior del ruido y del humo de los coches, como ocurría en sus recién finalizados Robin Hood Gardens. La idea de generar espacios "en calma" en los proyectos se mostraba como un asunto esencial para los Smithson y al que dedicaron una parte significativa de este libro, haciendo referencia a algunas intervenciones de sus maestros modernos, como las circulaciones semienterradas planteadas por Le Corbusier en el Capitolio en Chandigarh, o los sutiles mecanismos de separación del tráfico planteados por Mies en Lafayette Park.

En esa publicación, los Smithson expusieron brevemente las conclusiones extraídas de sus investigaciones sobre los emplazamientos en la antigua Grecia, realizadas en la década de 1950 y en las que defendían que la implantación de aquella arquitectura clásica resultaba de la adecuación a las necesidades funcionales y a las condiciones naturales del paisaje, como la topografía y el clima, más que a la imposición de leyes justificadas por criterios visuales. En aquellos estudios sobre los emplazamientos clásicos - publicados inicialmente por Peter Smithson en Theories Concerning the Layout of Classical Greek Buildings ${ }^{17}$ - fueron decisivas las observaciones de los Smithson acerca del trazado de las murallas de las antiguas ciudades de helenas, donde percibieron muestras inequívocas de una intencionada adaptación a la topografía del lugar.

Estas investigaciones sobre las fortificaciones griegas, realizadas por los Smithson al comienzo de su trayectoria, tuvieron continuidad años después en dos textos posteriores: un ensayo escrito por Alison Smithson -Ruminations on Founders Court ${ }^{18}$ - dedicado, en este caso, a los límites fronterizos romanos; y en otro, realizado por

15. SMITHSON, Alison and Peter, Without Rhetoric. An Architectural Aesthetic 19551972, Latimer New Dimensions, London, 1973; MIT Press, Cambridge MA, 1974

16. RISSELADA, Max. "A Critical Chronology", en Alison \& Peter Smithson. A Critical Anthology. Barcelona: Ediciones Polígrafa, 2011.

17. SMITHSON, Peter, "Theories Concerning the Layout of Classical Greek Buildings", in: AA Journal, February 1959, pp. 194-209.

18. SMITHSON, Alison, "Ruminations on Founders Court". Architectural Design, November 1973. 
Peter Smithson -Fortifications ${ }^{19}$ - en el que resumía la evolución de las construcciones defensivas desde la antigua Grecia hasta las planteadas por Francesco di Giorgio en el Renacimiento, las cuales según estos arquitectos poseían una destacada capacidad de adaptación a la topografía. En ambos casos, los Smithson destacaban de estas construcciones militares su intencionada vinculación con el territorio, a través del aprovechamiento de las particularidades del lugar y su habilidad para establecer acuerdos con el terreno. Estas condiciones forman, sin duda, parte esencial de las estrategias de enraizamiento.

In Pursuit of Lyrical Appropiateness ${ }^{20}$, escrito por Alison Smithson al poco tiempo de publicar Without Rhetoric. An architectural aesthetic, constituye igualmente un ejemplo de la instintiva atracción por el paisaje que poseían los Smithson. El texto nos desvela una comprensión del territorio a través de sus trazas, entendiéndolo como un soporte configurado a través del tiempo, tallado mediante "marcas" correspondientes a las diferentes huellas de asentamientos pasados. Así, los earthworks prehistóricos, el limes romano y los restos de las abadías medievales de los valles del norte de Inglaterra serán para Alison Smithson los principales exponentes de esas formas artificiales integradas en el paisaje autóctono, que lo estructuran y lo dotan de significado. In Pursuit of Lyrical Appropiateness es, asimismo, un reflejo del interés de los Smithson por poner en valor sus raíces inglesas-englishness- como una condición presente en toda su obra, fácilmente observable también en otros textos, como $A S$ in $D S$. An eye on the $\mathrm{rad}^{21}$, en donde Alison Smithson realizaba una personal descripción del paisaje inglés contemplado desde el trayecto por carretera, fundamentalmente, durante los viajes realizados desde Londres a Tisbury, donde se ubicaba Upper Lawn.

También en la década de 1970, los Smithson publicaron en la revista Architectural Design una serie de artículos, agrupados bajo el título general de Collective Design², centrados en analizar la evolución del lenguaje moderno. Por el interés que supone para esta investigación,

19. SMITHSON, Peter. «Fortifications». ILA\&UD Annual Report, Venecia, 1999.

20. SMITHSON, Alison, "Alla ricerca di un nuovo lirismo / In Pursuit of Lyrical Appropriateness", Spazio e Socièta, January/April 1976.

21. SMITHSON, Alison, AS in DS. An Eye on the Road. Delf: Delft University Press, 1983.

22. La serie denominada Collective Design consta de 7 artículos: SMITHSON, Peter 'Intitiators and Successors', in: Architectural Design, nr. 10, 1973, pp. 621623; SMITHSON, Alison, 'The Violent Consumer. Or Waiting for the Goodies', in: Architectural Design, nr. 5, 1974, pp. 274-279; SMITHSON, Peter , 'Lightness of Touch', in: Architectural Design, nr. 6, 1974, pp. 377-378; SMITHSON, Alison, 'Re-appraisal of Concepts in Urbanism', in: Architectural Design, nr. 7, 1974, pp. 403406; SMITHSON, Alison, 'Collective Quality', in: Architectural Design, nr. 11, 1974 , pp. 719-721; SMITHSON, Alison, 'The Good Tempered Gas Man', in: Architectural Design, nr. 3, 1975, pp. 163-168; SMITHSON, Peter , 'Making the Connection', in: Architectural Design, nr. 5, 1975, pp. 271-274. Para una explicación acerca de esta serie de artículos de Alison y Peter Smithson, véase, BOYER, Christine. «Why do Architects Write? The case of Team 10 and Alison \& Peter Smithson». Op.Cit. 
destaca el titulado Lightness of Touch ${ }^{23}$ : un artículo breve en el que Peter Smithson incluía entre los "nuevos principios de la arquitectura" la adecuación del edificio a su emplazamiento ${ }^{24}$. A través de una serie de dibujos esquemáticos que partían de los realizados por Le Corbusier para explicar la "máquina para habitar", Peter Smithson confrontaba la estratificación moderna con una nueva organización basada en el aprovechamiento del contacto con el suelo, en la que el edificio, antes desconectado del terreno por medio de los pilotis, se enraizaba en un suelo modelado artificialmente que albergaba en su sección la circulación rodada y contenía en su superficie espacios ajardinados en estrecha relación con el edificio.

Por último, The Upper Lawn Solar Pavilion Folly, ${ }^{25}$ que incluye las fotografías de la vida de la familia Smithson en su casa de fin de semana y las notas que conformaban el diario escrito por Alison Smithson durante los años de permanencia en la finca Fonthill, confirman la importancia que tuvo para los Smithson el contacto con la tierra en aquel entorno rural de Inglaterra. Especialmente significativas para esta tesis serán algunas fotografías y anotaciones que muestran la utilización del montículo de tierra del jardín como zona de juegos para los hijos y el proceso de reconstrucción del suelo frente al pabellón.

\section{Estado de la cuestión: fuentes indirectas}

El estado de la cuestión, en lo que se refiere a las investigaciones producidas por otros autores, está formado por trabajos que tratan de una manera general el vínculo de la arquitectura con el suelo en la obra de los Smithson. Por lo general, son textos breves que abordan otras cuestiones próximas al objeto de estudio de esta tesis o, en el mejor de los casos, lo hacen sin profundizar en su investigación.

La influencia del territorio en la arquitectura de los Smithson fue tratada por David Dunster en el prólogo de The Shift, ${ }^{26}$ en donde señalaba la apropiación que los Smithson hacía de algunas de las imágenes encontradas en el contexto de los proyectos. Dunster señalaba las colinas de Robin Hood Gardens o los montículos de Art into Landscape como ejemplos de la mirada selectiva que los Smithson proyectaron hacia algunos de los restos neolíticos del paisaje de Inglaterra y su característico relieve ondulado.

23. SMITHSON, Peter Smithson, "Lightness of Touch. Notes from a lecture given at the opening of Gund Hall, 16 October 1972" en Architectural Design, julio 1974, pp. 377-378

24. Peter Smithson comparaba el carácter "universal" de la arquitectura moderna con una nueva condición de especificidad y adecuación con el emplazamiento: place-connected, place-establishing. Ibid.

25. SMITHSON, Alison and Peter, Upper Lawn: Solar Pavilion, Folly, Edicions de la Universitat Politecnica de Catalunya, Barcelona, 1986

26. SMITHSON, Alison and Peter. The Shift. Op.cit. 
La conexión entre la arquitectura y el paisaje también fue reconocida por Richard Padovan en Seven small thoughts on the architects ' writings ${ }^{27}$ como uno de los temas recurrentes en la obra de los Smithson. Padovan analizaba este aspecto a través de un breve recorrido por algunas de sus publicaciones -como Ordinariness and Light ${ }^{28}$, Bath: within the walls ${ }^{29}$, y Upper Lawn: Solar Pavilion Folly ${ }^{30}$ - en las que se dejaba entrever el propósito de estos arquitectos por incluir el contacto con el entorno natural como parte esencial de sus edificios.

Marco Vidotto, en la introducción de su libro, Alison + Peter Smithson. Obras y Proyectos, ${ }^{31}$ apuntaba en un breve texto el vínculo con el lugar como un objetivo fundamental que perseguía la arquitectura de Alison y Peter Smithson. En Picking up, Turning over and Putting with..., ${ }^{32}$ Dirk Van den Heuvel interpretaba los proyectos de los Smithson bajo la misma apreciación de la influencia del contexto, indicando que algunos de los edificios de los Smithson se vinculaban a formas arquetípicas, anónimas y vernáculas, procedentes de su entorno ${ }^{33}$; como también destacaría Beatriz Colomina en Un aire aún no respirado, $1956^{34}$ en relación a la influencia de las formas arcaicas de las cuevas Les Baux de Provenza en el proyecto de la Casa del Futuro de Alison y Peter Smithson.

En el artículo Las montañas mágicas de Melbourne: un paisajismo emociona ${ }^{35}$, Jesús Vassallo destacaba algunos de los proyectos realizados por los Smithson en los años finales de sus trayectoria, correspondientes a los talleres desarrollados en ILA\&UD, destacándolos por poner en valor lo existente, a través de operaciones intencionadamente vinculadas al territorio. Vassallo, que también incidía en la atracción de los Smithson por las huellas primitivas, planteaba una conexión con el existencialismo de Heidegger, a

27. PADOVAN, Richard. «Seven Small Thoughts on the Architects' Writings». En Modernism without Rhetoric: Essays on the Work of Alison and Peter Smithson, editado por Helena WEBSTER y Alison and Peter SMITHSON, 195-205. London: Academy Editions, 1997.

28. SMITHSON, Alison and Peter, Ordinariness and Light.Urban Theories 1952-60, and Their Application in a Building Project 1963-70. Cambridge MA: MIT Press, 1970.

29.SMITHSON, Peter, "Bath: Walks Within the Walls". Architectural Design, September 1975.

30. SMITHSON, Alison and Peter, Upper Lawn: Solar Pavilion, Folly, Op.cit.

31. VIDOTTO, Marco. Alison + Peter Smithson. Obras y Proyectos, Barcelona: Gustavo Gili, 1997.

32. HEUVEL, Dirk van den, 'Picking Up, Turning over and Putting With...' in: From the House of the Future to a House of Today, edited by Dirk van den HEUVEL and Max RISSELADA, 13-28. Rotterdam: 010 Publishers, 2004.

33. Si bien, este análisis no se refiere de manera específica a la utilización de formas topográficas del paisaje, también resulta de interés por su relación con la hipótesis planteada en esta tesis. Véase, HEUVEL, Dirk van den, Ibid.

34. COLOMINA, Beatriz, 'Unbreathed Air 1968', in: From the House of the Future to a House of Today, Ibid.

35. VASSALLO, Jesús. «Las montañas mágicas de Melbourne: Un paisajismo emocional», en: Límite y Ocupación, Madrid: ETSAM/Mairea, 2010. 
partir de la capacidad que poseían algunas de las intervenciones de los Smithson de generar una experiencia del paisaje. Esta conexión con el existencialismo de Heidegger -presente también en otros arquitectos de su generación- fue analizada por Ignasi de Solà-Morales en Arquitectura y existencialismo ${ }^{36}$, realizando una destacada aproximación a la condición humanista y al clima cultural existencialista en los años posteriores a la Segunda Guerra Mundial.

En relación a las ground-notations, las investigaciones específicas sobre estas intervenciones se reducen, esencialmente, al artículo de Jonathan Sergison y Stephen Bates, Lessons Learnt from Alison and Peter Smithson ${ }^{37}$. Este texto analizaba las estrategias de proyecto esenciales de los Smithson, incluyendo entre ellas las groundnotations. El texto contenía una muy breve descripción de estas operaciones a partir de las explicaciones dadas por los Smithson, limitándose a recoger las citas y los ejemplos expuestos en Shifting the Track, sin realizar una revisión crítica. A pesar de su brevedad y de la escasa aportación al conocimiento de las ground-notations, el artículo de Sergison y Bates constituye un valioso artículo para esta investigación, especialmente, por tratarse del único texto que reconoce estas herramientas en la obra de los Smithson.

A pesar de no estar analizadas bajo la idea del enraizamiento, ni, en general, nombradas como ground-notations, algunas de las intervenciones topográficas de los Smithson -especialmente las más evidentes- han sido objeto de análisis por otros autores, aunque, en la mayoría de los casos, más que reflexiones críticas son breves explicaciones realizadas a partir de las dadas por los propios arquitectos.

En Robin Hood Gardens: A critical narrative $e^{38}$, Alan Powers analizaba el jardín de los Robin Hood Gardens, esbozando posibles conexiones con otros temas de interés de los Smithson, entre los que apuntaba los jardines paisajistas ingleses del dieciocho, los vestigios prehistóricos del territorio de Inglaterra o algunas obras de Land Art de la década de 1960.

En From the House of the Future to a House of Today ${ }^{39}$, publicado con motivo de la exposición del mismo nombre, Dirk Van den Heuvel y Max Risselada explicaban las casas de los Smithson, analizando, en algunos casos, sus estrategias de implantación: en la Casa Losey, señalaban la adaptación al lugar a través de unas operaciones de réplica de los muros de piedra locales, utilizados tradicionalmente para delimitar la propiedad en aquel territorio; y en la casa-estudio

36. SOLÀ-MORALES, Ignasi de Solà-Morales, 'Arquitectura y existencialismo', en Diferencias. Topografía de la arquitectura contemporánea, Gustavo Gili, Barcelona, 1995.

37. SERGISON, Jonathan, y Stephen BATES. «Lessons Learnt from Alison and Peter Smithson». En Sergison Bates Architects: buildings. Lucerne: Quart, 2012.

38. POWERS, Alan, ed. Robin Hood Gardens. Re-Visions, Op.cit.

39. HEUVEL, Dirk van den and RISSELADA, Max, Op.cit. 
para Eduardo Paolozzi revelaban los mecanismos del proyecto para conectar con el paisaje ondulado del emplazamiento.

Bruno Krucker, en Complex ordinariness: the Upper Lawn Pavilion by Alison and Peter Smithson ${ }^{40}$ señalaba brevemente algunas de las intervenciones en el suelo de Upper Lawn: la reconstrucción del pavimento de piedra frente al edificio, el montículo artificial de juegos —al que Krucker vinculaba a las ground-notations-; o los setos plantados en la cara interior del muro de piedra que rodeaba la finca. Los setos de Upper Lawn también serán objeto de análisis en la tesis doctoral Huellas de lo vernáculo en Team 10. Alison y Peter Smithson, Aldo van Eyck, José Antonio Coderch, ${ }^{41}$ donde su autora, Ana Rodríguez, investiga la conexión entre las plantaciones de vegetación de este proyecto con las técnicas vernáculas del jardín formal inglés.

Sobre el Garden Building, Marco Vidotto, en Alison y Peter Smithson y la prensa inglesa sobre el Garden Building en el St. Hilda's College de Oxford ${ }^{42}$ explicaba la articulación de este edificio con el suelo, recogiendo también las observaciones de Robin Middleton en The Pursuit of Ordinariness ${ }^{43}$ sobre la implantación del edificio sobre el terreno. Por otra parte, el artículo de Middlenton incluía un croquis inédito de emplazamiento -nunca publicado por los Smithson- que suscita otras posibles interpretaciones del proyecto, entorno a la idea de la repetición y de la conexión de edificios a través de una ruta sobre el plano del suelo.

En su tesis doctoral, Cinco ideas para hacer arquitectura ${ }^{44}$, Juan Mera, ofrecía un interesante análisis del abombamiento del terreno de la Casa Bates, sobre el que parece flotar el edificio, entendiéndolo como mediador entre la casa y la tierra. Esta tesis también señalaba la condición "real" que poseían los árboles dibujados por los Smithson en sus proyectos, frente a la abstracción de los representados por sus maestros Mies y Le Corbusier. También sobre los árboles y la tierra en la obra de los Smithson, Luis Martínez Santa-María, en su tesis doctoral Tierra Espaciada. El árbol, el camino, el estanque: ante la

40. KRUCKER, B., Complex Ordinariness: The Upper Lawn Pavilion by Alison and Peter Smithson. GTA /ETH Zürich, 2002

41. RODRÍGUEZ, Ana. 'Huellas de Lo Vernáculo En Team 10 : Alison Y Peter Smithson, Aldo van Eyck, José Antonio Coderch'. Tesis Doctoral. Universidad Politécnica de Madrid. ETSAM, 2016.

42. VIDOTTO, Marco. «Alison y Peter Smithson y la prensa inglesa sobre el St.Hilda's College de Oxford. Opiniones, problemas y prejuicios de un edificio interpretado a lo "femenino"». En St.Hilda's College, Oxford. La arquitectura del entramado. Alison \& Peter Smithson. Arquitecturas silenciosas 1. Madrid: COAM, 2001.

43. MIDDLETON, Robin, 'Pursuit of Ordinariness: Garden Building, St. Hilda's, Oxford'. Architectural Design, February 1971

44. MERA, Juan Ignacio. "Cinco Ideas para hacer Arquitectura». ETSAM Universidad Politécnica de Madrid, 2004. 
casa ${ }^{45}$ analizaba el suelo de Upper Lawn destacando sus condiciones de espesor, profundidad y capacidad de mostrar el paso del tiempo.

Los proyectos presentados por los Smithson en los X CIAM celebrados en Dubrovnik, en 1956, entre los que se encontraba las Close Houses y la Casa Bates, son analizados por Volker M. Welter en In-between space society. On some British roots of Team 10's urban thought in the 1950's ${ }^{46}$, desde la apropiación de la "sección del valle de Geddes", la cual mostraba la relación entre los asentamiento y la topografía. Del mismo autor, Post-war CIAM, Team X, and the influence of Patrick Geddes ${ }^{47}(2003)$ analizaba la conexión entre Geddes y los Smithson, explicando su influencia el contexto de los CIAM. Acerca de la figura de este biólogo y sociólogo escocés -de gran influencia en los primeros ańos de la trayectoria de los Smithson- la publicación de Jaqueline Tyrwhitt, Patrick Geddes in $I_{n d i a^{48}}$ revelaba el compromiso con el entorno natural que poseían sus intervenciones, como señalaba Lewis Mumford en la introducción de ese libro; una apreciación que también era apuntada por Iñaki Ábalos en Atlas pintoresco vol. $1^{49}$ donde ensalzaba sus propuestas como precursoras de intervenciones integradas en el territorio.

La presencia de "lo inglés" en los Smithson es analizada por varios autores como un rasgo destacado de su pensamiento, aproximándose al concepto Englishness desde diferentes enfoques: desde el contacto con la cultura popular y sus mitos, como trataba Francisco González de Canales en Una estancia en el exterior. Estampas de Puck y arquitecturas análogas ${ }^{50}$; desde la apropiación del estrecho vínculo con el paisaje que poseían los poblados tradicionales, como señalaba Christine M. Boyer en Why do Architects Write? The case of Team 10 and Alison \& Peter Smithson ${ }^{51}$; o, desde la comprensión del territorio de Inglaterra como un soporte de huellas, configurado por una superposición continua de patrones de asentamiento generados a lo largo de la historia, como explicaba Dirk van den Heuvel en su tesis doctoral Alison and Peter Smithson: A Brutalist Story, Involving the House, the City and the Everyday (Plus a Couple of Other Things). ${ }^{52}$

45. MARTÍNEZ SANTA-MARÍA, Luis. El árbol, el camino, el estanque, ante la casa. Colección Arquithesis, no15. Barcelona: Fundación Caja de Arquitectos, 2004.

46. WELTER, Volker M. "In-between space and society. On some British roots of Team 10's urban thought in the 1950s." in Team 10 In search of a Utopia of the past, 1953-81. Edited by Risselada M., van den Heuvel D. Rotterdam: NAI Publisher, 2006.

47. WELTER, Volker M. «Post-war CIAM, Team X, and the Influence of Patrick Geddes». TU Delft.

48. GEDDES, Patrick. Patrick Geddes in India. Editado por TYRWHITT, J. London, L. Humphries, 1947.

49. ÁBALOS, Ińaki (ed.). Atlas pintoresco Vol.1. El observatorio. Barcelona: Gustavo Gili, 2005.

50. GONZÁLEZ DE CANALES, Francisco. 'Una Estancia en el Exterior. Estampas de Puck y Arquitecturas Análogas’. DC. Revista de Crítica Arquitectónica, 2003

51. BOYER, M. Christine. Op.Cit

52. HEUVEL, Dirk van den. Op.Cit 
El pintoresquismo constituye también un tema relevante en el trabajo de los Smithson y que atañe a directamente esta investigación, por la influencia que tuvo la tradición inglesa de trabajo con el territorio en la manipulación del suelo en los proyectos de los Smithson. El revival pintoresco difundido por Nikolaus Pevsner en The Architectural Review a finales de la década de 1940, así como los textos de Reyner Banham. The New Brutalism ${ }^{53}$ y Revenge of the Picturesque: English Architectural Polemics, 1945-1965, ${ }^{54}$ definen el contexto para entender la controvertida relación de los Smithson con "lo pintoresco" en los inicios de su trayectoria.

Varios autores coinciden en señalar la existencia de rasgos pintorescos en la obra de Alison y Smithson. En Regarding the Smithson, ${ }^{55}$ Peter Cook señalaba la presencia inequívoca de un "instinto pintoresco" en algunos de los proyectos de esta pareja de arquitectos ingleses, a pesar de las reticencias de éstos por asumirlo; ${ }^{56}$ Bruno Krucker en Complex Ordinariness: The Upper Lawn Pavilion by Alison and Peter Smithson ${ }^{57}$ también se adentraba en esta cuestión, reconociendo a la existencia de ciertos "temas pintorescos" en el trabajo de los Smithson; y en Historias del presente inmediato, ${ }^{58}$ Anthony Vidler destacaba la "sensibilidad pintoresca" que poseían las fotografías de la Escuela Secundaria Hunstanton publicadas en The Architectural Review, ${ }^{59}$ calificándolas como "un paseo alrededor del edificio".

Asimismo, recientes investigaciones plantean puntos en común entre el Nuevo Brutalismo y el Pintoresquismo y por tanto, la imposibilidad de separarlos radicalmente. En este sentido, en ¿Pintoresco o Moderno?, ${ }^{60}$ Aníbarro, calificaba de "ironía" el interés de los jóvenes arquitectos brutalistas por la topología y las texturas con su rechazo frontal a la tradición pintoresca del descuido y el contraste; en The Picturesque. Architecture, Disgust and Other Irregularities ${ }^{61}$, John Macarthur veía en los preceptos brutalistas rasgos inequívocos del pintoresquismo, "en sus aspectos escenográficos y de integración con la topografía"; y en A Brutalist History, Dirk Van den Heuvel concluiría con la imposibilidad de separar el revival pintoresquista

53. BANHAM, Reyner, 'The New Brutalism'. The Architectural Review, December 1955 54. BANHAM, Reyner. 'Revenge of the Picturesque: English Architectural Polemics, 1945,-1965'. In Concerning Architecture: Essays on Architectural Writers and Writing Presented to Nikolaus Pevsner, edited by J. Summerson and Nikolaus Pevsner. Allen Lane, 1968

55. COOK, Peter. 'Regarding the Smithsons'. Architectural Review, July 1982

56. Ibid.

57. KRUCKER, B., Op.Cit.

58. VIDLER, Anthony. Historias del presente inmediato: la invención del movimiento moderno arquitectónico. Barcelona: Gustavo Gili, 2011.

59. Fotografías de Hunstanton publicadas en:

60. ANIBARRO, Miguel Angel. «Pintoresco o moderno? Nikolaus Pevsner y el debate de la arquitectura británica en la posguerra». Anales de Arquitectura, Madrid, 1993-94.

61. MACARTHUR, John, The Picturesque. Architecture, Disgust and Other Irregularities, Routledge, London, 2007 
-y palladiano- del siglo XX en Inglaterra con la invención del Nuevo Brutalismo, reconociendo, a su vez, ciertos aspectos diferenciadores entre el brutalismo de Banham y el de los Smithson.

La influencia del mundo antiguo en los Smithson apenas ha sido tratada, siendo analizada de manera breve y mediante concisas alusiones que impiden apreciar el verdadero alcance que tuvo en su trabajo. En la década de 1960, autores como Kenneth Frampton o Reyner Banham relacionaron la obra de los Smithson, The Economist (1959-62), con la Acrópolis griega, mencionando en sus respectivos escritos una posible conexión entre el plano de la antigua Grecia y la disposición de los volúmenes sobre la plataforma del edificio de Londres $^{62}$. En 1971, Robert Middleton, hacía alusión a los viajes por el Mediterráneo de los Smithson como fuente de inspiración para sus proyectos ${ }^{63}$. En 1982, David Dunster indicaba en el prólogo de "The Shift" que el conocimiento de la Grecia clásica era un factor clave de el pensamiento de los Smithson, aunque no aportaba más explicaciones al respecto. ${ }^{64}$ En 1997, Helena Webster seńalaba, en relación al conocimiento que los Smithson tenían de la historia, que "Peter era famoso por su conocimiento sobre el espacio y la arquitectura de Grecia, incluso en los ańos cincuenta" ${ }^{65}$ Recientemente, en 2003, Dirk Van den Heuvel en 'A Brutalist Story', ${ }^{66}$ calificaba las investigaciones realizadas por los Smithson sobre los sitios clásicos como "experiencias formativas"

Finalmente, la importancia de algunas de las experiencias vitales de Alison y Peter Smithson -esenciales para comprender la adopción de las ground-notations como herramientas de proyecto- se esboza en algunas de las entrevistas publicadas, como Friends of the Future: A Conversation with Peter Smithson ${ }^{67}$, de Beatriz Colomina; Smithson Time. A Dialogue ${ }^{68}$, de Hans Ulrich Obrist; y Peter Smithson. Conversaciones con estudiantes. ${ }^{69} \mathrm{El}$ artículo de Jeremy Baker $A$

62. Kenneth Frampton vinculaba The Economist con la Acrópolis: "It is dependent on the 'acropoli' of the ancient past", en FRAMPTON, Kenneth, "The Econocmist and the Haupststadt", 1965, en A\&PS A critical Anthology, p.181; y Banham señalaba que "The Economist (...) puede dar la visión de una nueva estructura comunitaria, pero lo hace sobre la base de un plano griego antiguo de Acrópilis (...)", en BANHAM, Reyner, $E l$ nuevo brutalismo en Arquitectura.GG, Barcelona,1967, p.134.

63. MIDDLETON, Robin, 'The Pursuit of Ordinariness', en, Architectural Design, February 1971, p.82

64. SMITHSON, Alison and Peter, Alison and Peter Smithson. The Shift, op.cit.

65. WEBSTER, Helena (ed.), Modernism without Rhetoric. Essayson the Work of Alison and Peter Smithson, Academy Editions, London, 1997. p. 97.

66. HEUVEL, Dirk van den. Op.Cit A Brutalist Story, Op.cit, p.236

67. COLOMINA, Beatriz, and Peter SMITHSON. 'Friends of the Future: A Conversation with Peter Smithson'. October, Fall 2000.

68. SMITHSON, Peter, and Hans Ulrich OBRIST. Smithson Time. A Dialogue. Colonia: Walther König, 2004.

69. SPELlMANN, Catherine, and Karl (eds) UNGLAUB, eds. Peter Smithson. Conversaciones con Estudiantes. Barcelona: Gustavo Gili, 2004 
Smithson File ${ }^{70}$ recoge un análisis crítico del primer periodo de la obra de los Smithson, incluyendo valiosas reflexiones de los propios arquitectos acerca de varios de sus ensayos y proyectos realizados hasta mediados de 1960. Asimismo, el análisis de la trayectoria de los Smithson que realiza Max Risselada en A Critical Chronology ${ }^{71}$ ofrece un valioso análisis del conjunto de la obra de los Smithson, destacando algunos momentos clave, como la sensibilidad hacia el territorio que mostraron sus proyectos, especialmente desde la década de 1970, y que permite definir el estado de la cuestión con la que arranca esta tesis doctoral.

70. BAKER, Jeremy. 'A Smithson File'. Arena. Architectural Association Journal, February 1966

71. RISSELADA, Max. Op.Cit. 


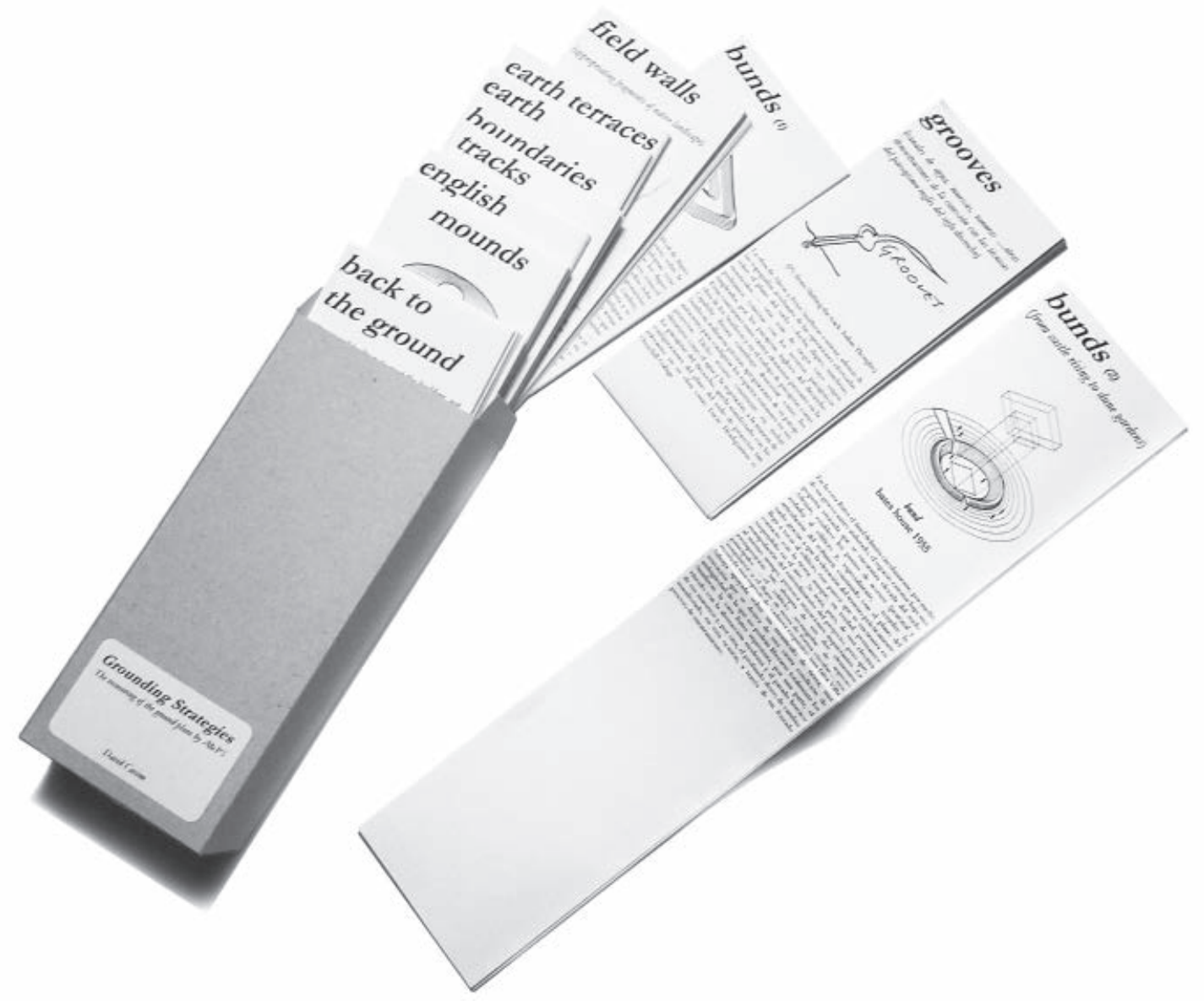

Grounding strategies

The recovering of the ground plan

David Casino 


\section{Objetivos e hipótesis}

El objetivo de esta tesis es investigar las ground-notations en la arquitectura de Alison y Peter Smithson, analizándolas como las herramientas esenciales de un conjunto de pautas proyectuales destinadas a recuperar el contacto de la arquitectura con el plano del suelo y que denominaremos estrategias de enraizamiento. Junto con este objetivo general, la tesis también comprende los siguientes objetivos específicos:

1 Demostrar en la obra de Alison y Peter Smithson la existencia generalizada de una intencionada manipulación del plano del suelo, destinada a configurar de manera específica la articulación del edificio con el terreno o, según los casos, estructurar con un propósito específico el espacio exterior del mismo. Este hecho pondrá de relieve el entendimiento del plano del suelo como un estrato manipulable mediante operaciones topográficas, destinado a favorecer el vínculo entre la arquitectura y su emplazamiento.

2 Analizar los proyectos de Alison y Peter Smithson atendiendo exclusivamente a las intervenciones realizadas en el plano del suelo. Este análisis permitirá no sólo identificar y clasificar cada una de las ground-notations, sino también exponer la obra de los Smithson mediante una nueva clasificación realizada según las tácticas desarrolladas para conectar los edificios con el plano del suelo. Asimismo, estos análisis estudio permitirán elaborar estudios específicos de cada una de las intervenciones del suelo vinculadas a los proyectos y a las apropiaciones del territorio de las que surgen.

3 Explicar ciertos aspectos vitales de estos arquitectos, relacionados con las experiencias y los estrechos vínculos que establecieron con el territorio, examinándolos desde la influencia que ejercieron sobre su trabajo, como impulsores de la formación de las ground-notations. Estos aspectos abarcan tres consideraciones diferentes en torno a su gestación: la primera de ellas atiende a ciertas cuestiones biográficas de interés que influyeron en el proceso de asimilación de estas herramientas de proyecto; la segunda atañe al vínculo con el territorio, explicando cómo ciertos fragmentos del mismo fueron objeto de apropiación para generarlas; y la tercera contempla su interpretación desde algunos aspectos relevantes del propio contexto cultural y arquitectónico en el que surgieron. 
A pesar de que no ha sido objeto de estudio analizar la continuidad ${ }^{1}$ y la vigencia de las estrategias de enraizamiento de los Smithson, la tesis parte de esta convicción y trata de reivindicar la importancia de la configuración del suelo en la arquitectura actual. La idea de enraizamiento que entendemos como los modos de articulación de los edificios con el suelo, las transformaciones topográficas de sus emplazamientos, o incluso la consideración del proyecto en una escala territorial, no son sólo asuntos ligados exclusivamente a la obra de los Smithson, sino cuestiones universales de la arquitectura que también forman parte del debate contemporáneo:" "construir y reconstruir la topografía es una operación fundamental del proyecto, algo que antecede a la construcción propiamente dicha, una acción necesaria para hacer posible la edificación". ${ }^{3}$

1. Las intervenciones en el suelo de los Smithson tendrán una continuidad varias décadas después en la obra de Enric Miralles, a quien conocían personalmente y con quien tenían amistad. A pesar del salto generacional, Miralles vio en la arquitectura de los Smithson una referencia importante para su trabajo. La arquitectura de los Smithson tenía que ver con cuestiones ligadas a la propia existencia; para Miralles, la arquitectura tampoco tenía que ver sólo con la construcción, sino sobre todo con la vida, la memoria, el clima, el lugar, etc. La conexión con Miralles actualiza la acción esencial de las estrategias de enraizamiento, la intervención sobre el suelo: "cavar aquí para alojar un edificio, amontonar allá y ofrecer recogimiento"*

(*)FAURA, Ramón, "Palacio de Deportes, Huesca 1988-1994; Club de Tiro con Arco, Barcelona 1989-1991”, en: Enric Miralles 1972-2000, Fundación Caja de Arquitectos, Barcelona, 2011).

2. Florian Beigel señalaba que "el suelo era, tal vez, el elemento más importante para los arquitectos". Su trabajo recoge muchos de los intereses planteados por los Smithson $y$, en especial, algunos directamente vinculados con el tema de esta tesis, como la reformulación del objeto mediante estrategias para centrar la atención sobre su espacio exterior; el empleo de la topografía como herramienta para la desaparición del objeto o la configuración de vacíos en lugar de edificios. Véase: BEIGEL, Florian, and Architecture Research Unit. Recycled Landscape. Madrid: Fundación COAM, 2002.

3. CORTES, Juan Antonio, "La complejidad de lo real", en El Croquis, n¹44 (Ejemplar dedicado a: EMBT 2000-2009 Miralles/Tagliabue), El Croquis Editorial, El Escorial, Madrid, 2009. 


\section{Método}

El método de este trabajo de investigación ha incluido cinco aproximaciones metodológicas: 1) la consulta los archivos de la familia Smithson, 2) las entrevistas con los hijos de los arquitectos y con otras personas relevantes en su trayectoria, 3) los viajes y visitas a los edificios y lugares de referencia de los proyectos de los Smithson; 4) el análisis teórico y bibliográfico de las investigaciones precedentes; y 5) el estudio, mediante dibujos analíticos, de los proyectos de Alison y Peter Smithson.

\section{The Hutte: los archivos de la familia Smithson}

Una parte fundamental de esta investigación ha sido la visita a The Hutte: el archivo privado de la familia Smithson, situado en Stamford (Inglaterra), que contiene el material del trabajo de Alison y Peter Smithson que no fue donado a la Biblioteca de la Universidad de Harvard tras la muerte de los arquitectos. La visita a The Hutte, en el año 2015, me permitió adentrarme en la obra de los Smithson a través de diferentes documentos inéditos, como fotografías, mapas, planos, textos y dibujos personales, que me revelaron intereses y experiencias de estos arquitectos que desconocía hasta aquel momento. El descubrimiento de todo ese material inédito me permitió no sólo confirmar mis hipótesis iniciales, sino también dar un nuevo impulso a mi investigación, basado en la consideración del enraizamiento como una estrategia directamente vinculada a la experimentación del territorio autóctono.

En el archivo de la familia Smithson pude acceder a sus fondos fotográficos, formados por numerosos álbumes y cajas de diapositivas clasificados por temas -Britain Pre-historic, Earthworks, Vernacular Villages o English Landscape-, que revelaban los lugares de Inglaterra sobre los que los Smithson sintieron una especial atracción. También tuve acceso a los planos de carreteras que utilizaban los Smithson en sus viajes en coche y sobre los que marcaban los puntos de interés en el paisaje, como los accidentes topográficos o las formaciones de tierra de origen prehistórico. Junto con esta cartografía, las anotaciones y los planos dibujados por los Smithson para localizar determinados lugares, eran manifestaciones explícitas del intenso contacto que los Smithson tuvieron con el territorio autóctono.

Asimismo, pude consultar el material que los Smithson tenían recopilado sobre los paisajes de Inglaterra $\mathrm{y}$ algunas de las construcciones sobre las que mostraron un interés específico, como las

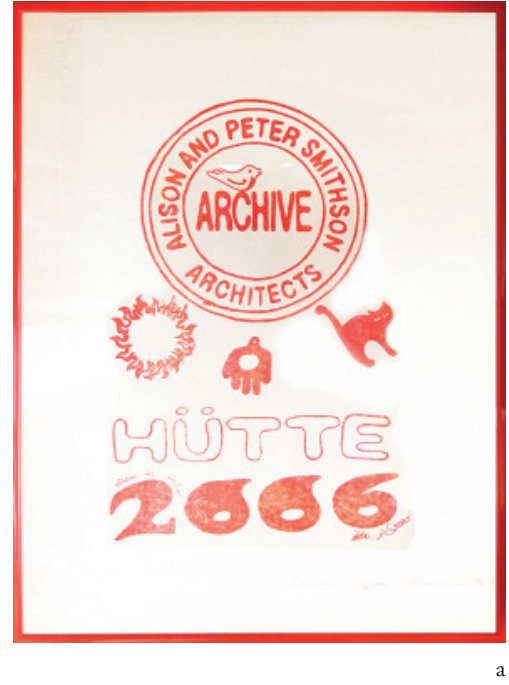

a. The Hutte. Soraya Smithson. Fotografía del autor. 


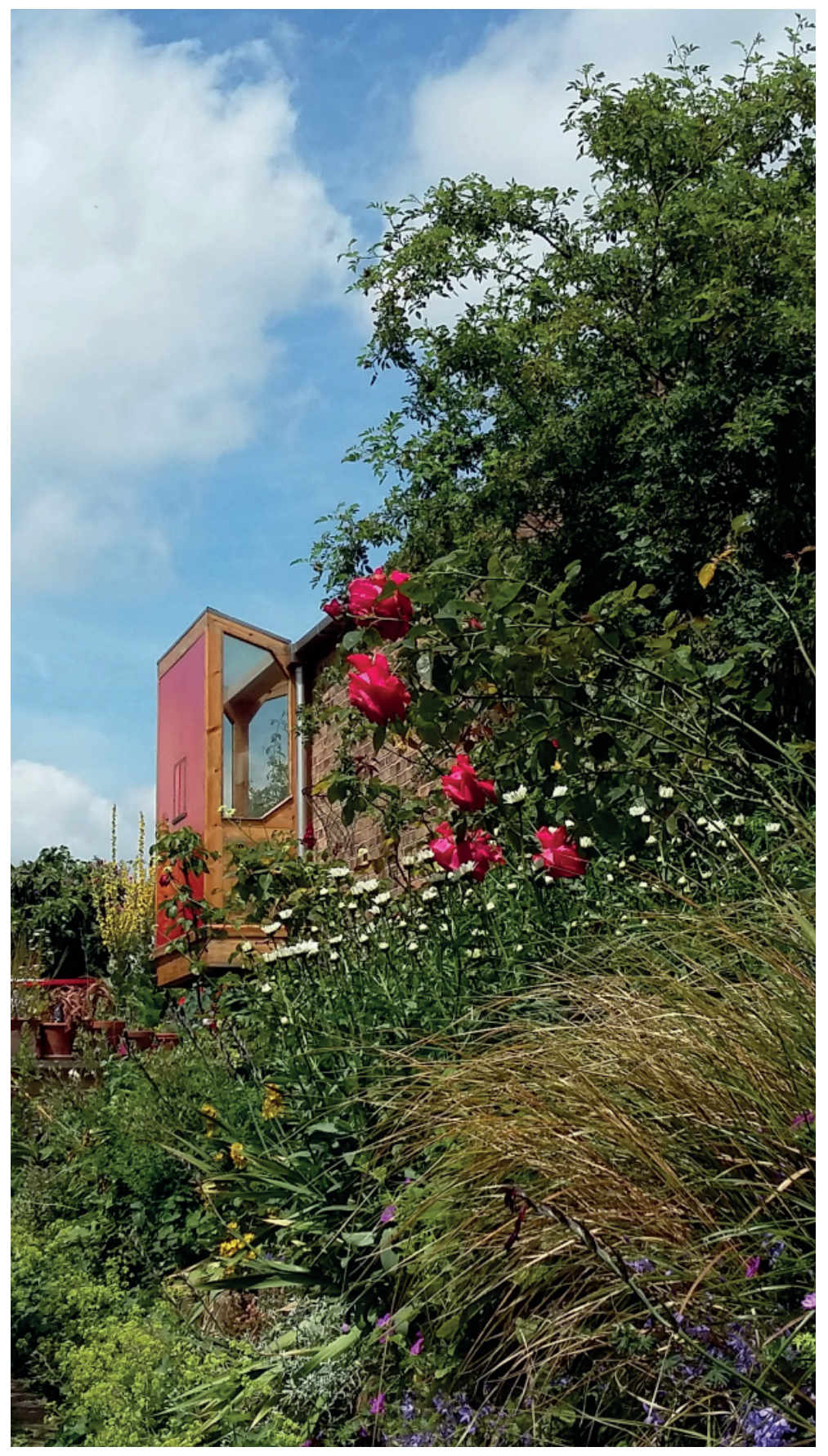

The Hutte

Fotografía del autor, 2015 
abadías y castillos medievales del norte de Inglaterra y, especialmente, la Muralla Adriana, de la cual conservaban numerosa información, como recortes de periódicos, postales, planos de rutas y folletos explicativos, que, sin duda, confirmaban el profundo interés de los Smithson hacia este limes romano.

Después de examinar cuidadosamente todo este material en los archivos, pude acceder, acompańado de Max Risselada, a un enigmático documento visual que desconocía hasta ese momento. Se trataba de The Big Scrapbook: ${ }^{1}$ un trabajo realizado durante años por Alison Smithson y que consistía en un "libro de recortes" elaborado sobre la enciclopedia visual de Charles Knight Old England: a Pictorial Museum of Regal, Ecclesiastical, Baronial, Municipal and Popular Antiquities ${ }^{2}$, a través de la introducción en sus páginas de cientos de fragmentos diferente procedencia: postales, fotografías, recortes de revistas y periódicos, etc. El resultado era una creativa reordenación de imágenes que propiciaba la aparición de vínculos y asociaciones sorprendentes entre ellas. Para mi investigación, este scrapbook también poseía un carácter revelador: entre las imágenes que lo componían se hallaban numerosas fotografías de paisajes estrechamente vinculados a la vida personal de los Smithson, así como imágenes de muchas de las formaciones artificiales del territorio de las que se valdrían para generar las ground-notations. Además, The Big Scrapbook mostraba una conexión con las estrategias de enraizamiento, basadas en la existencia, en ambos casos, de procesos de yuxtaposición.

Por último, al final de mi visita a The Hutte, dediqué algún tiempo examinar el extenso trabajo desarrollado por Alison Smithson en la década de 1980, titulado The Siting of Buildings, y cuyo valor principal para esta tesis radicaría en su capacidad para mostrar de manera explícita la condición esencial que los Smithson apreciaron en las ruinas clásicas: su instintiva manera de implantarse en el territorio, adecuándose intencionadamente a las condiciones particulares del territorio. Este trabajo inacabado, reúne y sintetiza a través de diferentes formatos -textos, dibujos y fotografías- esta idea clave, abriendo numerosas posibilidades de conexión e interpretación con los mecanismos de implantación desarrollados por los Smithson en sus proyectos.

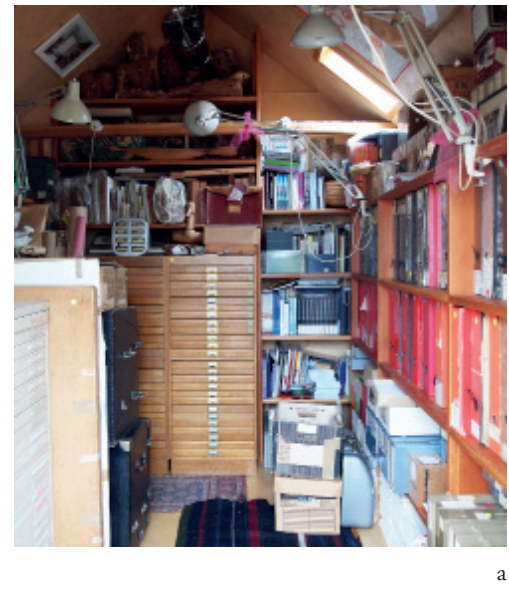

a

1. "The Big Scrapbook" era el nombre con el que La familia Smithson se refería a este libro de recortes.

2. KNIGHT, Charles, Old England: a Pictorial Museum of Regal, Ecclesiastical, Baronial, Municipal and Popular Antiquities. London, 1845.

a. The Hutte. Interior. Fotografía del autor, 2015 


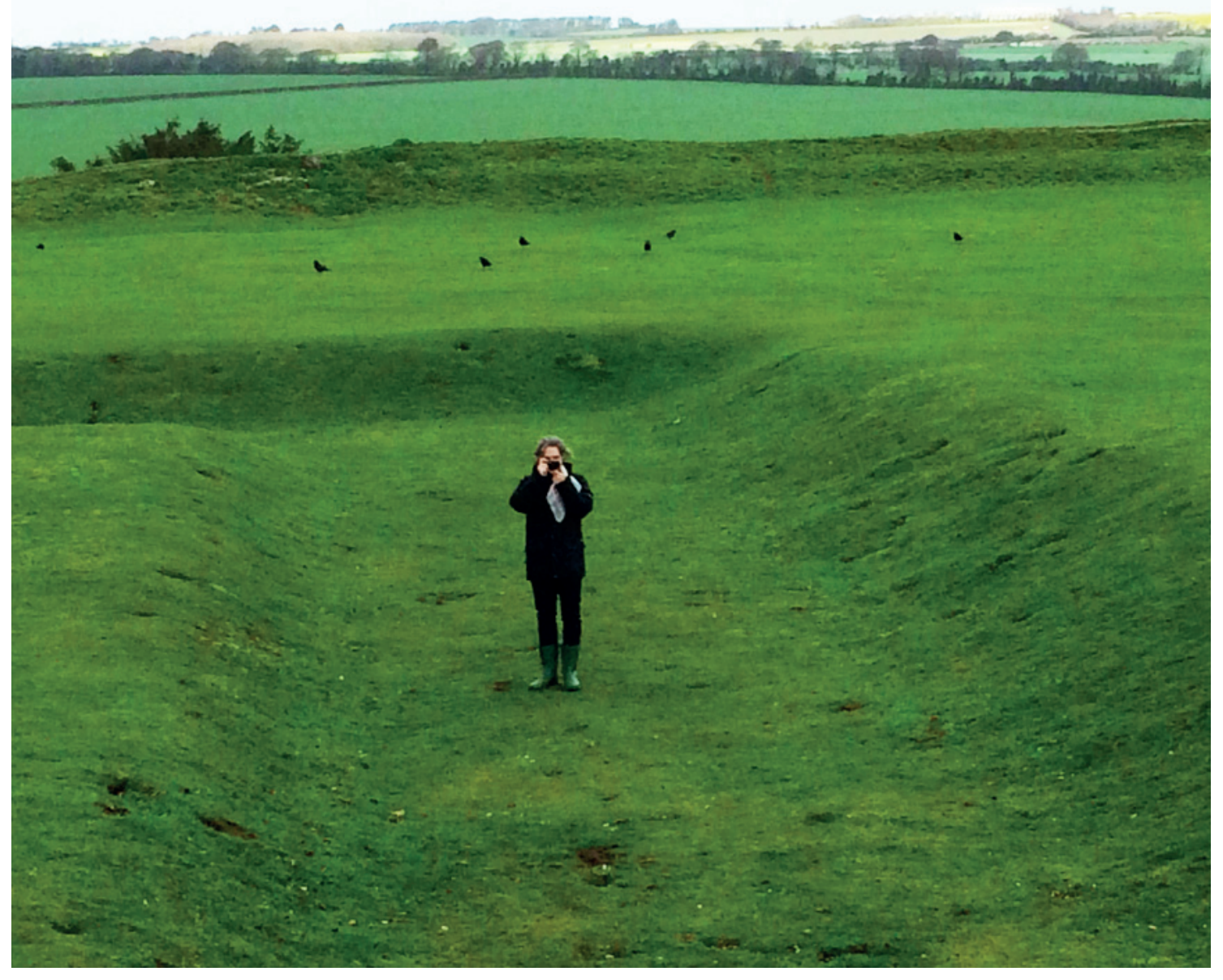

Old Sarum

Viaje de exploración, 2014 


\section{Entrevistas}

Otra parte esencial de esta investigación ha sido el contacto personal con los dos hijos arquitectos de Alison y Peter Smithson -Simon y Soraya- con quien mantuve varias entrevistas entre los años 2012 y 2017 en torno a la obra y el pensamiento de sus padres. En un tema tan ligado a las experiencias vitales de los Smithson, como es el que plantea este estudio, los comentarios acerca de algunos aspectos biográficos, como las excursiones y viajes — de los que ellos también formaban parte- o sobre ciertos intereses personales de estos arquitectos, contribuyeron a aclarar el camino de esta investigación. Las explicaciones de Simon y Soraya Smithson acerca del material consultado en los archivos familiares, resultaron claves para entender algunos de los documentos inéditos de sus padres y contextualizarlos en el conjunto de su obra. Asimismo, la visión de Max Risselada fue fundamental para este trabajo. Las varias entrevistas mantenidas con él desde el año 2013 y, especialmente, a través de mis estancias y visitas en la TU Delft, en los años 2015 y 2016, fueron apoyando y enriqueciendo con nuevos datos el desarrollo de mi investigación.

Este trabajo también se ha nutrido de algunas conversaciones con personas relevantes en la obra y en la vida personal de los Smithson, en particular, Ronald Simpson, arquitecto y amigo personal de Peter Smithson, con quien contacté en 2014 para comentar algunos hechos de interés para esta investigación, acontecidos cuando Peter y él eran todavía estudiantes. También ha formado parte de las conversaciones en torno a la figura de los Smithson, el contacto más puntual con Carme Pinós -amiga personal de los Smithson-y con algunos de los arquitectos colaboradores que formaron parte del estudio en la década de 1990-2000, como Pedro Pablo Arroyo, Pablo Olalquiaga y Alberto Nicolau.

\section{Viajes y visitas}

Para el desarrollo del trabajo han sido fundamentales los viajes realizados a Inglaterra para visitar los edificios más significativos de los Smithson, permitiéndome adquirir, a través de la experiencia propia y de la toma de notas, una percepción personal del diálogo que mantienen estas seis obras con el territorio: La Escuela Secundaria de Hunstanton, en Norfolk, el Garden Building en Oxford, los edificios de la Universidad de Bath, el pabellón Upper Lawn en Tisbury y The Economist y Robin Hood Gardens, en Londres. Pero, además de estos edificios, realicé visitas a algunos lugares claves en la formación del pensamiento topográfico de los Smithson: los earthworks prehistóricos de Salisbury Plain, como Silbury Hill, Avebury Henge y Old Sarum; las topografías defensivas de Castle Rising en Norfolk; los jardines pintorescos del siglo XIII, como Stourhead, Blenheim, y Stowe; las abadías medievales en los valles 
del norte, como Mount Grace Priory, Fountains y Rievaulx Abbey, y los restos del limes romano en la zona próxima a Newcastle, todos ellos esenciales para entender las apropiaciones del paisaje sobre las que se gestarían las estrategias de enraizamiento.

\section{Revisión teórica y bibliográfica}

Como no podía ser de otro modo, el desarrollo de este trabajo de investigación ha venido respaldado desde sus orígenes por una exhaustiva revisión y estudio de toda la extensa bibliografía relacionada con el tema de esta tesis, gracias a la cual he podido perfilar las preguntas de investigación e hipótesis y analizar con mayor seguridad los resultados. Parte esencial de esta bibliografía han sido los textos manuscritos inéditos de Alison y Peter Smithson consultados en los archivos, como Speaking to the Sky y Collective Design Sensibility Primers -algunos de los cuales se incluyen con Anexos en este trabajo- y la maqueta del libro no publicado de Alison Smithson The Anthology of Classical Sites.

\section{Análisis gráfico}

Como complemento y síntesis gráfica de la revisión de teórica y bibliográfica, he realizado una investigación de la obra de los Smithson mediante dibujos analíticos de sus proyectos más significativos. Este método gráfico ha examinado la ocupación del plano del suelo, generando un extenso catálogo de huellas que permite analizarlas según su forma, entendiéndolas como una primera acción para la incorporación de los espacios exteriores en los edificios. Posteriormente, he realizado dibujos esquemáticos de las diferentes configuraciones del suelo de los proyectos, con el fin de mostrar no sólo las operaciones topográficas que comprenden las ground-notations, sino también la yuxtaposición entre edificio y el suelo, producida en las estrategias de enraizamiento. El análisis gráfico también ha comprendido la realización de dibujos que evidencian las apropiaciones del paisaje llevadas a cabo por los Smithson. Mediante este método se ponen en relación el territorio y sus intervenciones en la sección del suelo, pudiendo trazar conexiones entre ciertos fragmentos del paisaje autóctono y las ground-notations de los proyectos de Alison y Peter Smithson. 


\section{Estructura}

Esta tesis se estructura en dos partes. La primera, La formación de un pensamiento topográfico, está compuesta por los tres primeros capítulos y analiza la influencia que ejerció en los Smithson el territorio, entendiéndolo como el responsable principal de una mirada operativa hacia el mismo, capaz de originar la apropiación de todo un catálogo de dispositivos de enraizamiento. Y la segunda, Ground-notations: tácticas de configuración del plano del suelo, está formada por 6 capítulos que abarcan el estudio de las groundnotations más relevantes, a través del reconocimiento y el análisis de estas herramientas proyectuales en el conjunto de la obra de Alison y Peter Smithson.

En el primer capítulo, Exploraciones: el conocimiento del territorio a través de la recolección y el montaje, se introducen y se explican los factores esenciales que contribuyeron a la génesis de estas intervenciones de manipulación del suelo, profundizando en dos aspectos principales: el conocimiento del territorio autóctono, adquirido a través del trabajo de campo y el análisis de la superficie del terreno por medio de la fotografía aérea, y la consideración del paisaje como material de proyecto, susceptible de ser manipulado, recombinado y reordenado mediante procesos creativos de montaje y yuxtaposición, en cierto sentido, análogos a los experimentos bidimensionales llevados a cabo por los Smithson en sus collages y scrapbooks y que se muestran de manera concluyente en The Big Scrapbook.

En el segundo capítulo, Apropiaciones: la interiorización del paisaje autóctono, se analizan las apropiaciones de ciertas huellas, topografías y construcciones vernáculas situadas en paisaje del norte Inglaterra (North East England y Yorkshire); en concreto, en 4 territorios ligados estrechamente a la vida personal de estos arquitectos. En el conjunto de la tesis, pero en especial en este capítulo, los documentos encontrados en los archivos y las conversaciones mantenidas con los hijos de los arquitectos, poseen un valor fundamental, ya que aportan datos reveladores acerca del vínculo que los Smithson mantuvieron con los territorios estudiados, así como las influencia que ejercieron en el desarrollo de los mecanismos de implantación llevados a cabo en sus proyectos.

En el tercer capítulo, Incursiones: la asimilación del mundo antiguo, 1951-1979, se analiza la influencia que tuvo en los Smithson la exploración en directo de los sitios clásicos -griegos y romanosen su renovada consideración de suelo como parte esencial del 


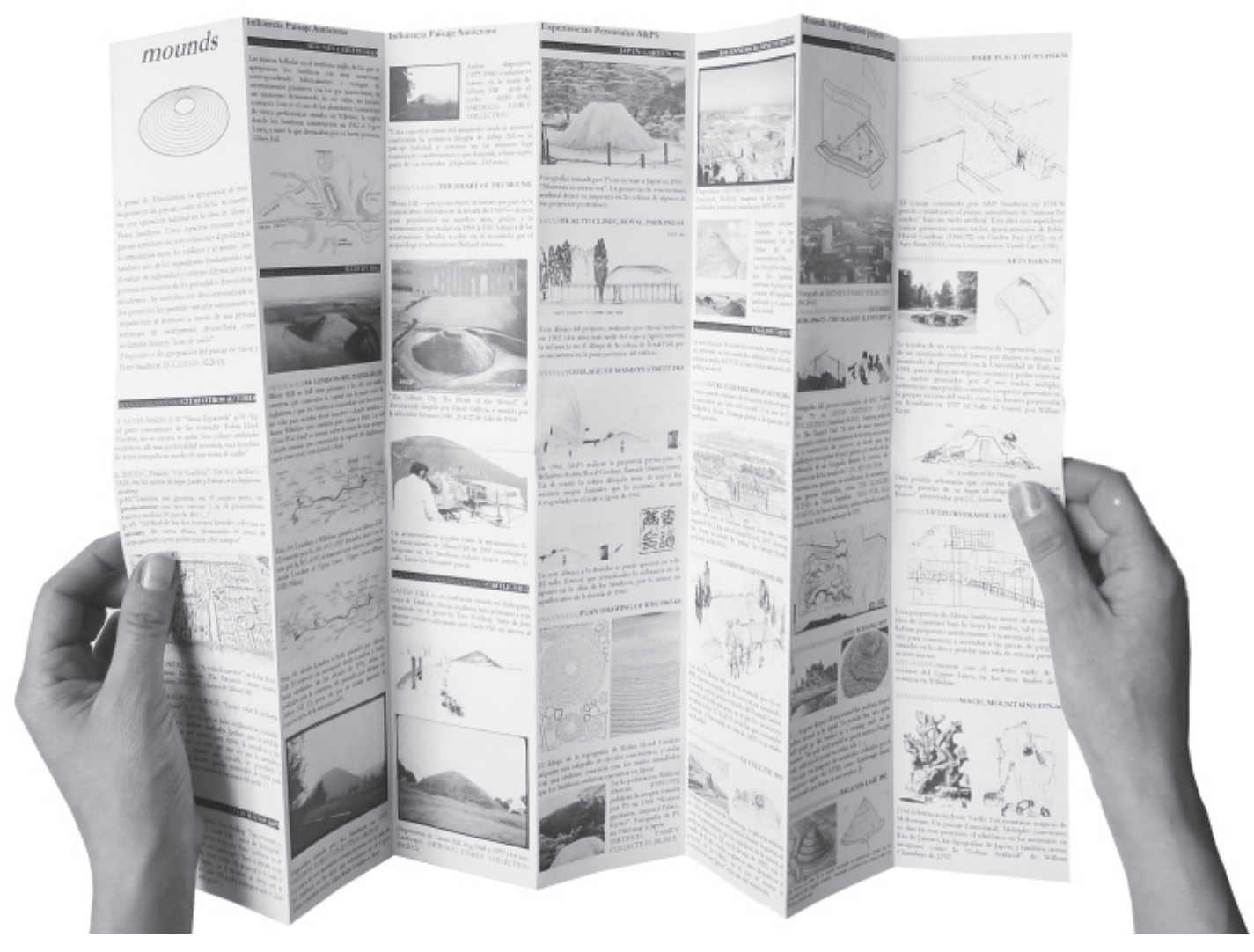

Grounding strategies

David Casino 
proyecto. En este capítulo, se explica el rechazo a las teorías de Rex Martienssen tras los primeros viajes a Grecia y la influencia, en la década de 1960, de las posteriores interpretaciones de Vicent Scully, basadas en la conexión de los templos con el paisaje. Asimismo se analiza el proyecto inédito de Alison Smithson, The Anthology of Classical Buildings, a través de los textos, fotografías y dibujos que consultados en los archivos de la familia Smithson.

La segunda parte de esta tesis comprende un estudio específico de las ground-notations, centrando los análisis en las 6 más relevantes: hahas, moats and ditches, earthwork terraces, bunds, mounds and bumps $\mathrm{y}$ trees and hedgerows. A lo largo de seis capítulos, estas operaciones son explicadas a través de los proyectos, clasificándolas según las intervenciones que generan sobre el suelo e interpretándolas como el resultado de una operación concreta de apropiación del paisaje. En ellas se analizan los efectos de enraizamiento que desencadenan, como son los mecanismos de contacto entre los edificios y el suelo y la configuración topográfica de los límites y la superficie del emplazamiento.

Las imágenes situadas en las páginas pares de este documento pretenden generar un atlas visual que ofrece un recorrido por las referencias, intereses y obsesiones personales que fundamentaron el trabajo de los Smithson con el plano del suelo. Estas imágenes, inéditas en su gran mayoría, proceden de fotografías realizadas por el autor en los viajes a los lugares clave de esta investigación, y en las visitas a The Hutte, los archivos personales de la familia Smithson en Stamford. 


\section{La formación de un "pensamiento topográfico"}

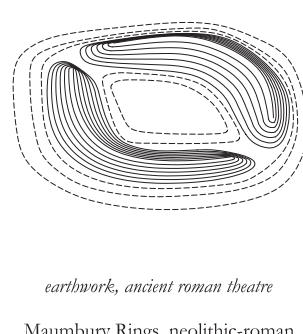

Maumbury Rings, neolithic-roman Dorchester, Dorset

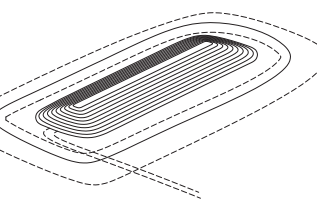

long mound-tumulus, Prebistoric barrow West Kennet Long Barrow, neolithic Avebury, Wiltshire.

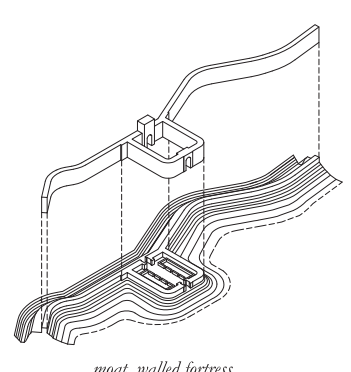

moat, walled fortress Milecastle 39, roman
Aadrian's Wall. Northumberlan Hadrian's Wall. Northumberland

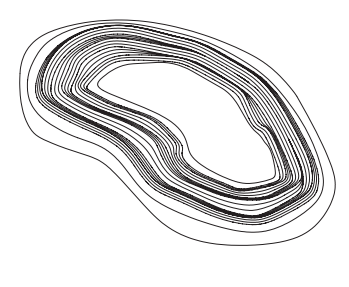

Earthwork, iron age billfort Maiden Castle, iron age
Dorchester, Dorset

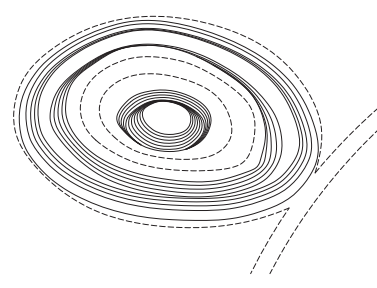

prehistoric artificial mound

Old Sarum, iron age

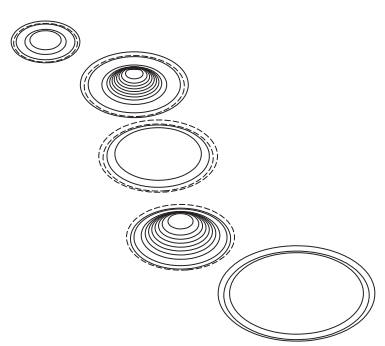

Barrow Cemetery

Normanton Down Barrows, neolithic Stonehenge, Wiltshi

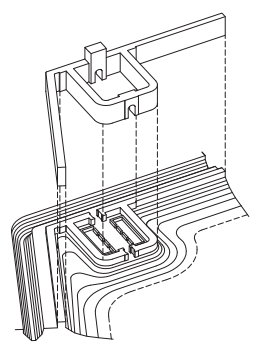

moat, walled fortress

Milecastle 26, roma Hadrian's Wall. Northumberland

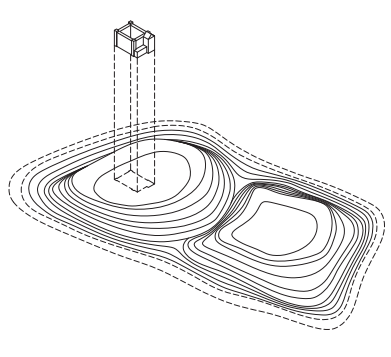

eartbwork

Castle Rising, 1138

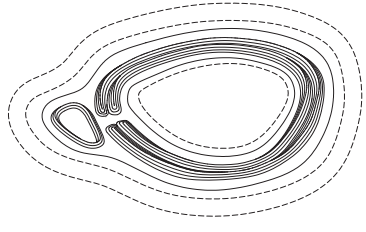

earthwork, iron age billfort

Yarnbury Castle, iron age
.

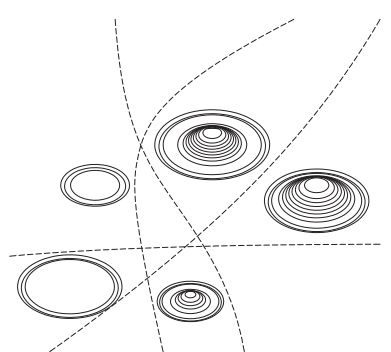

barrows, tracks
Disc Barrows
Bishops Cannings, North Down

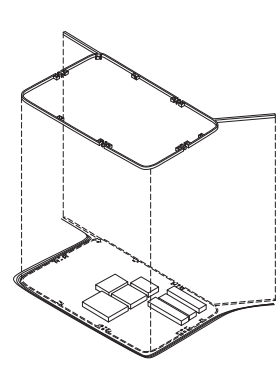

moat, walled fortress, enclosed groundmark.

Howsteads Roman Fort, roman
Hadrian's Wall, Northumberland

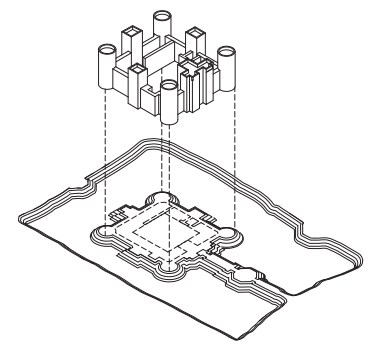

moat

Bodiam Castle, 1385 Robertsbridge, East Sussex

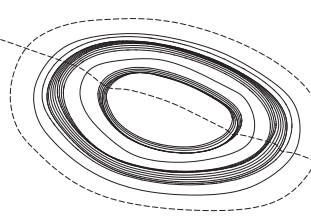

Neolithic Henge

Figsbury Rings, neolithic
Salisbury, Wiltshire

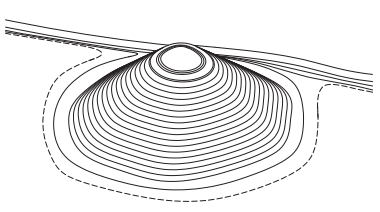

Silbury Hill, neolithic Avcbury, Wiltshire

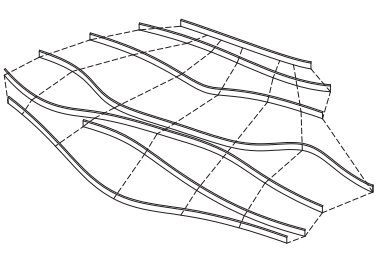

field walls

Stone Field Walls Yorkshire Dales

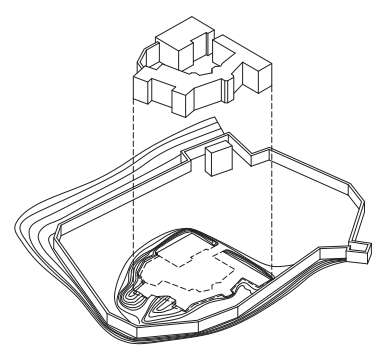

moat, earth ramparts

Kenilworth Castle, s. XII Kenilworth, Warwickshire 


\section{Primera Parte}

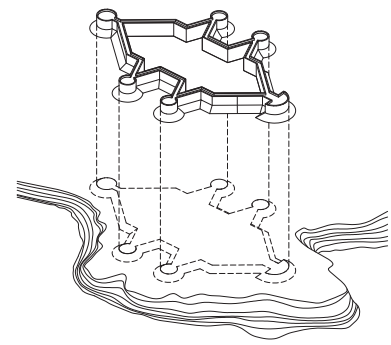

forffication

Tratado Artillería, 1470

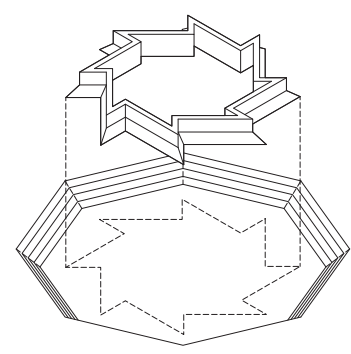

moat, fotrification

Tratado Artillería , 1470

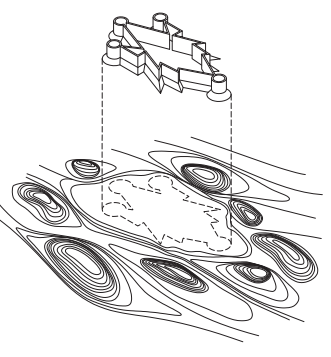

fortification topograpy adadapted

Tratado Artillería, 1470
Francesco Di Giorgio

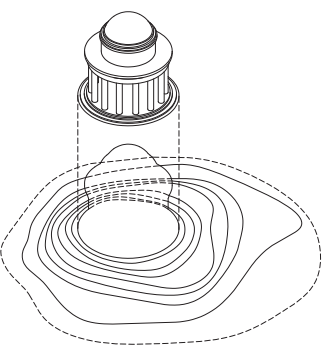

earth boundary, undulated ground

The Rotunda, Temple, 1741

Stowe, Buckinghamshire

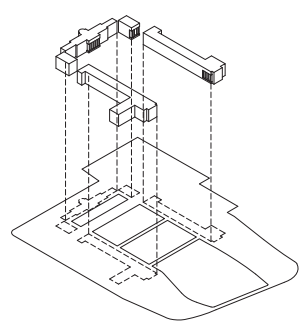

embracing ground mark.

Downing College, 1800

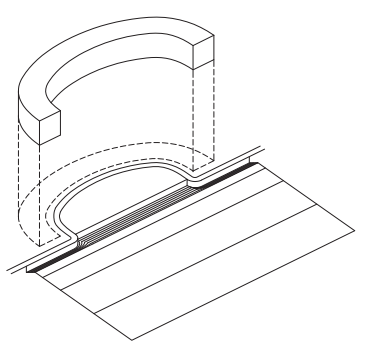

ba-ha, embracing-curved ground mark.

Royal Crescent, 1767-74

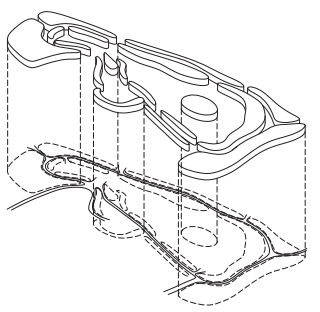

tree belts

Bournehill Cottage Garden, 1775
(Capability Brown) Cadland

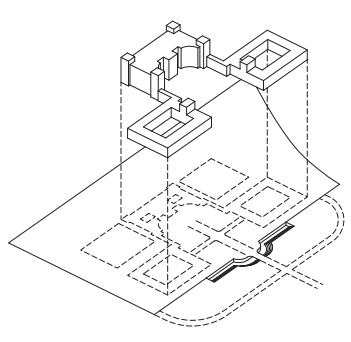

$b a-b a$

Blenheim Hall, 1705-22 Woodstock, Oxfordshire

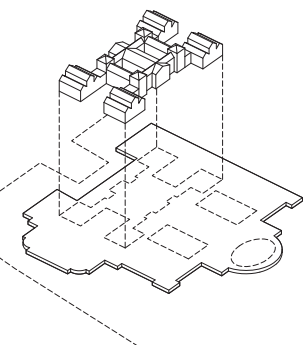

platform

Holkham Hall, 1734

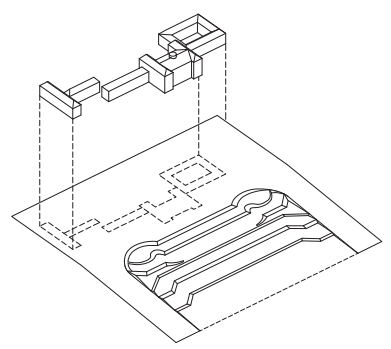

earthwork terraces

Castle Hill House, 1730

Filleigh, North Devon

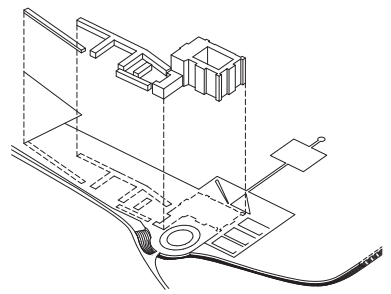

$b a-b a$

Burghley House, 1721

Stamford, Lincolnshir

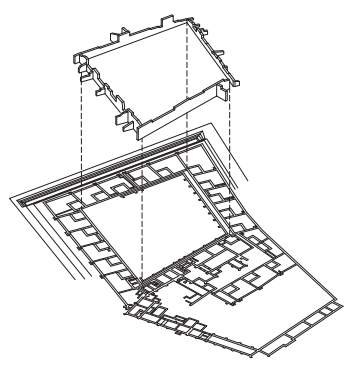

enclosed ground mark, moat

Mount Grace Priory, 1400

North Yorkshire

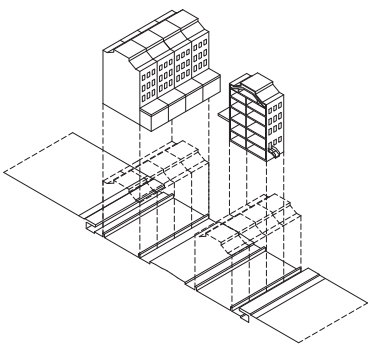

agitation of surface-ground

Georgian House

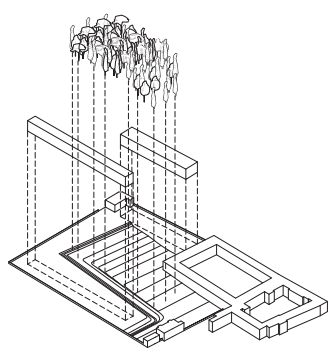

trees, agitation of surface-ground Gray's Inn, 1600 Londres

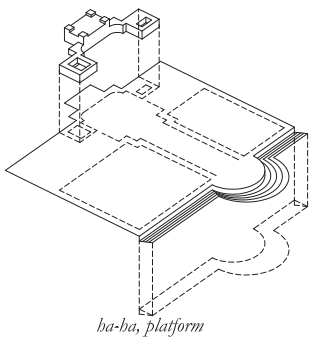

Houghton Hall, 1721
Norfolk

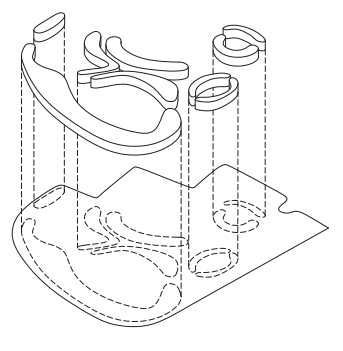

tree belts

Ashridge Garden, 1813 (Repton) Hertfordshire 


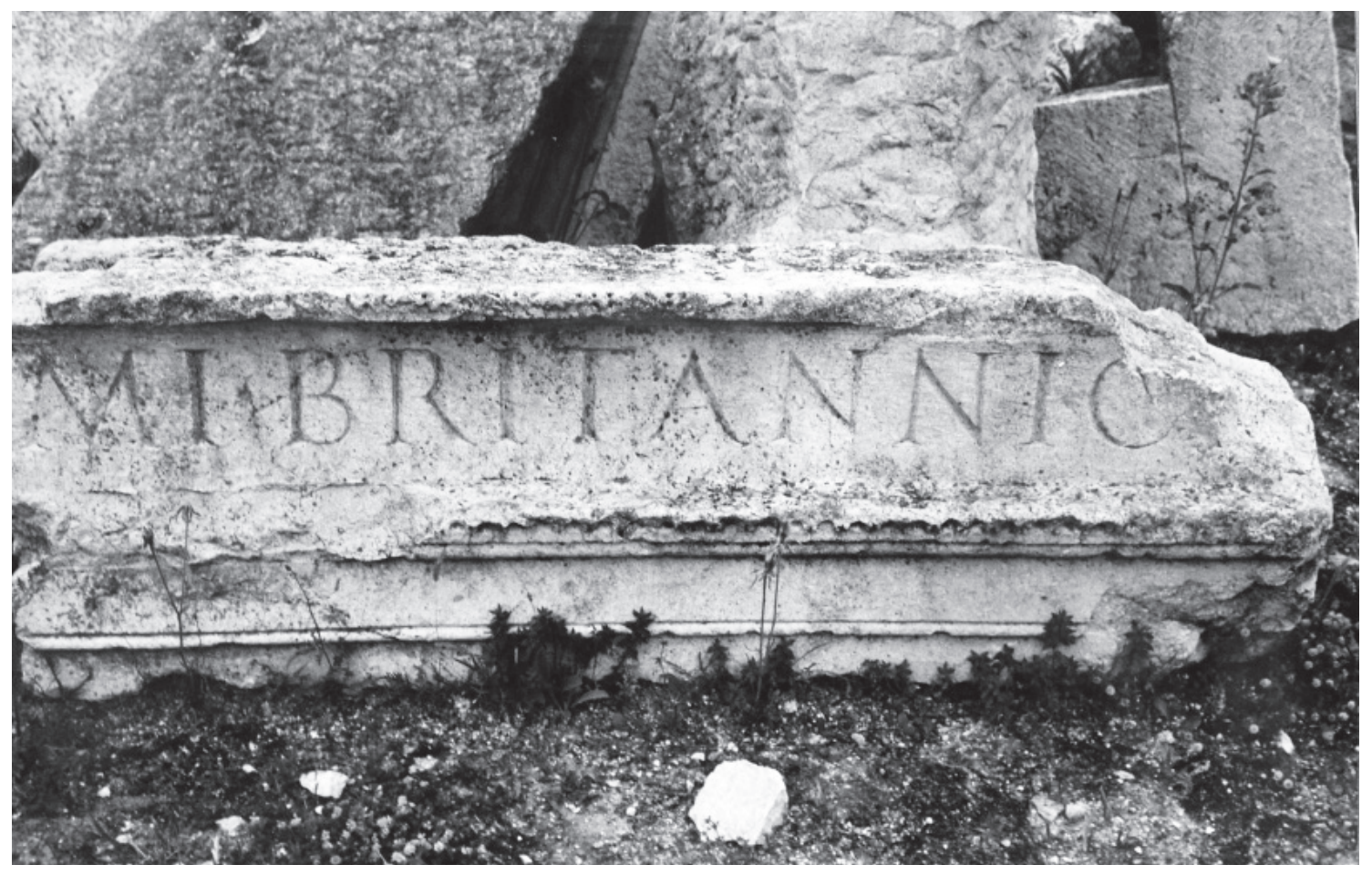

England 1972. Hadrian's Wall: Northumberland. Marked Cohort's stone Smithson Family Collection 


\section{La formación de un "pensamiento topográfico"}

En 1973, Alison Smithson publica Ruminations on Founders Court: ${ }^{1}$ un artículo acerca de la implantación de las ciudades romanas en el territorio, cuyo título ya nos revela, de entrada, el especial interés que los Smithson sentían por la arquitectura de aquellos ingenieros y arquitectos romanos a los que denominaban "fundadores". Este artículo analiza, entre otros aspectos, los Limites Romani o Limes, las fortificaciones fronterizas romanas levantadas a partir del siglo I en Europa y el Norte de África para proteger el Imperio de las invasiones, como el Muro de Adriano de la Britannia Romani; el Limes Germanicus situado en los cauces del Rhin y el Danubio, y las fortalezas de piedra del extenso Limes Arabicus.

Las imágenes seleccionadas por Alison Smithson ilustran que estos sistemas militares estaban formados por dos elementos de diferente naturaleza: una serie de construcciones realizadas en piedra o madera, como empalizadas, muros, castillos, torres de vigilancia o puestos fortificados, y un conjunto de operaciones topográficas, tales como fosos, diques, montículos y terraplenes de tierra. Estos últimos, localizados en las proximidades de las construcciones defensivas, constituían junto a ellas un eficaz sistema de protección frente a las amenazas de los territorios conquistados. Los límites defensivos romanos - tal y como ponía en valor Alison Smithson en su artículo- poseían una imaginativa capacidad de adaptación a las condiciones específicas del lugar, actuando como contrapunto a la imposición de la repetitiva trama de las ciudades romanas.

Esta condición de flexibilidad y acomodación al entorno que desarrollaron durante siglos las fronteras del Imperio según los diferentes contextos se basaba en dos aspectos principales. Por un lado, la necesidad de buscar emplazamientos estratégicos aprovechando las particularidades del lugar (topografía, clima, preexistencias naturales, etc.); por otro, la habilidad para establecer acuerdos con el paisaje y su topografía. Para ello, el conocimiento profundo del medio físico -el suelo- y la manipulación artificial del terreno constituían las herramientas fundamentales del proceso de implantación en el paisaje de estas construcciones romanas que, a pesar de su naturaleza exclusivamente funcional (defensiva), conseguían generar un intenso vínculo con el territorio, así como un fuerte sentido de pertenencia al mismo.

1. SMITHSON, Alison. «Ruminations on Founders Court». Architectural Design, noviembre de 1973 .
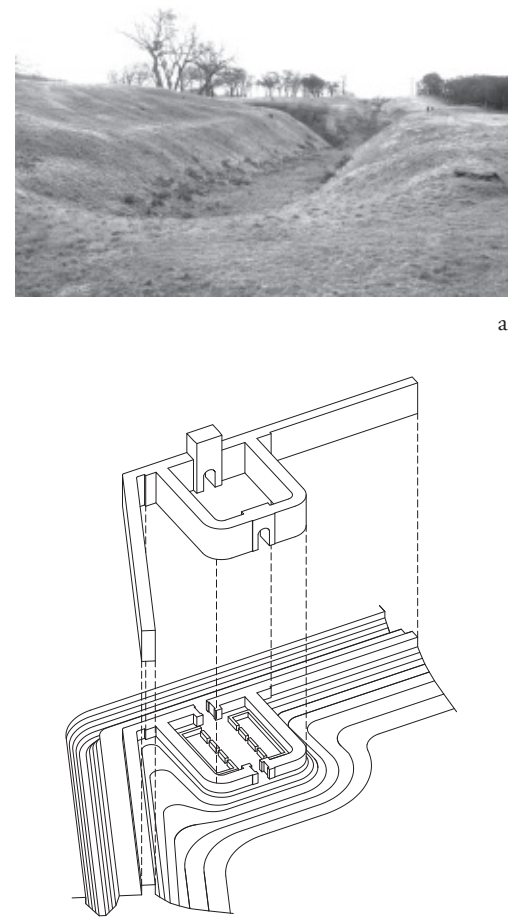

a. Intervenciones topográficas defensivas en Britannia.

b. Milecastle 37. Hadrian's Wall. Northumberlad. Adecuación a la topografía. Dibujo del autor. 


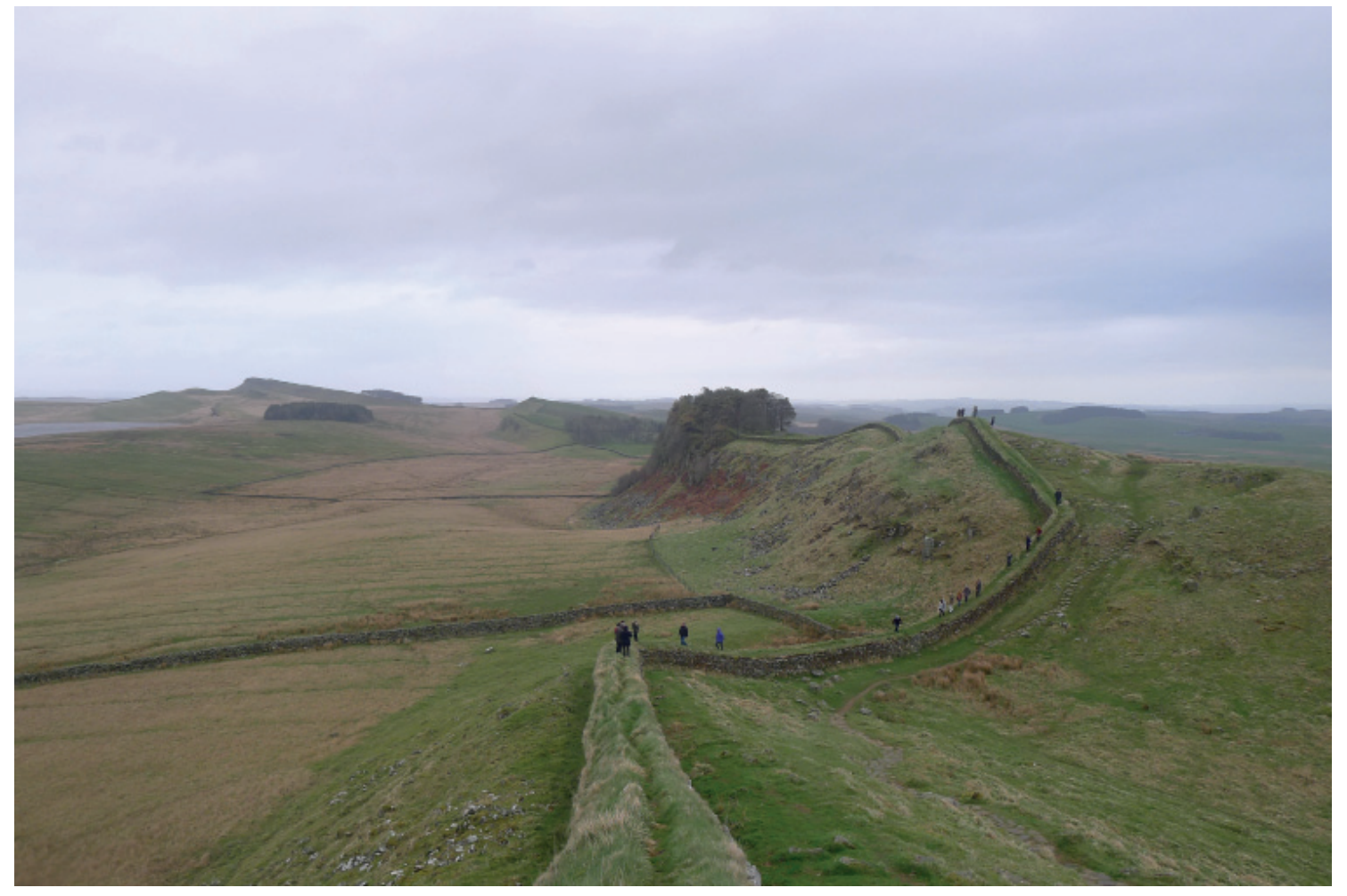

Hadrian's Wall

Fotografía del autor. 2014 
Las fortificaciones romanas eran bien conocidas por los Smithson ${ }^{2}$, especialmente por la experiencia directa con las ruinas del Limes situado en su territorio autóctono. La "gran huella",3 como denominaba Alison Smithson a la Muralla Adriana, definía el límite norte del Imperio Romano por el camino exacto ${ }^{4}$, desarrollándose a lo largo de más de 100 kilómetros mediante una sección constante de muro. La fortificación se adaptaba a las condiciones cambiantes del territorio, deslizándose por el ondulado paisaje del norte de Inglaterra hasta configurar el borde del Imperio. A su paso, un conjunto de movimientos de tierra definían su emplazamiento, configurando un complejo espacio defensivo en el que la muralla, construida con la piedra del lugar, se fundía en un paisaje agitado dramáticamente.

Esta adhesión al territorio que mostraban los Limites Romani era el resultado de una implantación topográfica perfectamente estudiada por los ingenieros romanos; una estrategia para generar un huella que sería parte indisoluble del paisajes: "(...) cuántos afanes para encontrar el emplazamiento exacto"6, aseguraba el emperador Adriano. Los Smithson admiraban la extraordinaria capacidad de estas infraestructuras militares para integrarse en el entorno; una habilidad para radicar en el lugar que obedecía a un intenso "pensamiento topográfico":

“(...) en conjunto, ese pensamiento topográfico implicaba configurar un terreno dado con suficiente detalle como para poder ser utilizado como parte esencial del proceso de diseño; esto es, poseer la destreza para tratar con la topografía con la misma habilidad como con cualquier otra parte del conocimiento".?

2. Además del Limes de la Britannia Romani, los Smithson investigaron también sobre las fortificaciones romanas del norte de África, algunas de las cuales fueron visitadas durante sus viajes por el Mediaterráneo. En Ruminations on Founders Court, Alison Smithson incluyó mapas e ilustraciones procedentes de los estudios más destacados sobre los restos de las fronteras africanas: Jean Baradez, Vue-Aerienne de l'organisation romaine dans le Sud-Algerien fossatum, Paris, 1949, y A. Poidebard: La trace de Rome dans le désert de Syrie: le limes de Trajan à la conquête arabe; recherches aeriennes (1925-1932), Paris, 1934.

3. “(...) lo que tenemos en nuestro paisaje es más significativo para nosotros: la 'gran huella romana', la Muralla Adriana; una 'marca' hecha con una verdadera dimensión heroica en la escala de los más audaces Limes del norte de África y de Siria” SMITHSON, Alison. «The City Centre full of Holes». AA Quarterly, 1977. p.17.

4. "Levantar fortificaciones, en suma, era lo mismo que construir diques: consistía en hallar la línea desde donde puede defenderse un ribazo o un imperio, el punto donde el asalto de las olas o de los bárbaros será contenido y roto. (...) YOURCENAR, Marguerite. Memorias de Adriano. Barcelona: Salvat, 1994.p.88

5. "Construir es colaborar con la tierra, imprimir una marca humana en un paisaje que se modificará asi para siempre". Ibid.

6. Ibid.

7. SMITHSON, Alison. "Ruminations on Founders Court". Architectural Design, vol. $43, n^{\circ} 8$, agosto 1973, p. 524 .

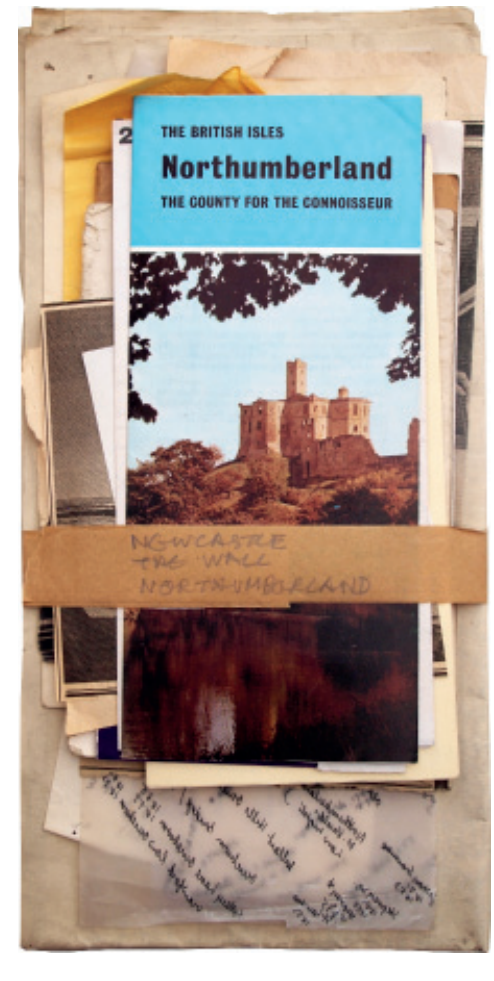

a. Documentación del territorio de Northumberland y la Muralla Adriana consultada en los archivos personales de la familia Smithson. Smithson Family Collection. 

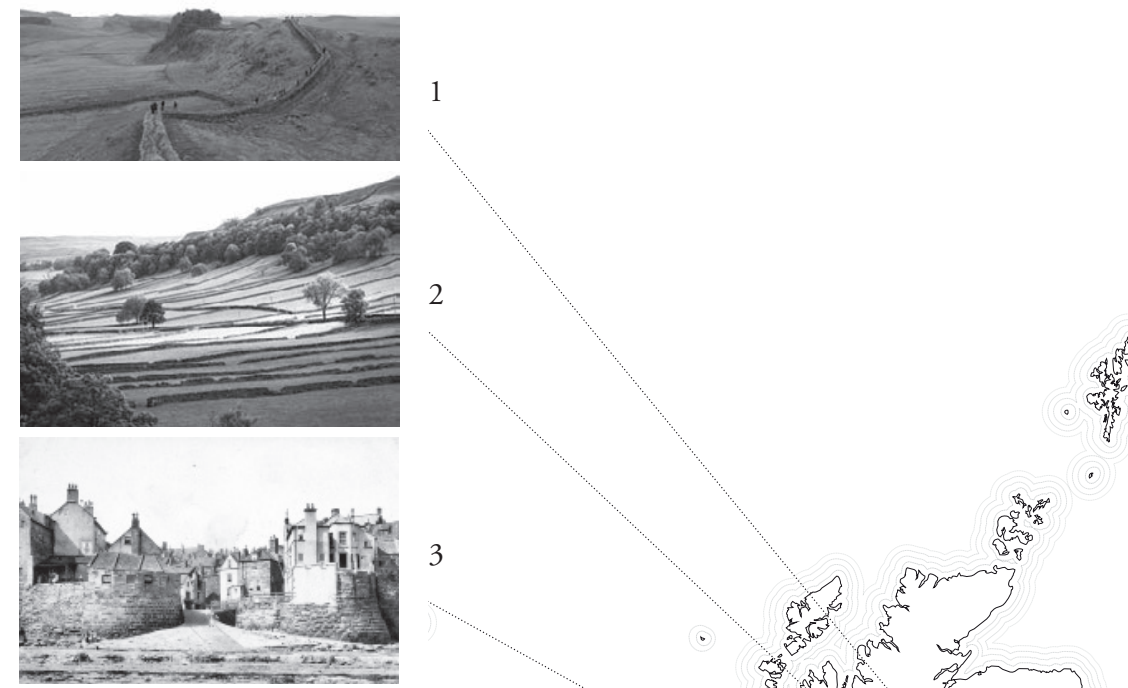

管
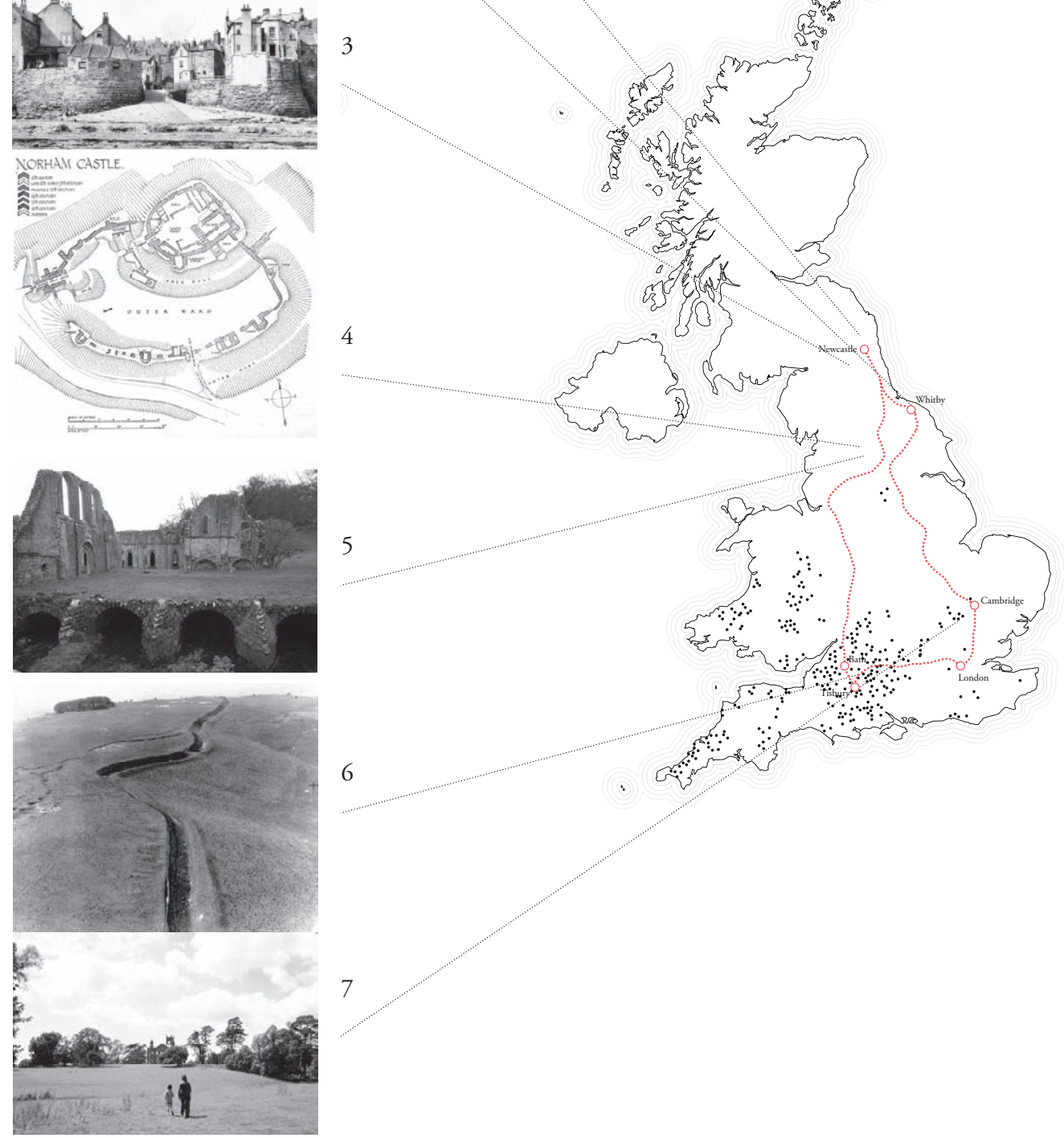

Apropiación del territorio autóctono Montaje del autor 
Al igual que aquellos arquitectos fundadores, los Smithson desarrollaron un "pensamiento topográfico" propio, consistente en una destreza semejante para definir la implantación de sus edificios mediante la manipulación de la sección del suelo. Se trata de un instinto que subyace latente en todos sus proyectos, como un aspecto clave en la definición del sentido del emplazamiento.

Consolidado a lo largo del tiempo, este pensamiento formaría parte sustancial de su manera personal de ver todo lo que les rodeaba: una mirada inclusiva en la que el suelo participaba como un estrato encontrado ${ }^{8}$, susceptible de ser reordenado y transformado topográficamente. Así, mediante este instinto operativo, los Smithson apreciaron el paisaje como astutos observadores", "cazadores" de mecanismos topográficos, de los que se valdrían posteriormente en sus proyectos para provocar desde el enraizamiento la conexión entre la arquitectura y el lugar.

El interés de los Smithson para proyectar el suelo se explica desde sus raíces biográficas. La profunda identificación ${ }^{10}$ que estos arquitectos sentían por el territorio del que procedían -el norte de Inglaterra ${ }^{11}$ permite entender la destreza con la que abordaban las cuestiones topográficas en sus proyectos. De aquel lugar, marcado por un fuerte carácter topográfico, los Smithson apreciaron, por encima de todo, la naturalidad con la que su arquitectura "anónima" se implantaba en el paisaje. ${ }^{12}$ Los muros primitivos de Yorkshire Dales, las ruinas de las abadías de North Yorkshire, los asentamientos vernáculos de

8. "Lo encontrado" conecta directamente con el concepto as found: "una nueva forma de ver lo ordinario, una apertura en lo que se refiere a cómo las cosas prosaicas podrían recargar de energía nuestra actividad creativa". SMITHSON, Alison and Peter. «The "As Found" and the "Found"", en The Independent Group. Postwar Britain and the Aesthetics of Plenty, editado por David ROBBINS, 201-2. Cambridge MA/London: MIT Press, 1990.

9. Aquí el suelo es entendido como parte de todo aquello que es encontrado en el camino, recogido y transformado en material de proyecto: una condición esencial en el método proyectual de los Smithson. En su "diario de viajes”, Alison Smithson señaló esta condición característica de su trabajo: “(...) an aspect of our belief that everything is important as indicators and/or as 'fodder'; everything can be picked up and examinated, turned over and thought freshly about to see if it will inform us directly of something we previously did not realise..." SMITHSON, Alison. AS in DS. An Eye on the Road. Delft: Delft University Press, 1983.

10. "There are some days on which a hill-bred person cannot bear looking at hobbema's road strtching to Middelharnis nor face one of Vermeer" 's distant views of Delf" Comienzo del texto escrito por Alison Smithson con motivo de la muerte de Jaap Bakema en 1981. On Bakema, en: RISSELADA, Max, Dirk van den HEUVEL (eds.), Team 10. In Search of a Utopia of the Present 1953-1981, NAi Publishers, Rotterdam, 2005, p. 240

11. Los Smithson eran originarios del norte de Inglaterra. Véase nota $\mathrm{n}^{\circ} 3$, página 15.

12. En una conversación con el autor, Simon Smithson explicaba así la interacción entre arquitectura y topografía que caracterizaba el entorno del que provenían sus padres: "Topography and buildings of course come together in Newcastle which has quite a dramatic setting" (05.2017).
Además del paisaje del norte existieron otros lugares explorados en el sur de Inglaterra que influyeron en la obra de Alison y Peter Smithson: el entorno prehistórico de Salisbury Plain (Wiltshire) visitado durante el tiempo que habitaron Upper Lawn y los parques paisajistas del siglo XVIII. Apropiaciones del territorio autóctono (imagen a la dcha).

1. Paisaje defensivo del Limes.

2. Field walls en Yorkshire Dales.

3. Asentamientos en la costa de Moors.

4. Castillos medievales en Yorkshire.

5. Abadias y monasterios en Yorkshire.

6. Earthworks primitivos en Wiltshire.

7. Jardines pintorescos. 


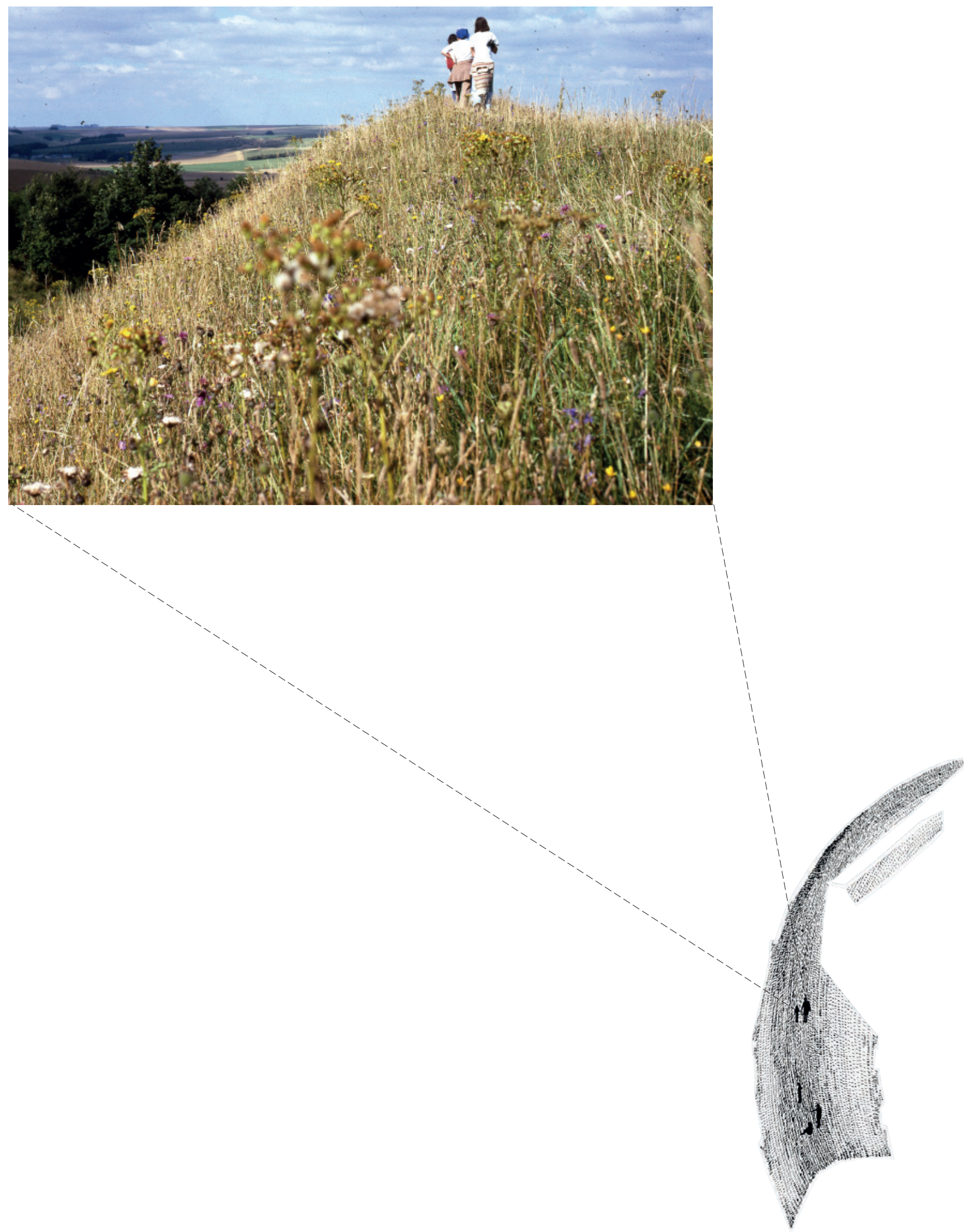

Exploraciones en el entorno prehistórico de Salisbury Plain, Wiltshire

Fotografía de la familia Smithson en Battlesbury Hill Fort.1969. Smithson Family Collection

Ficción de la familia Smithson sobre el bund de la casa Bates. Montaje del autor 
la costa de Moors ${ }^{13}$ o los restos romanos de Northumberland, ${ }^{14}$ se asentaban en aquel territorio con aparente normalidad, apropiándose de las particularidades del terreno como parte constituyente de la propia intervención. Para los Smithson, palpar esta condición de enraizamiento desde la infancia ${ }^{15}$ sería una experiencia que les marcaría durante toda su trayectoria, influyendo de manera decisiva en el alcance que tendría la configuración del suelo en su obra.

Además del norte, otro paisaje de diferente naturaleza será igualmente revelador para los Smithson: la planicie de Salisbury. Este mítico lugar de enterramientos y fortificaciones prehistóricas, situado en el sur de Inglaterra, fue explorado ${ }^{16}$ con detalle por los Smithson en las frecuentes excursiones que realizaron desde Wiltshire en los años que habitaron Upper Lawn ${ }^{17}$. El paulatino descubrimiento de aquellas formaciones de tierra $^{18}$ resultaba fascinante para los Smithson, especialmente para Alison, que trató de rastrear con insistencia todas aquellas manipulaciones topográficas primitivas, como se desprende del testimonio de sus hijos, ${ }^{19}$ quienes todavía recuerdan las intrépidas incursiones que hacían con sus padres en busca de marcas de tiempos remotos. Pasear por las huellas del pasado y examinar a través de las fotografías aéreas sus efectos sobre el paisaje, sería una experiencia inspiradora de muchas de las ground-notations de sus proyectos, producidas, como se verá más adelante, mediante estrategias específicas de apropiación de este evocador territorio.

13. La adecuación de estos pueblos a las condiciones específicas del territorio sería puesta en valor por los Smithson: “(...) sus estrechas callejuelas situadas en perpendicular al viento, lo canalizan desde la boca del puerto, evitando intencionadamente las corrientes y el oleaje del mar". SMITHSON, Alison and Peter. «An Alternative to the Garden City Idea». Architectural Design, julio de 1956.

14. El "pensamiento topográfico" que los Smithson veían en los asentamientos romanos estaba relacionado con las decisiones estratégicas para la elección del lugar. "They tend to select a rather special type of site: a valley-slope facing south or east, not too high up, with shelter from wind, exposure to the sun, and water close and hand". COLLINGWOOD, R.G. and MYERS, J.N.L., Roman Britain and the English Settlements, Oxford: Clarendon Press, revised edn 1937, p.209.

15. Soraya Smithson I think landscapes of one childhood leave a lasting impression. They both had Yorkshire somehow imbedded in their bones.

16. En los Smithson, el conocimiento del territorio vendrá dado por una doble exploración llevada a cabo a través de la experimentación in situ y la visualización del paisaje mediante la fotografía aérea. Véase "Exploración del territorio. Mapas, fotografías aéreas y trabajo de campo", en el Capítulo 1 de esta tesis.

17. 1959-1982

18. Cerca de Upper Lawn también se encuentran importantes huellas de sistemas de agricultura primitivos: "Such fileds can be most readly seen from the air, as Fyfield Down near Marlborough in Wiltshire". HOSKINS, W. G. The Making of the English Landscape, (First Edition by Hodder \& Stoughton 1955) Penguin Books, London, 1985. p.24.

19. "I believe my mother became fascinated with ancient pathways and boundary lines possibly first in Wiltshire. I remember excursions to these ancient ways from Upper Lawn with hair-raising drives along old ways and the resultant scratches along the sides of the Citroen with the car suspension on High. Lifting the car up to max was always great fun when we were children and my father relished this feature of the DSs". Relato de Simon Smithson, extra ído de una conversación mantenida con el autor en 2015.

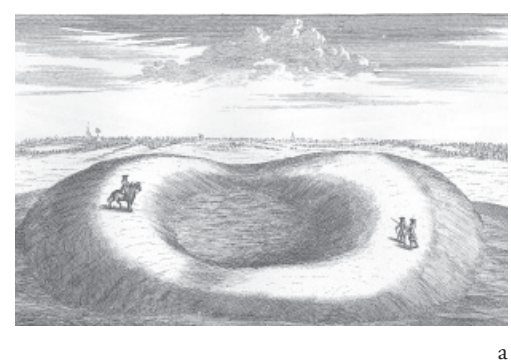

imagen izqda: En la Casa Bates (195355) los Smithson proyectaron una escalera exterior que comunicaba la vivienda con la parte superior del bund. Este elemento, que sobresalía del volumen compacto de la casa, conectaría a sus habitantes directamente con la tierra, permitiéndoles caminar sobre una topografía artificial desde la que contemplar el paisaje de la huerta de Burrows Lea Farm, donde se emplazaba la vivienda. La ficción de la familia Smithson caminando sobre el bund recrea una experiencia que contiene el recuerdo de las exploraciones de los Smithson en el entorno prehistórico de Wiltshire.

a. Richborough Castle, Oct.7.1724. William Stukeley. Esta "curiosidad", que llamaría tanto la atención a este anticuario inglés del siglo XVIII, se trataba de los restos de un antiguo anfiteatro romano que el tiempo y la sedimentación de materiales ha transformado en un extrańo montículo integrado en el paisaje. 


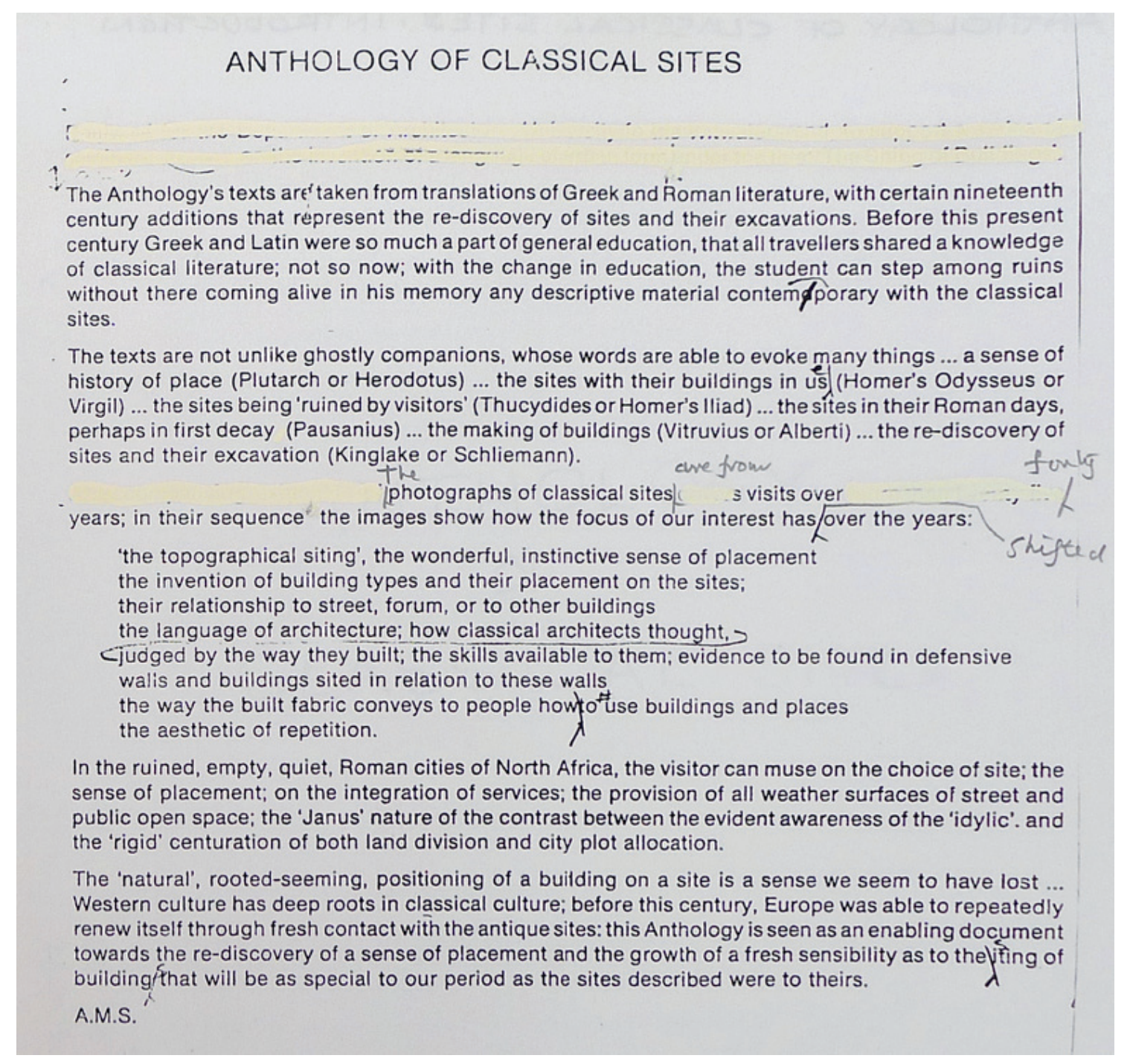

Extracto de la maqueta del libro Anthology of Classical Sites. Alison Smithson, 1979-81 Smithson Family Collection

Fotografía del autor 
$\mathrm{Al}$ mismo tiempo, los Smithson entraron en contacto con un lugar de características radicalmente diferentes: el Mediterráneo. A través de los emplazamientos de las ruinas clásicas -griegas y romanas-, repartidas por diferentes lugares del sur de Europa y del norte de África, los Smithson se adentraron en el conocimiento de sus mecanismos de ubicación en el paisaje. De la mano de las teorías, primero de Martienssen y, posteriormente de Scully, examinaron las antiguas ciudades griegas, desvelando la importancia de la topografía en la configuración de su traza. Lo que comenzó en 1951 con un simple viaje a Atenas para conocer de primera mano la Acrópolis -de la que Le Corbusier ya anunciaba en 1923 que poseía un "equilibrio oculto que sólo engañaba al profano"- ${ }^{20}$ se acabaría convirtiendo en toda una investigación por un territorio mucho más extenso, centrada en recuperar ciertas sensibilidades que la arquitectura había olvidado, o quizá, pasado por alto. En esta causa personal los Smithson invirtieron más de 25 años y 10 largos viajes, en los que interiorizaron el "maravilloso e instintivo"21 concepto de la implantación topográfica que descubrieron en el clasicismo del Mediterráneo.

\section{Experiencias previas}

En el origen del pensamiento topográfico de los Smithson, también influyeron algunas experiencias biográficas previas $^{22}$. Se trata de vivencias relacionadas con la experimentación de la topografía, acontecidas con anterioridad a 1949, fecha en la que los Smithson inician de manera conjunta su actividad como arquitectos. Estos hechos -algunos de ellos extraídos de las entrevistas mantenidas con sus hijos durante el desarrollo de esta investigación- nos revelan asimismo la importancia que tuvo la experiencia personal en la manera de proyectar de los Smithson ${ }^{23}$.

20. Le CORBUSIER, Hacia una arquitectura. Barcelona: Poseidón, 1978. (Ed. original: Vers une Architecture, Paris, 1923). En 1927, fue publicada la edición inglesa. Los Smithson se refirieron en varias ocasiones a este libro de Le Corbusier, del que Banham diría que su influencia "va más allá de la de cualquier otra obra arquitectónica publicado en este siglo hasta la fecha". BANHAM, Reyner. Theory and Design in the First Machine Age. Architectural Press, London, 1960.

21. "The topographical siting, the wonderful instinctive sense of placement". Alison Smithson, 1990. Texto no publicado (typoscript) sobre el proyecto The Antholoy of Classical Buildings, incluido como en los anexos de esta tesis.

22. Experiencias personales -algunas de ellas inéditas- extraídas de las conversaciones mantenidas por el autor con los hijos de Alison y Peter Smithson, así como con Ronald Simpson, amigo personal de los arquitectos y colaborador del estudio en algunos proyectos.

23. "El aspecto altamente individual de su método [proyectual] suponía que la naturaleza histórica general de la disciplina arquitectónica estaba estrechamente entretejida con la experiencia personal". HEUVEL, Dirk van den. «Picking up, turning over and putting with...», en From the House of the Future to a House of Today, editado por Dirk van den HEUVEL y Max RISSELADA, Rotterdam: 010 Publishers, 2004.
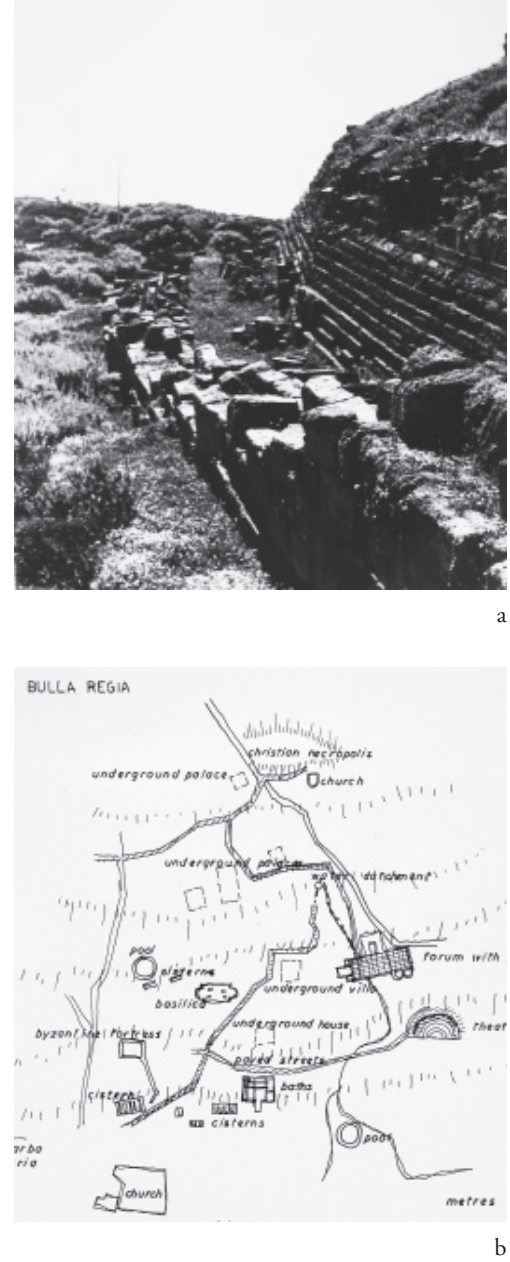

a. City Walls: Selinunte.1963. 'View along ruined outer wall, protecting "moat" and step-battered inner wall to east of city temple area. Antholoy of Classical Sites. Smithson Family Collection.

b. North Africa. Tunisia. Bulla Regia. All compiled and drawn. A.M.S, 1981. Antholoy of Classical Sites. Smithson Family Collection. Los Smithson visitaron los restos de los asentamientos romanos en el Norte de África en viajes anuales desde 1967 a 1973. La Trace de Rome, dans le Desert de Syrie (Antoine Poidebard, 1934) y Fossatum Africae, Vue-Arienne de lórganisation Romaine dans le Sud-Algerie (Jean Baradez, 1949) fueron investigaciones decisivas para los Smithson. Estas publicaciones mostraban mediante planos y fotografías aéreas los restos de las construcciones militares del Limes Africae como marcas en el terreno: movimientos de tierra que hacían referencia a las antiguas canalizaciones de agua, fosos defensivos y trazas de los campamentos. 


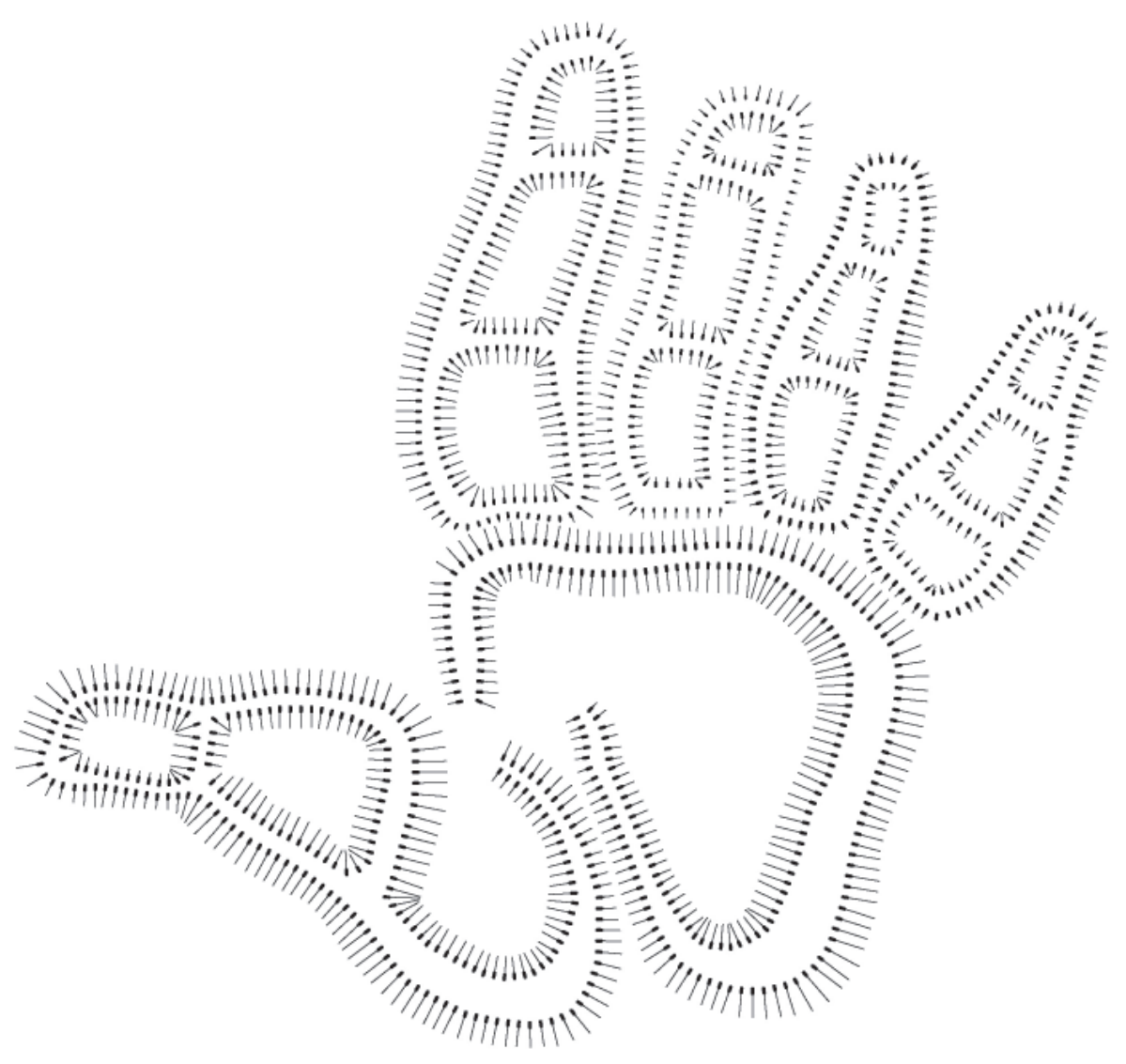

Bunds

Topografías ocultas en un cuadro de Peter Smithson

Dibujo del autor 
En el periodo de la Segunda Guerra Mundial, Peter Smithson realizó el servicio militar en Birmania (India), entre 1943 y 1945. Allí, alistado en el mítico ejército de los "zapadores de Madrás" —un cuerpo de ingenieros encargado de cavar trincheras ${ }^{24}$ — obtendría un conocimiento preciso de estas topografías militares. Los fosos y las trincheras entrarían a formar parte de las referencias de los Smithson, como demuestran su inclusión en sus scrapbooks ${ }^{25}$ y la alusión a los movimientos de tierra defensivos de las fortificaciones militares en algunos de sus textos. ${ }^{26}$

Durante aquel periodo en la India, Peter Smithson también pudo conocer los sistemas locales utilizados para contener el agua del terreno, los bunds, ${ }^{27}$ unas formaciones artificiales de tierra conformadas mediante taludes y terraplenes, cuya particular geometría inspiraría una de las ground-notations más relevantes de los Smithson. A pesar de que el término "bund" era un vocablo poco corriente en la lengua inglesa, los Smithson siguieron empleándolo en sus proyectos, posiblemente en recuerdo de aquellas infraestructuras topográficas primitivas que tanto impresionarían a Peter Smithson en su juventud y que volvería a examinar ańos después, junto a Alison Smithson, en un nuevo viaje a la India en $1960 .{ }^{28}$

De vuelta a Inglaterra, en 1947 y antes de finalizar la carrera, Peter Smithson realizó un revelador viaje de estudios a Escandinavia. A pesar de que el objetivo principal era conocer los edificios de Asplund $^{29}$, aquel viaje estaría marcado por el descubrimiento de los

24. "Ya sabes cómo llaman a los del cuerpo de ingenieros, los llaman zapadores, por las zapas, las trincheras que se cavaban (...)" en: COLOMINA, Beatriz, "Friends of the Future: A Conversation with Peter Smithson». October, Fall de 2000.

25. "Libros de recortes", entre los que destaca el realizado por Alison Smithson, denominado como The Big Scrapbook. Véase el punto 1.3 "Técnicas de Montaje. The Big Scrapbook"

26. "The earth becomes the defender", en: SMITHSON, Peter. «Fortifications». ILA\&UD Annual Report, Venecia, 1999.

27. Bund: (in India and the Far East) "an embankment; dyke". (Collins English Dictionary). Según ese mismo diccionario, el origen etimológico del término bund: "from Hindi band, from Persian; related to Sanskrit bandha band". Según el diccionario Merriam-Webster, el significado de bund es el siguiente: "an embankment used especially in India to control the flow of water".

28. Esta apropiación del término es confirmada por Simon Smithson. En los planos originales de Upper Lawn se puede ver escrita la palabra "bund" sobre la topografía del jardín (Véase: Cap. 7). En Imprint of India, Alison Smithson utiliza también ese término: "Occasionally the road runs on the bund alongside irrigation canals engineered by the same successive administrations". SMITHSON, Alison. "Interpretations of Q.F.K. : India. (Typescript)», Spring /01/1966-28/08/1972 de 1971.

29. En los Smithson el contacto con la arquitectura de Asplund: Gunnar Asplund Architect 1885-1940 (Holmdahl, G., Lind, S.I. and Ödeen, K (eds), 1943). SMITHSON, Peter. «Reflections on Hunstanton». ARQ, Summer de 1997. Sobre las intervenciones topográficas de Asplund, véase, entre otros: MARTÍNEZ SANTA-MARÍA, Luis. El árbol, el camino, el estanque, ante la casa, Colección Arquithesis, no15. Barcelona: Fundación Caja de Arquitectos, 2004. "En Skövde el terreno mesetario es revertido mediante la creación de una serie de pequeñas colinas a las que la cubrición de la capilla parece adherirse. Prácticamente no hay una obra asplundiana donde los temas psicofísicos de las ascensión y el descenso no estén contemplados y donde consiguientemente la tierra no vibre".
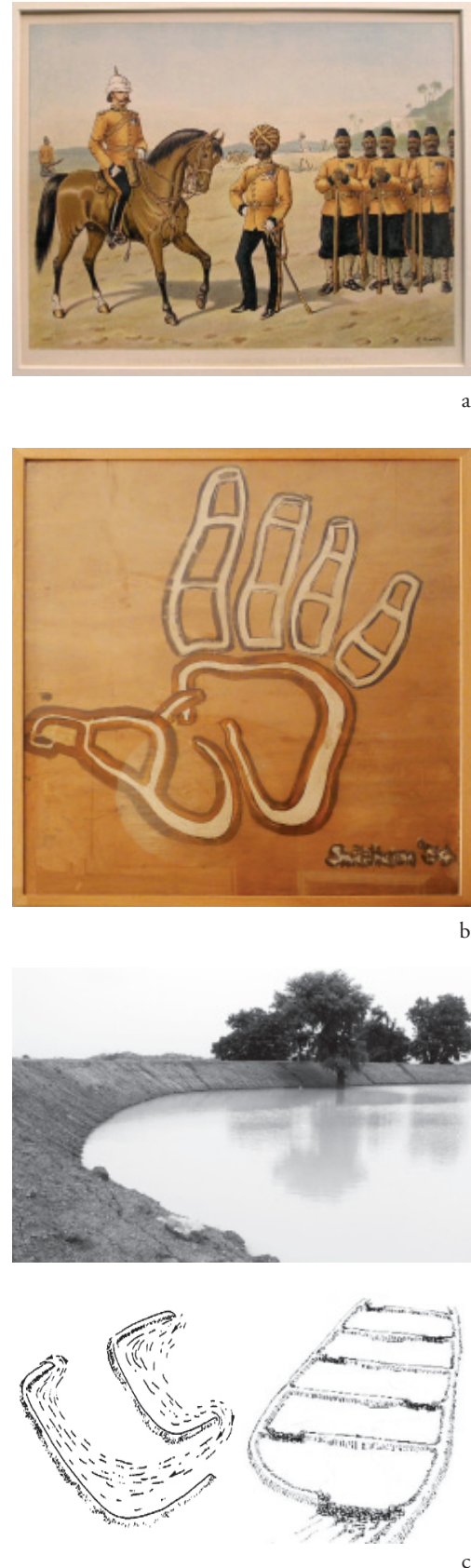

a.Ejército de zapadores de Madrás: The Queen's Own Madras Sappers and Miners.

b. Pintura realizada por Peter Smithson en 1954. Propiedad de la familia Smithson, fotografiado por el autor, 06.2014.

La diferenciación cromática de los trazos de esta pintura, traducida mediante códigos topográficos (líneas de máxima pendiente) conforma un relieve de contornos de tierra y vacíos que alude a los diques y terraplenes empleados en países como India para contener el agua en el terreno (imagen a la dcha).

c. Bunds en la India. Sistemas de contención de agua en el terreno. 


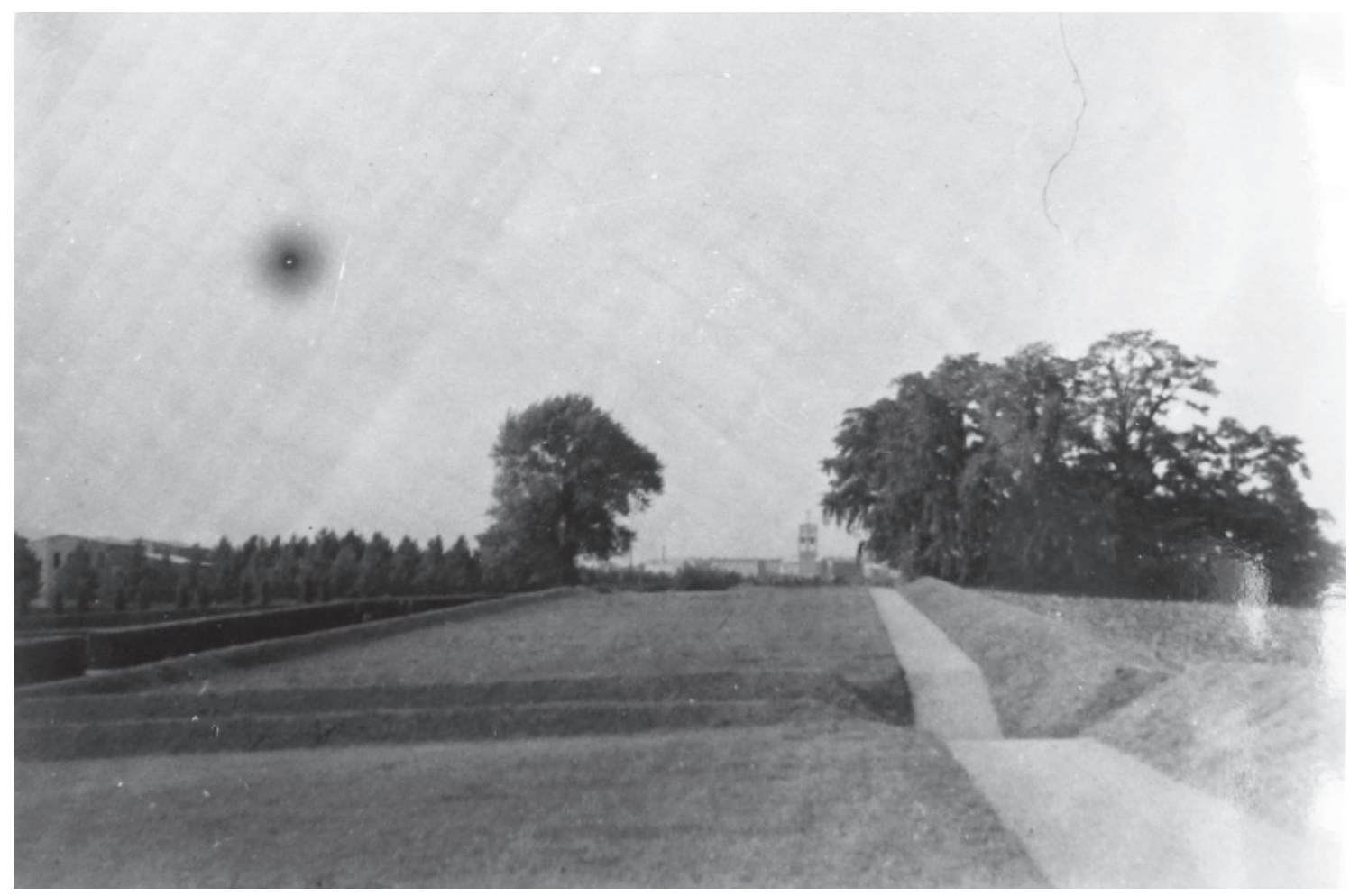

Terraces, Lewerentz Cemetery, Malmö.

Fotografía tomada por Peter Smithson en 1947 en el cementerio de Malmö Smithson Family Collection 
paisajes artificiales de Lewerentz ${ }^{30}$. Ronald Simpson ${ }^{31}$, compañero de Peter Smithson en aquel viaje, todavía recordaba, más de 50 años después, aquella vivencia: "un estudiante de arquitectura de Copenhague nos sugirió ir a visitar el cementerio de Lewerentz en Malmö, una de sus primeras obras más importantes: fue una revelación deslumbrante, todavía tengo aquella experiencia entre mis recuerdos". ${ }^{32}$ Aquel encuentro casual con las terrazas y los suelos hinchados de Malmö quedaría plasmado por Peter Smithson en unas intencionadas fotografías ${ }^{33}$ que nos demuestran la sensibilidad con la que apreció la esencia topográfica de las intervenciones Lewerentz, caracterizadas por una profunda tensión entre geometría y naturaleza. ${ }^{34}$

Por su parte, Alison adquirió desde su infancia un especial interés en la jardinería; una afición que heredaría de su madre y cuya impronta se dejaría sentir en diferentes proyectos de los Smithson, caracterizados por una utilización estratégica de la vegetación empleada para la delimitación de ámbitos exteriores de uso, la protección contra el viento y las vistas o la creación de sugerentes cromatismos en los suelos junto a los edificios. De este interés por lo natural provendría la incorporación de determinados elementos vegetales, como las pantallas de setos y árboles, las cuales aparecen frecuentemente en los planos de los proyectos como condiciones preexistentes o nuevas plantaciones destinadas a configurar el emplazamiento.

\section{Principios pintorescos}

Junto a estas experiencias individuales, tampoco hay que olvidar que, como arquitectos ingleses, los Smithson heredaron una destacada tradición paisajista que contemplaba el territorio como un medio en el que actuar e introducir transformaciones, ${ }^{35}$ generar experiencias ${ }^{36}$

30. SMITHSON, Alison. «L'albero e la colonna. The Landscape that can Survive and the Lewerentz Connection». Spazio e Società, marzo de 1984. En este texto, Alison reconocería la deuda contraída con Lewerentz en sus años de formación: (...) my recognition of the extensión of the landscape language was in the work of Lewewrentz in the cementery at Malmö

31. Ronald Simpson colaboraría en los años siguientes en algunos proyectos de A\&PS

32. Esta experiencia es descrita por Ronald Simpson, compañero de viaje y amigo de Peter Smithson en: SIMPSON, Ronald, 'From the Beginning' en Architecture is not made with the brain: The labour of Alison and Peter Smithson, AA Publications, Londres, 2003, pp.78-79.

33. Fotografías consultadas por el autor en los archivos de la famila Smithson.

34. LINAZASORO, José Ignacio. «Los Túmulos de Uppsala». Circo, 1998.

35. "Parliamentary enclosure and the Landscape", en HOSKINS, W. G. The Making of the English Landscape, (First Edition by Hodder \& Stoughton 1955) Penguin Books, London, 1985.

36. STEENBERGEN, Clemens, y (Wouter) REH. "La geometría de lo pintoresco. El jardín pintoresquista inglés del siglo XVIII" en: Arquitectura y paisaje. La proyectación de los grandes jardines europeos. Barcelona: Gustavo Gili, 2001, pp. 244-261.
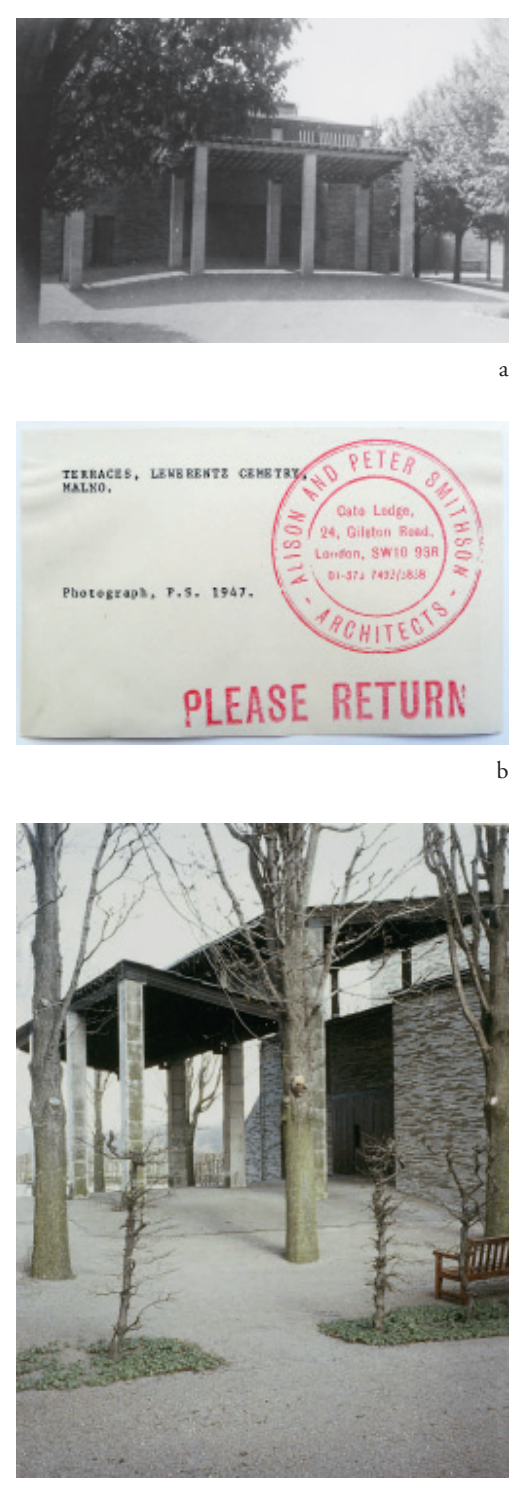

a. Portico Lewerentz Chapel, 1945, Malmö. Fotografía tomada por Peter Smithson en 1947 en la que se puede apreciar el "suelo hinchado" en la zona de acceso a la capilla. Smithson Family Collection.

b. Terraces, Lewerentz Cemetery. Parte posterior de la fotografía tomada por Peter Smithson en 1947 en el cementerio de Malmö (Imágen pagina anterior). La fotografía muestra intervenciones en el plano del suelo, como eran los taludes que configuraban los bordes de los caminos, el ondulamiento del suelo y la colina artificial al fondo.

c. Cemetry at Malmö. Sigurd Lewerentz 1943. Fotografía tomada por Alison Smithson en 1980. Smithson Family Collection. 


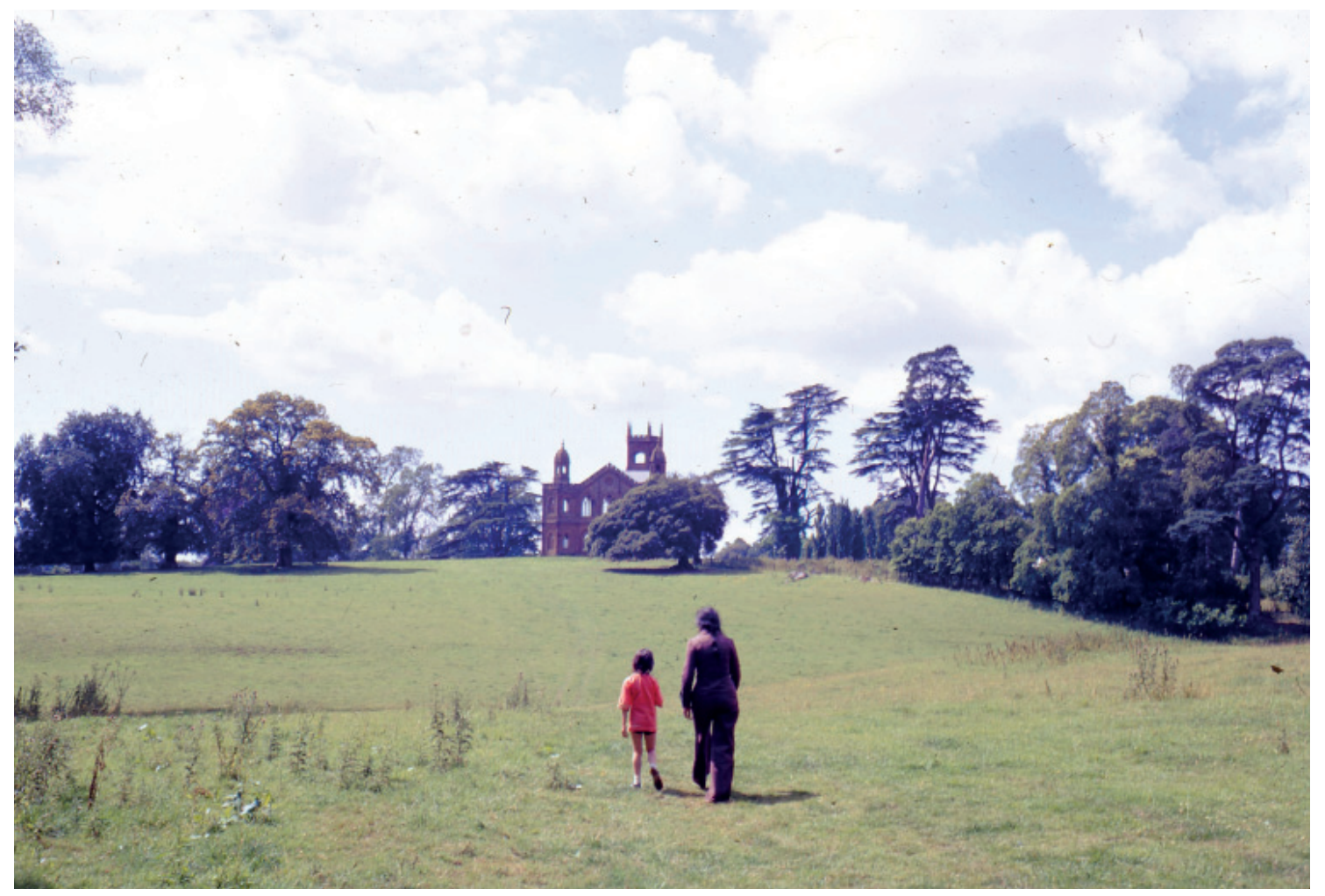

English landscape garden

Alison Smithson con uno de sus hijos en el jardín de Stowe

Fotografía: Peter Smithson: 1971. Smithson Family Colecction 
y recrear un "sitio"37. Esta herencia recibida junto con el profundo conocimiento que poseían de las realizaciones de los jardineros de la época - a través de la literatura ${ }^{38}$ y la experimentación in situ de los jardines paisajistas de Brown, Kent o Repton ${ }^{39}$ — impulsaría en los Smithson la aparición de una particular manera de modelar el terreno, enriqueciendo sus "instintos topográficos" e incorporando en sus proyectos la sensibilidad inglesa ${ }^{40}$ hacia el paisaje y las técnicas de configuración del suelo inspiradas en los artificios pintorescos iniciados en el siglo XVIII. Los $h a-h a$, montículos, terrazas, taludes, cinturones de árboles y las láminas de agua que utilizaron para modelar el suelo en varios de sus proyectos, hunden sus raíces en los tratamientos artificiales de Stowe, Stourhead, Claremont o Blanheim: escenarios pintorescos examinados durante ańos por la atenta mirada que los Smithson proyectaron hacia todo aquello les rodeaba.

En 1995, dos ańos después de la muerte de Alison, Peter Smithson manifestaba la influencia determinante que tuvo el Pintoresquismo en su obra:

"Picturesque not as picture, but people in the centre, sensitiveness and feeling, the Picturesque as a root of our thoughts" 41

Esta reflexión, realizada al final de su trayectoria, en un momento del estudio caracterizado por la introspección y la reelaboración de antiguos proyectos, nos dirige hacia una apreciación más profunda del concepto de "lo pintoresco" en la obra de estos arquitectos ingleses, alejada de su estricta vinculación al origen etimológico del término - "pintura" - y más próxima a sus preceptos originales: aquellos enunciados por los teóricos ingleses de la segunda mitad del siglo XVIII que definieron "una forma intelectual bajo la cual los británicos entendieron el mundo, el territorio, el paisaje y la ciudad, durante la centuria que abarca entre 1730 y $1830 " .{ }^{42}$

37. Sobre el significado de generar un "sitio" en los jardineros paisajistas del s. XVIII, véase: WILLIAMS, Raymond. El campo y la ciudad. Buenos Ai, Paidós, 2001.

38. Los Smithson hicieron numerosas referencias a la literatura de Austen y Cobbet, para aludir a la sensibilidad inglesa hacia el paisaje. Véase: SMITHSON, Alison. AS in DS. An Eye on the Road. Op.cit. y los fragmentos de textos de CLARK, H.F. (The English Landscape Garden, Pleaides Books) recogidos por los Smithson en Without Rethoric.

39. En los archivos de la familia Smithson se encuentran fotografías y diapositivas que reflejan las visitas a los jardines ingleses de Stowe, Stourhead, Chatsworth, Kew, Biddulph Grange o Chatsworth, entre otros.

40. En los Smithson, esta "sensibilidad inglesa" se observa en algunos textos, como los agrupados bajo el título Sensibility Primers: AS in DS, Q.F.Ky 1916 A.S.O. En los anexos de esta tesis se incluyen fragmentos de textos inéditos realizados por Alison y Peter Smithson (década de 1970) referidos a los tres escritos que componen Sensibility Primers.

41. KRUCKER, B., Complex Ordinariness: the Upper Lawn Pavilion by Alison and Peter Smithson. GTA /ETH Zürich, 2002, p.17.

42. MADERUELO, Javier. "La mirada pintoresca". Universidad de Santiago de Compostela. Servicio de Publicaciones e Intercambio Científico. 2012
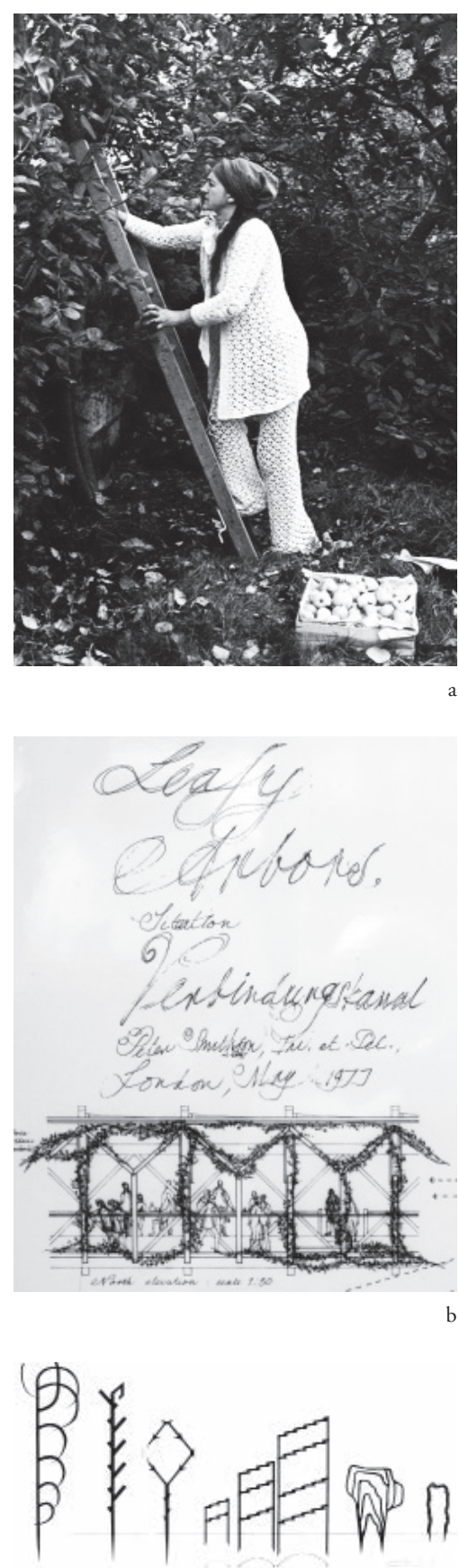

a. A\&P Smithson Upper Lawn Solar Folly, Septiembre, 1978

b. Leafy Arbours over the Verbindungskanal. Charlottenburg, Berlin, 1977. Smithson Family Collection.

c. Plant Frames. Alison Smithson, 1987. Flying Furniture (1999). 


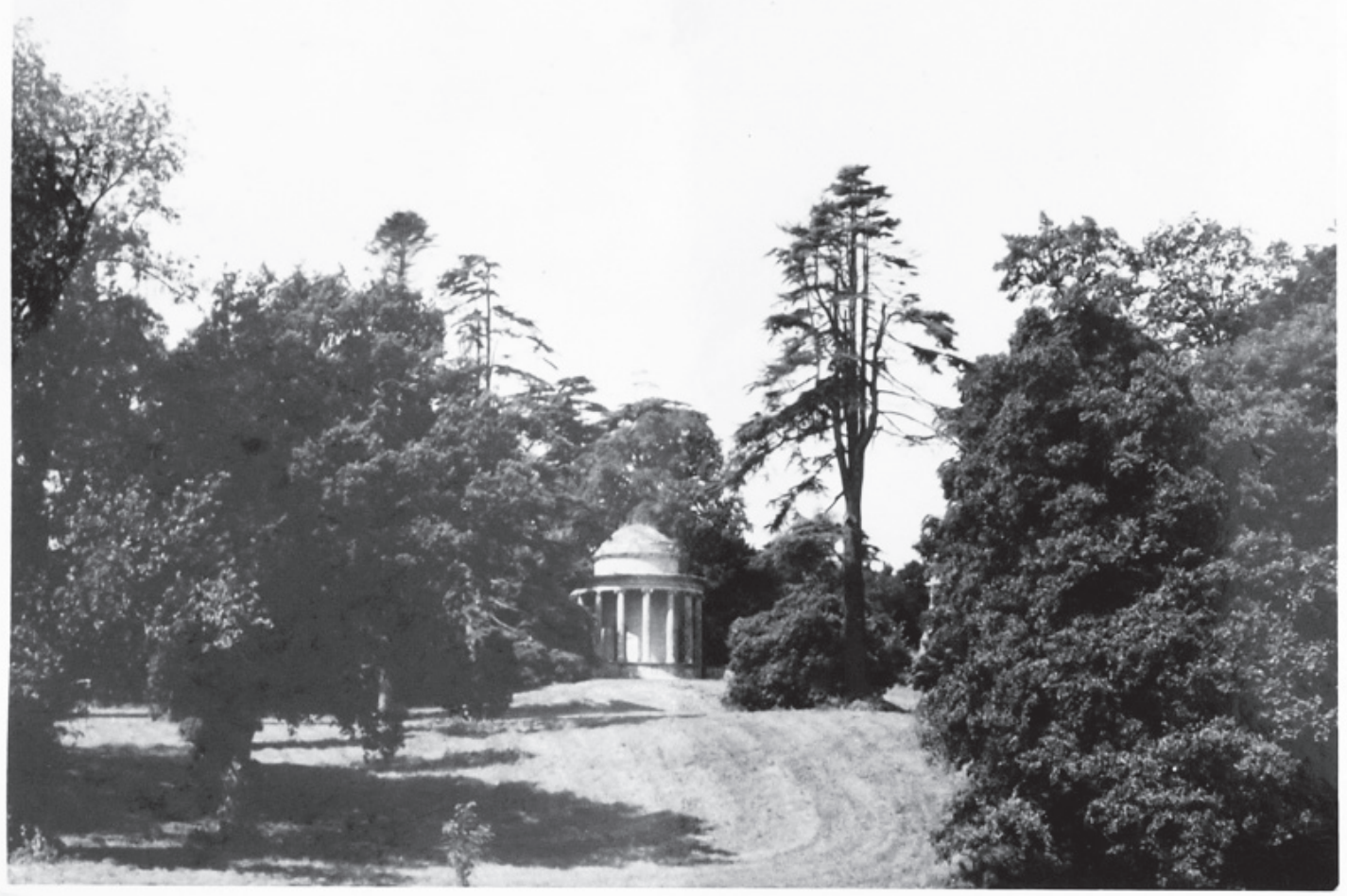

English landscape garden

The Rotondo (J. Vanbrugh, 1720-21), Stowe

Fotografía: Peter Smithson. Smithson Family Colecction 
Este sistema estético holístico, ${ }^{43}$ capaz de influir no solo en la configuración del territorio sino también en el resto de ámbitos de la cultura inglesa ${ }^{44}$ contiene técnicas y principios aplicados a la jardinería paisajista que subyacen en la obra de los Smithson: la interacción entre arquitectura y paisaje, la respuesta a las condiciones del lugar, el valor del recorrido y la experiencia temporal, las condiciones simultáneas de mezcla, artificio y conexión ${ }^{45}$ y la incorporación de efectos sensitivos ${ }^{46}$ son aspectos latentes en sus proyectos que provienen de una relectura contemporánea de los enunciados teóricos de Uvedale Price y Richard Payne Knight. ${ }^{47}$

Peter Cook, sería el primero ${ }^{48}$ en advertir, en 1982, la importancia de "lo pintoresco" en el trabajo de los Smithson, señalando, al mismo tiempo, la ausencia de un reconocimiento más explícito, por parte de éstos, acerca de esta influencia en su propia obra:

"(...) in the end it is their congruity with those especially English characteristics of contemplation and gentle assembly of the ambiguous that remains uppermost. In their own words their aesthetic is created "without rhetoric", but what emerges also is a perceptible taste for the picturesque that they might never admit to, but which also exposes their characteristic Englishness". ${ }^{49}$

En los comienzos de la trayectoria de los Smithson, esta supuesta falta de claridad hacia el influjo de lo pintoresco - a la que se refería Cook - estaría relacionada con la controversia surgida en torno al Pintoresquismo en los años de la posguerra británica, en la que el término adquirió un significado "negativo" entre los jóvenes arquitectos ingleses, entre los que se encontraban los propios Smithson. Recordemos brevemente que en aquel contexto de principios de la década de 1950, se enfrentarían dos posiciones que trataban de

43. ÁBALOS, Ińaki (ed.). Atlas pintoresco Vol.2. Los viajes. Barcelona, G. Gili, 2005. p.21.

44. "En Inglaterra, lo pintoresco fue algo más que una simple moda en jardinería, fue la puerta por la que se descubrió y valoró el paisaje y con él ciertos sentimientos emotivos y determinados sentimientos emocionales. Esta valoración hizo que la mayoría de los terratenientes contemplaran sus fincas no solo como propiedades productoras de rentas sino con ojos pictóricos, procurando su mejora estética. Así durante este periodo, toda la campiña inglesa se transformó, convirtiéndose las ideas sobre el gusto, lo pintoresco y el paisaje en temas de discusión filosófica, interés político y repercusión social”, MADERUELO, Javier, "El punto de vista de Christopher Hussey", en HUSSEY, Christopher, Lo Pintoresco. Estudios desde un punto de vista. Edición de Javier Maderuelo, Madrid, 2013, p.16.

45. ROBINSON, Sidney K. Inquiry into the Picturesque, The University of Chicago Press, Chicago 1991. p. $x i$

46. "John Ruskin entendía lo pintoresco como un estado perceptivo que, entre 1730 y 1830 permitió pasar del clasicismo intelectualista a un arte imaginativo y sensitivo", en: MADERUELO, Javier, "El punto de vista de Christopher Hussey", op.cit. p.16.

47. “(...) Uvedale Price, who with Richard payne Knight became the most outspoken advocate for the Picturesque in the late eighteenth century”. Ibid p.1

48. Según señala Dirk Van de Heuvel en: A Brutalist Story, op cit, p.150

49. COOK, Peter, Regarding the Smithsons, The Architectural Review, Julio 1982, pp. 36-43.

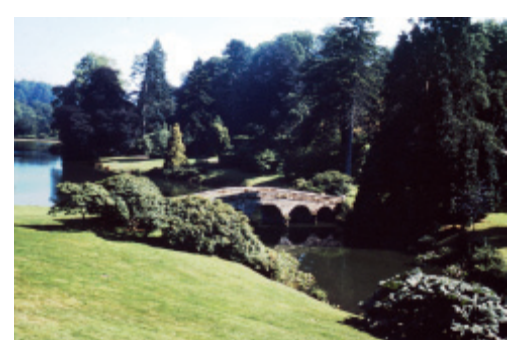

a a. English Garden. Stourhead, 1972. Smithson Family Colecction 


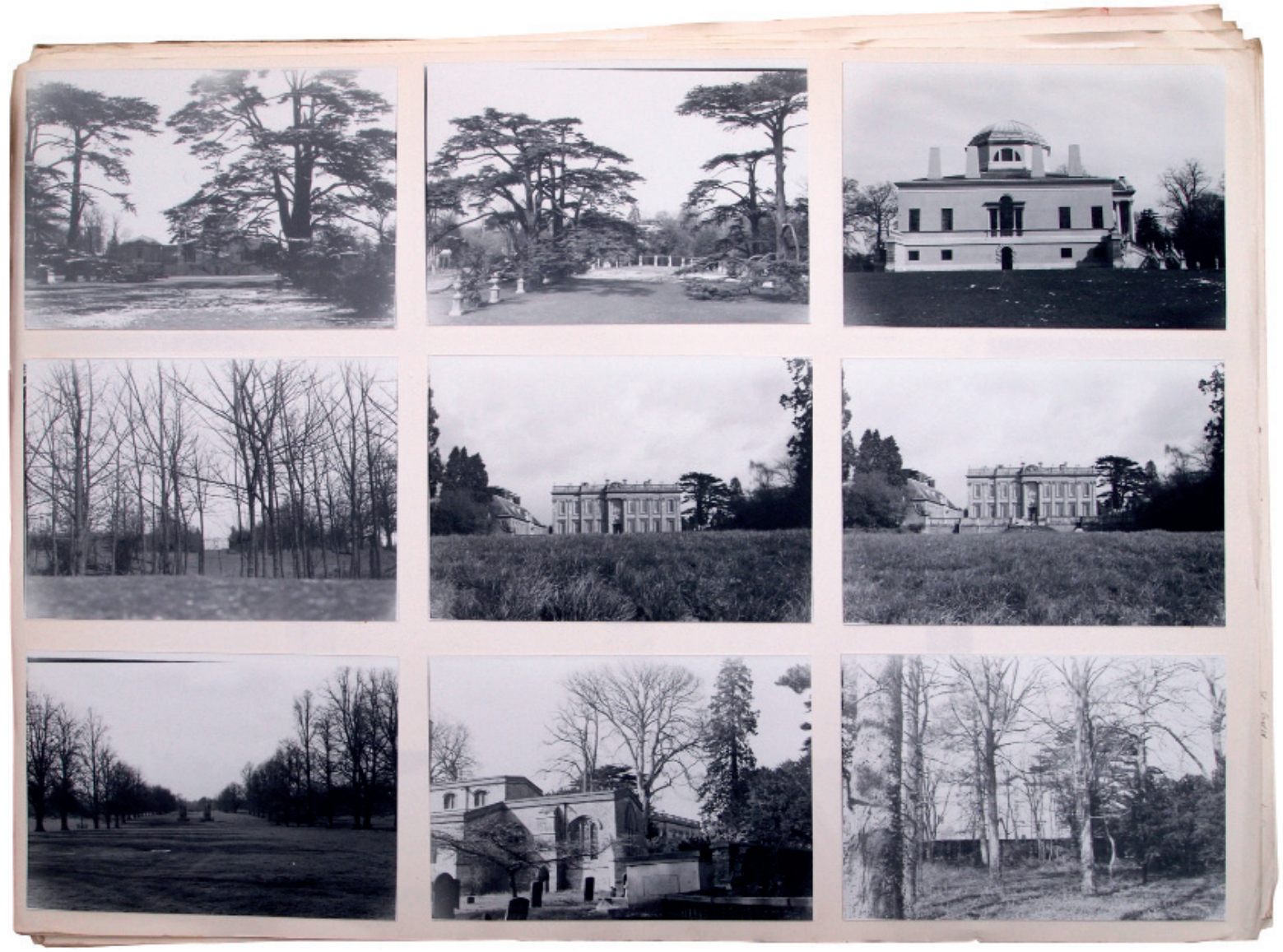

Exploraciones en el paisaje de Inglaterra Álbum de fotografías A\&P Smithson Smithson Family Colecction 
revitalizar el estancamiento ${ }^{50}$ de la arquitectura moderna desde dos modelos aparentemente antagónicos. Por un lado, la tendencia neo-pintoresquista ${ }^{51}$ defendida por Pevsner desde las páginas de The Architectural Review, que trataba de hacer ver la estética "amable" de lo Pintoresco —el "verde", los techos inclinados y los muros de carga de ladrillo- como la única capaz de satisfacer las demandas de la arquitectura del siglo $\mathrm{XX}^{52}$; y por otra, la que pretendía recuperar "lo moderno" desde la técnica y la radicalización de algunos de sus principios esenciales ${ }^{53} \mathrm{como}$ la sinceridad de los materiales y exhibición de la estructura. Ésta última tendencia, impulsada en Inglaterra por Reyner Banham, dio lugar a una nueva actitud que trataría de combatir el interés por los efectos visuales pintorescos mediante una deliberada voluntad anticompositiva: ${ }^{54}$ el Nuevo Brutalismo.

Los proyectos de Alison y Peter Smithson realizados a principios de la década de 1950 -la Catedral de Coventry (1951), la Casa Soho (1952), las viviendas Golden Lane (1953), la Universidad de Sheffield (1953) y la Escuela Secundaria de Hunstanton (1954) $)^{55}$ - eran, para Banham, los ejemplos más representativos de esa tendencia y de los que se valió, en 1955, para armar su programa brutalista, ${ }^{56}$ estableciendo tres aspectos fundamentales: la visibilidad material y constructiva, la utilización de materiales "as found" y la "memorabilidad como imagen". Los Smithson, como actores principales de este movimiento fueran calificados por Banham como "enemigos declarados de lo Pintoresco". ${ }^{57}$

50.“(...) ese debate [brutalista] tenía lugar en un contexto en el que la arquitectura heredera de los presupuestos de Movimiento Moderno empezaba a dar muestras de estancamiento". VALCARCEL, María Teresa. «El nuevo brutalismo: una aproximación y una bibliografía». Cuaderno de Notas, Madrid, 1999, p.138.

51. Estas propuestas recogían los modelos suecos del Nuevo Empirismo que tenían como finalidad dotar de una condición más "humana" a los modelos funcionalistas modernos, a través del "verde", los techos inclinados y los muros de carga de ladrillo. Propagadas con insistencia por la revista The Architectural Review, pretendían conectar con la tradición británica y la "ciudad jardín" y fueron aplicadas en Inglaterra a algunos modelos urbanos residenciales que introducían criterios estilísticos pintorescos en su trazado y en la configuración de sus volúmenes.

52. ANIBARRO, Miguel Angel. «Pintoresco o moderno? Nikolaus Pevsner y el debate de la arquitectura británica en la posguerra». Anales de Arquitectura, Madrid, 1993-1994, p.132.

53. “[el Nuevo Brutalismo] intentaba rescatar los auténticos principios que habían dado origen a la arquitectura moderna”. VALCARCEL, María Teresa. «El nuevo brutalismo, otra vuelta de tuerca». Cuaderno de Notas, Madrid, 2000, p.139.

54. 'La voluntad de 'no componer' del Nuevo Brutalismo significaba ante todo la renuncia a esa disposición demasiado cuidadosa de las piezas cuyo fin era lograr un efecto visual, característicamente neopintoresco”. ANIBARRO, “¿Pintoresco o moderno?”, op.cit, p.137.

55. "Hunstanton y la Casa Soho pueden servir como puntos de referencia arquitectónica a través de los cuales se puede definir el Nuevo Brutalismo". BANHAM, Reyner, "The New Brutalism", en The Architectural Review vol 118, dic.1955, pp 354-361.

56. Establecido, en 1955, a partir de tres aspectos fundamentales: la visibilidad material y constructiva, la utilización de materiales "as found" y la "memorabilidad como imagen". BANHAM, Reyner. "The New Brutalism». The Architectural Review, diciembre de 1955.

57. BANHAM, Reyner. «Revenge of the Picturesque: English Architectural Polemics , 1945,1965». En Concerning Architecture: Essays on Architectural Writers and Writing Presented to Nikolaus Pevsner, editado por J. Summerson y Nikolaus Pevsner. Allen Lane, 1968, p.773 


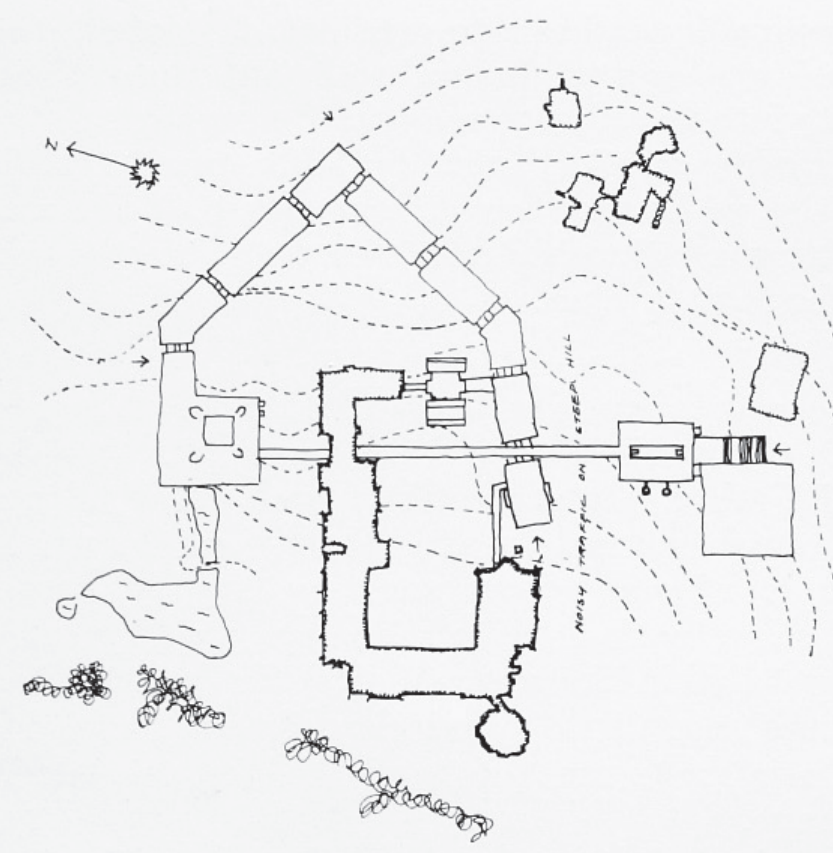

145. Sheffield University competition project. Site plan

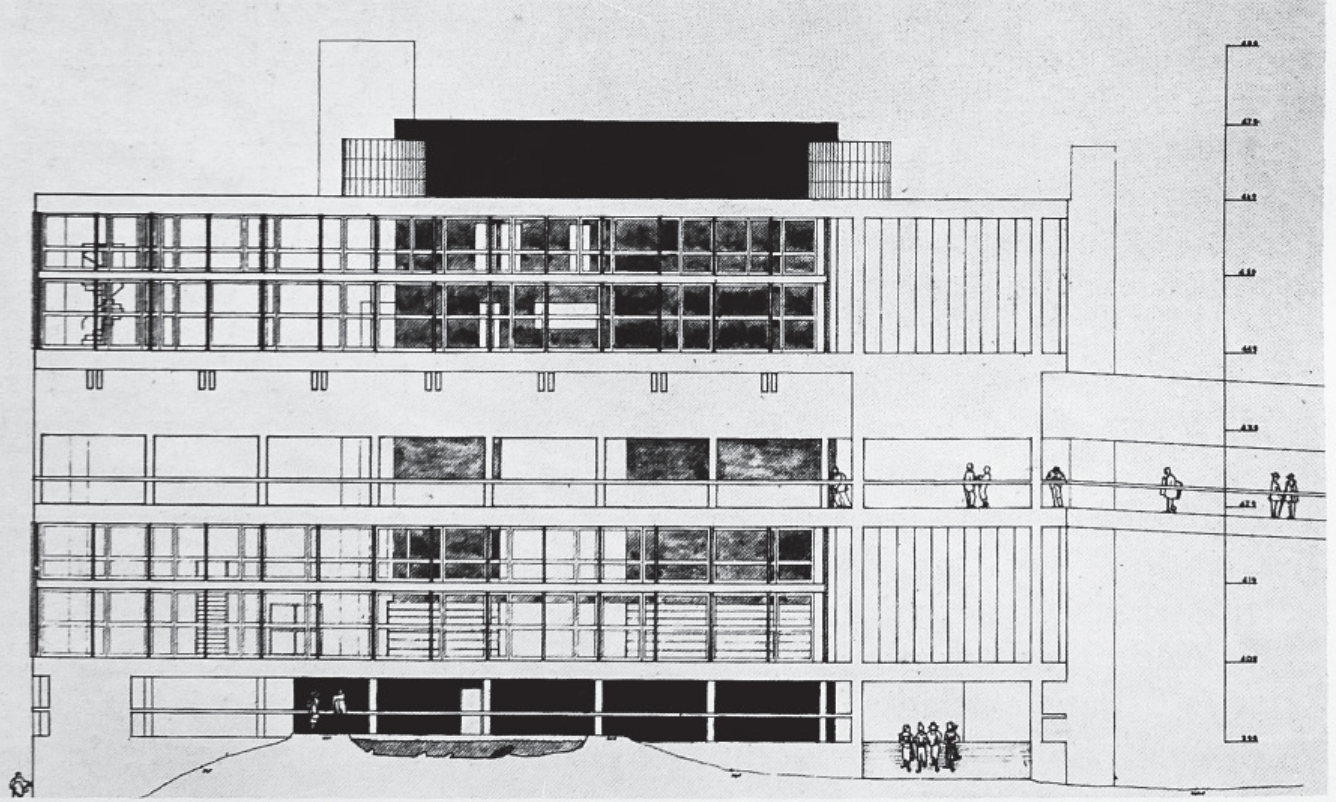

146. Sheffield University. Library façade seen from the park, the route entering from the right 
Las propuestas de los Smithson a las que se referiría Banham eran absolutamente rotundas en su concepción, atentas a los valores originales que habían impulsado la obra de sus maestros modernos — "verdaderas cuestiones arquitectónicas - y por lo tanto, alejadas de la arquitectura neopintoresquista "débil", "provinciana” y "preocupada por los efectos superficiales", como la calificaban los jóvenes brutalistas. ${ }^{58}$ A pesar de este hecho, ¿hasta qué punto se pueden considerar aquellos proyectos de los Smithson tan "antipintoresquistas" como fueron etiquetados por Banham? ¿Estaban, en realidad, tan alejados de toda clase de influencias de la tradición inglesa como fueron mostrados?

Si observamos estos proyectos desde un enfoque más libre, sin las etiquetas que intentaban encasillarlos en aquel tiempo, es posible observar en ellos innegables contaminaciones "inglesas" que fueron olvidadas o pasadas intencionadamente por alto. En la Escuela Secundaria de Hunstanton, el límite de la plataforma sobre la que sitúa el edificio de aspecto miesiano se configura mediante un $h a-h a$ : uno de los inventos clave del jardín paisajista inglés. Su existencia sería intencionadamente olvidada por Banham en la descripción del edificio, pero también, por Philip Johnson en su artículo sobre Hunstanton publicado en The Architectural Review. ${ }^{59}$ En el proyecto para la Catedral de Coventry — calificado por Banham, de manera explícita, como totalmente "anti-pintoresquista" 60 — observamos una destacada atención a las cualidades materiales y sensitivas del suelo, como podemos apreciar en los expresivos dibujos del concurso que representan con detalle la textura del terreno y el foso "medieval" que rodea la intervención.

$Y$ en Sheffield -aquel proyecto que, según Banham, "habría constituido el ejemplo más extremo de arquitectura brutalista" ${ }^{61}$ percibimos, de nuevo, la sensibilidad hacia la implantación en el paisaje en el modo en el que el edificio se sitúa en contacto con el montículo y el pequeño lago existente: un diálogo "pintoresco" entre naturaleza y artificio, olvidado completamente en las interpretaciones brutalistas de esta radical propuesta.

Este reconocimiento de "lo pintoresco" en los primeros proyectos brutalistas de los Smithson, también se extiende a otros realizados en esos mismos años, como la Casa Bates (1953-55) o la Casa Sugden (1955-56), los cuales reflejan la influencia de la tradición inglesa de trabajo con el territorio en su personal aproximación a las cuestiones topográficas. Ese temprano vínculo con su herencia paisajista también podemos apreciarlo en artículos como "Cluster City”, (1957), donde los Smithson incluyeron intencionadamente

58. ANIBARRO, Miguel Angel. «¿Pintoresco o moderno?, op.cit,p.136.

59. JOHNSON, Philip. «School at Hunstanton, Norfolk». Architectural Review, 1954.

60. BANHAM, Reyner, "The New Brutalism”, op.cit.

61. Ibid
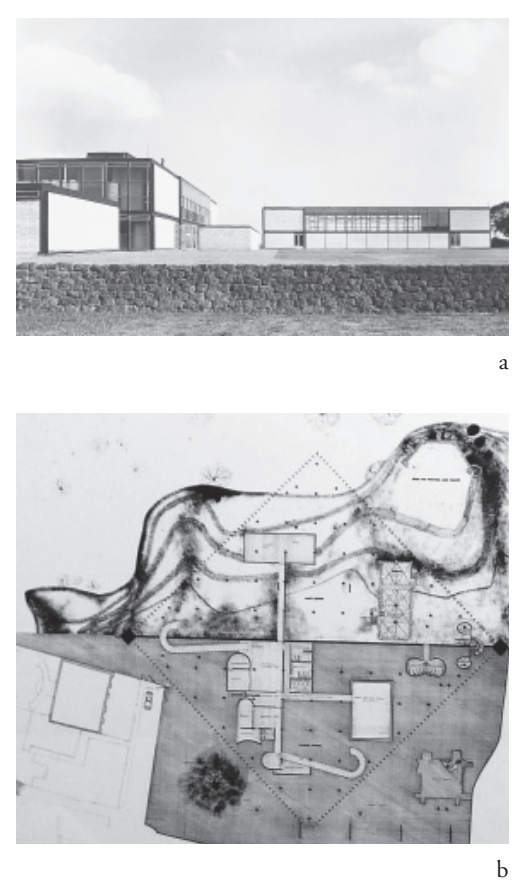

b

a. Hunstanton. A\&P. Smithson, 194954. View from ha-ha (John Maltby). The Charged Void: Architecture.

b. Coventry Cathedral. A\&P. Smithson, 1950-51. Plan of ancillary buildings at ground level. 


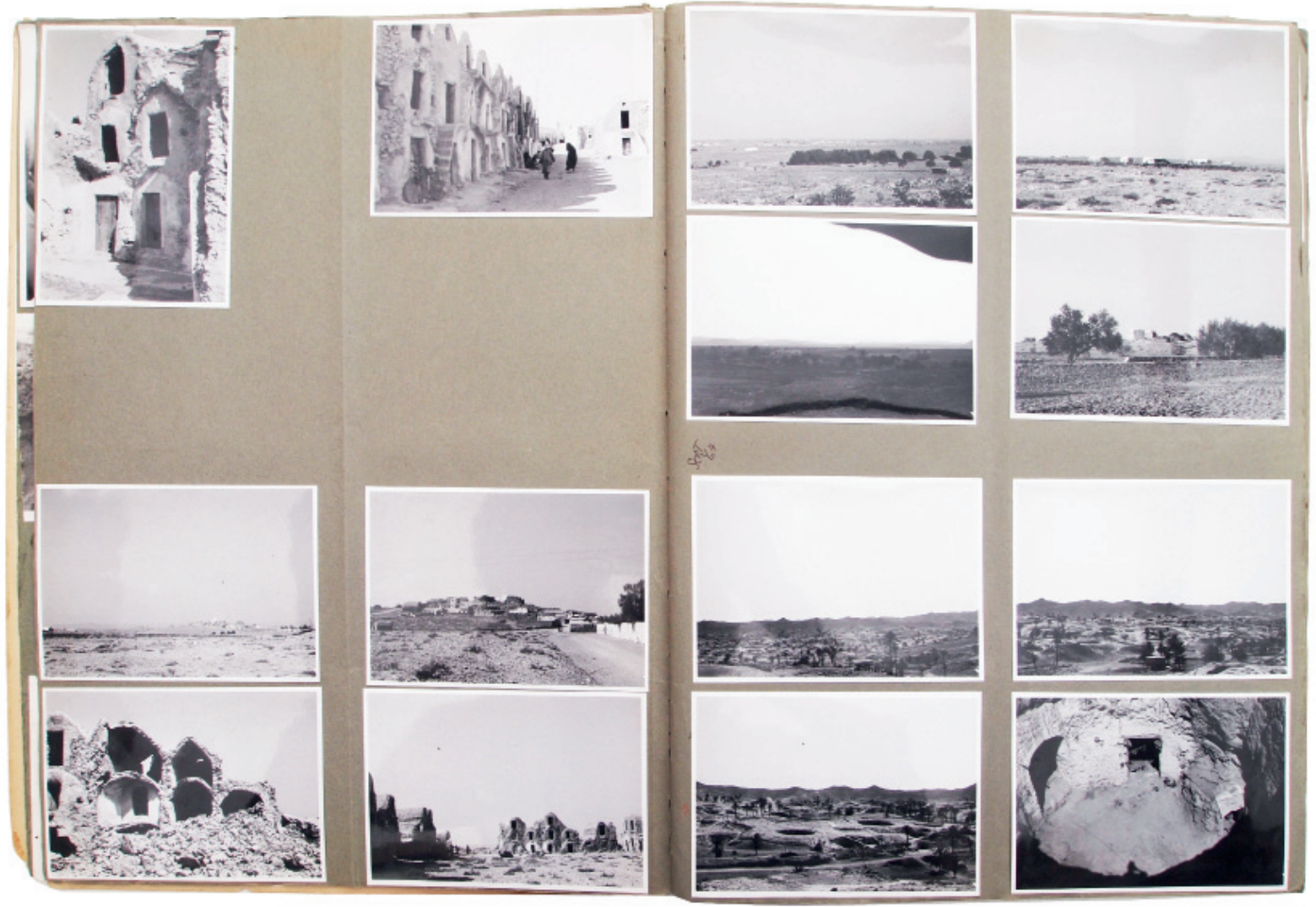

Ghorfa. Túnez 1960's

Álbum de fotografías A\&P Smithson.

Fotografía del autor 
un fragmento de un cuadro de Poussin - Landscape with the Ashes of Phocion (1648)—; un ejemplo de aquellas pinturas que dieron lugar en Inglaterra al origen de una especial sensibilidad para apreciar e intervenir en el paisaje:

"Those paintings by Claude and Poussin brought back by the English from the Grand Tour somehow made visible to all, their national sensibility to the landscape: the paintings becoming 'enabling images' in the development of the English Landscape Garden, a genre virile enough to be re-exported" ${ }^{2}$

Este reconocimiento de "lo pintoresco" en los proyectos de los Smithson, refleja la interpretación personal que hacen de la tradición paisajista inglesa, alejada del neopintoresquismo reivindicado por Pevsner, ${ }^{63} \mathrm{y}$ al mismo tiempo, compatible con el legado moderno sobre el que construyen su propia trayectoria, reactivándolo mediante una particular sensibilidad "inglesa” que se hará especialmente patente en el trabajo con el plano del suelo.

\section{Topografías de posguerra}

El contexto de la posguerra británica también contribuiría a la consolidación del pensamiento topográfico de los Smithson, a través de la influencia de ciertas manifestaciones culturales y artísticas que, desde distintos ámbitos del conocimiento, como la antropología, la arquitectura y el arte, trataron de abordar la crisis de valores que acontecía en la década de 1950. Estas manifestaciones, surgidas en un clima existencialista ${ }^{64}$, buscaron nuevos referentes en modelos primitivos ${ }^{65}$, con el fin de contrarrestar la abstracción y el exceso de contaminación técnica que habían obviado las necesidades fundamentales del individuo. En la arquitectura, un nuevo sistema estético desplazaría todo tipo de mecanicismo, adquiriendo nuevos objetivos que se explicaban mediante términos como "esencial", "específico" o "auténtico": un nuevo marco de valores en el que "lo topográfico" -entendido desde la recuperación del contacto con la tierra- comenzaría a tener un papel destacado.

62. SMITHSON, Alison. «The City Centre full of Holes». AA Quarterly, 1977, p.16

63. Como se ha apuntado brevemente en la Introducción de este trabajo, recientes investigaciones plantean puntos en común entre el Nuevo Brutalismo y el Pintoresquismo, señalando, por tanto, la imposibilidad de separarlos radicalmente.

64. Para una aproximación al término "humanismo" y al clima cultural existencialista de los años posteriores a la Segunda Guerra Mundial, véase SOLÀ-MORALES, Ignasi de. "Arquitectura y existencialismo", en: Diferencias: topografía de la arquitectura contemporánea. Barcelona: GG, 2003.

65. La mirada hacia la condición primitiva era poner en valor lo "natural", que significa 'simple' y 'no adulterado', 'espontáneo' e 'irreflexivo'. COLLINS, Peter. Los ideales de la arquitectura moderna: su evolución (1750-1950). Changing Ideals in Modern Architecture, 1750-1950. 1st edition 1967); Traducido por Ignasi de SOLÀ-MORALES. Barcelona: G. Gili, 1970, 1998, p.92.

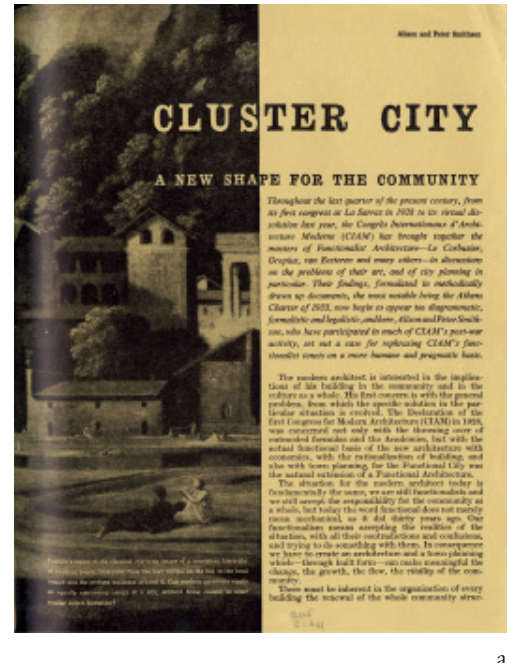
(n)

(1)




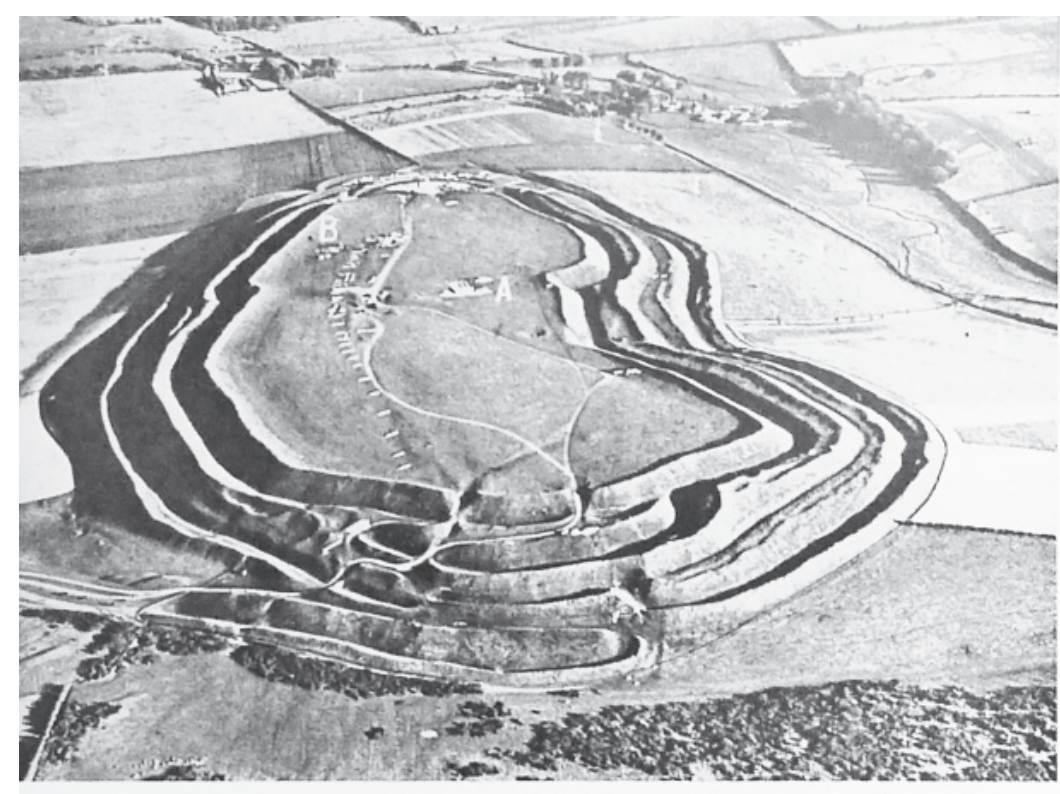

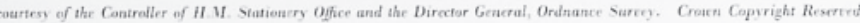

HILLTOP SETTLEMENTS

82

EVGLAND Dore

Maiden Castle

On the edtetern height were Stone lpe fortifications, deserted at the lewinuing of the Bronze Ige. They consi-ted at Wwo or three concentric ditches, In the

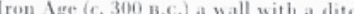
(1)

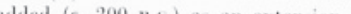
(a) inctula the wertron heights: Abou 100 B.C. the simple defence work- were replaced by the present rampart an ditches and the entrances on eat an wet were rlaborately rede-igned the the conciues of south-we-tern fouland the site was alo (a) ithe the atandoned ramp wat in partial us again and a equare temple of RomasCeltic type wa- built in-ide it (B)

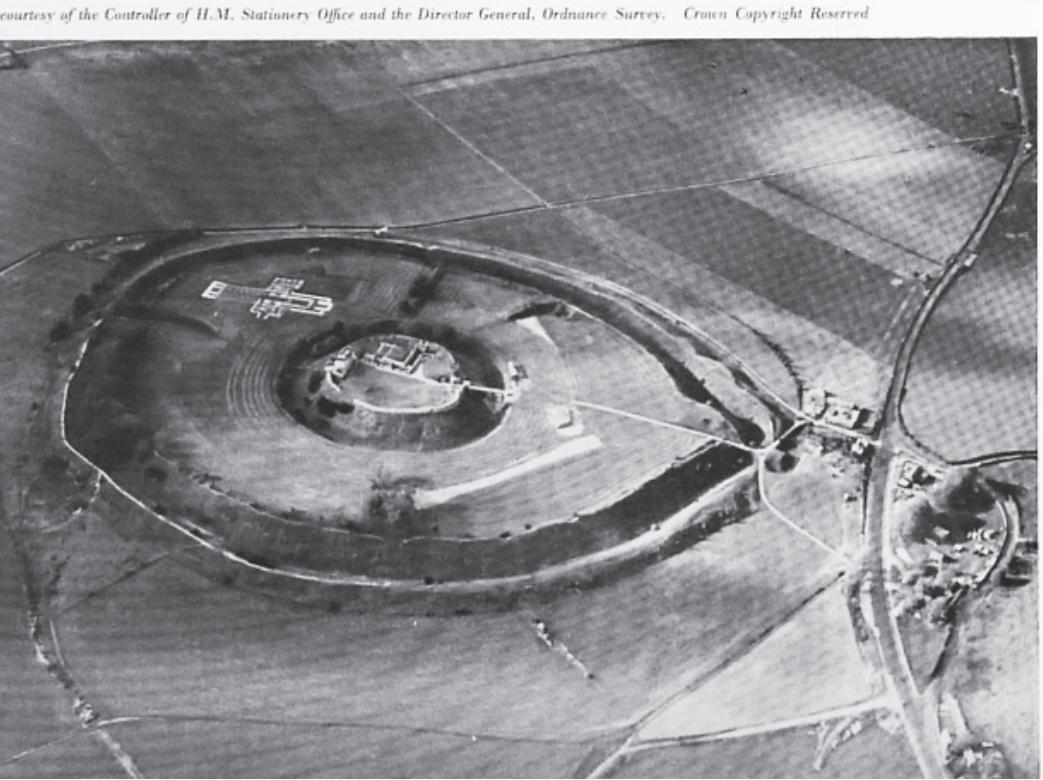

83

FNGLAND Wiltshire

Old Sarum

A medieval castle built in the centre of an Iron Ige round camp. It - circular rampart and moat are till clearly vi-ible. To the -ide of the central mound a mediaval church was situated. Its plan was expored by exravation.

Página 8 Our world from the Air. Erwin. A. Gutkind, 1952 Earthworks: Maiden Castle (Dorset); Old Sarum (Wiltshire) 
En Inglaterra, a principios de la década de 1950, Erwin Gutkind se encargó de difundir desde las páginas de Architectural Design estas referencias primitivas, a través de una serie de artículos titulados How other peoples dwell and live $e^{66}$, publicados en 1953, en los que daba cuenta de asentamientos vernáculos de otras culturas, carentes de normas estilísticas y en los que el sentido del orden provenía de una adecuación intencionada al individuo $\mathrm{y}$ al territorio. Los Smithson, sensibles a estos ejemplos que mostraban valores olvidados, como la sensibilidad para integrar la topografía en el proyecto, los usarían igualmente como referencia en sus proyectos, llegando incluso a visitar algunos de los mostrados por Gutkind, como las ghorfas ${ }^{67}$ de Túnez, los almacenes de grano construidos en el siglo X por las tribus bereberes. También de Erwin A. Gutkind, ${ }^{68}$ el libro de fotografías aéreas Our World from the Air. An International Survey of Man and his Environment (1952), ${ }^{69}$ sería otra referencia fundamental para los Smithson. A través de sus fotografías pudieron ampliar el conocimiento de aquellos asentamientos y formaciones de tierra de origen remoto por las que ya mostraban interés en la década de 1950. Desde el aire, la relación entre el paisaje natural y las construcciones artificiales se revelaban con mayor claridad $^{70}$, haciéndose evidentes sus mecanismos topográficos.

Por otra parte, y también dentro del discurso crítico con el funcionalismo moderno, la recuperación de las ideas de Patrick Geddes, basadas en la consideración de la singularidad local, las

66. GUTKIND, E.A, "How other peoples dwell and build: 1 Houses of the South Seas," AD 23, Jan. 1953, pp.2-4; "How other peoples dwell and build: 2 Houses of Japan" AD 23, Feb. 1953, pp. 31-4; "How other peoples dwell and build: 3 Houses of China," AD 23, Mar. 1953, pp. 59-62; "How other peoples dwell and build: 4 Indigenous Houses of Africa," AD 23, May. 1953, pp. 121-34; "How other peoples dwell and build: 5 Mohammedan Houses," AD 23, June. 1953, pp. 159-62; y "How other peoples dwell and build: 6 Houses of North American Indians," AD 23, July.1953, pp.193-97.

67. Como se ha podido comprobar en los álbumes de fotografías consultados durante esta investigación en los archivos de Alison y Peter Smithson.

68. M.Christine Boyer analiza la influencia de E.A.Gutkind en la generación de arquitectos ingleses de posguerra, como Alison y Peter Smithson, a través de sus primeras publicaciones como: Revolution of Environment (E. A. Gutkind, London: Keagan Paul, Trench, Trubner \& Co., Ltd., 1946) y Community and Environment: a Discourse on Social Ecology (E. A. Gutkind, London: Watts and Co., 1953). BOYER, M. Christine, «An Encounter with History: the Postwar Debate between the English Journals of Architectural Review and Architectural Design (1945-1960)». Delft: Faculty of Architecture TU Delft, 2006. En ese mismo artículo, Boyer analiza la confrontación entre las imágenes primitivas de Gutkind publicadas en Architectural Design y el revival pintoresco difundido por Pevsner desde Architectural Review.

69. GUTKIND, E. A.. Our world from the Air. An International Survey of Man and his Environment. Readers Union with Chatto \& Windus, 1952. Según Van den Heuvel, al menos en dos ocasiones, los Smithson utilizaron las imágenes de Gutkind en sus textos. HEUVEL, Dirk van den. Alison and Peter Smithson: A Brutalist Story. Op.Cit. p.199. Durante esta investigación, el autor ha podido comprobar la existencia de un ejemplar de este libro de Gutkind en la biblioteca de Alison y Peter Smithson.

70. JACKSON, John Brinckerhoff, Landscape, 1, primavera 1951, ps 4-5: "Desde el cielo, la verdadera relación entre el paisaje natural y el paisaje humano se revela con la máxima claridad"

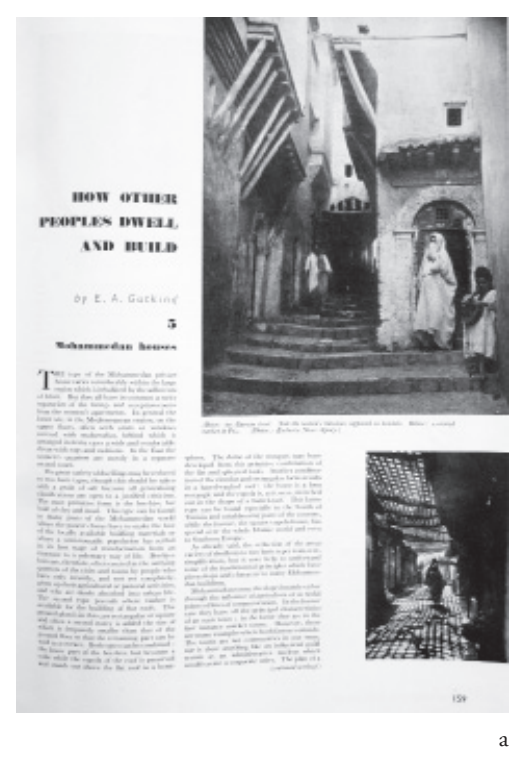



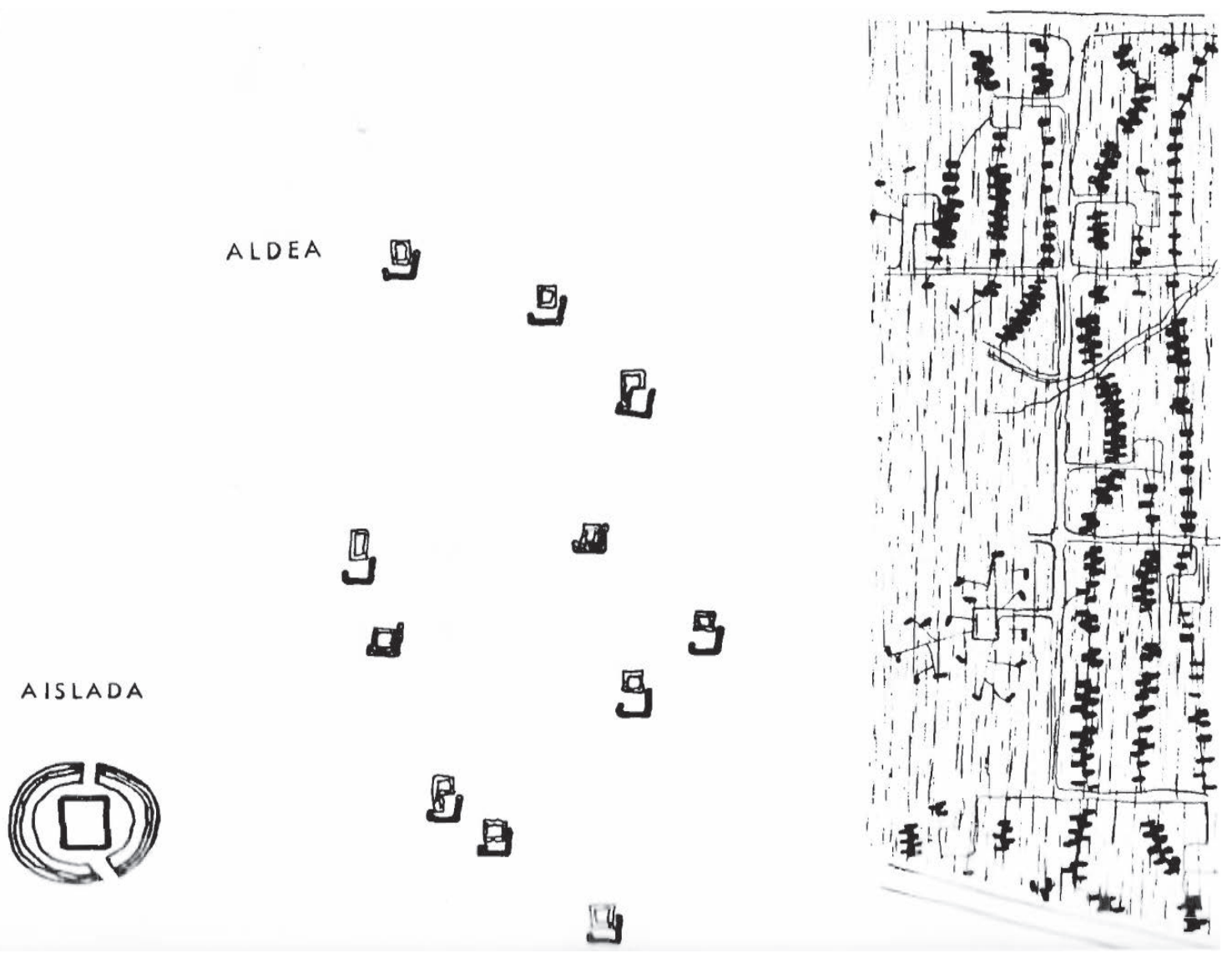

Huellas sobre el plano del suelo

A\&P Smithson. Propuestas para la "Sección del Valle de Geddes". X CIAM, 1956 
formas de vida ${ }^{71}$ y el establecimiento de conexiones con el territorio, influirían en los comienzos de los Smithson ${ }^{72}$. Éstos, que ya conocían los postulados de Geddes desde su época de estudiantes en la Universidad de Durham ${ }^{73}$, se apropiaron, en 1953, de la "sección del valle": un diagrama realizado por este urbanista y biólogo escocés en 1909 que sintetizaba gráficamente su idea acerca de la relación entre los asentamientos y la topografía:

In the 1930s Patrick Geddes was not a name mentioned so the Outlook Tower never visited, but his Zoo was perhaps at its perfection ... however it was with Geddes' diagrammatic thinking that Team 10's way of thinking started, particularly with the diagram in the Doorn Manifesto, 1954. The manifesto was in effect saying that if you wish to insert a new oyster in the shell of the old city, the urbanist has to become as the fabric of the old so as to understand in his own fabric how to welcome the irritant and perhaps form a pearl. ${ }^{74}$

Los Smithson utilizaron la "sección del valle" en el Manifiesto Doorn, como oposición a la falta de atención a las particularidades del emplazamiento que poseían los modelos maquinistas modernos. Asimismo, en los CIAM X de 1956, los Smithson utilizaron este diagrama como referencia conceptual de una serie de pequeños proyectos esbozados sobre la base de patrones tradicionales ingleses. Estos proyectos -"las propuestas del valle de Geddes"- se construían desde una respuesta específica al suelo: definiendo una singular articulación entre el edificio y el terreno, como sucedía en Burrows Lea Farm (1953), o conservando intactas las cualidades del paisaje, como ocurría en la propuesta para las Close Houses (1954) en la que los edificios "cabalgaban" sobre la ondulación de la tierra sin apenas dejar huella.

En la posguerra británica, la aparición de un "regionalismo" que miraba hacia el entorno rural para buscar en él nuevas vías para la arquitectura moderna ${ }^{75}$, sería una idea extendida entre los jóvenes

71.El epílogo del libro de Victoria Walsh sobre Henderson, escrito por Peter Smithson, finaliza con la siguiente pregunta: "Behind all this, in Écochard and ourselves, an echo of Patrick Geddes?”. En este breve texto P. Smithson reflexiona sobre el encuentro entre las formas de vida y la singularidad local con la forma arquitectónica. WALSH, Victoria, Nigel Henderson: Parallel of Life and Art. London: Thames \& Hudson, 2001. p.151.

72. Véase: WELTER, Volker M. «Post-war CIAM, Team X, and the Influence of Patrick Geddes». TU Delft; y WELTER, Volker M. «In-between Space and Society. On some British roots of Team 10`s Urban Thought in the 1950s». En Team 10 In Search of a Utopia of the Past, 1953-81, Op.Cit. pp. 258-263.

73. WELTER, Volker M. «Post-war CIAM, Team X, and the Influence of Patrick Geddes». Op.Cit

74. SMITHSON, Alison and Peter. The Space Between. Editado por Max RISSELADA. Köln: Verlag der Buchhandlung Walther König, 2017. p.67.

75. MONEO, Rafael. Inquietud teórica y estrategia proyectual., Op.Cit. p.9
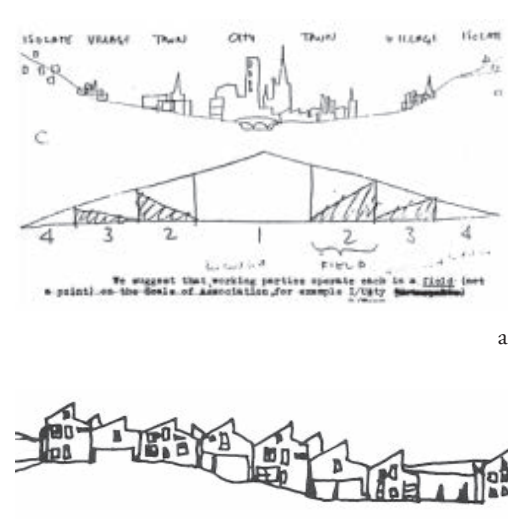

b

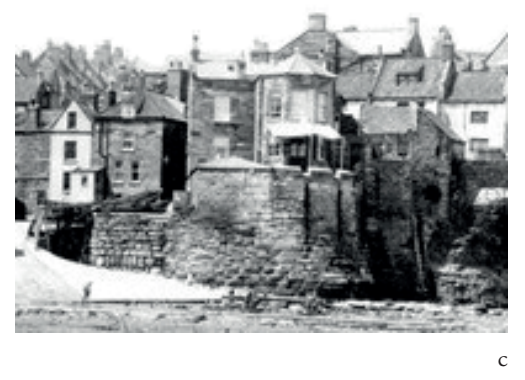

a. Draft statement for CIAM 10 with Patrick Geddes' Valley Section. (Volker M., Welter, «Post-war CIAM, Team $\mathrm{X}$, and the Influence of Patrick Geddes». TU Delft.)

b. Close Houses. A\&PS.1954: Riding the Landscape. The Charged Void: Architecture.

c. Fotografía de Robin Hood's Bay, 1901. Francis Firth Collection. 


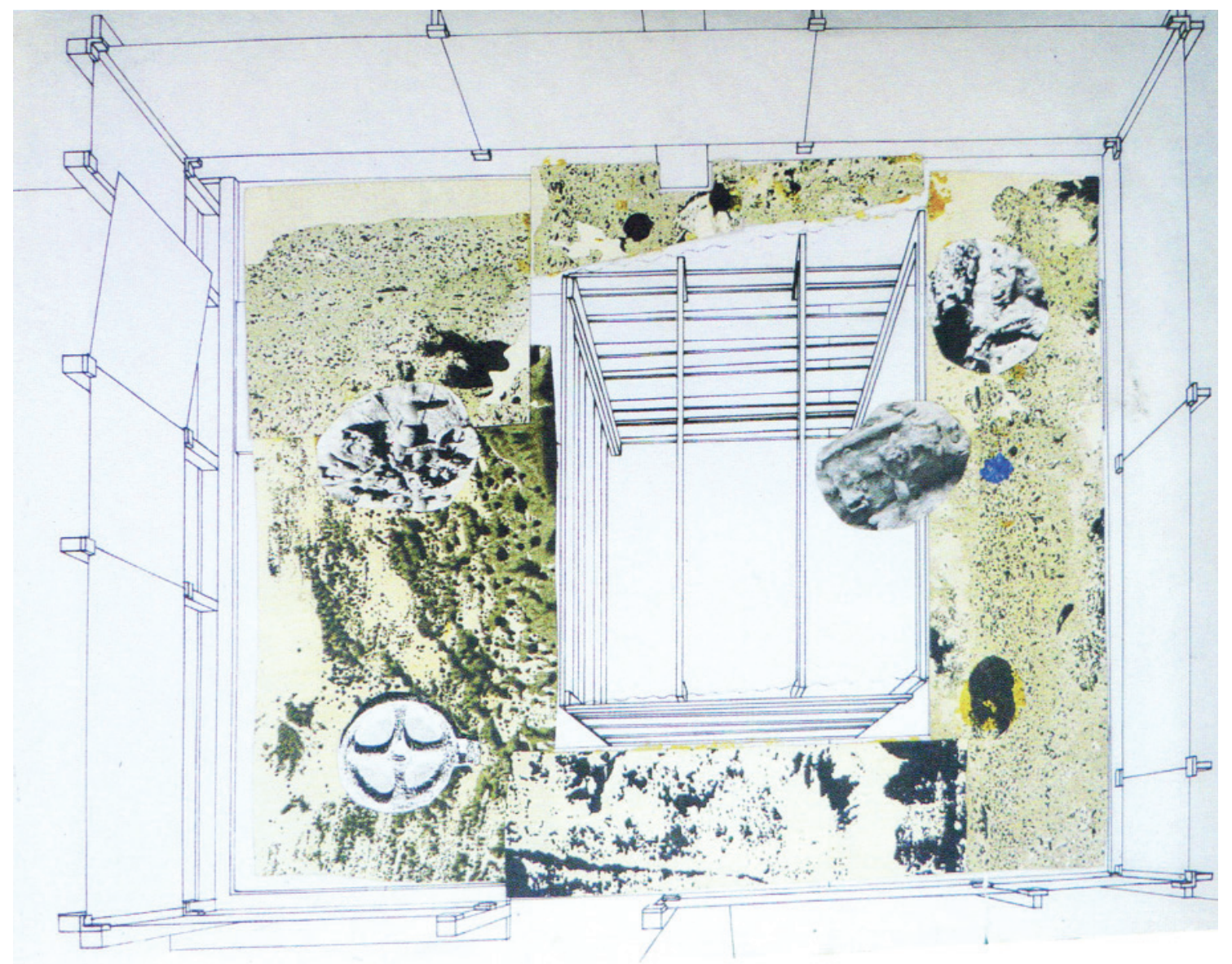

A\&P Smithson's collage of the Pation \& Pavilion for "This is Tomorrow". 1956 Smithson Family Collection

Not Quite Architecture. C.Boyer 
arquitectos británicos ${ }^{76}$. James Stirling en Regionalism and Modern Architecture $^{77}$ (1957) aludía a referencias inglesas como el urbanismo medieval o la arquitectura pintoresca del siglo XVIII ${ }^{78}$ que también serían compartidas por los Smithson, teniendo un reflejo directo en la utilización de similares sistemas de contacto con la tierra, como podemos apreciar en algunos de los proyectos realizados por ambos en la década de 1950. Las basamentos terrosos que Stirling utiliza como mecanismos de implantación en el concurso del Churchill College (1958) o en el Pabellón del Brunswick School en Camberwell (1959) tendrían relación con operaciones topográficas semejantes de los Smithson, como las llevadas a cabo en la Casa Sugden (1955-56) o en la Casa Bates (1953-55). Una atención a la topografía compartida por ambos arquitectos que también vemos a través de las maquetas de la Casa Woolton (1954) de Stirling y la Casa Bates (1953-55) de los Smithson, las cuales se fotografían intencionadamente sobre un suelo natural modelado con arena. Este valor de la identidad regional de los cincuenta sería más adelante recogido por Frampton en Towards a Critical Regionalism. Six Points for an Architecture of Resistance, ${ }^{79}$ en donde incluiría entre sus puntos clave la topografía de un emplazamiento como un aspecto decisivo de la recuperación de una relación dialéctica más directa con la naturaleza.

El interés de los Smithson por la topografía también se vería alimentado por el contacto con los artistas Eduardo Paolozzi y Nigel Henderson. El interés común que los cuatro tenían por explorar nuevos referentes estéticos ${ }^{80}$, daría como resultado la organización en 1953 de Parallel Life and Art, una exposición de sugerentes imágenes en la que sus autores revelaban sus "fuentes" de inspiración, tal y como delataba el nombre original de la misma (Sources). En un apartado específico de esta exposición se trataba uno de los temas por los que todos ellos se sintieron fascinados -"Aerial Topography"y que influiría en el posterior desarrollo de la obra de los cuatro integrantes del Independent Group.

En aquellos años, Paolozzi evolucionó sus esculturas hacia masas

76. HEUVEL, Dirk van den. Alison and Peter Smithson: A Brutalist Story. Op.Cit. p.197. 77. STIRLING, James, Regionalism and Modern Architecture. Elek Books. Architects' Year Book 8. London, 1957.

78. MONEO, Rafael. Inquietud teórica y estrategia proyectual., Op.Cit. p.9

79. FRAMPTON, Kenneth, "Towards a Critical Regionalism: Six Points for an Architecture of Resistance». en Postmodern Culture, 6. pr., 16-30. Hal Foster, eds. Pluto Classic. London: Pluto Press, 1995. (Primera edición: "Towards a Critical Regionalism: Six Points for an Architecture of Resistance", en: The Anti-Aesthetic: Essays on Postmodern Culture. edited by Hal Foster, Bay Press, Port Townse, 1983.

80. "A new ordering of image-making, as a comprehensible language, was possible". SMITHSON, Alison and Peter. The Charged Void: Architecture. New York: The Monacelli Press, 2001, p.84.
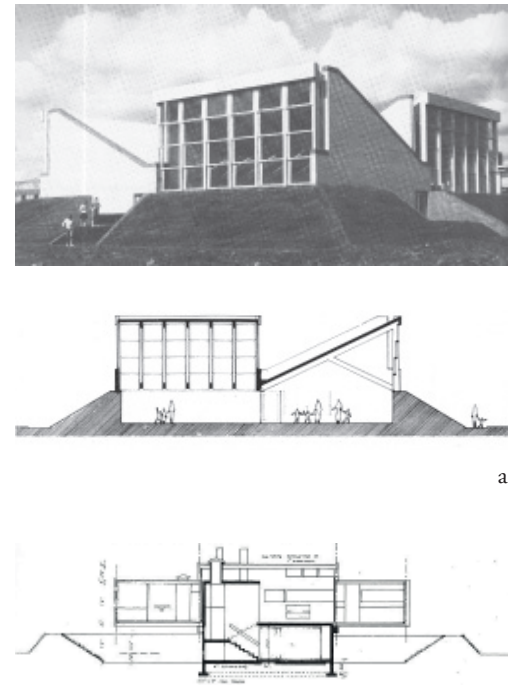

b
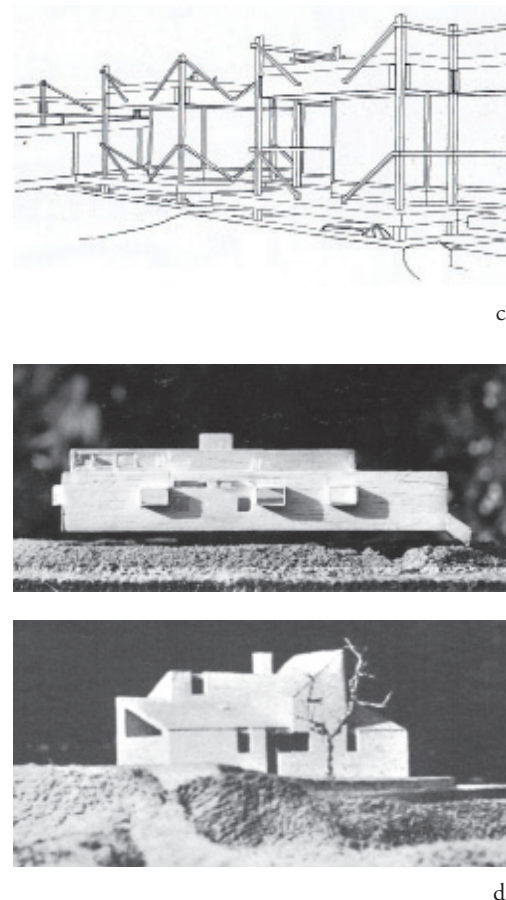

a. Stirling - Gowan. School Dining Hall 1958-60. Camberwell, London.

b. A\&PS. Bates House, 1953-55

c. A\&PS. Lucas Headquarters, 1973-74

d. Comparación maquetas de la casa Bates House (A\&PS, 1953-55) y Woolton House (Stirling-Gowan, 1954). 


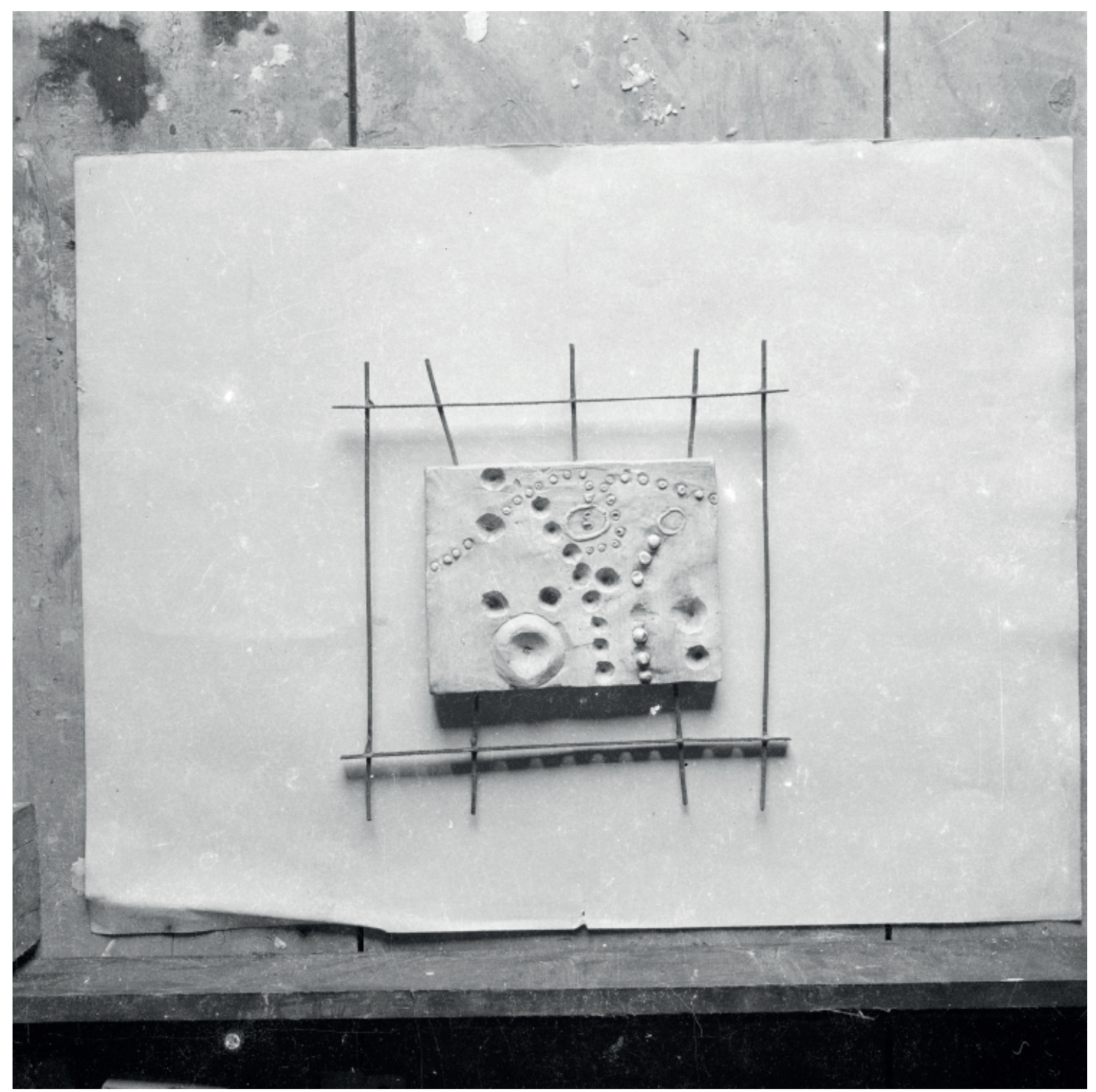

Nigel Henderson: Photograph showing artwork by Eduardo Paolozzi. c.1949-c.1956 The Eduardo Paolozzi Foundation \& The estate of Nigel Henderson 
amorfas, semejantes a trozos de tierra con "larvas incrustadas"81 y a insólitos relieves que recordaban topografías de fondos marinos ${ }^{82}$, o como señalaría David Sylvester, excavaciones arqueológicas vistas desde el aire ${ }^{83}$. Henderson, impactado por su experiencia como piloto en la II Guerra Mundial, convirtió las imágenes del microscopio en extrañas formas que aludían a las texturas y a las trazas del territorio contempladas desde sus vuelos militares ${ }^{84}$. Y, por su parte, los Smithson se valieron igualmente de imágenes de topografías aéreas para generar sus proyectos, como ocurrió en el caso de las Close Houses (1954), en donde la estrategia de implantación se basaba en unas formaciones topográficas del Sáhara denominadas "water holes" y que procedía de una imagen de una revista recortada y guardada cuidadosamente por Alison Smithson en su scrapbook $;^{85}$ imagen que, por otra parte, guardaba un sorprendente paralelismo con algunas de las esculturas de Paolozzi, también realizadas en los primeros años de la década de 1950 .

Para los Smithson, los primeros años de la década de 1950 marcaron un creciente interés por la obra de le Corbusier ${ }^{86}$, coincidiendo, precisamente, con los proyectos del arquitecto suizo que comienzan a evidenciar un mayor contacto con el suelo y un interés específico en la construcción del lugar. ${ }^{87}$ Las casas Jaoul (1952) y Chandigarh (1954), ambos incluidos en la publicación Euvre Complète 1946-52 -a la que tendrían acceso al poco de publicarse ${ }^{88}$ - serían referencias destacadas para la pareja de arquitectos británicos.

81. KITNICK, Alex. «The Brutalism of Life and Art». October, Spring de 2011.

82. BANHAM, Reyner. «A Man and his Objects». Art News and Review, enero de 1952. 83. SYLVESTER, David, Kenneth King, Eduardo Paolozzi, William Turnbull, exh. cat. (London: Hanover Gallery, 1950), n.p.

84. Las imágenes de Henderson también evocaban "imágenes del mundo natural" a través de una personal interpretación del mundo que provenía tanto de la visión aérea y la microscópica: "desde el aire, la topografía del mundo se vuelve como 'piel de tigre', mientras que las formas vegetales microseccionadas dan paso a 'deltas y arroyos'. KITNICK, Alex, op.cit,

85. "Recorte" incluido en The Big Scrapbook, p.367 (paginación contada por el autor)

86. Kenneth Frampton reconoce la influencia en los Smithson de algunas de las obras de Le Corbusier de la década de 1950: "The completion of Le Corbusier's Unité d'Habitation in Marseille in 1952, having been underway since 1948, broke upon the English scene like a thunderbolt and encouraged the Smithsons to move away from Mies in their Golden Lane competition entry of the same year". FRAMPTON, Kenneth. The English Crucible. Articulo disponible en www.team10online.org

87. “Tras la segunda posguerra (...) la arquitectura de Le Corbusier se revela mucho más elaborada. (...) sus edificios de aspecto arcaico e intemporal definen por medio de su carácter cuasi geográfico -opuesto a los 'artefactos' de la primera época- la construcción de un lugar". "Chandigarh, por otra parte, y pese a las críticas recibidas, recupera la relación entre edificio y espacio público inexistente en sus primeras propuestas urbanas". LINAZASORO, José Ignacio, La memoria del orden, op.cit. p.93-94.

88. "Aquella también fue la época que marcó el interés creciente de los Smithson por la obra de posguerra de Le Corbusier que llamó su atención en 1952 a través de la publicación sobre el arquitecto Euvre Complète 1946-52". RISSELADA, Max, "Casa Bates", en: HEUVEL, Dirk van den, y Max RISSELADA, eds. From the House of the Future to a House of Today. Rotterdam: 010 Publishers, 2004.
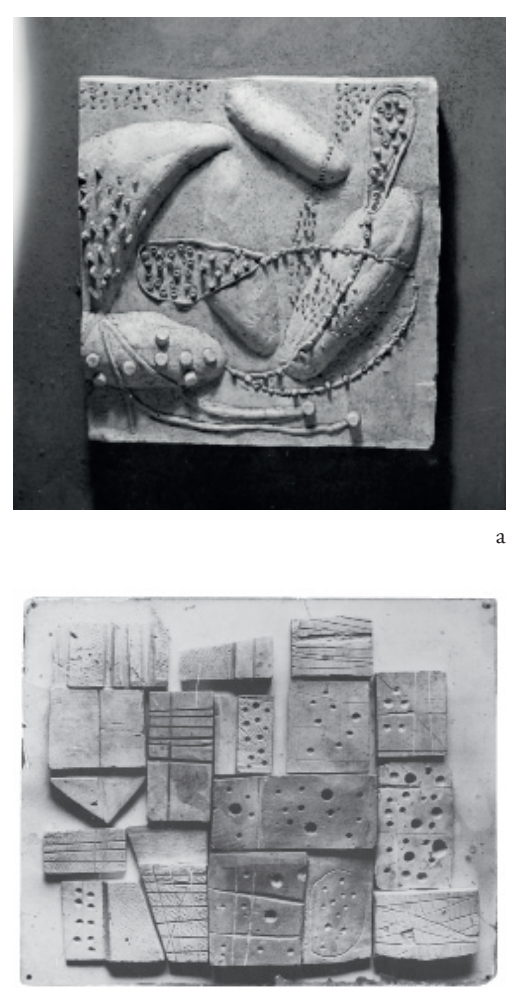

b

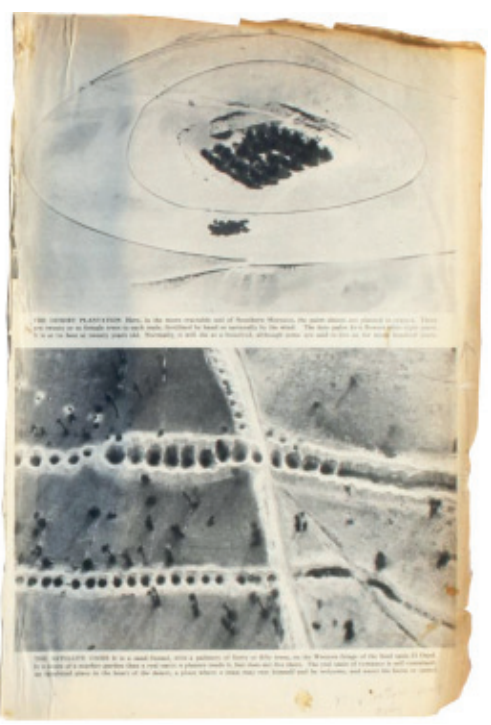

a. Nigel Henderson. Photograph showing work by Eduardo Paolozzi. Tate Archive.

b. Nigel Henderson. Photographic panel showing Cat No 108 - 'Plaster Blocks, Eduardo Paolozzi, 1952. Tate Archive.

c. Sahara Holes. "Recorte" original en The Big Scrapbook, p.367. Smithson Family Collection 


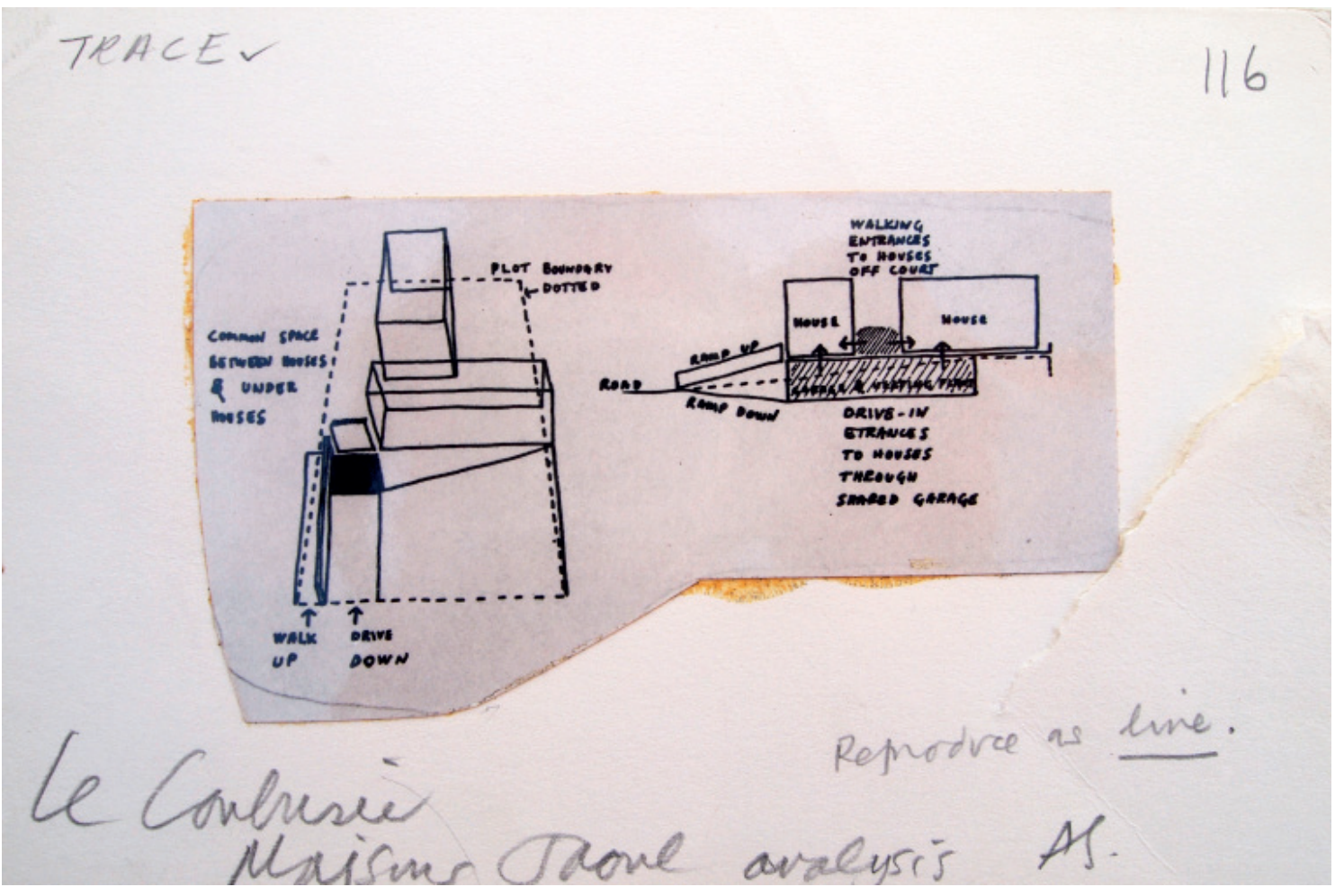

Alison Smithson

Le Corbusier, Maisons Jaoul Analysis. 1953

Smithson Family Collection 
Del primer proyecto, los Smithson destacaron la separación de los espacios exteriores y la zona de coches por medio de una sutil intervención en la sección del terreno. Un croquis, realizado por Alison Smithson en 1952 e incluido en uno de sus primeros textos de esos ańos ${ }^{89}$, analizaba la plataforma ideada por Le Corbusier como la operación esencial del proyecto. Del segundo, los Smithson apreciaron su táctica de implantación, como muestra la elección de una fotografía de la maqueta del conjunto del proyecto como portada para su libro Without Rethoric, de 1972. El espectáculo topográfico de calles semienterradas, jardines hundidos y colinas que planteaba Le Corbusier, planteaba cuestiones que los Smithson retomarían en algunos de sus proyectos de la década de 1970, como Robin Hood Gardens o Lucas Headquarters, en los que los edificios, al igual que ocurría en Chandigarh, se enraizaban en un suelo tallado que establecía intencionadas e inmutables relaciones de posición. ${ }^{90}$

Los Smithson afirmaban que era difícil precisar las influencias concretas en sus proyectos: "las relaciones con la gente y con las ideas se forman alrededor de intereses, atracciones y tiempos comunes, y todo se fusiona cuando uno empieza a proyectar" ${ }^{\prime 1}$. En relación a su "pensamiento topográfico", aparentemente sucede lo mismo: un conjunto de ideas y temas complejos ${ }^{92}$, solapados entre sí, contribuyeron simultáneamente a su formación. A pesar del carácter híbrido que envuelve la gestación de este instinto profundamente arraigado en su manera de proyectar, la experimentación del territorio sobresale como un factor determinante. El "pensamiento topográfico" de los Smithson se formó, principalmente, a través del intenso contacto que mantuvieron con diferentes lugares próximos a sus vidas, en los que desarrollaron una afilada mirada hacia el contexto natural: un instinto operativo por medio del cual se apropiaron de los mecanismos topográficos del paisaje para producir, a partir de ellos, todo un conjunto de operaciones de enraizamiento denominadas ground-notations.

89. Le Corbusier, Maisons Jaoul Analysis, 1953. Una fotografía de este dibujo original tomada por el autor es incluida en esta tesis.

90. CAPITEL, Antón. «Topografía y suelo en la tierra de Chandigarh». Pasajes de Arquitectura y Critica, septiembre de 1999.

91. SPELlMANN, Catherine, y Karl (eds) UNGLAUB, eds. Peter Smithson. Conversaciones con estudiantes. Barcelona: Gustavo Gili, 2004, p.91

92. "Un híbrido de ideas y temas complejos". PUENTE, Moisés y PUYUELO, Anna (eds.). 2G No 34 Sergison Bates. Editorial Gustavo Gili, Barcelona, 2005.

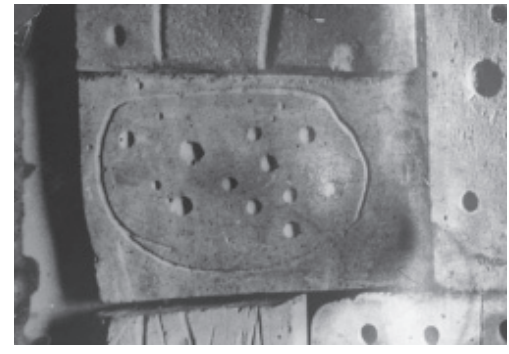

a
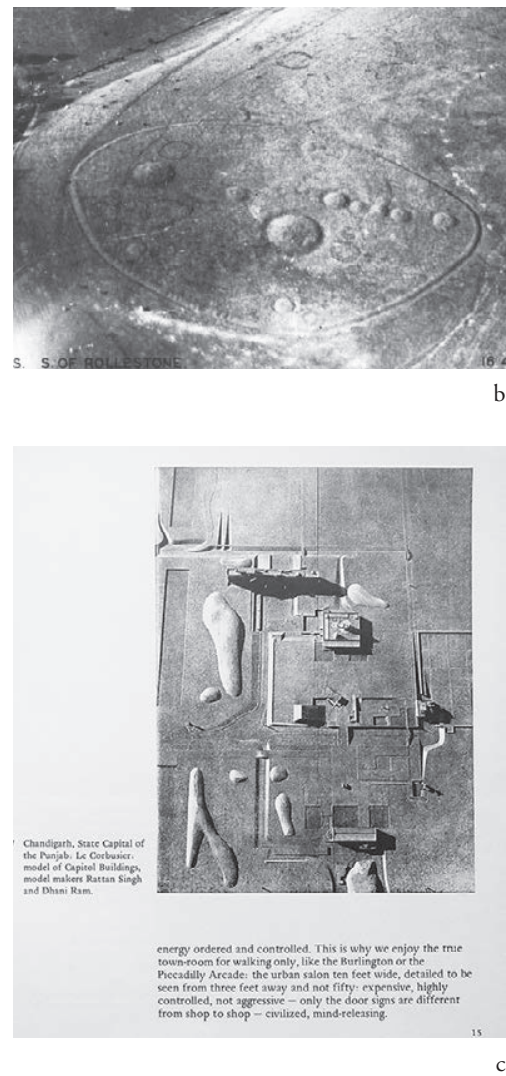

a. E. Paolozzi. Detalle de Plaster Blocks, 1952. Tate Archive

b.Major G.W.G. Allen. Winterbourne, Stoke Rollestone. Bronze Age Bowl Barrow Cemetery. 16/04/1933

c. Alison and Peter Smithson, Without Rhetoric. An Architectural Aesthetic 1955-1972. London: Latimer New Dimensions, 1973, p.15. 


\section{Exploraciones}

El conocimiento del territorio: colecciones, fotografías aéreas y montajes 


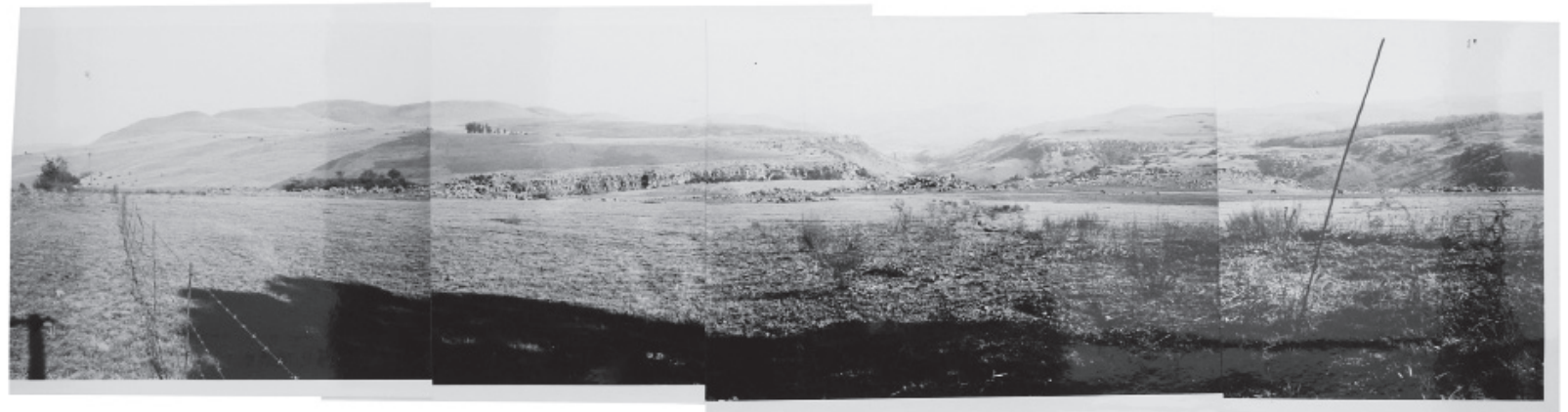

Formaciones topográficas en Northumberland Álbum de fotografías A\&P Smithson Smithson Family Collection 
Exploraciones. El conocimiento del territorio: colecciones, fotografías aéreas y montajes

Las formaciones prehistóricas de Salisbury Plain, los vestigios romanos de Britannia, los artificios del periodo pintoresco o las construcciones vernáculas de Yorkshire, constituyen las principales huellas examinadas en directo por Alison y Peter Smithson en sus numerosas incursiones por el territorio de Inglaterra. Las visitas a estos entornos históricos quedaron registradas a través de un intenso trabajo de campo, formado por fotografías, diapositivas, mapas, apuntes, folletos, guías y "recortes". Este extenso material, seleccionado y clasificado en sus archivos en forma de colecciones, refleja el alcance de tuvo en estos arquitectos la experimentación personal con el paisaje.

Los Smithson encontraron en la fotografía aérea otro medio de conocimiento. Las imágenes desde el aire les proporcionaban un "nuevo punto de vista" alternativo, complementario a la exploración en directo, más objetivo y formal: un mirada gestaltica que se superponía a la percepción fenomenológica y sensorial del paisaje. Desde principios de la década de 1950, varios libros y archivos de imágenes aéreas recogían el trabajo realizado por arqueólogos y expilotos de aviación militar de la II Guerra Mundial. Conocedores de estas fuentes, los Smithson se valieron de ellas para obtener un entendimiento más preciso de ciertosasentamientos y configuraciones artificiales del paisaje autóctono: referencias esenciales en su trabajo que impulsarán la creación de intervenciones topográficas en sus proyectos.

Junto a esta forma de asimilación dual -desde el suelo y desde el aire- las técnicas de montaje, llevadas a cabo a través de collages y scrapbooks, colaboran desde otro enfoque a la apropiación del territorio. The Big Scrapbook, como el ejemplo más destacado de estos trabajos personales -realizado por Alison Smithson durante añoscontienen un multitud fragmentos de paisajes intencionadamente recortados y puestos relación en busca de una fricción creativa. Este scrapbook muestra, a través de sus más 700 páginas, el territorio de un modo absolutamente personal, manipulado y liberado de su significado y contexto original; preparado para ser ya utilizado como material de proyecto. 


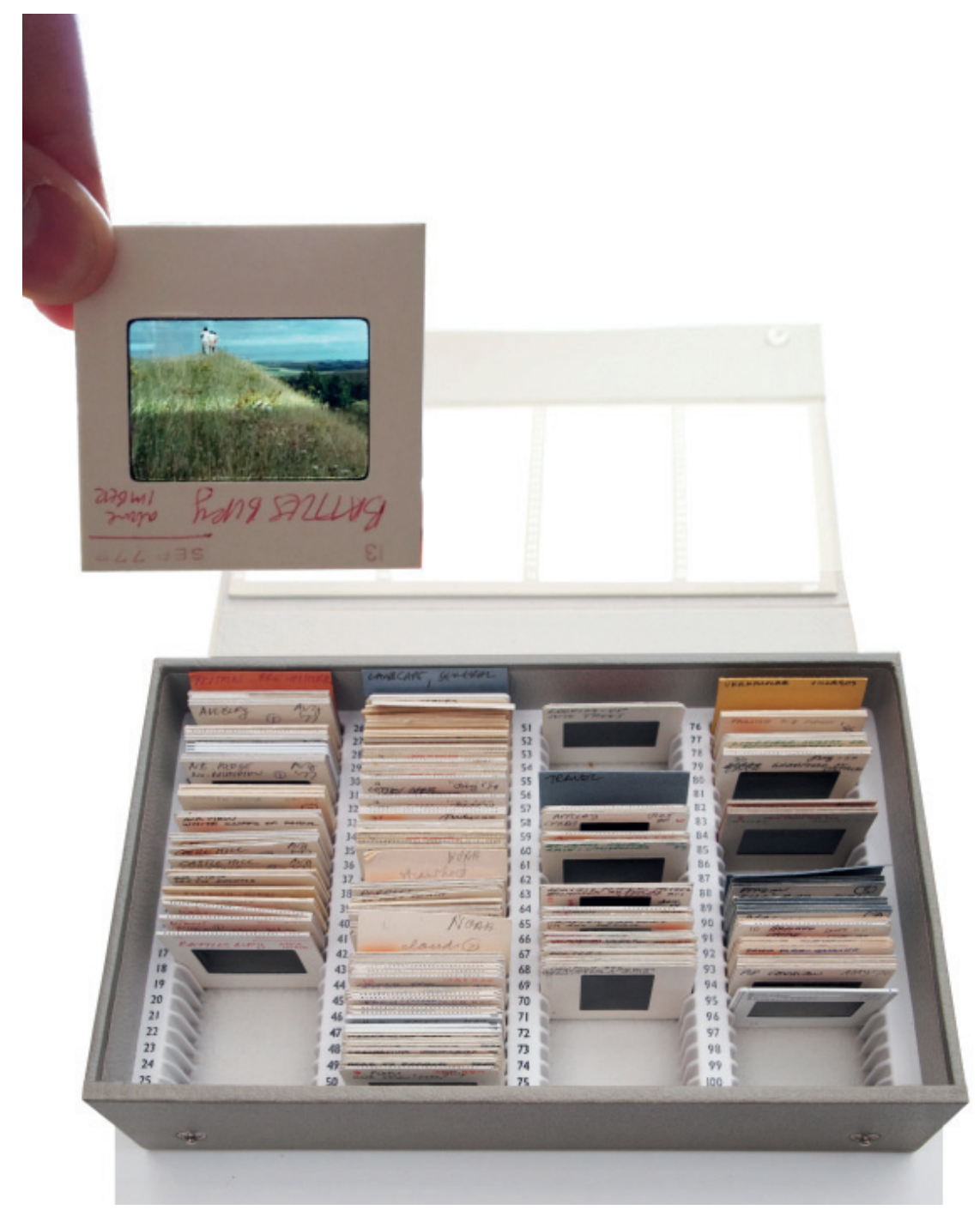

Colecciones de diapositivas

The Hutte. Smithson Family Collection

Fotografía del autor 
Las colecciones de fotografías, diapositivas, mapas, folletos, apuntes y "recortes" de revistas y periódicos que encontramos en los archivos personales de Alison y Peter Smithson están formadas por el material recogido y elaborado durante sus viajes por el territorio de Inglaterra. Conforman un extenso repertorio de fragmentos entre los que se establecen relaciones abiertas y susceptibles de ser reelaboradas a lo largo del tiempo: un sistema flexible de agrupación de documentos capaz de transformarse con la incorporación -o supresión- de nuevos componentes. ${ }^{1}$ La extensión y el carácter diverso de estas colecciones refleja la intensidad con la que estos arquitectos se adentraron en el paisaje autóctono, atentos a cualquier tipo de organización artificial del mismo. Además, poseen un valor añadido para esta investigación, por su capacidad para revelarnos algunas de las referencias vernáculas de las que se valieron para elaborar sus personales intervenciones de configuración del plano del suelo en sus proyectos.

\section{Diapositivas y álbumes fotográficos}

Los Smithson clasificaban sus dispositivas temáticamente. Los títulos que organizaban por contenidos las cajas de filminas nos revelan algunas referencias y temas clave de su obra las cuales procedemos a sintetizar a continuación: ${ }^{2}$

El apartado "Britain pre-historic", incluye imágenes de los diferentes earthworks que los Smithson visitaron, fundamentalmente, en el sur de Inglaterra, entre las décadas de 1950 y 1980. Las imágenes tomadas en Fisbury Rings, Yarnbury Castle, Maiden Castle, Old Sarum, Wansdyke, Castle Hill, Battles Bury y Silbury Hill, reflejan una atención particular a los relieves topográficos — fosos, terraplenes, montículos - de estas formaciones de tierra prehistóricas que inspiraron algunas de las manipulaciones topográficas de sus proyectos.

1. "La colección es un sistema de relaciones abierto e inestable en permanente transformación, una construcción artificial y fragmentaria fruto del montaje y la superposición" ROJO de Castro, Luis, "Ceci nést pas une pipe" Cuadernos de Proyectos Arquitectónicos, no 3. 2012

2. Entre esta extensa documentación fotográfica —álbumes de fotografías y cajas de diapositivas - analizada en los archivos de la familia Smithson, nos fijaremos en aquella vinculada a la configuración del territorio — especialmente en Inglaterra- y cuya influencia se reconoce de manera directa en la formación de las ground-notations. Por ello, en este punto, no incluimos la descripción de otros registros fotográficos, como los agrupados con títulos como "Pop".
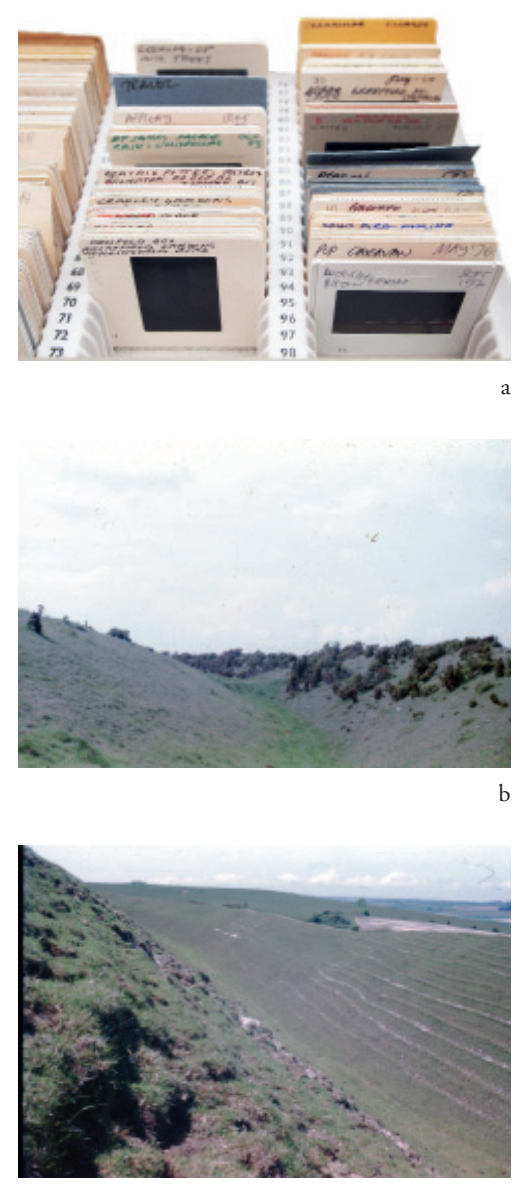

a. Colecciones de diapositivas, The Hutte. Smithson Family Collection. Fotografía del autor.

b. Relieve topográfico del earthwork prehistórico Yarnbury Castle, 1956. Smithson Family Collection.

c. Fosos del earthwork prehistórico Maiden Castle, 1956. Smithson Family Collection. 


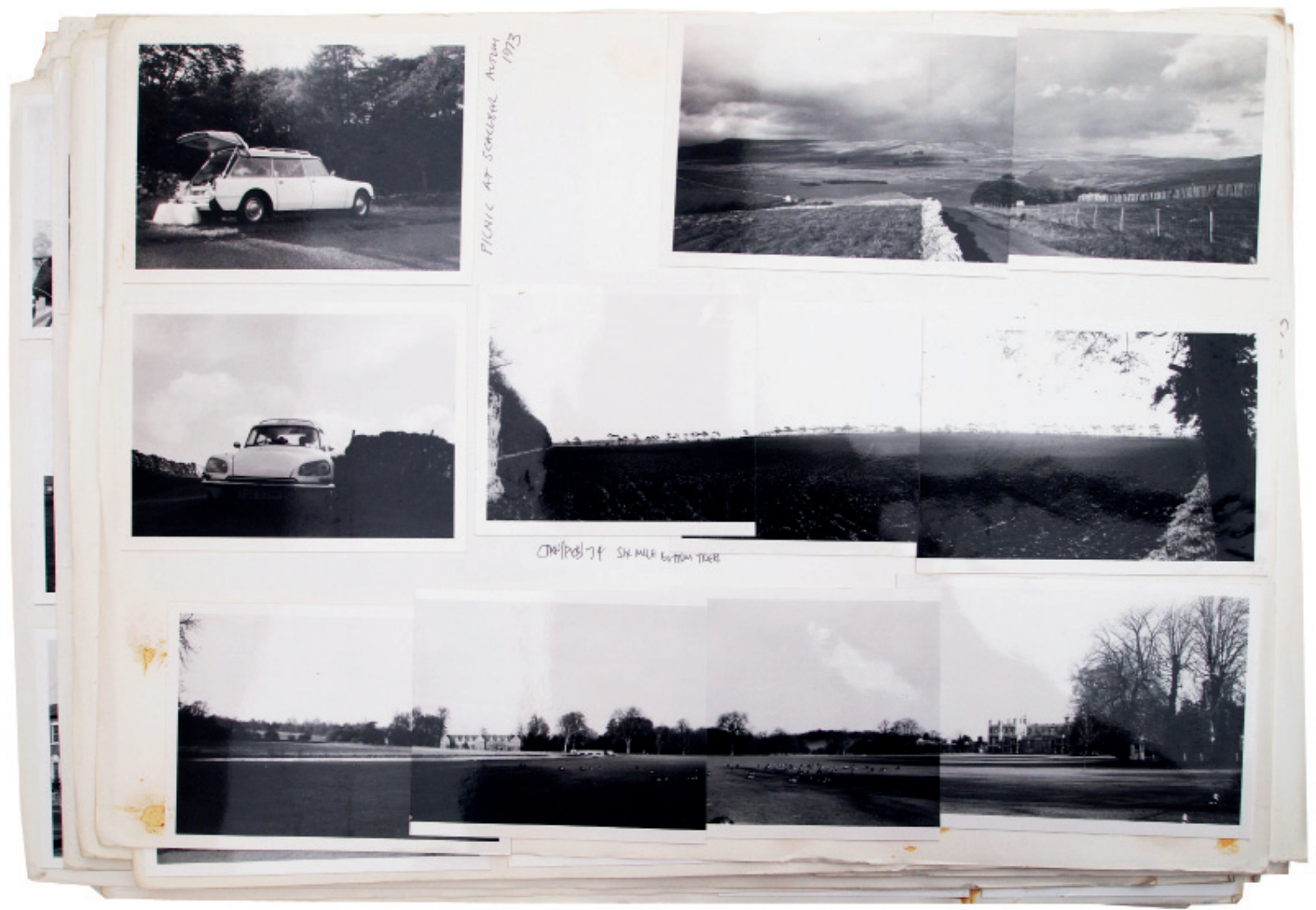

Exploraciones del paisaje

Álbum de fotografías A\&P Smithson

Smithson Family Collection 
"Landscape" comprende un buen número de diapositivas tomadas durante los paseos por los parques pintorescos como Stourhead, Stowe, Kew o Chatsworth. En ellas, se identifican artificios "naturales" de la jardinería paisajista que reaparecerán en sus proyectos transformados en configuraciones de los límites y los espacios exteriores: ha-has, pantallas de setos, agrupaciones de árboles o lagos y láminas de agua artificiales. Incluidas en este apartado, también hallamos una atención específica a los muros de piedra que fragmentan los valles de Yorkshire Dales. ${ }^{3}$ Estas huellas características del "aislado" paisaje rural del norte de Inglaterra, formaban parte esencial del paisaje ingles "interiorizado" por los Smithson. Su influencia se aprecia en las diferentes alusiones a los field walls que realizaron en sus textos, así como en las apropiaciones de sus formas sobre las que se construyen algunos de sus proyectos.

"Vernacular Villages" contiene varias diapositivas tomadas en los pueblos de la costa de North Riding, como Whitby, Staithes o Robin Hood's Bay. Estos lugares, especialmente vinculados a la infancia y juventud de Peter Smithson, constituían ejemplos de asentamientos vernáculos adaptados al lugar a través de su trazado y la relación con la topografía. La naturalidad con la que esa arquitectura anónima gestionaba el relieve del terreno proporcionará a los Smithson algunas claves que darán sentido a estrategias como Riding the landscape.

Algunas de las ciudades de Inglaterra, ligadas a la vida personal y profesional de los Smithson, como Londres, Bath y Edimburgo aparecen representadas mediante diapositivas y otros "recortes" que incidían en algunos aspectos concretos sobre los que fijaron su atención. En la sección "Londres" señalaremos el conjunto de imágenes tomadas en 1970 en el interior del espacio público de Gray's Inn — situado muy próximo a su lugar de residencia ${ }^{4}$ — las cuales mostraban diferentes visiones del parque, prestando atención a los efectos visuales a través de los árboles y sus ramas.

En "Bath" se identifican varias diapositivas de edificios representativos de la arquitectura georgiana como St Mary's Building y Royal Crescent, los cuales aparecen fotografiados numerosas veces y en diferentes años. Para los Smithson, la capacidad de esta ciudad para incluir el entorno natural en su trazado constituía una demostración única de la sensibilidad inglesa hacia el paisaje:

"Bath is English Landscape theory and practice moved into the city" 5

3. En el capítulo 2.2 se muestran algunas de las fotografías tomadas por los Smithson en el paisaje de North Yorkshire.

4. Véase capítulo 5 "Moats and Ditches" sobre Gray's Inn.

5. Ibid, p. 35
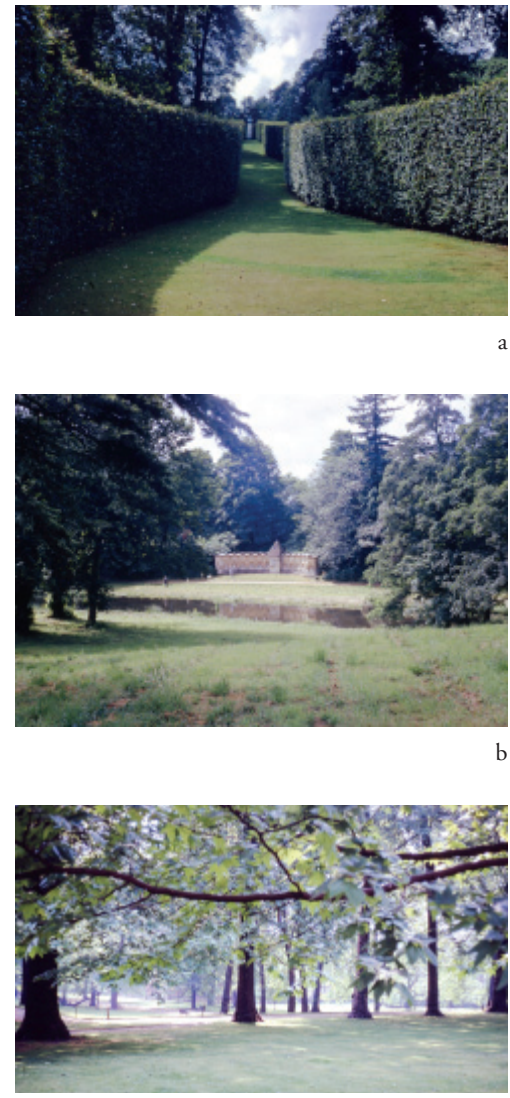

\section{.}




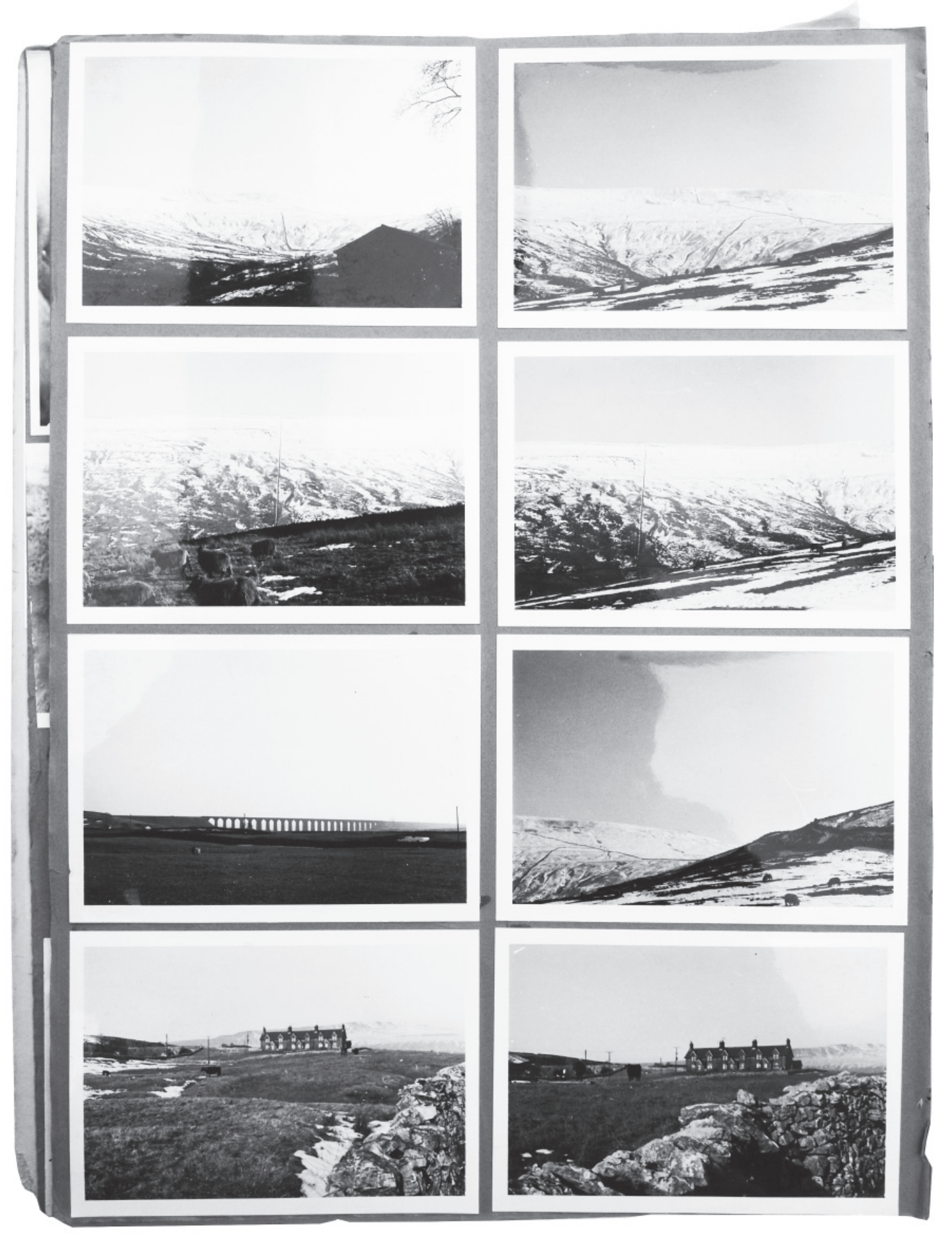

Yorkshire Dales

Álbum de fotografías Smithson Family Collection

Fotografía del autor 
Sus álbumes fotográficos, organizados cronológicamente, inciden sobre los contenidos anteriormente apuntados, ampliando algunos de ellos. Las instantáneas de los field walls tomadas en la década de 1970, aparecen en relación con otras "huellas lineales" que surcan el paisaje de Inglaterra, como acueductos, puentes o carreteras, poniendo en primer plano la configuración artificial del paisaje autóctono. ${ }^{6}$

Los canales de agua, como el de Chatsworth, fotografiado en 1975, o el serpenteante del jardín de Rousham, realizado por William Kent y fotografíado en 1989, aluden a otro tipo de huellas artificiales sobre el terreno. Los caminos y senderos recorridos en sus excursiones se incluyen a través de fotografías que muestran la atención por la cualificación material de estas "marcas" de carácter más superficial.

Las experiencias en los jardines pintorescos, como Stowe, forman parte destacada de sus álbumes. Varias imágenes tomadas en ese parque en 1971, se detienen en la visión de uno de los templos clásicos - the Rotunda - a través de un recorrido de aproximación, en el que esta arquitectura aparece y desaparece de la visión del observador. Los efectos "pintorescos" por la acción de la vegetación y la topografía son intencionadamente recogidos en estas serie de fotografías. Además de la "multiplicidad de vistas", los Smithson detienen su mirada sobre la sutil plataforma sobre la que se asienta este templo: un ligero abombamiento del suelo que podemos reconocer en algunos de los mecanismos de articulación entre el edificio y el terreno desarrollados en sus proyectos.

Las fotografías de los viajes realizados por los Smithson fuera de Inglaterra reflejan la atención por diversas configuraciones artificiales del paisaje. Destacan las imágenes tomadas en 1970 a los montículos de la ciudad Johannesburgo, producidos por la extracción de oro; las realizadas, en 1965, a las excavaciones de las minas de Christalina, en Brasil; o las correspondientes a diferentes tipos de intervenciones y asentamientos sobre el terreno visitados en sus viajes a Túnez, Kuwait y Egipto, entre los años 1967 y 1973.
6. "No forzar la naturaleza sino revelar las "capacidades" del lugar, y magnificar su variedad y singularidad" forma parte de el análisis "pintoresco" que hace Robert Smithson sobre la obra de Serra. Véase: BOIS, Yve-Alain: Paseo pintoresco en torno a Clara-Clara, en: ABALOS, Ińaki. Naturaleza y artificio: el Ideal pintoresco en la arquitectura y el paisajismo contemporáneos. Barcelona: Gustavo Gili, 2009. pp, 49-81
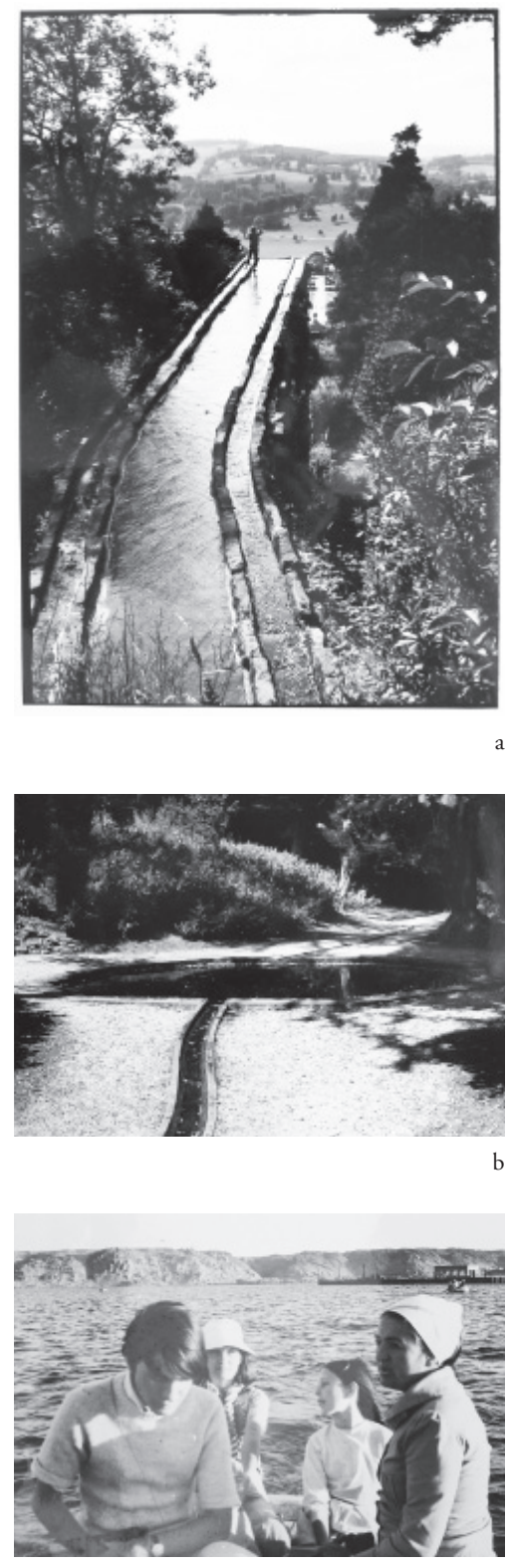

a. Acquaduct serving the fountains at Chatsworh, derbyshire, Photograph: P.S. 1975.Smithson Family Collection.

b. "The Garden at Rousham, Oxfordshire". A perfect instance of kent's serpentine line is the little stonechannelled rill carried through one of the alleys at Rousham..." (Christopher Hussey). Photograph: P.S., july 1989. Smithson Family Collection.

c. La familia Smithson cerca de la isla de Philae (Egipto). Fotografía tomada por Peter Smithson en 1972 en Egipto. Smithson Family Collection. 


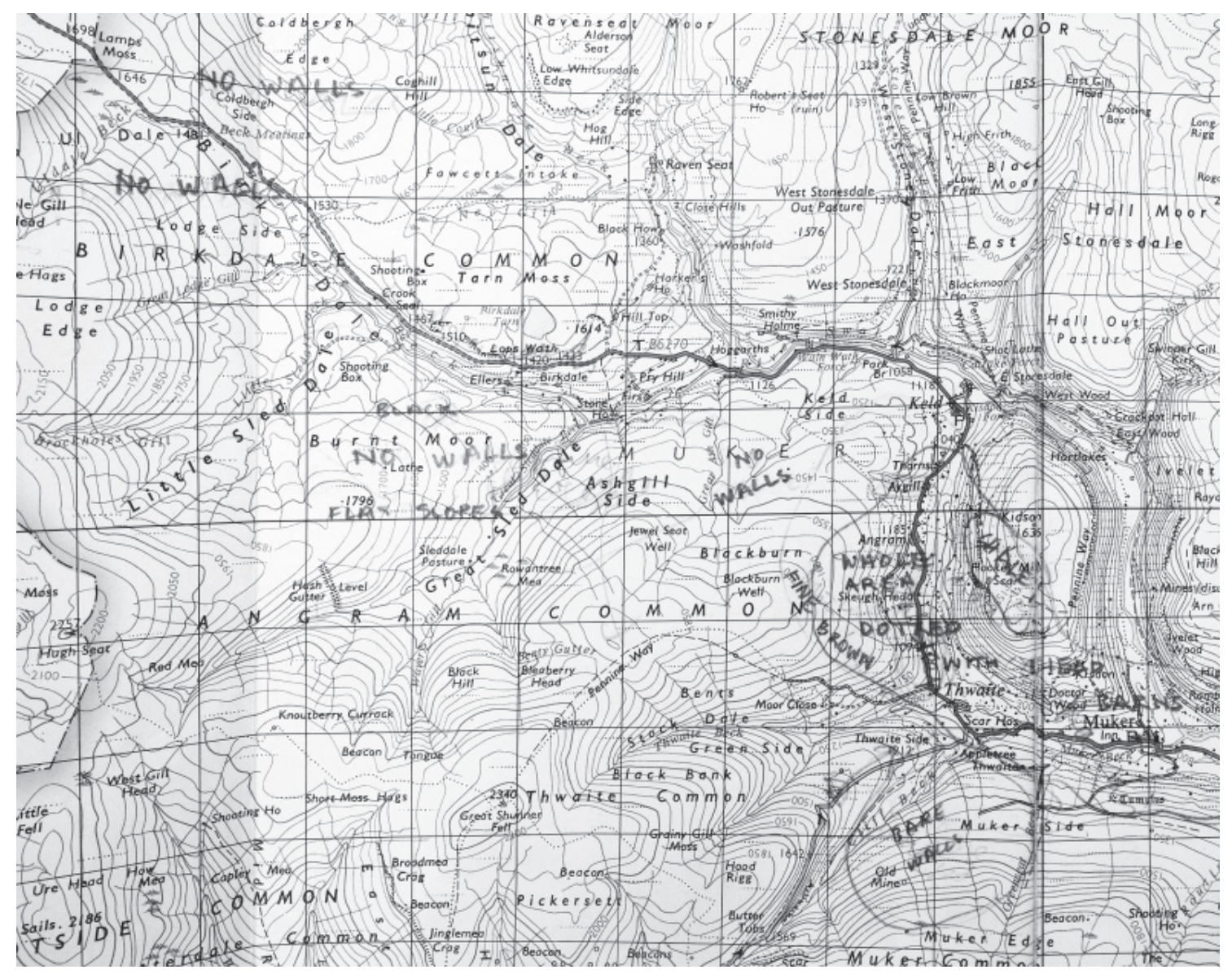

Anotaciones de Alison Smithson sobre el mapa de Wensleydale Smithson Family Collection 


\section{Mapas y trabajo de campo}

Los mapas de carreteras utilizados por los Smithson en sus viajes por Inglaterra nos aportan datos relevantes sobre algunos de los lugares o aspectos concretos de los paisajes explorados. Entre los mapas encontrados en los archivos, varios de ellos están dedicados a las regiones de Wensleydale y North Yorkshire Moor, en el norte, y Salinsbury Plain y Hampshire-Dorset, en el sur. Algunos fragmentos de éstos ejemplares fueron incluidos por Alison Smithson para ilustrar el diario de viajes de su libro $A$ s in DS: an eye on the road.

Varias de estas cartografías contienen anotaciones manuscritas realizadas por los propios arquitectos durante sus viajes. Uno de los mapas de la región de Wensleydale destaca por las numerosas anotaciones escritas a lápiz por Alison Smithson, que señalan algunas construcciones o rasgos topográficos propios de aquel territorio del norte de Inglaterra.

Las palabras escritas por Alison, como "walls", "no walls", "long walls" o "excellent walls on bare moor", hacen referencia directa a los antiguos muros de piedra que fragmentan los valles de esta región y que serán, como se verá en el trascurso de esta tesis, objeto de un interés específico por parte de los Smithson. A través de estas anotaciones, Alison trataba de situar y caracterizar los diferentes tipos de field walls. Los términos "bare tops" "bare wall" o "crags obvious" aluden a otros rasgos topográficos de aquel territorio que igualmente llamarían la atención a los Smithson en sus excursiones.En este mismo mapa también se reconocen anotaciones acerca de otro tipo de huellas, como "hedges" y "ha-ha".

En otros de los mapas de carreteras utilizados por los Smithson aparecen reseñas sobre la situación de restos prehistóricos. Especialmente significativa es la anotación realizada sobre la portada de uno de los dedicados a la parte sur de Inglaterra, South-West England, en la que muestra la localización de uno de los earthworks situados en este territorio: "Stockton earthwork at $45 \mathrm{mph}$ short count as the hedge begins one crest at 3, turn". En este caso concreto, se trata de una huella de un asentamiento de origen romano situado en la zona sur de Wiltshire, a tan solo 6 millas de Tisbury, donde se ubica Upper Lawn.

Junto a esta documentación, también hallamos croquis realizados por los propios Smithson para situar los lugares visitados. Destaca el dibujado por Alison Smithson, con anotaciones escritas a mano, que indican la situación de Crickley Hill: un emplazamiento neolítico situado en Gloucestershire que destaca por los contornos topográficos que formaban el recinto prehistórico. La relativa proximidad de Crickley Hill a Upper Lawn nos hace suponer que su visita formaría también parte de las numerosas excursiones que los Smithson realizaron para conocer las huellas prehistóricas del sur de Inglaterra.
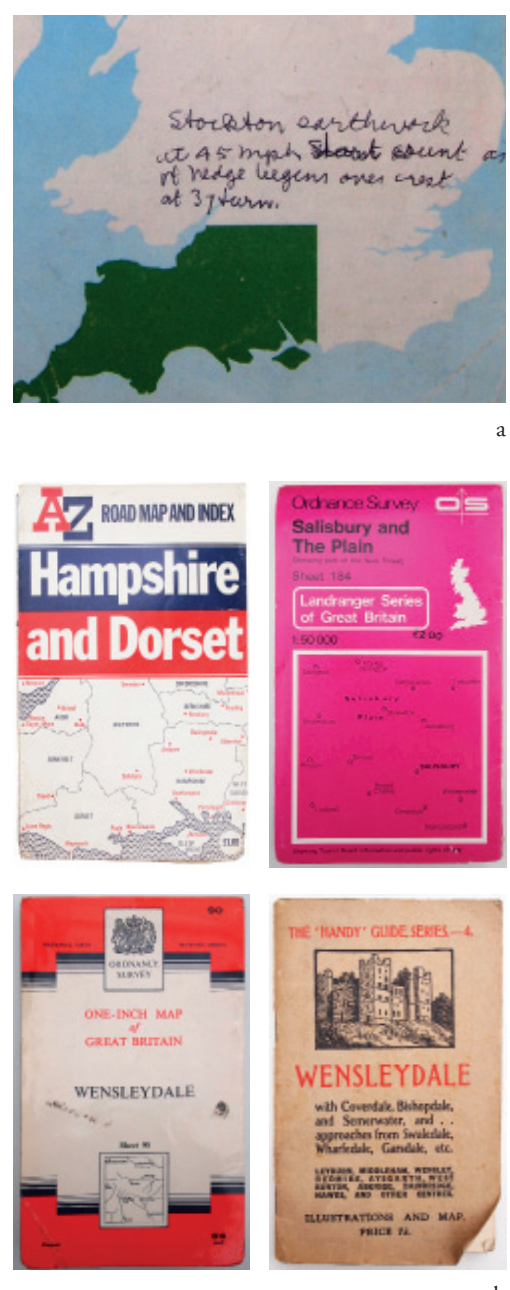

a. Fragmento del mapa de carreteras correspondiente a la zona suroeste de Inglaterra. En la parte inferior se observa la anotación relativa a la ubicación de uno de los earthworks prehistóricos de Salisbury Plain: "Stockton earthwork at $45 \mathrm{mph}$ short count as the hedge begins one crest at 3, turn”. Fotografía del autor.

b. Mapas de carreteras del sur de Inglaterra: "Hampshire and Dorset" y "Salisbury Plain" | Mapas de Carreteras de North Yorkshire: "Wensleydale". Fotografías del autor. 


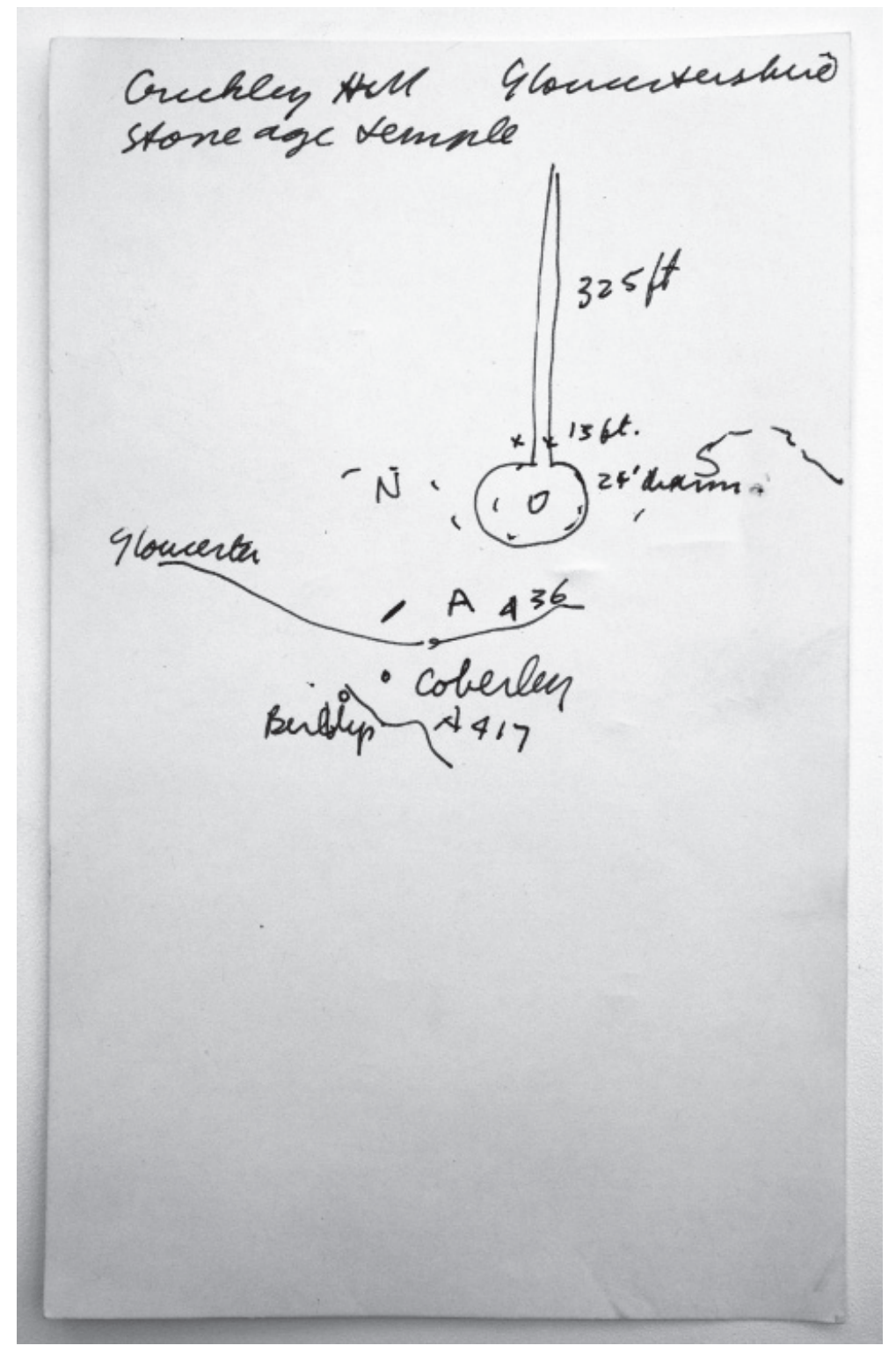

Dibujo de Alison Smithson acerca de la situación de la colina neolítica Crickley Hill Smithson Family Collection

Fotografía del autor 


\section{Folletos, guías y otros recortes}

En sus archivos, encontramos además otras colecciones que recogían la información relativa a diferentes temas de interés. Este material estaba formado por "recortes" de revistas y periódicos, folletos de información, catálogos, guías de viaje y otras publicaciones.

Las colecciones se guardaban en cajas o sobres, permitiendo incorporar nuevos documentos a lo largo del tiempo. Entre ellas, destaca el material recogido acerca del territorio de Northumberland que incluye material diverso sobre la Muralla Adriana y los restos de asentamientos romanos en esa zona del norte de Inglaterra, así como la serie de publicaciones breves acerca de castillos y abadías medievales, editadas por Ministry of Public Buildings and Works. Otros enclaves de reiterado interés por parte de los Smithson, como Edimburgo, aparece en diversos recortes de revistas, postales y fragmentos de artículos sobre esta ciudad. ${ }^{7}$

El material relacionado con los viajes recopilaba itinerarios, apuntes y documentación vinculada a sus visitas, como se recoge en la realizada a Irlanda en 1979, "Irish Field", para explorar las huellas de asentamientos prehistóricos como New Grange, Loughcrew, Loungh Gur o Dun Aillinne Hillfort.
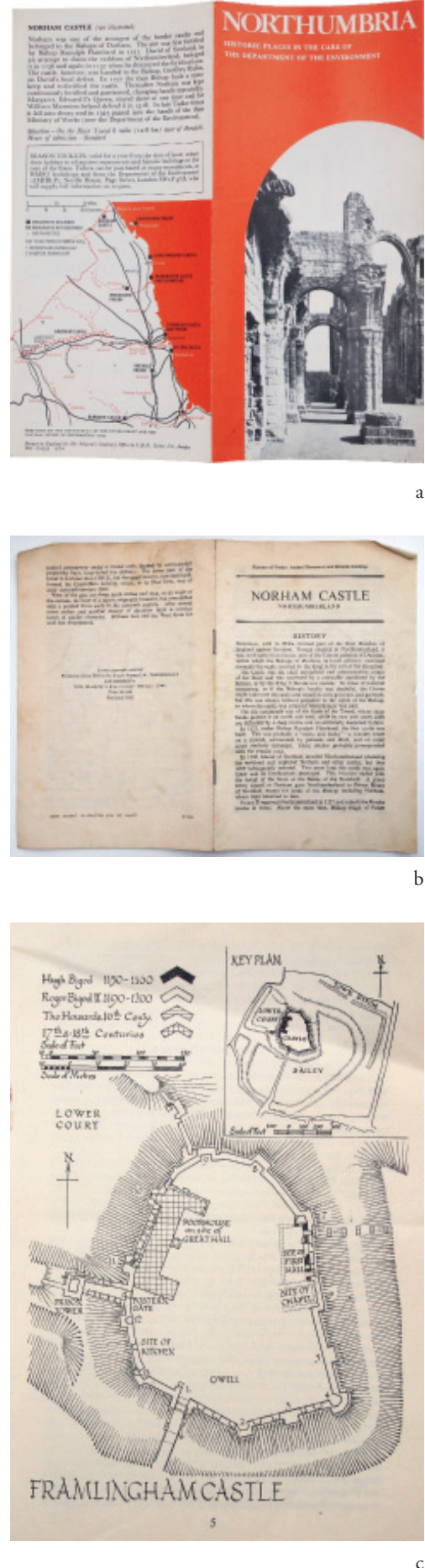

7. Uno de ellos publicado en 1952 ("The Lesson of Edimburgh", de Robert GardnerMedwin); y otro publicado en The Architects 'Journal, del 16 de Enero de 1974, del que se desconoce el título.

a. Northumbria. Publicado en 1972. Smithson Family Collection.

b. Norham Castle. Ministry of Public Buildings and Works. Fotografía del autor.

c. Framlingham Castle. Ministry of Public Buildings and Works. Fotografía del autor. 


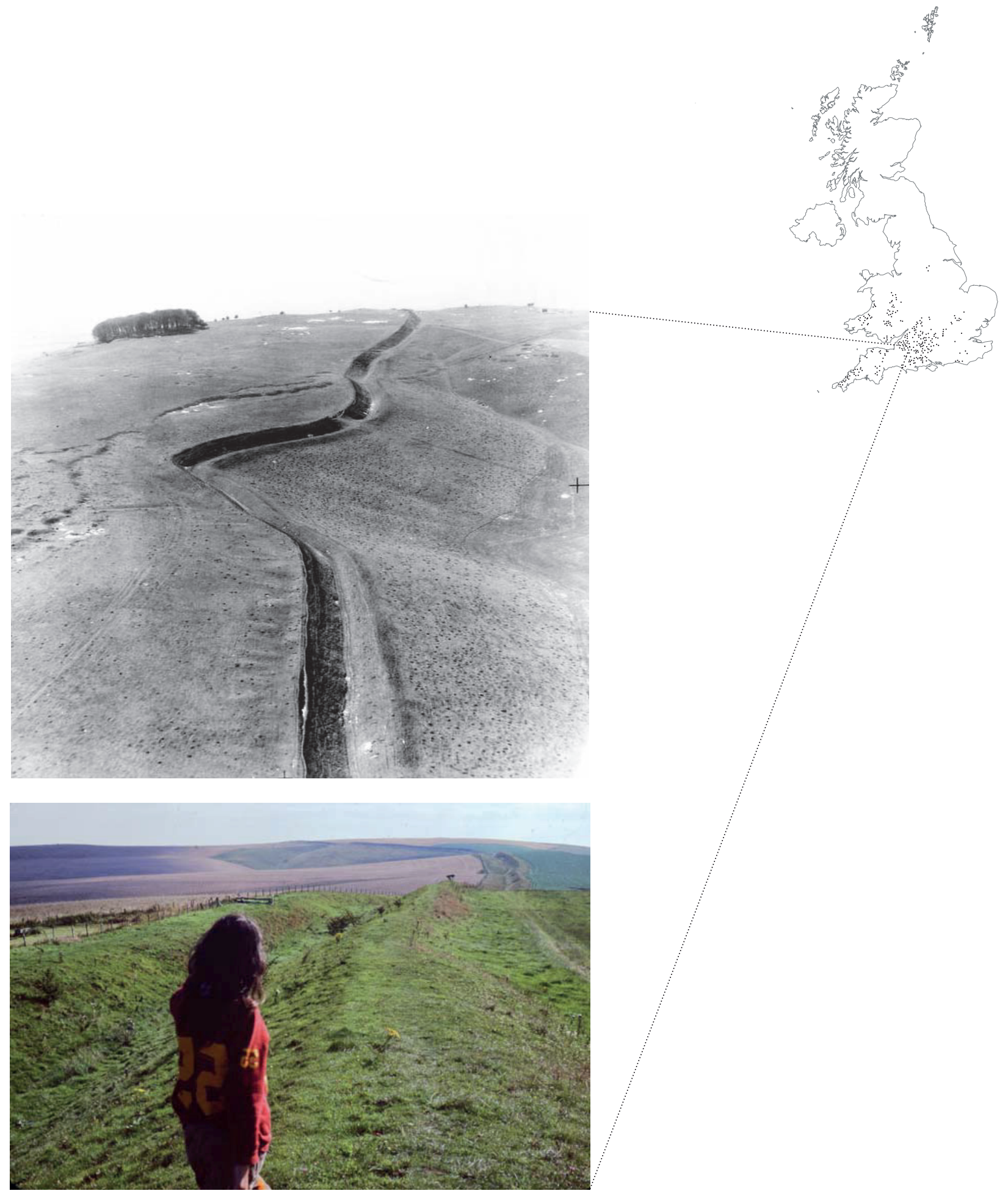

Fotografía aérea de Wansdyke. The Cambridge University Collection of Aerial Photography Soraya Smithson en Wansdyke, Wiltshire. Septiembre, 1977.Smithson Family Collection Montaje del autor 
La combinación de experimentación directa con la exploración a través de la fotografía aérea sirvió a los Smithson como herramienta para adentrarse en el paisaje de Inglaterra. Estas dos aproximaciones complementarias al conocimiento del territorio — desde el suelo y desde el aire- generaban una asimilación más profunda del mismo. Ambos modos de percibirlo sucedían sin un orden establecido; en unas ocasiones, la experiencia directa con la tierra precedía a su contemplación desde el aire $^{8} \mathrm{y}$, en otras, ocurría lo contrario: la fascinación por la imagen aérea era el motivo de una visita de reconocimiento.

La exploración in situ proporcionaba una experiencia personal en la que se apreciaban las verdaderas capacidades del lugar, su variedad y singularidad. Esta percepción sobre el terreno permitía capturar los aspectos más profundos e intangibles del paisaje, como la escala, la sensación de refugio, la protección frente al clima, el aislamiento acústico, la sombra, o la fertilidad de la tierra. Se trataba de una experiencia sensitiva y fenomenológica, como se deduce de las explicaciones de los propios arquitectos:

“(...) los lugares nos seducen por razones que van más allá de las sensaciones derivadas de los cinco sentidos...algún tipo de identificación profunda opera en nosotros, percibida a través de una inextinguible sensibilidad animal (...) la sensación que experimentamos en ese lugar es similar a la que debe de sentir un lagarto al mudar su piel; allí, el aire huele diferente, la vegetación es perfumada, incluso el polvo de la tierra se levanta de una manera totalmente diferente"?

Frente a este tipo de experiencia personal, la visualización de fotografías aéreas aportaba, en cambio, una lectura formal desde el aire en la que el suelo se percibía como un "cuadro", un soporte abstracto tallado por diferentes patrones de marcas e incisiones. La fotografía aérea ofrecía, por tanto, una comprensión adicional más teórica y contemplativa: ${ }^{10}$ un entendimiento analítico del paisaje a través del cual era posible apreciar con precisión sus características físicas, su variedad y singularidad de un modo objetivo:

8. Los Smithson consiguieron una fotografía aérea de Upper Lawn que incluyeron en el libro dedicado a este proyecto. Véase: SMITHSON, Alison y Peter. Upper Lawn Solar Follie. op.cit.

9. SMITHSON, Alison \& Peter, "Territory", en Italian Thoughts, p.32

10. BESSE, Jean-Marc, "Geografías Aéreas", en, MACLEAN, Alex S. La fotografía del territorio. Barcelona, España: Editorial Gustavo Gili, 2003. p.341.

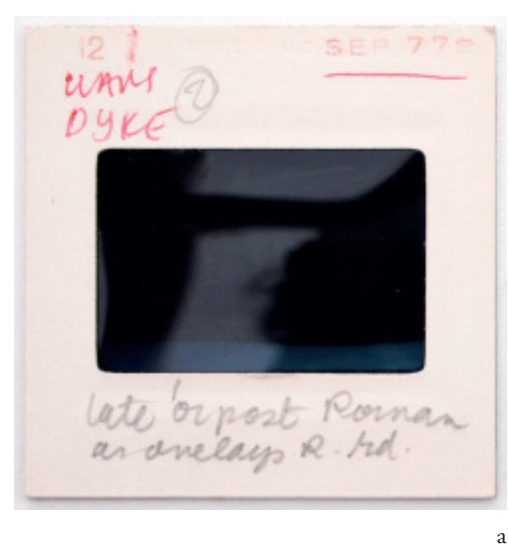

a. "Wansdyke; late or post Roman as one lays R.rd. Sep.1977". Smithson Family Collection. Fotografía del autor. La diapositiva muestra la exploración de este earthwork situado en Wiltshire. 

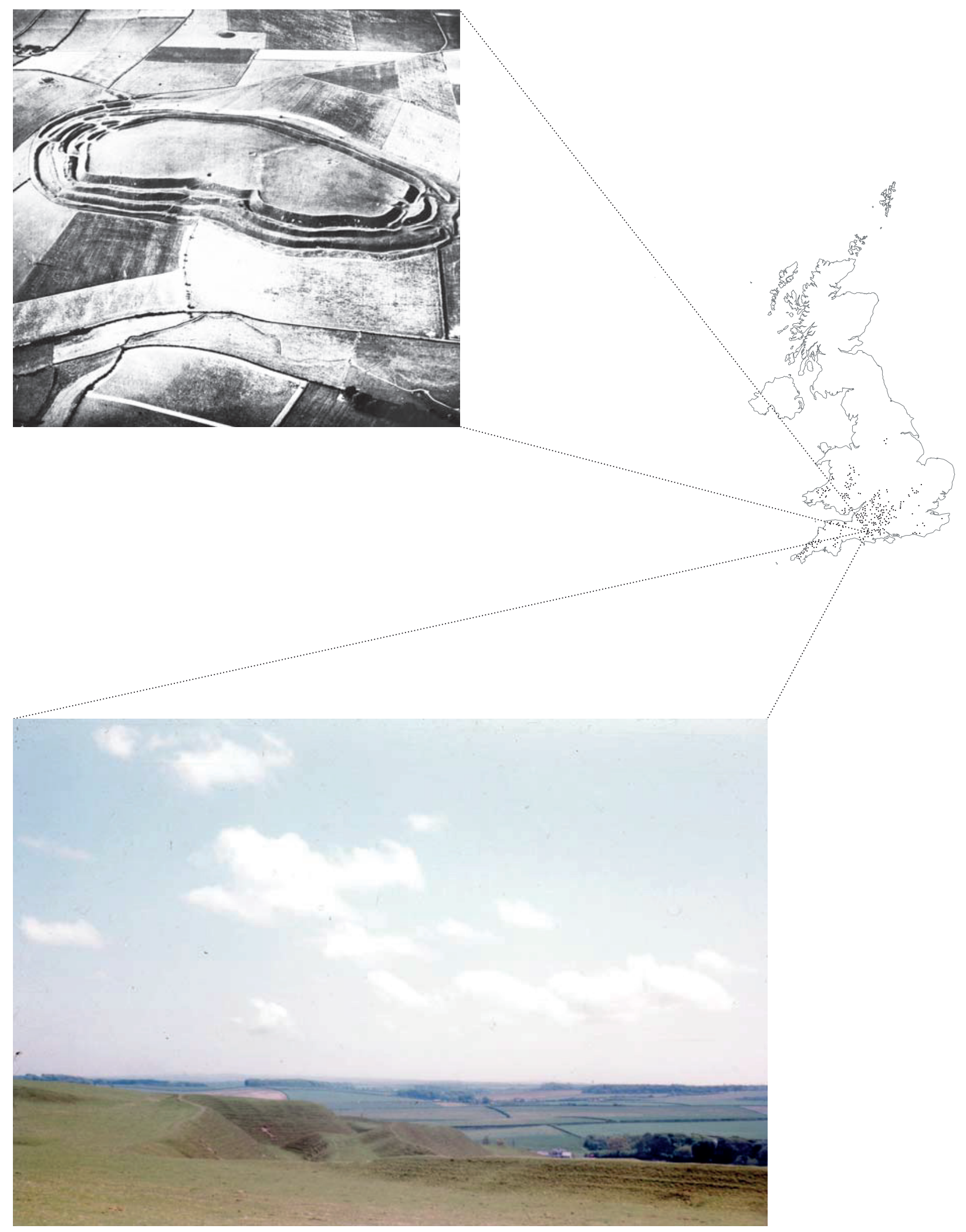

Earth Fortifications at Maiden Castle, Dorset. Ministry of Works Maiden Castle. Fotografía de A\&P Smithson. 1956. Smithson Family Collection Montaje del autor 
"el distanciamiento aéreo de la mirada respecto al suelo, y su lejanía respecto a los compromisos concretos en los recovecos de las cosas, conducen la mirada hacia una especie de abstracción y le confieren un poder de inteligencia sobre la realidad que no habría podido tener de haber permanecido anclado en los detalles del mundo". ${ }^{11}$

A principios de la década de 1950, el papel de la imagen aérea en la producción de conocimiento sobre el territorio estáya definitivamente consolidado. ${ }^{12}$ Desde el comienzo de su trayectoria, los Smithson utilizaron la fotografía aérea como parte de su pensamiento y la producción de proyectos y escritos. En sus comienzos, diferentes ejemplos realizados en aquellos ańos, como la exposición de 1953, Parallel Life and Art, ${ }^{13}$ los proyectos presentados en el X Congreso de los CIAM de $1956^{14}$ y algunos textos de Urban re-identification, escritos en 1952 y $1953,{ }^{15}$ utilizan el poder evocador de las imágenes aéreas del territorio con diferentes enfoques. Al final de su trayectoria, la fotografía aérea del territorio está especialmente presente en varios de los proyectos y textos desarrollados en el contexto de los talleres ILA\& UD en la década de 1980 y 1990, que inciden en cuestiones directamente vinculadas a la configuración del paisaje.

La atracción por la imagen aérea se manifiesta con fuerza en sus trabajos más personales, como diarios y scrapbooks, que incluyen imágenes de este tipo procedentes fundamentalmente de revistas y publicaciones de prensa. The Big Scrapbook —el libro de los recortes de Alison Smithson y al que nos referiremos con más detalle en el siguiente apartado de la tesis - contiene una importante cantidad de fragmentos que muestran, desde el aire, la acción del hombre sobre el paisaje, incluyendo diferentes escalas de aproximación: desde la más territorial que evidencia las trazas generales de los asentamientos humanos, hasta las más cercana que muestra huellas de menor tamaño como construcciones o formaciones topográficas específicas.

11. Ibid, p.340

12. Ibid, p.337

13. Parallel Life and Art, de 1953, ya contenía fotografías del territorio tomadas desde el aire. Peter Smithson afirmaba que Parallel Life and Art sucedió en una época en la que los artistas estaban interesados en la fotografía microscópica y la aérea. Aquellas fotografías, según Peter Smithson "eran novedosas y cuando un material es novedoso, inspira". ULRICH OBRIST, Hans, "Smithson Time", p.7-8

14.Los paneles de los Smithson presentados en en los X CIAM, de 1956, contenían fotografías aéreas del territorio que mostraban asentamientos vernáculos ingleses en el norte de Inglaterra, como los de la costa de los Moors, y formaciones de tierra primitivas como Castle Hill o Maiden Castle, en el sur.

15. Incluidos en: SMITHSON, Alison and Peter. Ordinariness and Light. Urban Theories 1952-60, and their Application in a Building Project 1963-70. Cambridge MA: MIT Press, 1970.

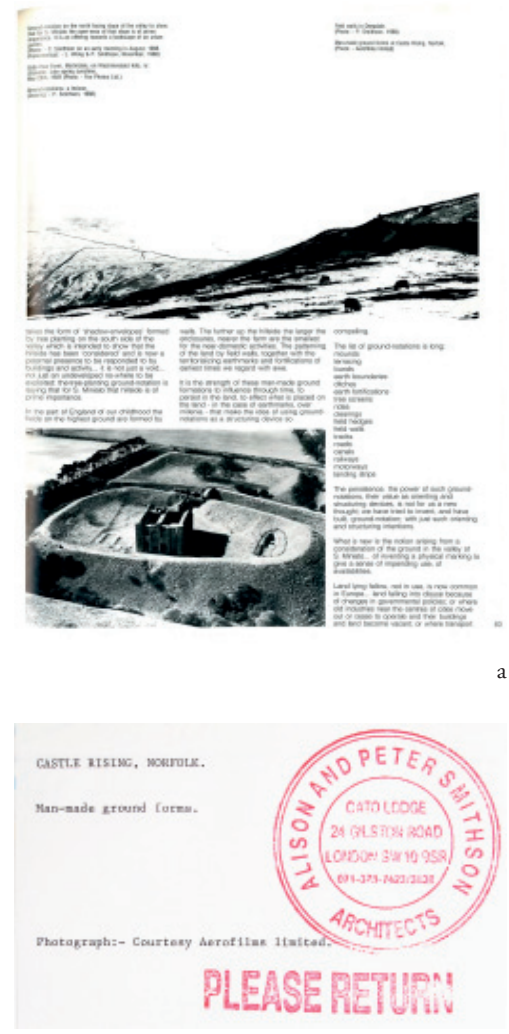

b

a. El conocimiento dual del paisaje: La primera página de Shifting the Track (A\&PS 1989) muestra una fotografía del paisaje de Deepdale, tomada por Peter Smithson en 1968, y la imagen aérea de la formación de tierra primitiva de Castle Hill, procedente de los archivos de Aerofilms.

b. Dorso de la fotografía aérea del earthwork de Castle Rising, procedente de Aerofilms e incluida en el artículo Communications and Dispositions (Ordinariness and Light, 1970) y en Shifting the Track (ILA\&UD Annual Report, Siena 1990). 


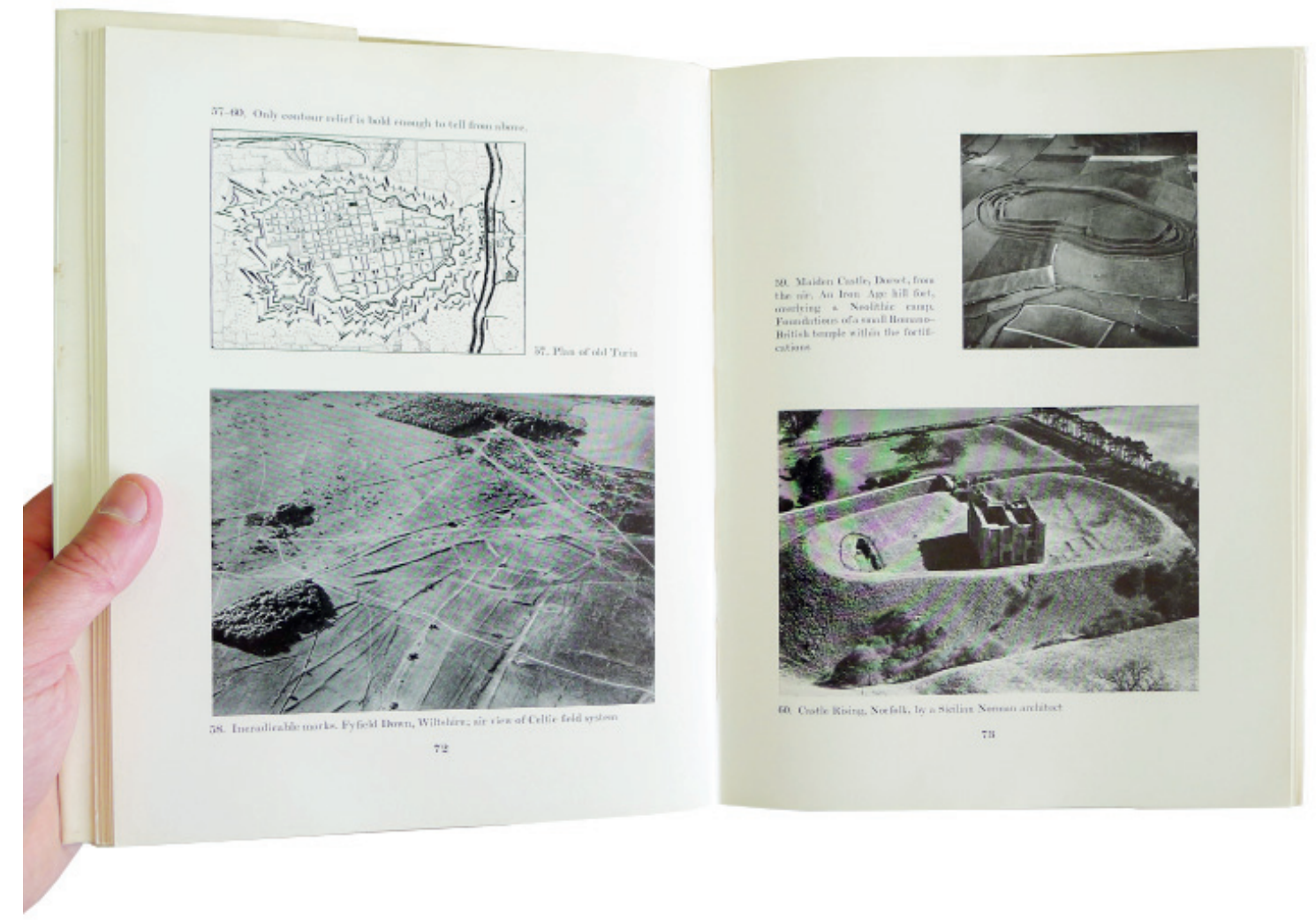

Imágenes aéreas

Alison \& Peter Smithson, Ordinariness and Light, 1970, p.72-73

Fotografía del autor 


\section{Archivos y fuentes de imágenes aéreas}

Las fotografías aéreas utilizadas por los Smithson provenían de los archivos fotográficos de pilotos de aviación ingleses, ${ }^{16}$ como Francis Lewis Wills, Claude Grahame-White, Major Allen, Derrick Newton Riley y K. St. Joseph y arqueólogos como O.G.S.Crawford. Las imágenes de estos archivos estaban gestionadas por The Ministry of Public Works, por compañías como Aerofilms ltd, o instituciones como Oxford Ashmolean Museum y Committee for Aerial Photography of the University of Cambridge. El contacto con estas fuentes $y$ algunos libros de fotografía aérea, publicados en la década de 1950, les proporcionaron un conocimiento más preciso y analítico del territorio, fomentando su interés sobre la configuración artificial del paisaje y la consideración del plano del suelo como un "soporte" manipulado topográficamente.

\section{Aerofilms}

La primera empresa comercial inglesa dedicada a la fotografía aérea fue Aerofilms Ltd. ${ }^{17}$ Fundada en 1919, por los expilotos de la Primera Guerra Mundial, Francis Wills and Claude Graham White, contiene el archivo más importante de fotografías aéreas de Gran Bretaña tomadas antes de 1939. En la década de 1950, el establecimiento que tenía en Londres, permitía consultar su catálogo y solicitar los pedidos. En 1954, la empresa publicó The Aerofilms book of Aerial Photograps, ${ }^{18}$ un volumen que recogía una amplia selección de sus imágenes aéreas divididas en diferentes capítulos: arqueología, arquitectura, geología, etc.

Alison y Peter Smithson extrajeron de Aerofilms al menos cinco de las fotografías aéreas que ilustraban sus primeros textos de mediados de la década de 1950 y que fueron publicados posteriormente en su libro Ordinariness and Light. ${ }^{19}$ Entre ellas estaría la imagen de Castle Rising, en Norfolk, un castillo medieval del siglo XII encerrado en un movimiento de tierra de forma oval que actuaba como un dispositivo defensivo. La imagen de este earthwork, además de ser publicada en uno de los capítulos de Urban Re-identification (Communications and Dispositions) era una de las imágenes que los Smithson incluyeron en uno de los cinco paneles presentados en el X Congreso del CIAM

16. Como se ha comentado brevemente en la Introducción de este trabajo, cabe destacar la influencia de Nigel Henderson y su experiencia como piloto en la II Guerra Mundial, en el interés de los miembros del Independent Group por la visión del territorio desde el aire.

17.www.rsacl.co.uk

18. Un ejemplar de este libro se encuentra en la biblioteca de Alison y Peter Smithson, como se ha podido comprobar durante el desarrollo de esta tesis.

19.SMITHSON, Alison and Peter. Ordinariness and Light. Urban Theories 1952-60, and their Application in a Building Project 1963-70. Cambridge MA: MIT Press, 1970.
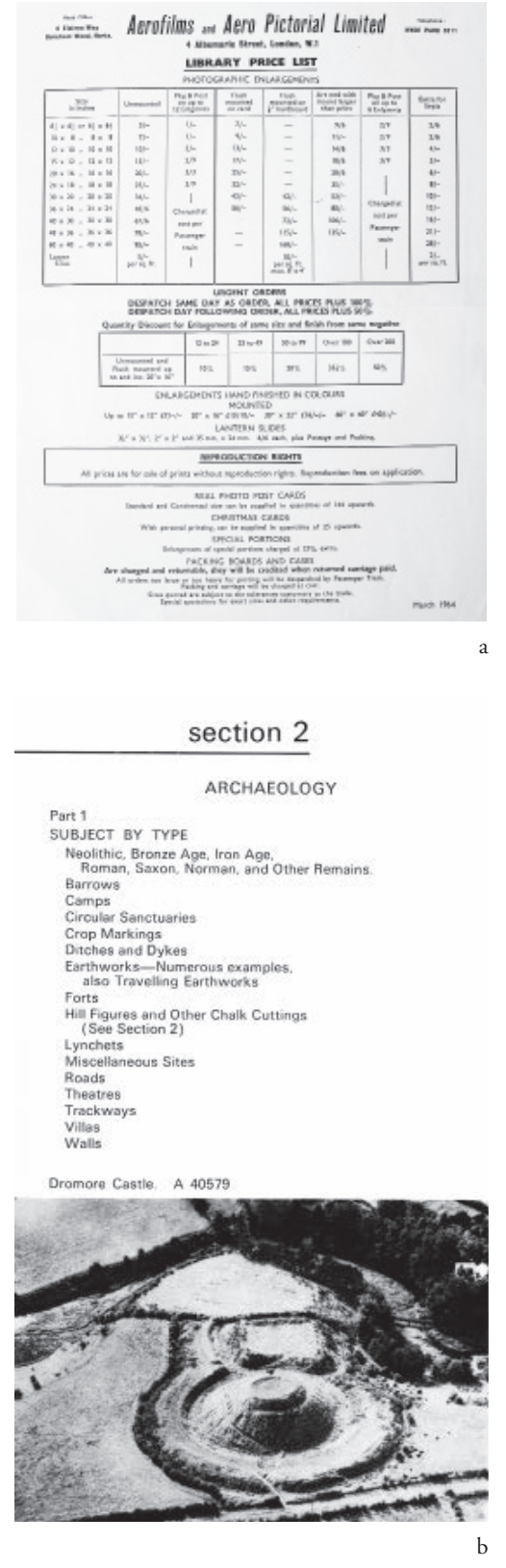

a. Aerofilms: "Library Price List". The Aerofilms Book of Aerial Photographs. London, Aerofilms Limited, 1964.

b. The Aerofilms Book of Aerial Photographs. London, Aerofilms Limited, 1965, p.14. Sección "Arqueología” en la que se incluyen las imágenes aéreas de las formaciones prehistóricas en Inglaterra. 


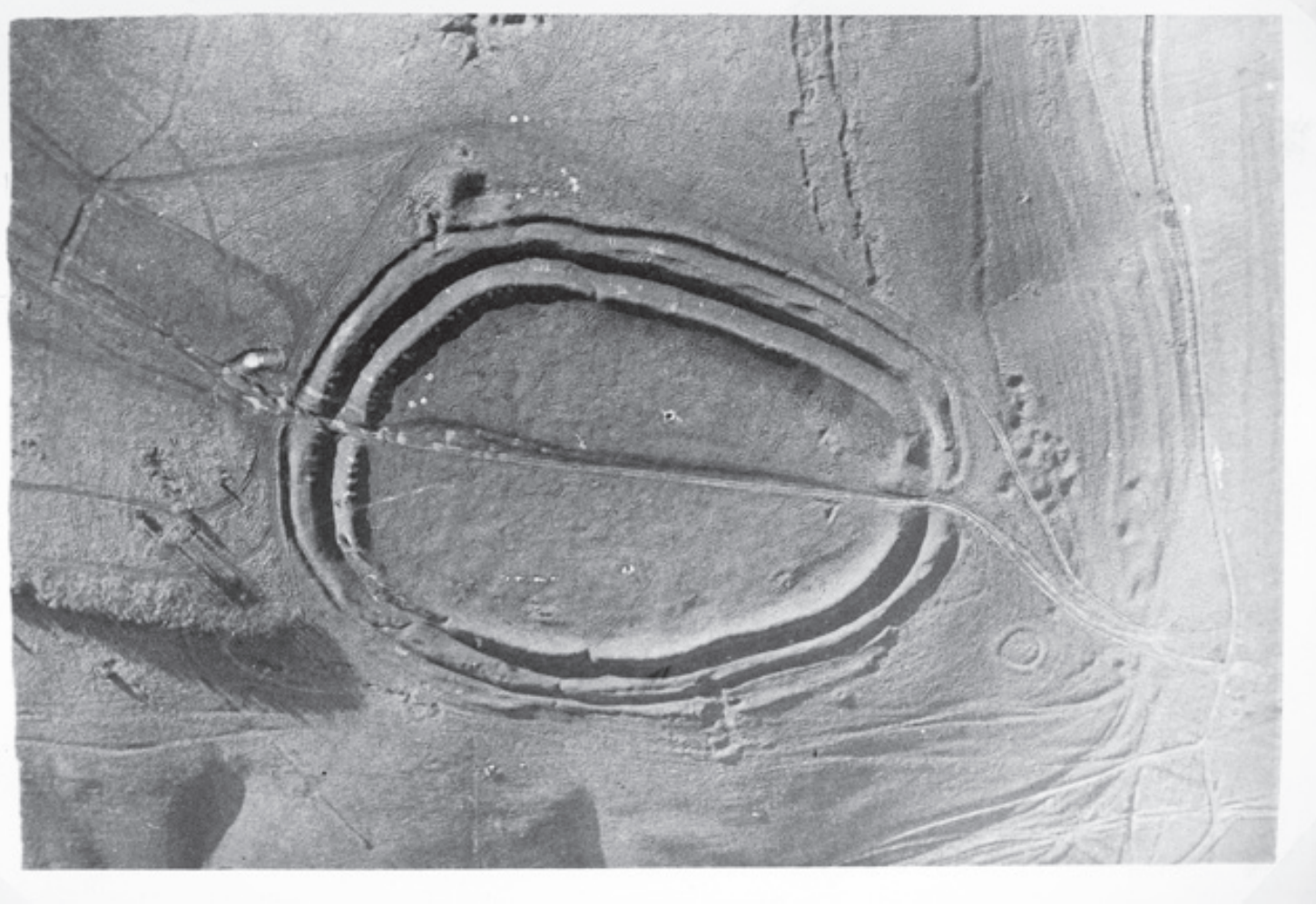

Ogbourne St.Andrew, Barbary Castle, Wiltshire D.N. Riley, Ashmolean Museum, Universidad de Oxford Fotografía del autor 
en Dubrovnik, de $1956^{20}$. El earthwork de Castle Rising, será, como podrá comprobarse en apartados posteriores de este trabajo, una de las formaciones de tierra clave para los Smithson y cuya esencia se encuentra en varios de sus proyectos. En la exposición Parallel Life and Art, de 1953, los Smithson ${ }^{21}$ utilizaron imágenes aéreas ${ }^{22}$ procedentes de Aerofilms: Erbill ancient Assyrian city over 4000 years old, en la sección de "arquitectura" o Patterns in mud, Grimsby, en "arte", entre otras. Aerofilms incluía en su catálogo de $1954^{23}$ numerosas imágenes aéreas de las huellas de restos romanos ${ }^{24}$, objeto de interés para los Smithson, además de los ubicados en el entorno más próximo de la Muralla Adrina: Cawthorne, en North Yorkshire; Hod Hill, en Dorset; Richborough Roman Fort, en Kent; Verulamium, en St. Albans, cerca de Londres; o Silchester: un campamento romano ubicado en el trayecto que une Londres con Tisbury. ${ }^{25}$

\section{G.W.G. Allen; D.N. Riley: Ashmolean Museum}

El Museo de Arte y Arqueología de la Universidad de Oxford posee actualmente la colección de fotografías tomadas por el piloto de aviación Major G.W.G. Allen (1857-1940) ${ }^{26}$ entre 1933 y 1939. Las imágenes de Allen contribuyeron en gran medida a la interpretación de varios de los lugares arqueológicos de Inglaterra, especialmente en la zona de Oxfordshire. El conjunto de imágenes recopiladas tras su muerte en 1941 y donadas al Museo contenía, aproximadamente, unas 2000 fotografías. ${ }^{27}$ A diferencia del catálogo de Aerofilms, que abarcaba temas de interés diverso, el de Allen se centraba exclusivamente en los puntod de interés arqueológico de Inglaterra, conteniendo un exhaustivo listado de la mayoría de los earthworks y trazas primitivas repartidas por el territorio inglés. En el texto Urban Re-identification, publicado en Ordinariness and Ligh, los Smithson utilizan una de las fotografías aéreas del catálogo de Allen. Se trata de las trazas de asentamientos celtas de Fyfield Down, situadas en Wiltshire, ${ }^{28}$ que, probablemente, despertarían muy

20. El texto que acompaña la fotografía: "Historical Parallel: a house isolated by a circular earthwork (Castle Rising, Norfolk, England)"

21.Alison y Peter Smithson con Nigel Henderson, Eduardo Paolozzi y Ronald jenkins 22. Véase fragmentos del catálogo de la exposición en: The Independent Group: Postwar Britain and the Aesthetics of Plenty, editado por David ROBBINS, 194-95. MIT Press, 1990.

23. AEROFILMS. Classified index to the library of aerial photographs. Londres, 1954

24. Véase en el catálogo de AEROFILMS: The Vallum of Hadrian's Wall and surrounding countryside, Winshields.

25. Emplazamiento de Upper Lawn.

26. He served again in the military during the First World War and was awarded the Military Cross, re-joining his father's company after the war.

27.http://britisharchaeology.ashmus.ox.ac.uk

28. Los Smithson incluyeron la fotografía "Ineradicable marks. Fyfield Down, Wiltshire; air view of Celtic field system", en Urban re-dentification. Ordinariness and Light. $\mathrm{n}^{\circ}$ imagen 58 , p.72
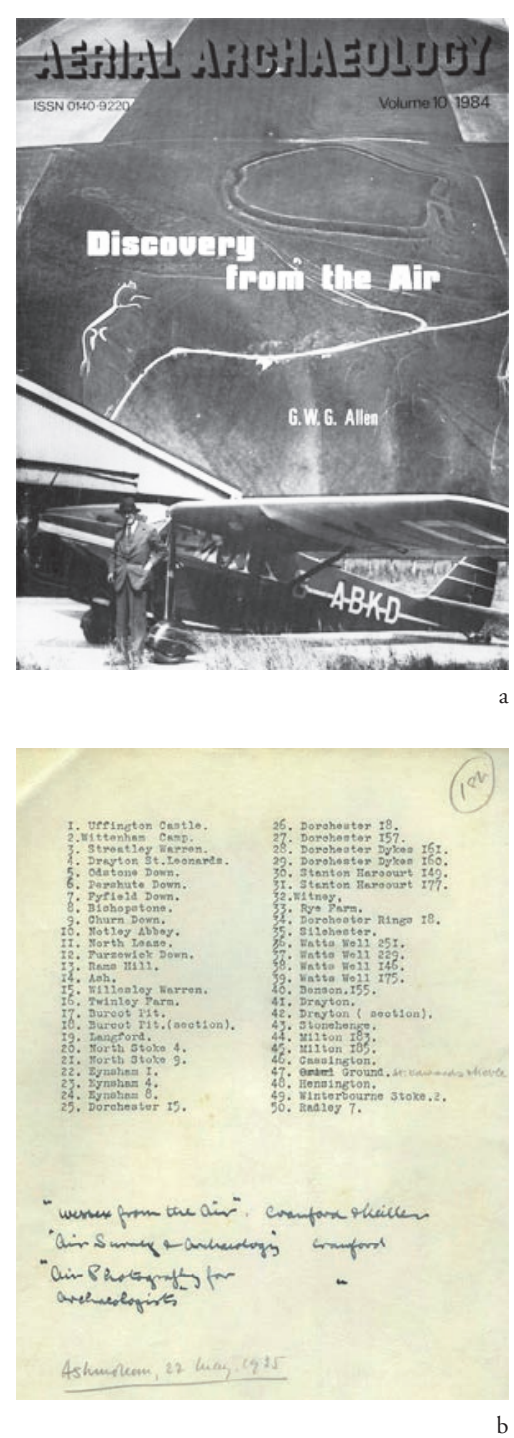

a. G.W.G. Allen: Discovery form the Air: Aerial Archeology. Portada de la publicación editada por Ashmolean Museum, en 1984, sobre los vuelos de Major Allen.

b. Lecture Slides. G.W.G. Allen. Extraído de Ashmolean Museum. 


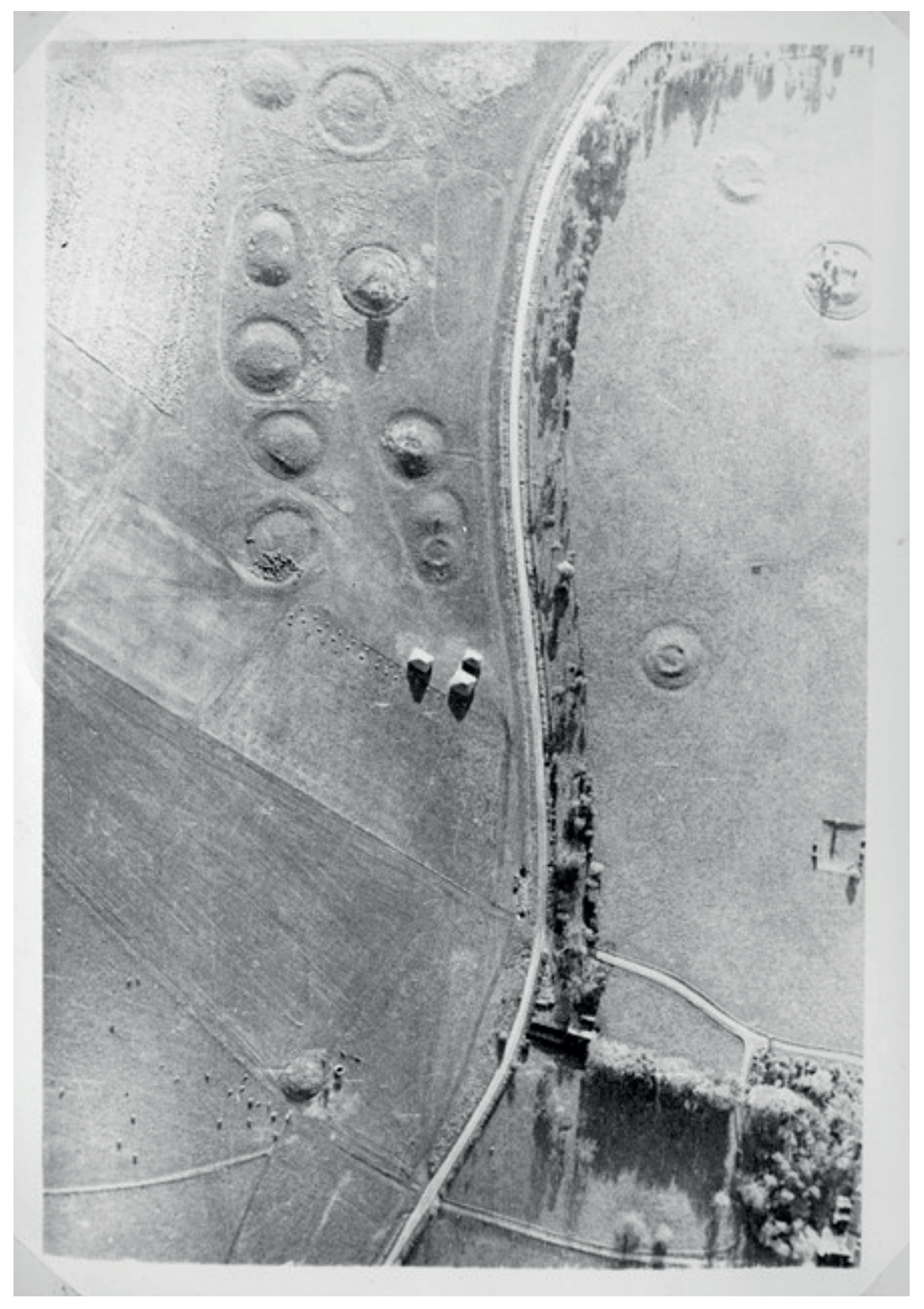

Ashmolean Museum,

D.N. Riley: Prehistoric Earthworks, Lambourn, Berkshire. 
pronto su atención por la proximidad con Upper Lawn. Además de estas, el Museo posee entre sus fondos la colección de fotografías del piloto D.N.Riley ${ }^{29}$. Aunque de menor extensión que la de Major Allen, contiene unas 250 fotografías aéreas tomadas en la década de 1940 en los alrededores de Oxfordshire, sobre algunos de los yacimientos arqueológicos de mayor interés de Inglaterra, como Barbary Castle ${ }^{30}$. En la década de 1980, publicó varios libros sobre los descubrimientos de earthworks en Inglaterra. ${ }^{31}$

\section{The Committee for Aerial Photography University of Cambridge}

Fundado por Kenneth St. Joseph, este centro de fotografía aérea contenía el trabajo fotográfico realizado ${ }^{32}$, desde 1947, por este arqueólogo sobre los asentamientos romanos en Britannia. Las fotografías publicadas en The Journal of Roman Studies, constituían el archivo más importante de imágenes aéreas sobre los restos romanos en Gran Bretaña e incluía una extensa documentación sobre el Limes. Alison y Peter Smithson utilizaron este extenso archivo fotográfico, como puede observarse en la referencia al mismo que contiene su publicación Ordinariness and Light. ${ }^{33}$

\section{The Ministry of Public Works}

Otras de las fuentes utilizada por los Smithson fueron las publicaciones que The Ministry of Public Works editó en las décadas de 1940 y 1950, con el nombre de Archeological Reports. Entre éstas, se encontraban fortificaciones prehistóricas cuyas fotografías fueron utilizadas en varios textos por estos arquitectos. Además de estos Archaeological Reports, los Smithson también conservaban en sus archivos otras publicaciones editadas por este departamento como eran las referentes a castillos o abadías de Inglaterra, como Pevensey Castle o Gisborough Priory, editadas en la colección Ancient Monuments and Historic Buildings.

29. The Ashmolean Museum has a collection of around 250 photographs taken by Riley in 1943 of Oxfordshire and the surrounding counties. http://britisharchaeology. ashmus.ox.ac.uk/ Véase:

30. Iron Age bivallate hillfort and ponds

31. Sobre Riley, véase, entre otros: RILEY, D.N. Aerial Archaeology in Britain. Park West Publications, 1982

32. Las fotografías de St Joseph pertenecían, desde la década de 1950, a la Universidad de Cambridge (The Cambridge University Collection of Aerial Photography.CUCAP), formando parte de los artículos publicados en The Journal of Roman Studies, a través de los cuales se difundían los hallazgos de las excavaciones arqueológicas llevadas a cabo en los sitios romanos. Véase, entre otros: ST JOSEPH, Kenneth. Air Reconnaissanse in Britain 1955-57, The Journal of Roman Studies, vol.59 no1/2. 1969, p.104-128.

33.
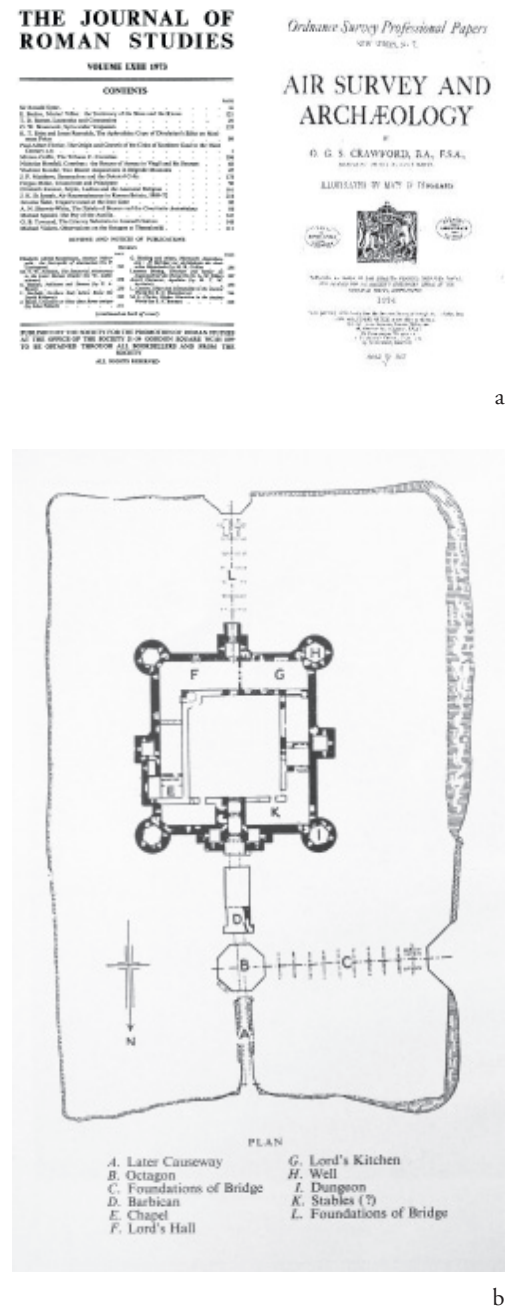

a. Kenneth St. Joseph: The Journal of Roman Studies, 1973 | O.G.S. Crawford: Air Survey and Archeology. Ordnance Survey Professional Report, 1924.

b. Bodiam Castle (Sussex) Ministry of Works. Smithson Family Collection 


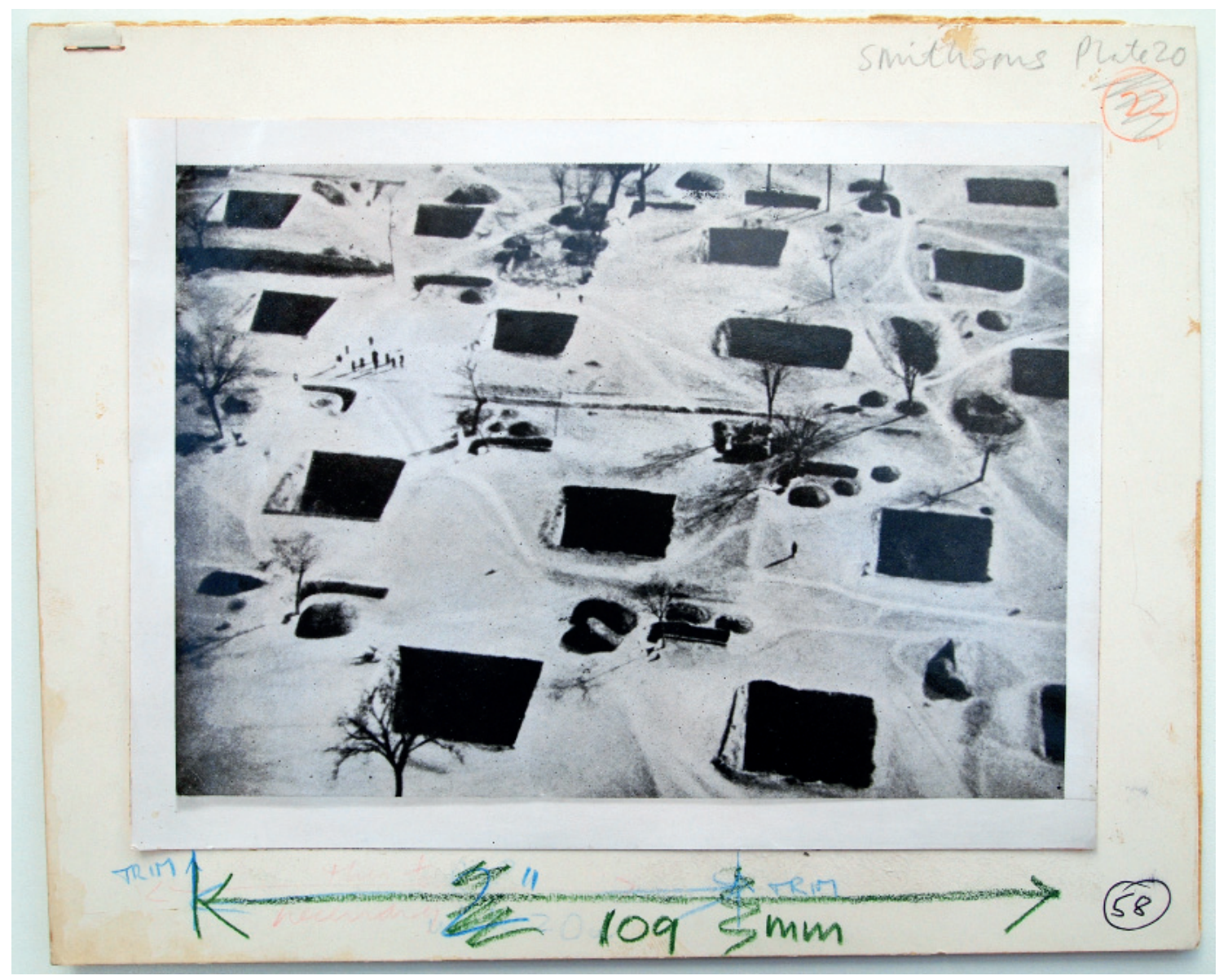

Honan

Procedente de E.Gutkind: One World from the Air. Smithson Family Collection

Fotografía del autor 


\section{O.G.S.Crawford: Antiquity Journal}

En el desarrollo de la fotografía aérea, como instrumento de reconocimiento del territorio en Inglaterra, destaca la labor del arqueólogo O.G.S.Crawford (1886-1957), fundador de Antiquity Journa ${ }^{44} \mathrm{y}$ descubridor de los field systems prehistóricos: unas marcas topográficas situadas en Salisbury Plain que formarían parte de los earthworks visitados por Alison y Peter Smithson durante su estancia en Wiltshire.

\section{Erwin Gutkind: One world from the Air}

Alison y Peter Smithson tuvieron acceso a varios libros de fotografía aérea editados en los primeros años de la década de 1950, como los publicados por Erwin Gutkind, Expanding Environment y One world from the Air. An International Survey of Man and his Environment., En aquellos años Gutkind sería una figura relevante en el conocimiento del territorio y su relación con los asentamientos humanos, contribuyendo decisivamente a la difusión de hábitats procedentes de otras latitudes. ${ }^{35}$ One world from the Air ${ }^{36}$ contenía un extenso conjunto de imágenes aéreas de intervenciones sobre el territorio, entre las que se incluían algunas muy relevantes de Inglaterra, correspondientes a épocas prehistóricas. Además de Maiden Castle, ${ }^{37}$ también se mostraría la fotografía de Avebury: otro importante conjunto neolítico del sur de Inglaterra $^{38}$ del que destacan el Henge de Old Sarum. La capacidad del trabajo de Gutkind para poner el acento en las transformaciones del territorio por la acción del hombre no pasaría desapercibida para los Smithson, quienes utilizaron, al menos, $\operatorname{dos}^{39}$ de sus fotografías aéreas para incluirlas en Ordinariness and Light (1970) y en su artículo The Recovery of Parts of the Gothic Mind (1990).

34.CRAWFORD, O. G. S 1924: Air Survey and Archaeology. Ordnance Survey Professional Papers. New Series No. 7. Southampton.- 1954: A century of Air Photographs. Antiquity 28, 206-210

35. BOYER, M. Christine: "An Encounter with History: the postwar debate between the English Journals of Architectural Review and Architectural Design (1945-1960)".

36. Actualmente en posesión de la familia Smithson, como se ha podido comprobar en el desarrollo de esta investigación - fotografía biblioteca de Simon Smithson

37. Fotografía no 82: GUTKIND, Erwin Anton. Our world from the Air. An International Survey of Man and his Environment. Readers Union with Chatto \& Windus, 1952. (Imágen incluida en la página 78 de este trabajo de investigación).

38. Old Sarum está situado en Salisbury Plain, a escasas millas de Upper Lawn. Las fotografías de los archivos de los Smithson demuestran que lo visitaron varias veces, en la década de 1970. En The Big Scrapbook, también se encuentran recortes de esta topografía primitiva.

39. "The Smithsons used at least two of Gutkind's images published in his Our World from the Air. (...) image nr. 53 of Chinese Honan, which the Smithsons published in Ordinariness and Light, 1970, p. 42, and image 252 of Isfahan re-appears as an analytic drawing also in Ordinariness and Light, 1970, p. 41; as late as 1991 they use an image of NY freeways in 'The Recovery of Parts of the Gothic Mind', in: ILA\&UD Year Book 1990-1991, p. 50". HEUVEL, Dirk van den. Alison and Peter Smithson: A Brutalist Story, op.cit.
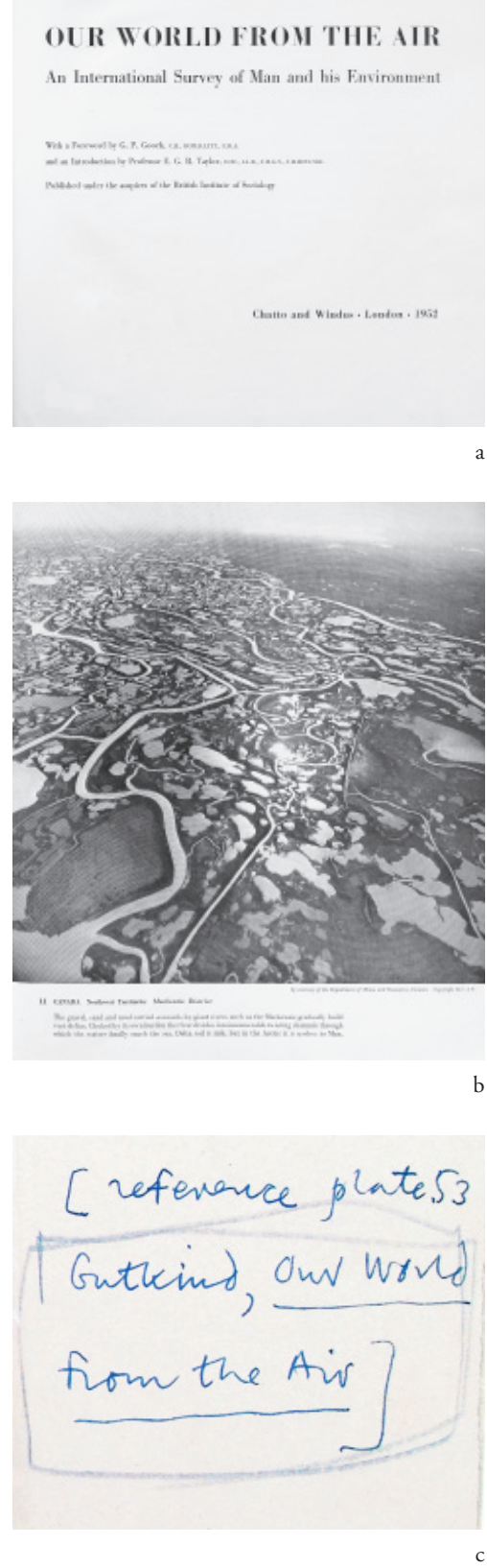

a. E.Gutkind: Our world from the Air. An International Survey of Man and his Environment.

b. E.Gutkind: Our world from the Air. Fotografía, 11.

c. Dorso de la fotografía de Honan en la que aparece manuscrita su procedencia: "Reference plate 53, Gutkind, Our World from the Air". Esta imagen sería utilizada por Alison Smithson en la publicación How to Recognise and Read Mat-Building, de 1974. 


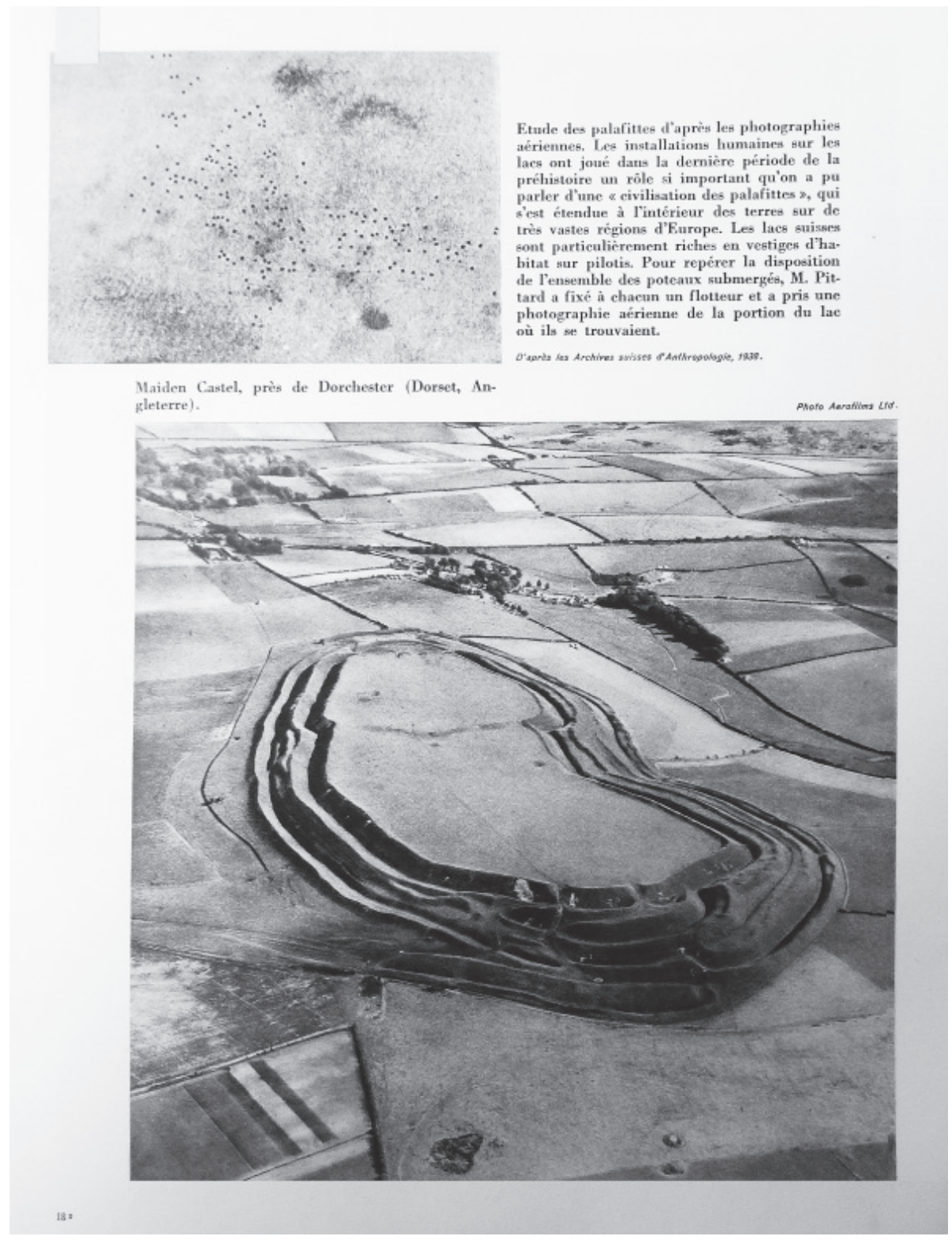

Paul Chombart de Lauwe: Découverte Aérienne Du Monde, p.182

"Palafitos en el sur de Europa", "Maiden Castle, en Dorset, Inglaterra" Fotografía del autor 


\section{Paul Chombart de Lauwe: Découverte Aérienne du Monde}

Découverte Aérienne du Monde, publicado en 1948, mostraba más de 300 asentamientos humanos localizados en diferentes lugares del mundo, entre las que también se incluían algunas de las huellas prehistóricas de Inglaterra: Maiden Castle y las marcas prehistóricas de Northfield ${ }^{40}$. Las imágenes de Chombart de Lauwe revelaban desde el aire estructuras de asentamiento que respondían mediante su trazado a las condiciones específicas del territorio donde se implantaban. En la década de 1950, los ejemplos de primitivos y vernáculos mostrados en este libro contribuyeron, al igual que los mostrados por Gutkind, a alimentar la reflexión sobre la recuperación de modos alternativos de ocupación del territorio, procedentes de contextos y culturas diferentes a las occidentales, y que actuaban en el aquel contexto existencialista, como una contrapunto de revitalización de la arquitectura.

Como señala Avermaete ${ }^{41}$, los textos y fotografías aéreas de Chombart de Lawwe tuvieron una influencia decisiva entre los arquitectos del Movimiento Moderno, a principios de la década de $1950 .{ }^{42}$ Durante el VIII Congreso de los C.I.A.M, en 1951, gracias al uso de la fotografía aérea, se ampliaron los campos de estudios a otros ámbitos más allá de la arquitectura, como la historia, geografía, diseño y la ciudad.

En el IX Congreso de 1953, en Aix-en-provence, la imagen aérea era una herramienta clave para el entendimiento de la estructura de la ciudad, y el planeamiento urbano ${ }^{43}$. En los C.I.A.M de 1953, su uso fue especialmente significativo en la propuesta de Bodiansky, Candilis, Piot y Woods: Habitat du plus grand nombre. Esta propuesta contenía numerosas imágenes aéreas de asentamientos del norte de África —algunas de las cuales procedían de Découverte Aérienne du $M_{\text {onde }}{ }^{44}$ - que servían para explicar cómo los tradicionales patrones de asentamientos de aquellos lugares eran tomados como base para la creación de sus nuevas estructuras de vivienda contemporánea ${ }^{45}$.

40. Imágenes extraídas, a su vez, del archivo Ashmolean Museum de Oxford. Véase: CHOMBART de LAUWE Paul. Découverte Aérienne Du Monde. Horizons De France Grand. Paris, 1948.

41. AVERMAETE, Tom, The Another Modern, 2005

42. Especialmente significativo es la utilización del trabajo de Chombart de Lauwe por Van Eyck. Éste mostró en la Universidad de Delft, donde era profesor, los textos y fotografías realizadas por de Lauwe sobre los pueblos Dogon. Chombart de Lauwe, antes de publicar, en 1948, Découverte Aérienne du Monde, ya había participado con Marcel Griaule en 1936 en los viajes por África que dieron lugar a los escritos acerca los pueblos de Dogon (Griaule, 1938)

43. DAINESE, Elisa: "Le Corbusier, Marcel Griaule, and the Modern Movement: exploring the habitat from the airplane".

44. En el libro de Combart, la imagen de "la ville arabe" se incluye también en el panel de Habitat du plus grand nombre.

45. Tom Avermaete. Team $10,1953-81$, in search of a utopia of the present, p.26

\section{DÉCOUVERTE} AERIENNE

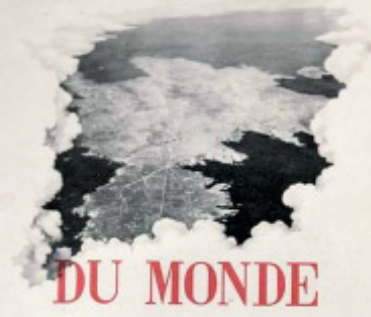

HOB OZONS
OE FBACE
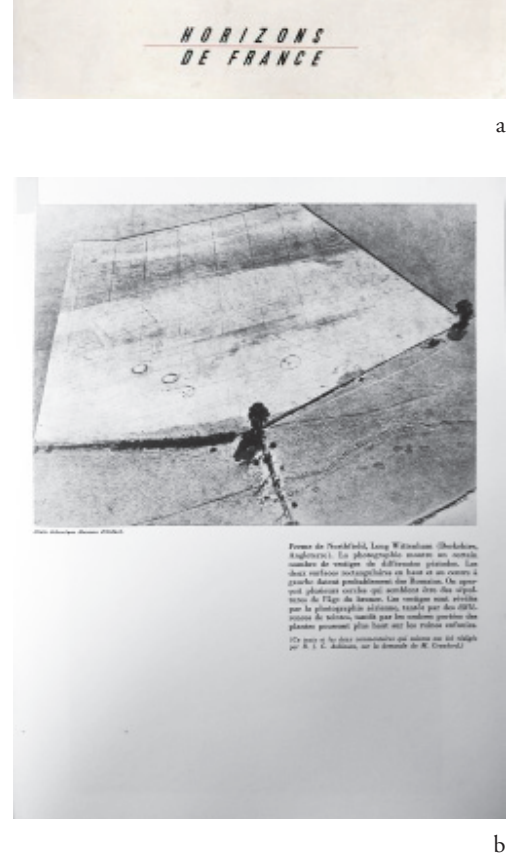

a. Paul Chombart de Lauwe: Découverte Aérienne Du Monde. Horizons De France Grand. Paris, 1948. Portada

b. "Huellas prehistóricas de Norhfield, Inglaterra”. Découverte Aérienne Du Monde. 


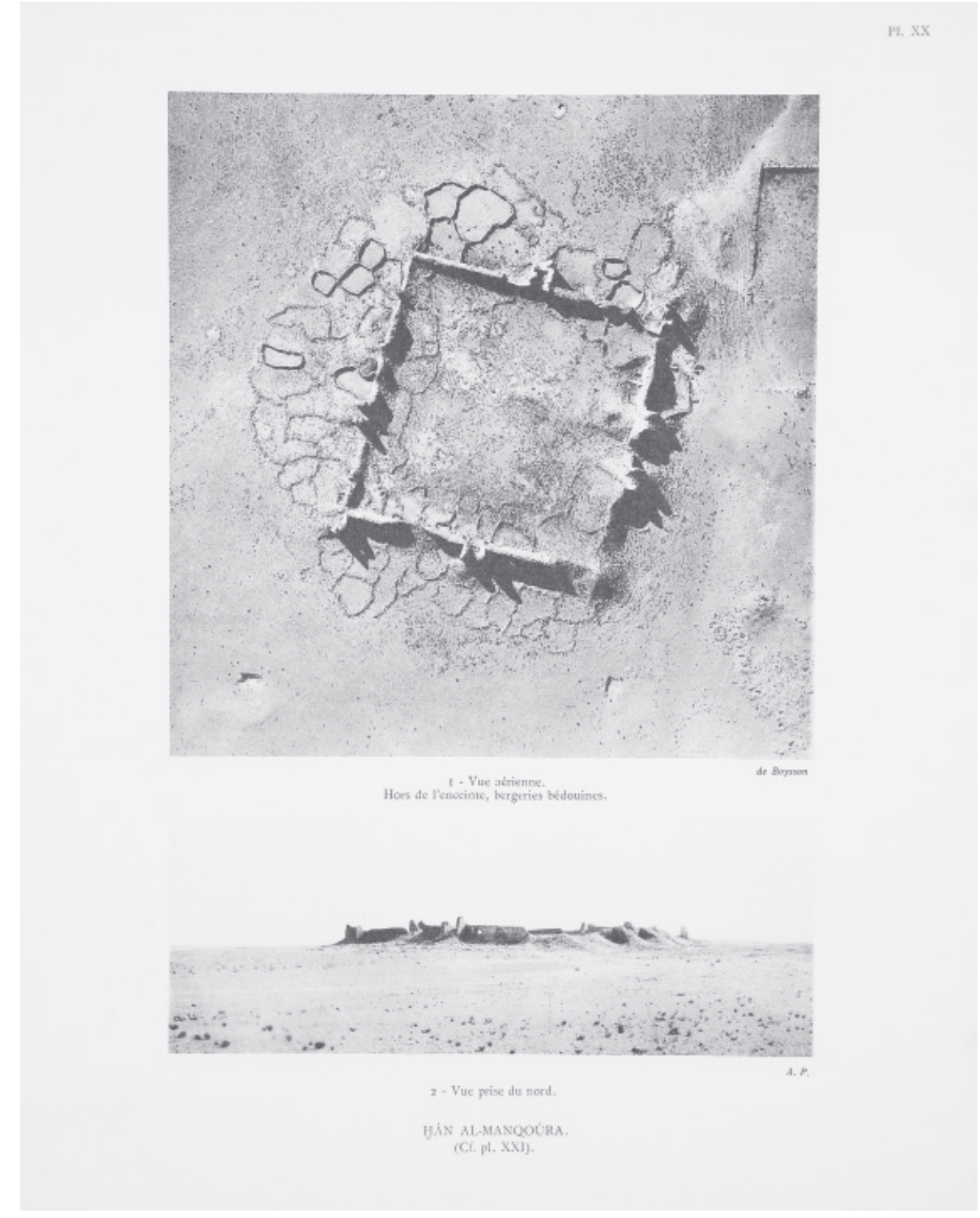

Vue aérienne. Hors de l'enceinte, bergeries bédouines La Trace de Rome dans le Désert de Syrie: le Limes de Trajan à la Conquête Arabe; Recherches Aériennes 
La propuesta de Alison y Peter Smithson, presentada bajo el título Urban Re-Identification, no incluía fotografías aéreas, pero sí algunos dibujos de patrones de implantación en el territorio, que recuerdan trazas primitivas del territorio de Inglaterra. En la siguiente edición, celebrada en Dubrovnic en 1956, los Smithson ya recurrieron a este tipo de imágenes desde el aire para explicar su propuesta The Valley Section. Las fotografías escogidas por los Smithson mostraban asentamientos vernáculos del norte de Inglaterra, ${ }^{46}$ unas sugerentes topografías de arena del desierto Sáhara y el earthwork de Castle Rising.

Los Smithson también tuvieron contacto con otras dos fuentes, éstas ya alejadas de las islas Británicas, como La Trace de Rome, dans le Desert de Syrie de Antoine Poidebard y Fossatum Africae, Vue-Arienne de lórganisation Romaine dans le Sud-Algerien Jean Baradez. Ambas publicaciones tuvieron un gran valor documental para sus investigaciones sobre la configuración del paisaje del limes y los asentamientos romanos en el Norte de África llevadas a cabo durante sus viajes por el Mediterráneo.

\section{Antoine Poidebard: La Trace de Rome, dans le Desert de Syrie}

Este trabajo de Antoine Poidebard, uno de los pioneros de la fotografía aérea, ${ }^{47}$ analiza los vestigios del limes romano en Siria, a través de imágenes y análisis gráficos de sus huellas. Los Smithson conocían La Trace de Rome, dans le Desert de Syrie, publicado en 1934, como refleja la inclusión de varias fotografías de esta obra en el artículo de Alison Smithson, Ruminations on Founders Court. ${ }^{48}$ Para los Smithson, el estudio de los restos del limes africano formaba parte de un interés más amplio por conocer y examinar la condición topográfica de las fronteras romanas, cuyo mayor exponente la muralla Adriana - formaba parte indisoluble de sus vidas. Las fotografías aéreas de Poidebard mostraban con claridad los límites y la geometría de estas antiguas construcciones defensivas en el desierto que el paso del tiempo había diluído en el paisaje.

46. Steithes, Brainbridge, West Burton

47. "una primera campańa entre 1925 y 1932, le permiten establecer el trazado del limes imperial en Siria, de Bosra a Palmira y al Tigris". BESSE, Jean-Marc Besse. p.348 48. La imagénes 1, 11,12,13, 14 y 17 de este artículo de A. Smithson proceden del libro de Poidebard. SMITHSON, Alison. "Ruminations on Founders Court", Architectural Design, 1973.
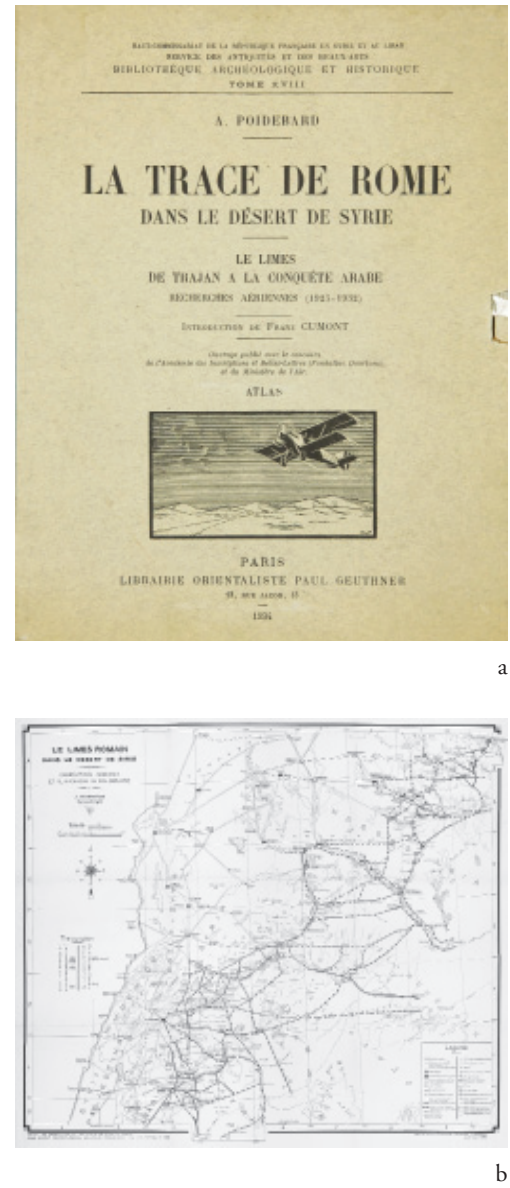

a. Antoine Poidebard: La Trace de Rome dans le Désert de Syrie: le Limes de Trajan à la Conquête Arabe; Recherches Aériennes (1925-1932), 1934. Portada.

b. El Limes romano en el desierto de Siria. La Trace de Rome dans le Désert de Syrie. 


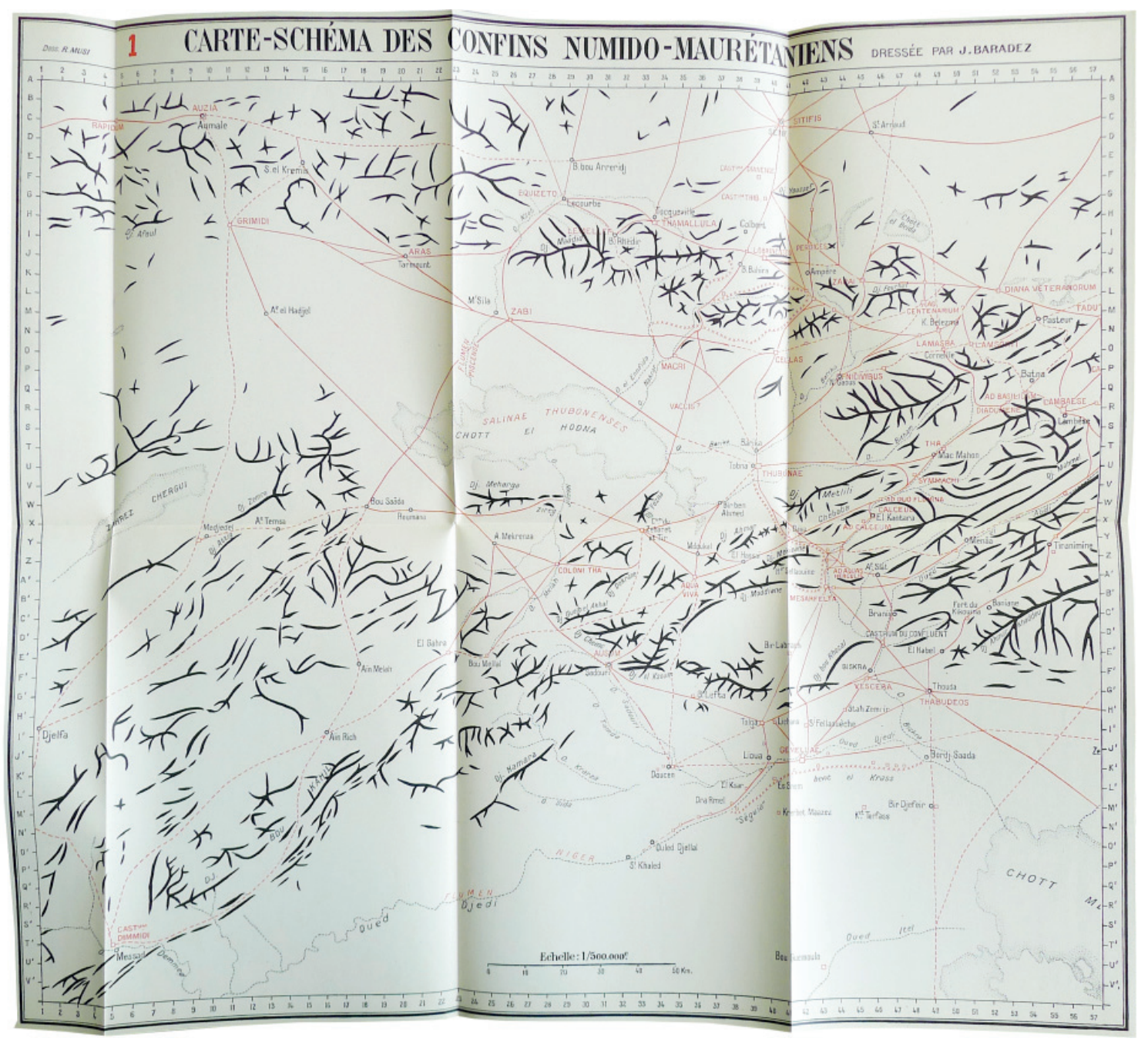

Jean Baradez, 1949

Fossatum Africae, Vue-Arienne de lórganisation Romaine dans le Sud-Algerien Fotografía del autor 


\section{Jean Baradez: Fossatum Africae}

Las investigaciones de Alison Smithson en el Norte de África también estuvieron apoyadas en los estudios de Jean Baradez. Las fotografías aéreas incluidas en Fossatum Africae, Vue-Arienne de lórganisation Romaine dans le Sud-Algerien, ${ }^{49}$ muestran las desaparecidas construcciones militares — canalizaciones de agua, fosos defensivos, asentamientos militares - como incisiones, elevaciones y deformaciones del suelo. Superpuestas a las imágenes aéreas del territorio, aparecen mapas y dibujos explicativos que revelan de manera certera las trazas de aquellos asentamientos romanos y, lo que será más importante, su relación con las condiciones topográficas del territorio. En Ruminations on Founders Court, Alison Smithson incluía varias imágenes y fragmentos de la obra de Baradez, como el dedicado a la descripción de las actividades de construcción del Limes africano durante la época del emperador Adriano.

49. BARADEZ, JEAN. Vue Aérienne de l'Organisation Romaine dans le Sud-Algérien: "Fossatum Africae». Préface de Louis Leschi. París: Arts et métiers graphiques, 1949.
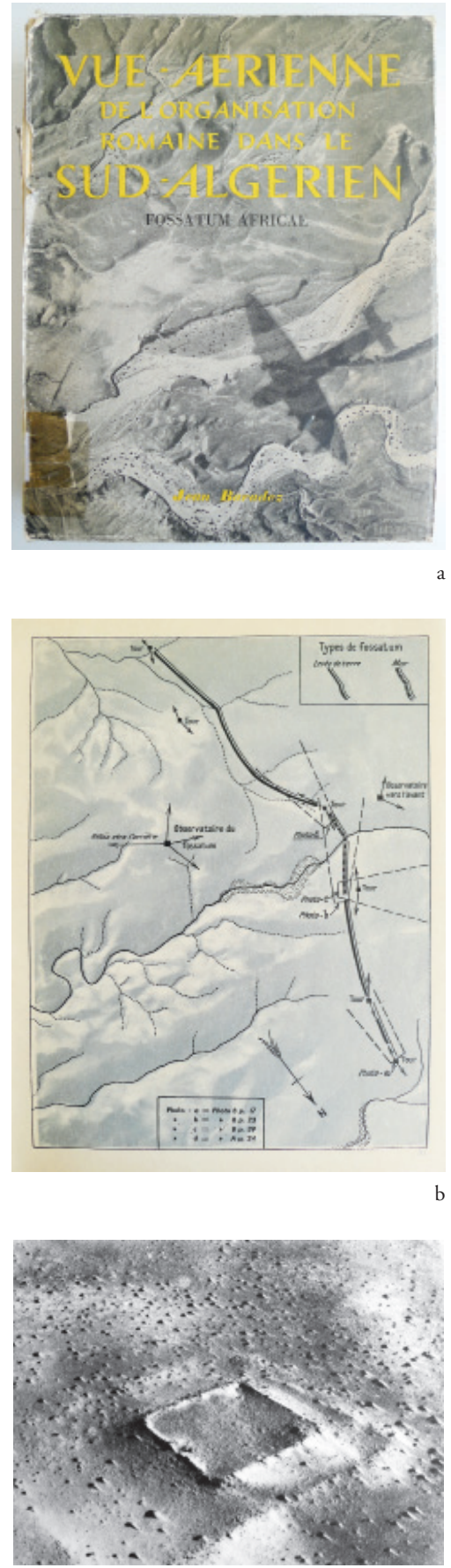

a. Jean Baradez: Vue Aérienne de l'Organisation Romaine dans le SudAlgérien: "Fossatum Africae», 1949. Portada.

b. Trazado del Fossatum Africae. J. Baradez, Vue Aérienne de l'Organisation Romaine dans le Sud-Algérien.

c. Huella de fortificación romana, próxima a Gemellae, Algeria. J. Baradez, Vue Aérienne de l'Organisation Romaine dans le Sud-Algérien. 


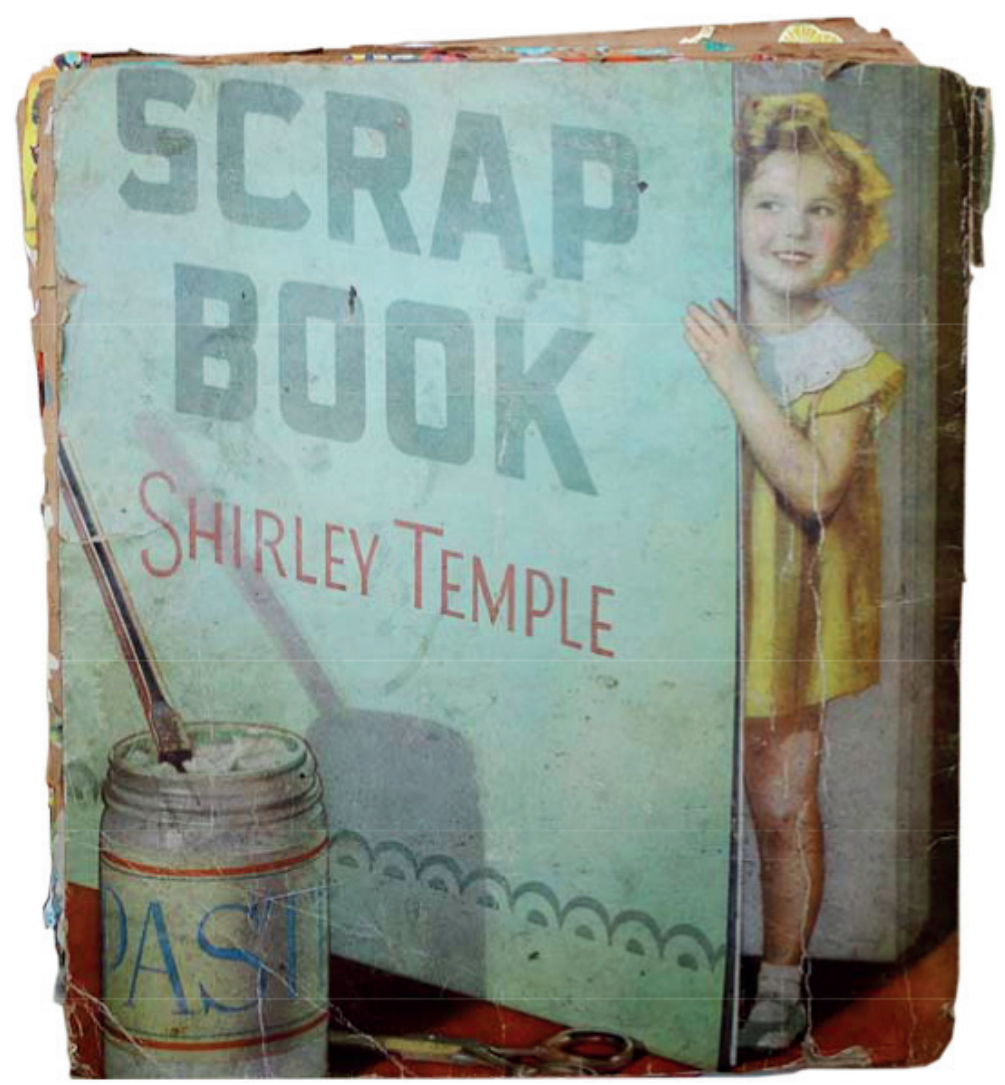

Scrapbook de Alison Smithson Smithson Family Collection 
"But today we collect ads" ${ }^{50}$, publicado en la revista finlandesa Ark, en 1956, permite apreciar cómo la actividad de coleccionar objetos y cosas comunes, como "recortes" de revistas y periódicos, ya formaba parte sustancial del trabajo de los Smithson en los inicios de su trayectoria. El origen de este interés provenía, fundamentalmente, de Alison Smithson, quien, desde muy joven, seleccionaba y guardaba los anuncios de publicidad ${ }^{51}$ de las revistas americanas que su abuela recibía de Estados Unidos durante la II Guerra Mundial. ${ }^{52}$ Primero como un entretenimiento, ${ }^{53}$ y posteriormente, como una herramienta personal de pensamiento, la acción de recopilar, manipular y pegar fragmentos de imágenes produjo toda una serie de cuadernos denominados scrapbooks. Estos "libros de recortes", eran un mecanismo creativo que buscaba la aparición de conexiones inesperadas entre los elementos que los formaban. La yuxtaposición entre "recortes" aparentemente dispares y ausentes de relación propiciaba nuevas relaciones entre sus componentes que iban más allá del significado de cada uno de ellos a nivel individual.

En los Smithson, el desarrollo de estas técnicas de ensamblaje estaría influenciado por el intenso contacto que mantuvieron con los artistas Henderson y Paolozzi. El conocimiento adquirido por este último durante su estancia en París ${ }^{54}$ a finales de la década de 1940, les introduciría de lleno en la realización de transgresores montajes empleados por los integrantes de The Independent Group como un eficiente antídoto para contrarrestar el estancamiento estético que encorsetaba el contexto cultural y artístico de la posguerra británica.

50. SMITHSON, Alison y Peter, "But Today We Collect Ads", en: Ark. Journal of the Royal College of Art, November 1956, pp. 49-50.

51. "Aquellos anuncios de publicidad eran, en aquella época de escasez en Inglaterra, imágenes 'refrescantes' de una sociedad de consumo que todavía no había llegado a Europa". Véase, "Amigos del Futuro: una conversación con Peter Smithson", en: COLOMINA, Beatriz. Doble exposición: arquitectura a través del arte. Arte Contemporáneo 17. Madrid: Akal, 2006.

52. Según explica Peter Smithson en una entrevista, el interés por coleccionar "recortes" se remonta a la época en la que Alison estuvo viviendo con su abuela en Edimburgo, después de ser exiliada tras los bombardeos de South Shields, en 1939. Ibid.

53. Antes de la aparición de la televisión, los scrapbooks eran un divertimento muy popular en Inglaterra, asociado a la creación de álbumes familiares, de recuerdos o aficiones.

54."During his stay in Paris from 1947 to 1949 he came into close contact with proponents of Surrealism and encountered the work of Duchamp". Véase: LICHTENSTEIN, Claude, y Thomas (eds) SCHREGENBERGER, eds. As found: the Discovery of the Ordinary. Baden: Lars Muller, 2001. p, 59. La influencia de Paris es reconocida por Peter Smithson cuando habla de: "inheritance from Paris". Véase: SCALBERT, Irénée. "Parallel of Life and Art». Daidalos, 2000. La autora señala en este artículo:"The impact of these three figures [Tzara, Tápie y Duchamp] can be felt in Parallel of Life and Art".
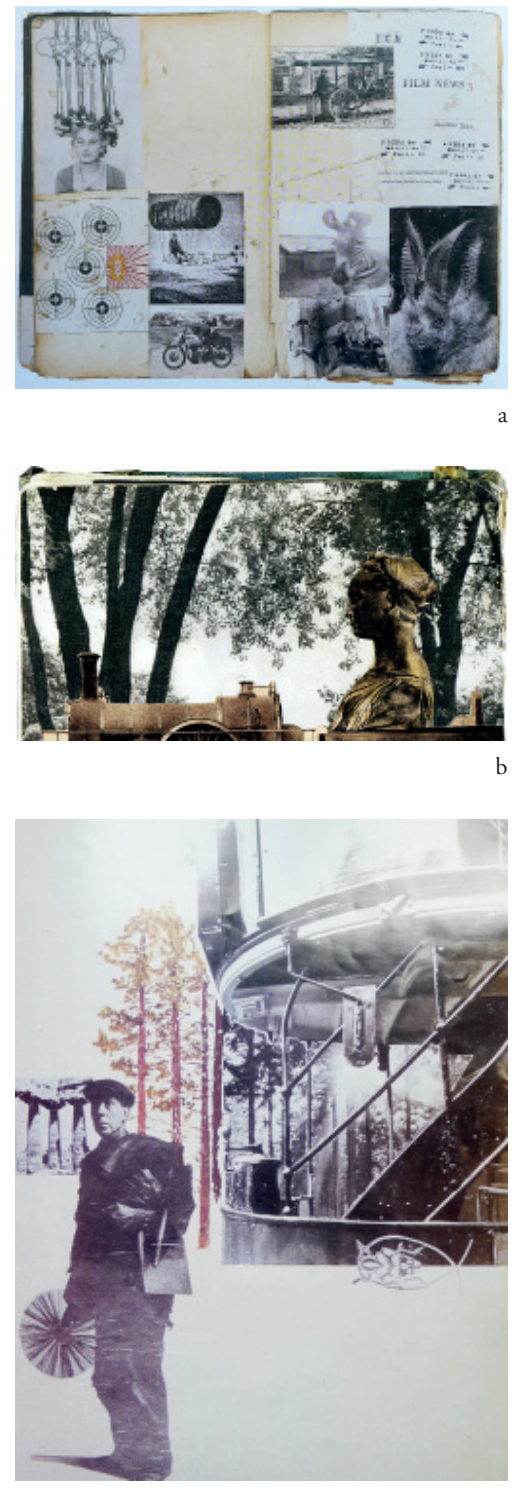

a. Scrapbook de Nigel Henderson, 1952

b. Collage. Eduardo Paolozzi. Publicado en, As found: the Discovery of the Ordinary (2001).

c. Alison Smithson. Collage publicado en The Shift, (A\&P Smithson, 1982). 


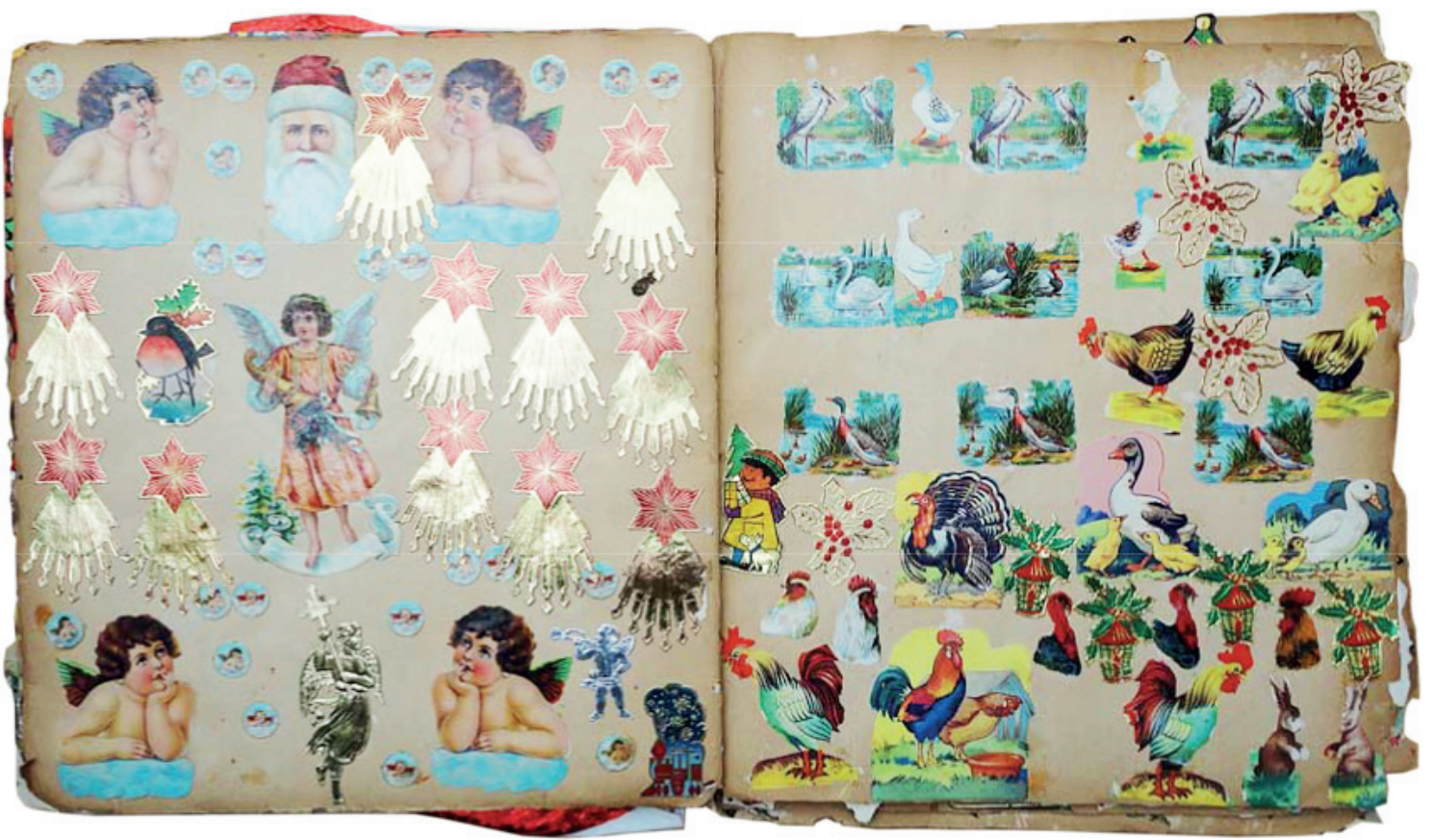

Scrapbook de Alison Smithson Smithson Family Collection 
Como señala Alex Kitnik, ${ }^{55}$ a principios de la década de 1950, los collages y los scrapbooks ya formaban parte esencial del trabajo de los Smithson, constituyendo el recinto más privado de su pensamiento: el lugar donde reflejaban sus intereses personales y sus fuentes de inspiración.

Este procedimiento de reordenación que estimulaba la aparición de procesos creativos gracias a la "fricción" de sus componentes, también se reconoce en algunas de sus publicaciones. En The Heroic Period of the Modern Architecture ${ }^{56}$ y Urban Structuring, ${ }^{57}$ ambas realizadas en la década de 1960, los Smithson procedieron como si se tratara de libros de "recortes", yuxtaponiendo fragmentos y poniendo en valor una técnica narrativa en la que la imagen adquiría un destacado impulso como instrumento de argumentación..$^{58}$ En otras posteriores, como The 1930 's, ${ }^{59}$ o Scaffolding, ${ }^{60}$ volvieron a insistir en este procedimiento visual capaz de revelar relaciones ocultas, o no evidentes, entre imágenes diversas.

En sus exposiciones, el método de formación de los scrapbooks adquiría un papel relevante. La aparente aleatoriedad y falta de jerarquía con la que estaban presentadas las fotografías en Parallel of Life and Art -imágenes de formas naturales, biológicas, tecnológicas, artísticas o sociales- contenía implícita la técnica del montaje, como explicaban sus autores:

"Las imágenes no se encuentran organizadas siguiendo una secuencia formal, sino permitiendo que entre ellas se establezcan complejas relaciones cruzadas entre los distintos campos del arte y la técnica. Así producirán un amplio panorama de asociaciones y fructíferas analogías...como si formaran parte de una nueva Piedra Rosetta. Así presentarán una fugitiva delineación de los rasgos que caracterizan nuestro tiempo" ${ }^{\text {"1 }}$

Estos procesos de coleccionar, recombinar y establecer nuevas relaciones estaban directamente asociados al concepto as found: un término que los Smithson no llegaron a definir de manera explícita

55. KITNICK, Alex. «The Brutalism of Life and Art». Op. Cit

56. "The Heroic Period reads as a cleverly composed scrapbook with inserted comments taken from earlier writings, mostly Peter's". HEUVEL, Dirk van den. A Brutalist Story. Op.cit.p.50.Véase: SMITHSON, Alison and Peter. «The Heroic Period of Modern Architecture». Architectural Design, diciembre de 1965.

57.SMITHSON, Alison and Peter. Urban Structuring. Studies of Alison and Peter Smithson. London / New York: Studio Vista / Reinhold Publishing Corporation, 1967.

58. "The predominant, visual dimension is important to note, because until then the seminal historiographies of modern architecture, such as Johnson and Hitchcock's, Pevsner's, as well as Giedion's depended on the textual, intellectual argument." HEUVEL, Dirk van den. Alison and Peter Smithson: A Brutalist Story. Op.cit.p.50

59. SMITHSON, Alison y Peter. The 1930's. Lauenförde: Berlin and TECTA Möbel, 1985.

60. SMITHSON, Alison. «Scaffolding». A3 times, 1989.

61.SMITHSON, Alison y Peter, The Charged Void, Architecture. Op.cit. p.118.
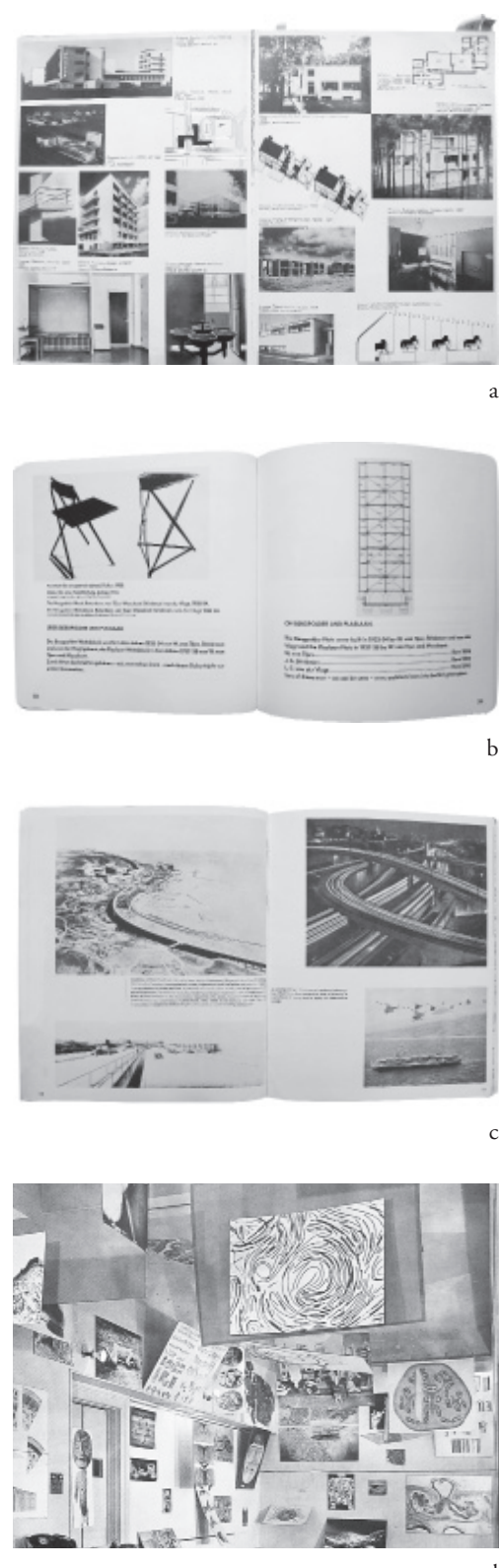

d

a. Scrapbook de Nigel Henderson, 1952

b. A\&PS The 1930's, 1985, pp.52-53. Imagen mobiliario de Duiker (Furniture for an open-air school, Duiker, 1933) y del proyecto The Bergpolder Block, Rotterdam, van Tijen/Maaskant/ Brinkman/van der Vlugt, 1933-34. La yuxtaposición genera vínculos a través de la estructura diagonal.

c. A\&PS Urban Structuring, 1967, pp.42-43. Imagen del proyecto de Le Corbusier para Algeria y un sistema de autopistas. La conexión revela un paralelismo en el trazo sobre el territorio.

d. "Parallel of Life and Art", Exhibition I.C.A. 1953. Genaral view of Exhibition. 


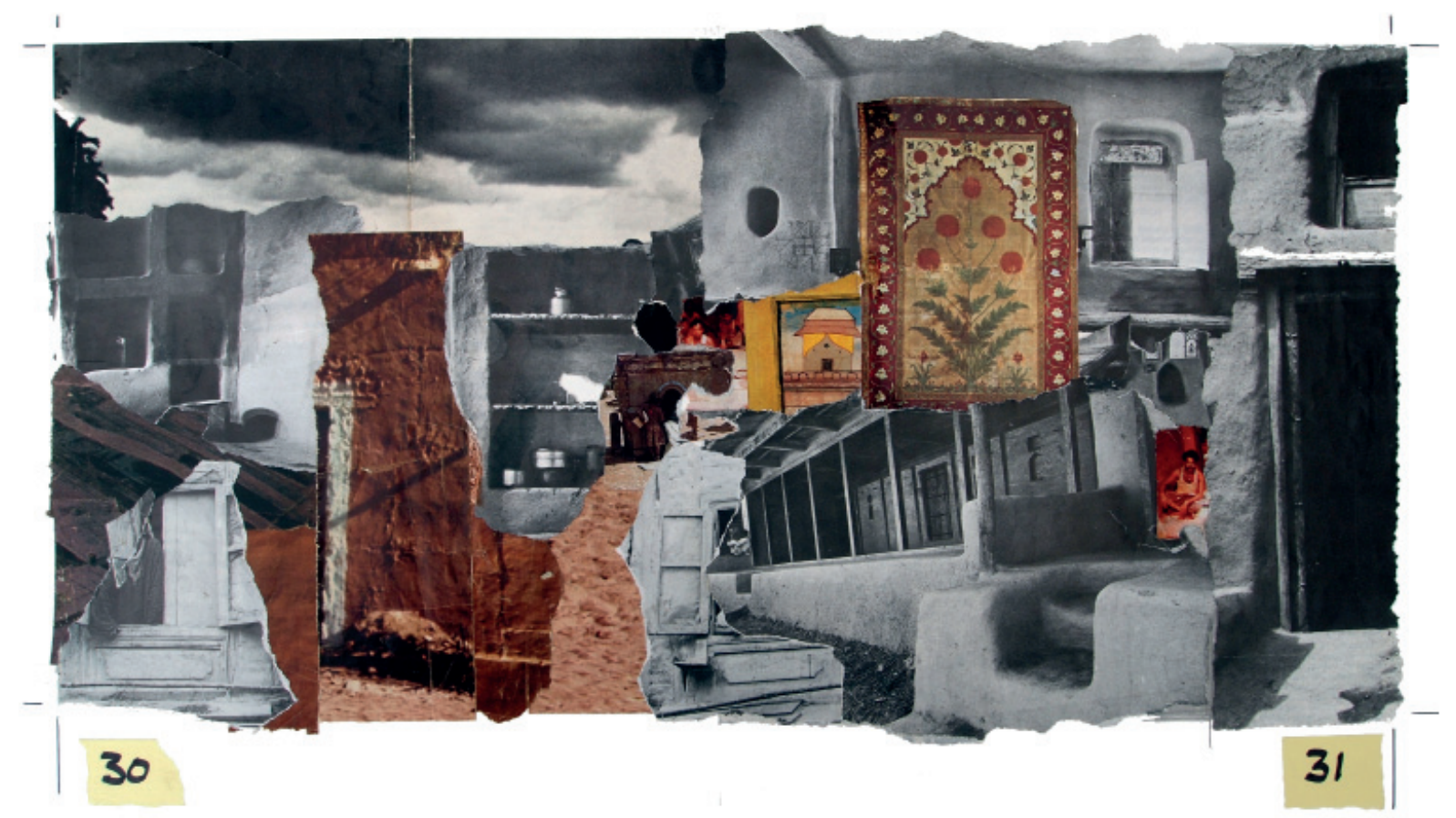

Collage realizado por Alison Smithson Smithson Family Collection 
hasta los años finales de su trayectoria, a pesar de vertebrar toda su obra. Según explicaron a finales de la década de $1980,{ }^{62}$ as found poseía dos significados complementarios.

Por una parte, aludía a una nueva percepción de la realidad existente que implicaba un tipo de sensibilidad especial para apreciar el contexto ordinario de un modo más amplio, incorporando "todas aquellas huellas que constituyen recordatorios en un lugar y esperan ser leídas a través del descubrimiento de cómo lo construido llegó a ser tal cual era". ${ }^{63}$ En ese sentido, as found apuntaba directamente a la revitalización de lo ordinario, de las cosas modestas o banales, con las que arrancar con ellas nuevos pensamientos: ${ }^{64}$ "una apertura en lo que se refiere a cómo las cosas prosaicas podrían recargar de energía nuestra actividad creativa". ${ }^{65} \mathrm{Y}$ por otra, as found incorporaba en su significado la propia transformación de la realidad, mediante la yuxtaposición de las cosas disponibles al alcance, con la idea de generar resultados no prefijados de antemano. Este enfoque, netamente operativo sería definido como: "recoger, dar la vuelta y poner al lado de". ${ }^{66}$

La elasticidad del concepto as found permitía también relacionarlo con la idea de "escoger y disponer" que los Smithson tomaron directamente de los Eames. Parte de la admiración ${ }^{67}$ de los Smithson por esta pareja de diseñadores americanos se fundamentaba en su particular mirada de la realidad, capaz de apreciar "elementos culturalmente dispares en conjunto y perfectamente compenetrados entre si' ${ }^{68}$ Sus operaciones consistentes en seleccionar objetos dispares y agruparlos para formar una nueva composición eran apreciada por los Smithson como "un método de diseño en el que se utilizan los objetos para lo que son y cada objeto se ve ensalzado y habla más claramente de sí mismo por la virtud de su disposición”" ${ }^{69}$

62.SMITHSON, Alison and Peter. "The "As Found" and the "Found"». en The Independent Group. Postwar Britain and the Aesthetics of Plenty, editado por David ROBBINS, 201-2. Cambridge MA/London: MIT Press, 1990.

63.Ibid

64. "Some artists, able to use collage techniques, utiling materials of Duchampian ordinariness — 'materials as found' - did so with a free inventiveness the envy of us as architects of the same generation, struggling for a new ordinariness". SMITHSON, Alison y Peter, "Devices and Decorations", en Italian Thoughts, p.30

65. SMITHSON, Alison and Peter. «The "As Found" and the "Found". Op.cit,

66. "Visto desde finales de los ochenta: lo as found (según se encuentra) donde el arte implica recoger, dar la vuelta y poner al lado de... y lo found (lo encontrado) donde el arte se encuentra en el proceso y en el ojo vigilante". ROBBINS, David

67. "The fascination this process held by Smithsons may be understood in terms of their admiration for the Eames". KRUCKER, Bruno, Op. cit, p.18

68.SMITHSON, Alison and Peter. Cambiando el arte de habitar. Barcelona; México: Gustavo Gili, 2001. Ed. original: Alison and Peter Smithson, Changing the Art of Inhabitation, Artemis, London, 1994.

69.Ibid.
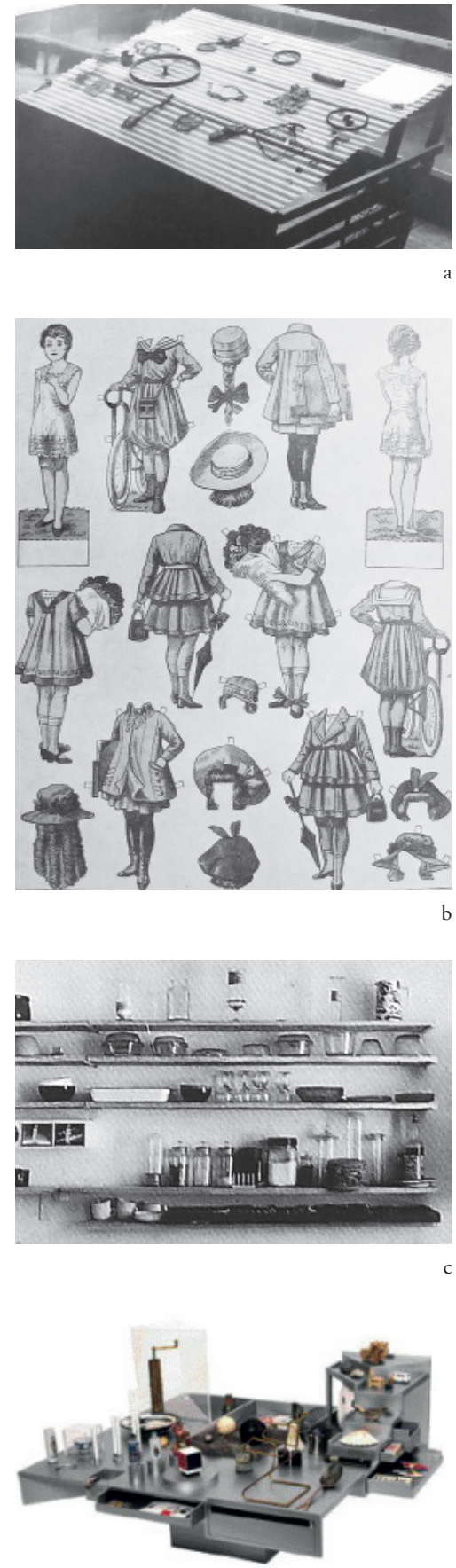

a. Pation and Pavilion "This is Tomorrow Exhibition", 1956.

b. The select and arrange technique: "Poupées a habiller". (Without Rethoric, 1973).

c. "Kitchen equipment", Fotografía de la cocina de la casa de A\&P Smithson (Priory Walk) PS, 1961. (The Charged Void)

d. A. Smithson, "Collector's Table". Tecta, 1983. "A tribute to Charles and Ray Eames and their 'select and arrange' technique" (Dirk van den Heuvel, 2004). 


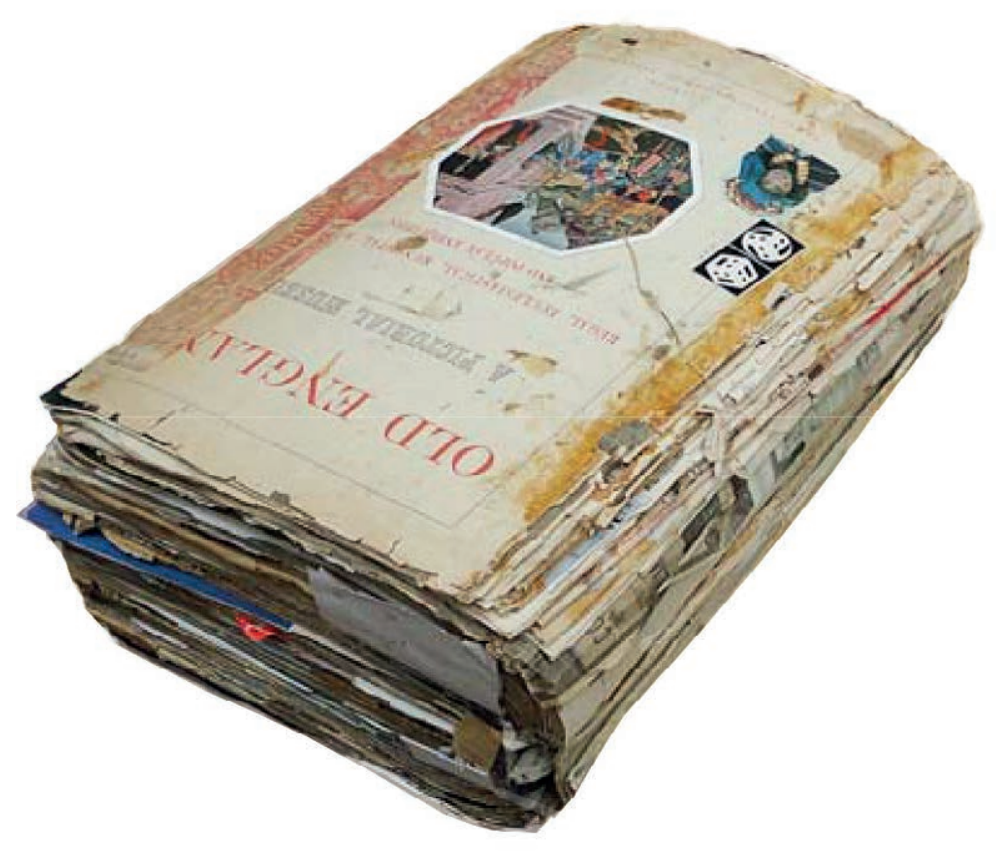

The Big Scrapbook. Alison Smithson

Fotografía tomada en The Hutte 


\section{El "libro de recortes" de Alison Smithson}

The Big Scrapbook $k^{70}$ es un documento visual de más de 800 páginas $^{71}$ del que apenas existe referencia. ${ }^{72}$ Tiene la particularidad de estar confeccionado sobre un libro ya editado: el primer volumen de la enciclopedia visual de Charles Knight, titulada Old England: a Pictorial Museum ${ }^{73}$, publicada en Inglaterra, en 1875, que pretendía dar a conocer el patrimonio arquitectónico de ese país, ${ }^{74}$ a través de un atlas de dibujos de arquitecturas, objetos y personajes ordenados cronológicamente, desde la época prehistórica hasta el siglo XV.

La decisión de Alison Smithson de utilizar el libro de Knight como base para su scrapbook se desconoce, ya que no existe ninguna explicación acerca de este trabajo. Podemos interpretar que esta elección pudo obedecer, más a una cuestión de necesidad ${ }^{75}$ que a un propósito definido. Aunque, no debemos descartar una cierta ironía o provocación por parte de su autora en la idea de manipular el patrimonio cultural de Inglaterra, "refrescándolo" mediante la introducción de nuevos fragmentos de la cultura visual de su tiempo. ${ }^{76}$ Debido a la falta de información, tampoco podemos precisar cuando fue realizado. Simón y Soraya Smithson recordaban que su madre estuvo trabajando en él "prácticamente durante toda su vida" y que "dejó de completarlo en el momento en que pareció estar lleno... como cuando una pintura parece acabada" ${ }^{77}$

70.La familia Smithson se refería al "libro de recortes" de Alison Smithson como "The Big Scrapbook", según ha podido saber el autor.

71. The Big Scrapbook carece de paginación, por lo que ésta ha sido realizada por el autor, contando 407 pliegos (814 páginas). A lo largo de este trabajo de investigación, la numeración de este scrapbook hará referencia a pliegos de 2 páginas (p.)

72. La única referencia al mismo conocida por el autor está en el trabajo aún no publicado de Christine M. Boyer: Not Quite Architecture. Writing around Alison and Peter Smithson (fecha prevista de publicación: 2017)

73. KNIGHT, Charles, Old England: a Pictorial Museum of Regal, Ecclesiastical, Baronial, Municipal and Popular Antiquities. London, 1845.

74. “(...) we propose to open to all ranks of the people, at the cheapest rate, a complete view of regal, ecclesiastical, baronial, municipal, and popular antiquities, by the publication of the largest collection of engravings with explanatory letterpress, that has ever been devoted to this important branch of general information. Our work is addressed to the people; but the knowledge which it seeks to impart will be as scrupulously accurate as if it were exclusively intended for the most critical antiquary. To be full and correct is not necessary to be tedious and pedantic. That knowledge will be presented, for the most part, in a chronological order; and thus our work will be a Companion and a key to every English History. The Engravings will embrace the most remarkable of our Buildings from the earliest times - Druidical Remains, Cathedrals, Abbeys, Churches, Colleges, Castles, Civic Halls, mansions...(...)". Fragmento de la introducción de Old England: a Pictorial Museum

75.La década de 1950 cuando los Smithson comienzan su trayectoria profesional es una época de posguerra marcada por la escasez de recursos.

76. Esta interpretación ha sido comentada por el autor con Simon Smithson. Oct. 2015.

77. Conversación con Simon y Soraya Smithson. 2015.

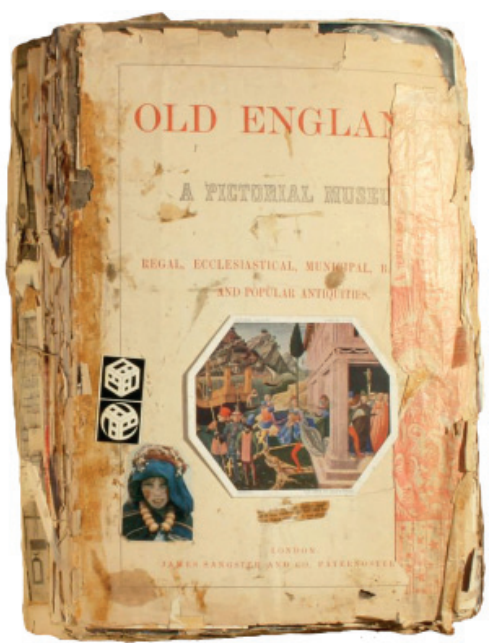

a. The Big Scrapbook. Portada 

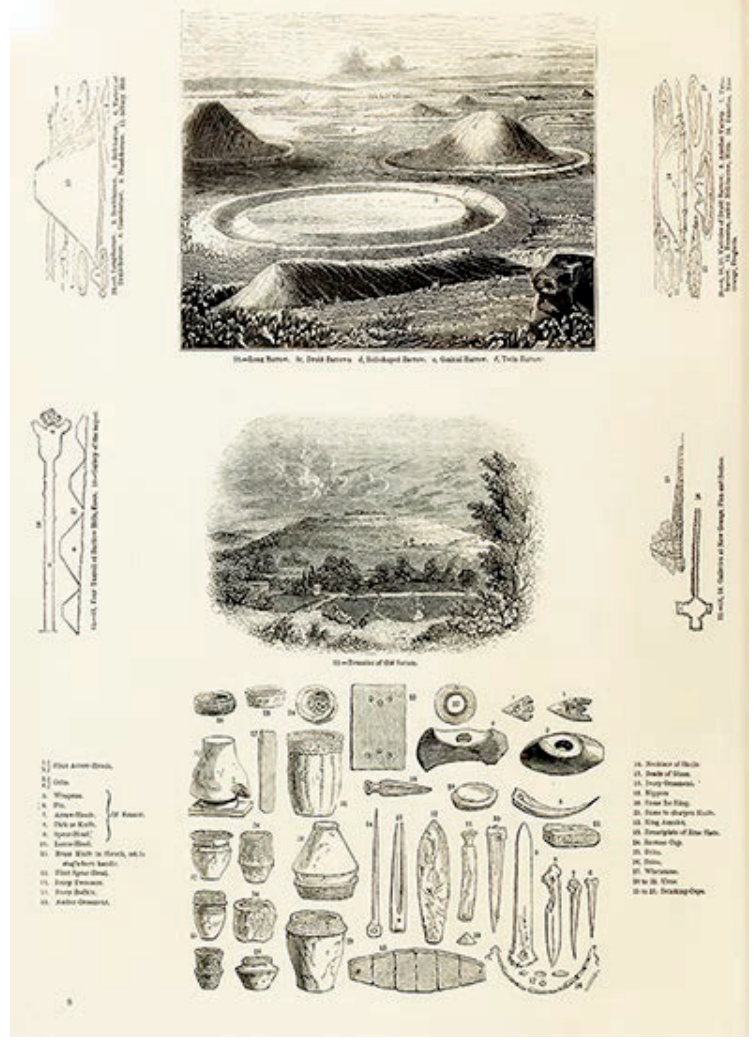

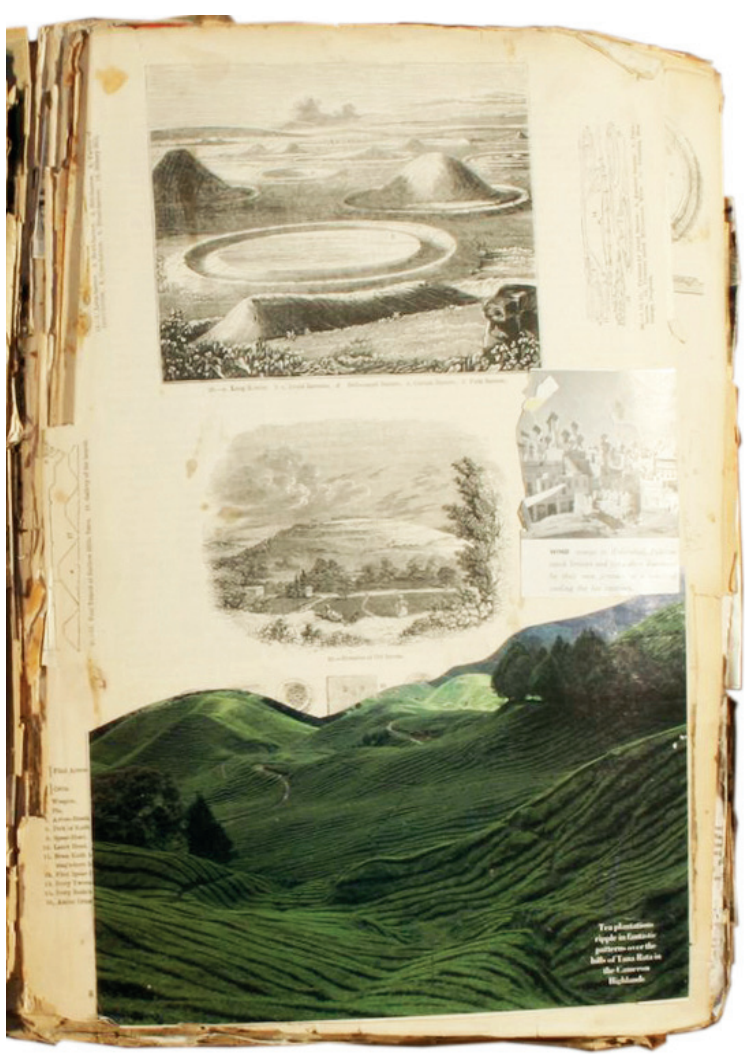

Transformación

Old England: a Pictorial Museum > The Big Scrapbook

Montaje del autor 
Alison Smithson confeccionó este scrapbook actuando como un bricoleur, ${ }^{78}$ obrando sin un plan previo, operando con fragmentos, seleccionando y recortando trozos de periódicos, revistas o postales e insertándolos entre las páginas del libro de Knight. La mayor parte de éstas aparece completamente cubiertas por las nuevas imágenes introducidas, aunque, en algunos casos, se observan ciertos dibujos originales del libro que quedaron a la vista, formando parte de una nueva composición. A primera vista, los recortes parecen haber sido insertados sin ningún orden preestablecido, ${ }^{79}$ superponiéndose azarosamente al contenido original del libro. Sin embargo, en un análisis más en detalle, reconocemos algunas posibles conexiones entre los fragmentos: analogías formales, relaciones históricas o de proximidad geográfica.

\section{Fragmentos del territorio}

Repartidos a lo largo de todo el scrapbook, hallamos imágenes de aquellos paisajes y arquitecturas vernáculas de Inglaterra que influenciaron su trabajo: ${ }^{80}$ earthworks prehistóricos, como Maiden Castle, Silbury Hill y Avebury Henge; vestigios romanos, como la Muralla Adriana y el asentamiento de Housesteads en Northumbria; estructuras de división del paisaje, como los muros primitivos de piedra de Yorkshire Dales; arquitecturas medievales en ruina, como Mount Grace Priory y la abadía de Rievaulx en North Yorkshire y los castillos de Warlworth, Richborough, Pevensey y Bodian Castle.

Además de estas referencias clave para la formación de su "pensamiento topográfico", el "libro de recortes" contiene un variado repertorio de imágenes de diversas intervenciones en el paisaje de Inglaterra, como canales de agua, carreteras, viaductos, puentes o líneas de ferrocarril, que reflejan el interés de los Smithson por la configuración artificial del territorio y el impacto de sus infraestructuras de gran escala. En este scrapbook, también están incluidas imágenes de paisajes pintorescos y pueblos tradicionales del norte de Inglaterra, que denotan el interés específico de los Smithson por la capacidad de sus construcciones vernáculas de integrarse respetuosamente

78. En la década de 1960, Levi-Strauss veía en los collages la idea del bricolage: "la boga intermitente de los collages, nacida en el momento en que el artesano expiraba, podría no ser, por su parte, más que una transposición del bricolage al terreno de los fines contemplativos". LEVI-STRAUSS, "El pensamiento Salvaje", Ed. Fondo de Cultura Económica Madrid 2002 (1962), Capítulo 1, La Ciencia de lo concreto, p.35, p.55. Acerca de la conexión entre las prácticas de montaje y el collage con el pensamiento de Lévi-Strauus véase en: PRADA, Manuel de, "El sentido del montaje y la técnica del collage". Cuaderno de Notas, no10. Ed. ETSAM, 2004; y del mismo autor en: Arte y Naturaleza. El sentido de la irregularidad en el arte y la arquitectura, p.86.

79. La intuición también será un aspecto que caracteriza la actividad del bricoleur de Lèvi -Strauss: una ciencia primera que se fundamenta en el hecho de sentir que ésto se relaciona con aquello, a pesar de la diferencia

80. Además de en este capítulo, estas imágenes aparecerán repartidas a lo largo de la tesis, demostrando el interés que estas referencias vernáculas suscitaron en los Smithson.

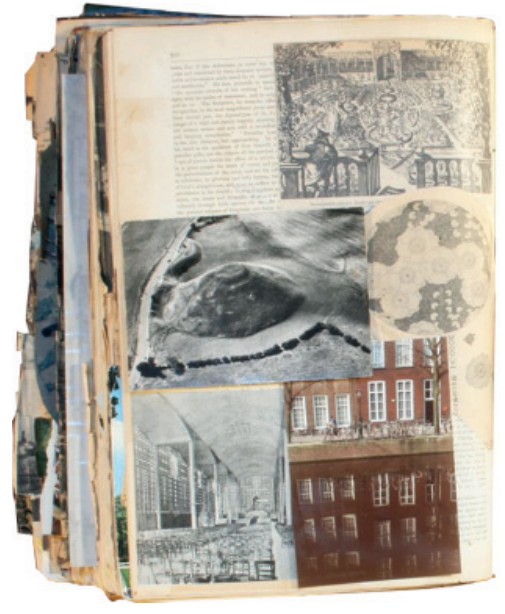

a

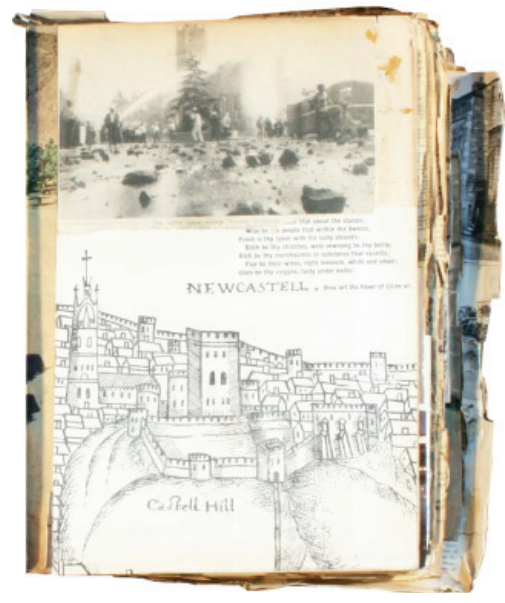

imagen izqda: Transformación de la página 6 del libro de Charles Knight mediante la introducción de 'recortes' de imágenes.

a. The Big Scrapbook. p. 315. En el centro de la página, se observa una fotografía aérea del earthwork de Silbury Hill, Wiltshire, Inglaterra. La página 8, contiene tres recortes de formaciones de tierra prehistóricas.

b. The Big Scrapbook. p. 309. Las referencias al territorio del norte de Inglaterra son constantes. En esta página, el recorte principal muestra el castillo de Newcastle. 

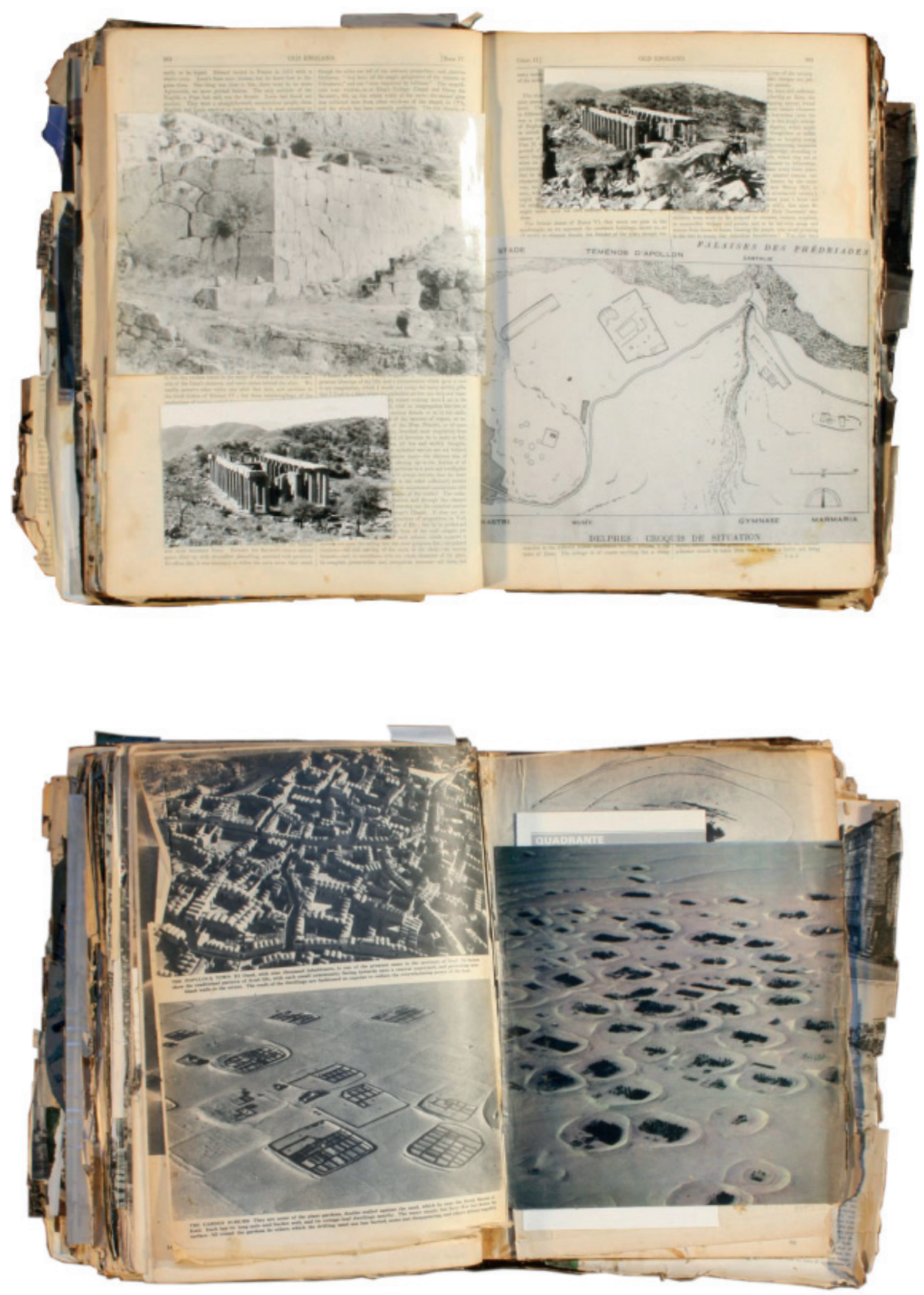

Grecia Clásica. The Big Scrapbook p.185

Kasbah y plantaciones en el desierto del Sahara The Big Scrapbook p.261 Smithson Family Collection 
en el paisaje. ${ }^{81}$ Los jardines y sus elementos naturales —árboles y formaciones de setos y arbustos- también aparecen como referencias comunes dentro de este scrapbook.

Junto a las imágenes del paisaje autóctono, encontramos fragmentos de imágenes de otros territorios fuera de las islas Británicas. Entre ellas, destacan las que muestran configuraciones del territorio llevadas a cabo mediante el modelado del terreno, como las que podemos apreciar en las fotografías aéreas de las plantaciones en el desierto del Sahara ${ }^{82} \mathrm{El}$ interés por los asentamientos primitivos y la configuración de estructuras de kasbash, se manifiesta a través de fotografías de poblados y construcciones arcaicas que nos recuerdan las imágenes publicadas por E. Gutkind a principios de la década de $1950 . .^{83}$ La influencia del mundo antiguo en los Smithson aparece igualmente representada en los numerosos "recortes" de emplazamientos y ruinas griegas y romanas, las cuales serían objeto de las exploraciones que llevaron a cabo por diferentes lugares del Mediterráneo.

\section{El orden oculto de los recortes}

La yuxtaposición genera la aparición de nuevas conexiones entre los fragmentos. Las imágenes insertadas en el libro aparecen liberadas de su significado y contexto original, quedando conectadas entre sí a través de un nuevo orden. Las leyes que relacionan los "recortes" son ajenas y arbitrarias: ${ }^{84}$ obedecen al azar o la intención personal de su autora, Alison Smithson. De entrada, desconocemos estas relaciones; permanecen escondidas tras los fragmentos y hemos de descubrirlas. Apoyándonos en algunas evidencias y el conocimiento de los intereses y obsesiones personales en los que se basaba el trabajo de los Smithson, trataremos de hacer explicar las conexiones de algunas de sus páginas, con el fin de esclarecer el orden que subyace en las páginas de The Big Scrapbook.

81.En The Big Scrapbook se reconoce un interés simultáneo por intervenciones de gran impacto en el territorio y los entornos rurales. Las infraestructuras de gran escala (puentes, viaductos, autopistas, vías férreas) y los paisajes bucólicos de los pueblos vernáculos del norte de Inglaterra actuaban, al mismo tiempo, como estímulos para sus proyectos. Acerca de "lo heroico y lo cotidiano", véase: BOYER, Christine. «Why do Architects Write? The case of Team 10 and Alison \& Peter Smithson». En Team10Keeping the Language of Modern Architecture Alive, editado por Dirk van den HEUVEL y Gijs de WAAL, 33-71. Delft: Faculty of Architecture TU, 2006.

82. Una de estas imágenes ("water holes") formaría parte de los paneles presentados por Alison y Peter Smithson en los X C.I.A.M de 1956.

83. GUTKIND, Erwin Anton. Our world from the Air. , op.cit.

84. "El coleccionista opera a la inversa del etnógrafo, re-agrupando los artefactos de una realidad cultural desmembrada y des-familiarizada de acuerdo con unas leyes nuevas, ajenas y arbitrarias. Cada objeto, al entrar a formar parte de una colección, es separado no sin violencia de su propio sistema, aquel en el que se ha producido y dentro del cual tiene un función. ROJO de Castro, Luis, "Ceci nést pas une pipe" Cuadernos de Proyectos Arquitectónicos, no 3.2012

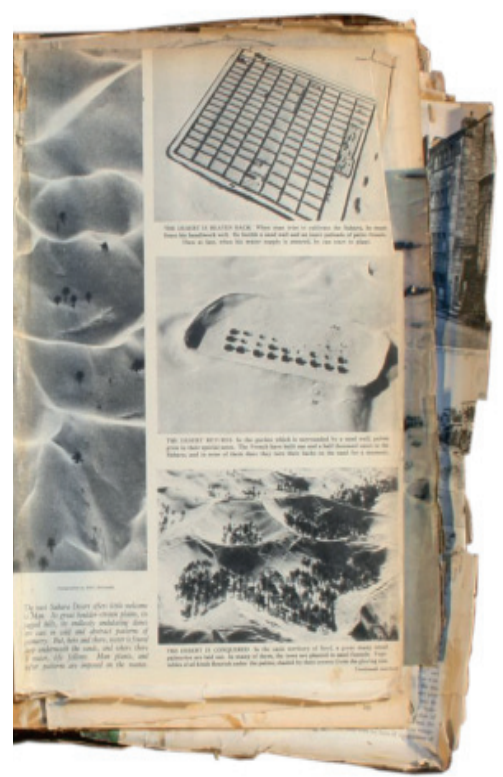

a

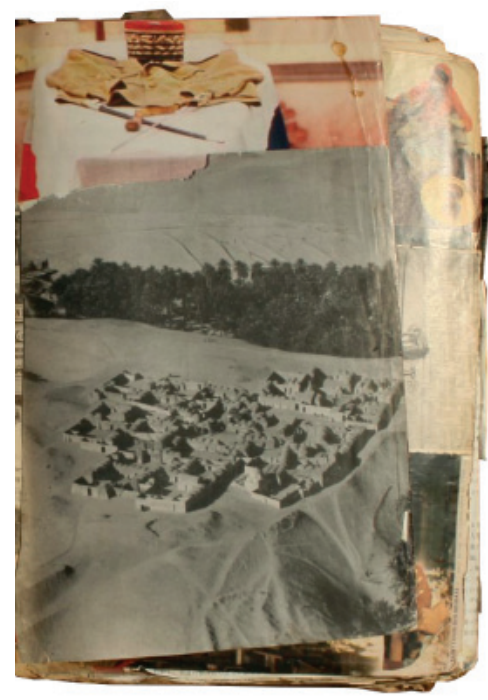

b

La imagen de la izquierda del "libro de recortes" (Grecia Clásica) se aprecian dos fotografías del Templo de Apolo Epicurio en Bassae, el podio del Templo de Apolo en Delfos; y un plano de implantación de este último.

a. The Big Scrapbook. p. 365. "Sahara from the air"

b. The Big Scrapbook. p. 16. Estructuras de clusters. 


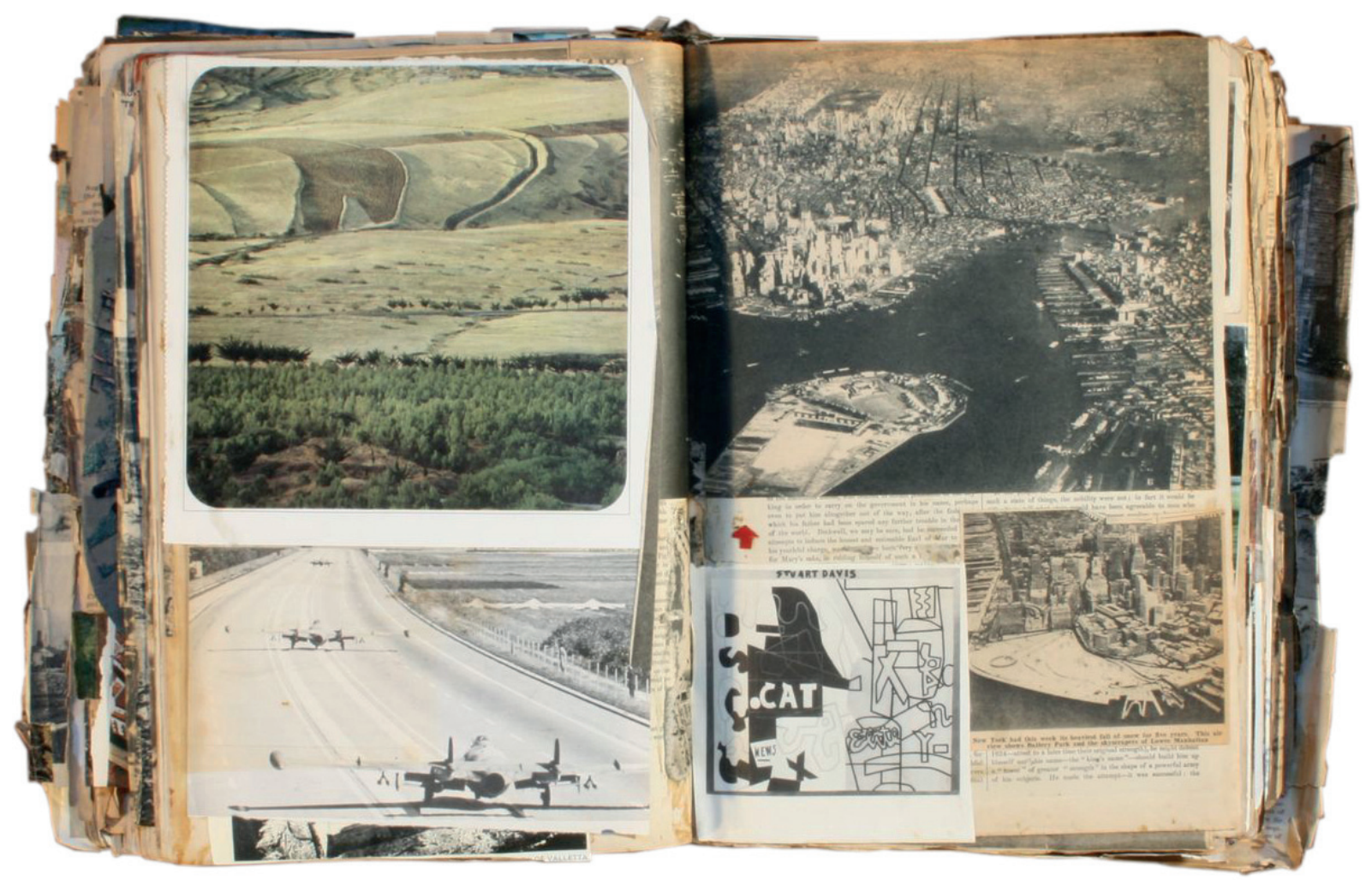

The Big Scrapbook p.261

Smithson Family Collection 
En ocasiones, los nexos entre los recortes parecen responder a analogías formales. Este sería el caso del pliego 261, en la que tres imágenes tan distantes, cultural y temporalmente, como la huella en el paisaje de un earthwork primitivo — probablemente Wansdyke-, la fotografía aérea de la ciudad de Manhattan y la imagen de una pista de aterrizaje se ponen en relación observadas desde un "enfoque topográfico", como incisiones, cortes y hendiduras lineales talladas sobre la superficie del territorio. En el ejemplo concreto de la imagen de las avenidas de Manhattan, éstas son interpretadas como surcos profundos excavados en la masa de rascacielos.

La forma también se muestra como el argumento principal que conecta dos de los "recortes" del pliego 135: la fotografía aérea de la plaza de San Pedro de Roma y el estampado impreso en la tela de un vestido. Las exedras semicirculares de Bernini entran en relación con el patrón del vestido, manifestando con ello la fascinación de los Smithson por este tipo de geometrías envolventes empleadas en varios de sus proyectos y que darían lugar a todo un personal catálogo de huellas dobladas y enroscadas. Esta sorprendente comparación refleja la "flexibilidad intelectual" de los Smithson, así como la amplitud del concepto as found, anteriormente comentado, el cual permite apreciar en lo más ordinario oportunidades con las que originar procesos creativos. ${ }^{85}$

En el pliego 123, aparecen yuxtapuestas una imagen vista al microscopio y la fotografía de un puente. La geometría de líneas diagonales que se aprecia en la primera, plantea un paralelismo formal con la estructura triangulada de la segunda: un juego de asociación surrealista que revela la enorme capacidad de los Smithson por interpretar la realidad de un modo absolutamente personal. El vínculo que se establece entre ambos "recortes" refleja el interés particular por los entramados y las cualidades espaciales de los estratos: un hecho que también explica las numerosas referencias que encontramos en el scrapbook a diferentes tipos de mallas, redes, celosías y entramados. ${ }^{86}$

Además de las analogías formales, detectamos otro tipo de conexiones basadas en conceptos recurrentes en el trabajo de estos arquitectos, como la "repetición". Las siguientes páginas del scrapbook muestran el interés acerca de cómo los elementos constituyentes de una colección mantienen su individualidad y autonomía dentro de un conjunto: un tema clave en su arquitectura que podremos también apreciar en las relaciones que los edificios establecen con el plano

85. La intención de poner en contacto estas dos imágenes tan dispares puede ser relacionada con la comparación que realizó Alison Smithson de las casas de los cuentos de Beatrix Potter, con las viviendas de Le Corbusier. SMITHSON, Alison. «Beatrix Potter's Places». Architectural Design, diciembre de 1967.

86. El interés por los entramados impulsaría intervenciones basadas en la superposición de estratos. SMITHSON, Peter. «The Lattice Idea». ILA\&UD Annual Report, Venecia, 2000.

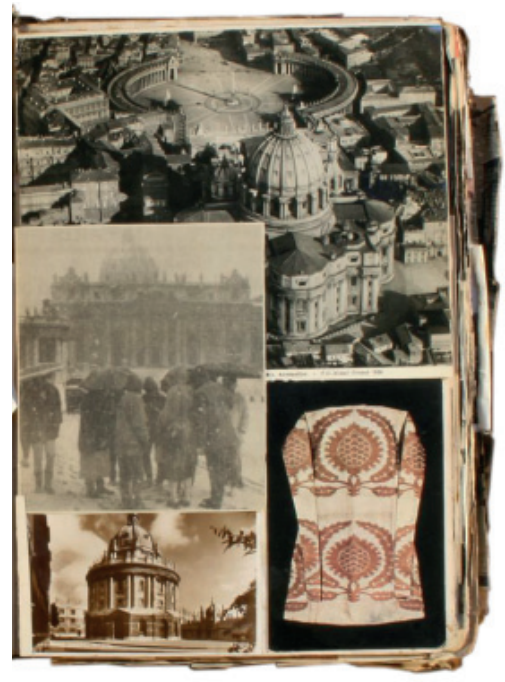

a

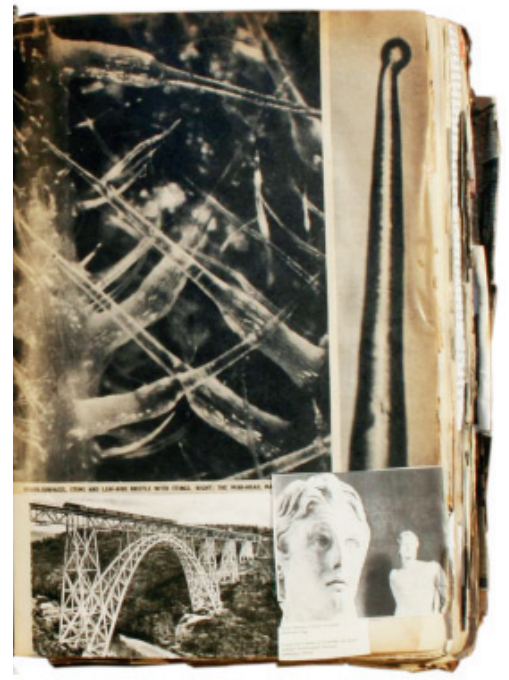

b

\footnotetext{
a. The Big Scrapbook. p. 135. Conexiones entre "geometrías envolventes".

b. The Big Scrapbook. p. 123. Relaciones entre "entramados".
} 


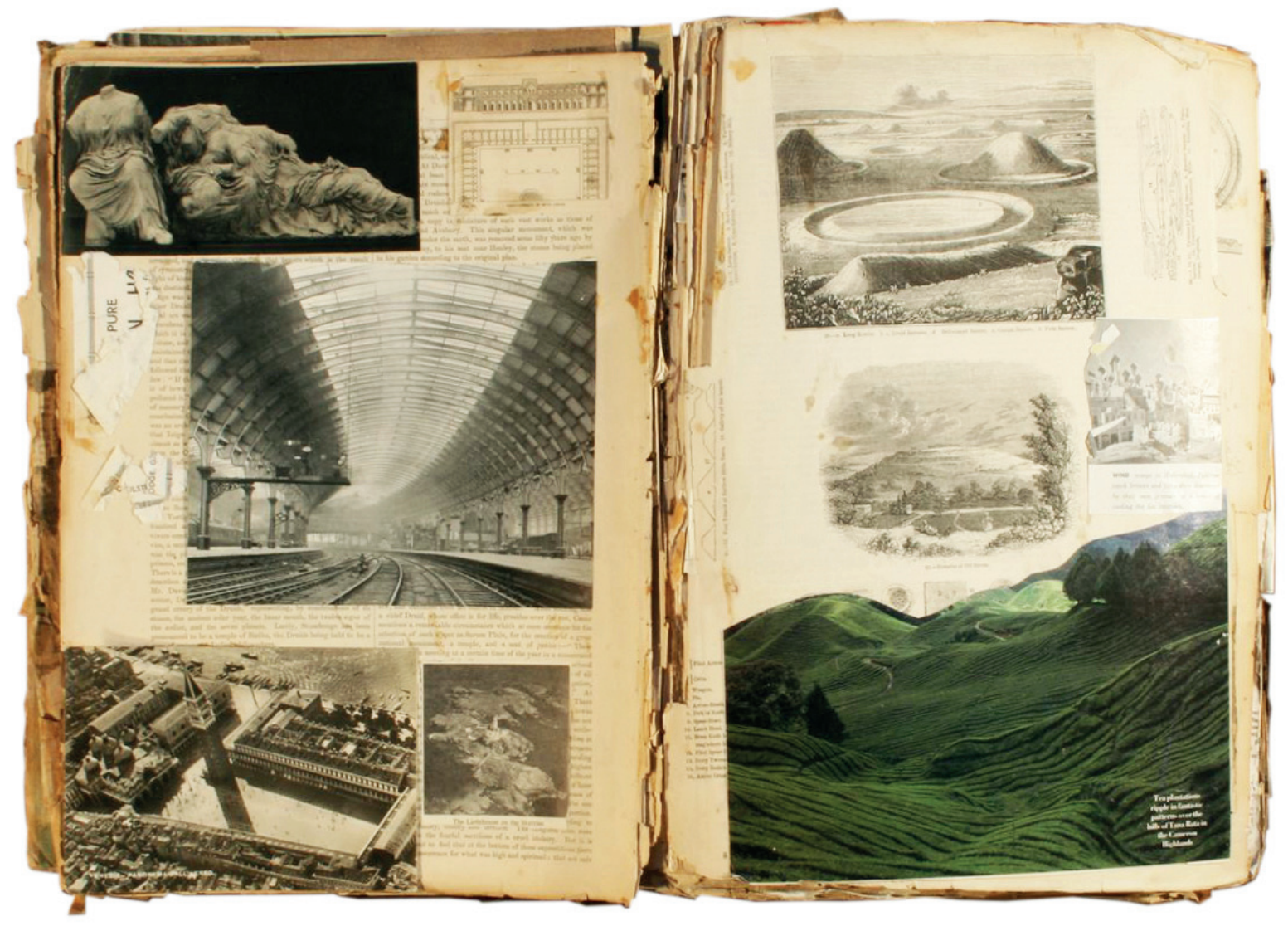

El orden oculto de los recortes

The Big Scrapbook p.20

Smithson Family Collection 
del suelo. ${ }^{87}$

Los "recortes" que componen el pliego $\mathbf{1 8 7}$ relaciona las estructuras abovedadas de las ghorfas de Túnez ${ }^{88}$ con otras imágenes de conjuntos familias de objetos y personas. El interés por la seriación también explicaría la conexión entre dos las imágenes de los field walls de los valles de Yorkshire Dales y aquella que muestra la serie formada por "osos de peluche" del pliego 70. La formación de patrones mediante la repetición de un mismo elemento tendría su reflejo en el pliego 378, en el que se observa la confrontación entre las fotografías de dos tipos de "enjambres" estáticos y adaptables" (una manada de patos y la dispersión de personas en una revuelta ${ }^{90}$ ) que aludirían a los patrones celulares o ramificados de los cluster iniciados por los Smithson en la década de 1950.

Las superposición "recortes" en las páginas de la enciclopedia de Knight genera conexiones múltiples entre éstos y los dibujos originales sin cubrir. En el pliego 6, formado por varios fragmentos, podríamos identificar las siguientes relaciones:

1.Entre los dibujos de las formaciones prehistóricas intencionadamente dejados a la vista por Alison Smithson (la colina de Silbury Hill y los túmulos) y la imagen del paisaje ondulado cubierto de vegetación se establecería una primera conexión a través de temas recurrentes, como la topografía y la configuración artificial del territorio.

2. El patrón de líneas curvas que forman las terrazas de ese paisaje natural se vincularía formalmente a los pliegues de las esculturas clásicas y a la estructura de arcos que forma la estación de Newcastle Central. Estos relieves (escultóricos, constructivos o topográficos) contienen implícita la idea de la repetición: un concepto que, como hemos visto anteriormente, está presente en un elevado número de recortes del scrapbook.

4. La inclusión de la imagen de la estación central de Newcastle alude a las raíces biográficas de los Smithson, al territorio del norte de Inglaterra de donde ambos provenían. Esta alusión consciente a lugares estrechamente vinculados a su vida personal también podemos reconocerla en los dibujos de las topografías prehistóricas ubicadas en el paisaje de Wiltshire donde habitaron Upper Lawn durante más de dos décadas.

87. "Preguntas acerca de cómo los elementos pueden mantener su propio carácter, cómo pueden desarrollarse en el tiempo y en el espacio de acuerdo a sus propias leyes, y cómo pueden al mismo tiempo formar parte de un todo mayor, contribuyendo a un sistema cooperativo más amplio sin verso comprometidos, se repite como un leitmotiv en toda la obra de Alison y Peter Smithson." HEUVEL Dirk van den, "Recogiendo, dando la vuelta y poniendo al lado de...", op. cit, 88. Esta fotografía fue tomada por los Smithson en su viaje a Tunez, en 1967.

89.VALLE, Daniel, "Enjambres. Sistemas seguros", en Fisuras de las Cultura Contemporánea, septiembre 200, pp 26-31.

90. Disturbios durante el fracasado alzamiento bolchevique, Petrogrado, julio de 1917.
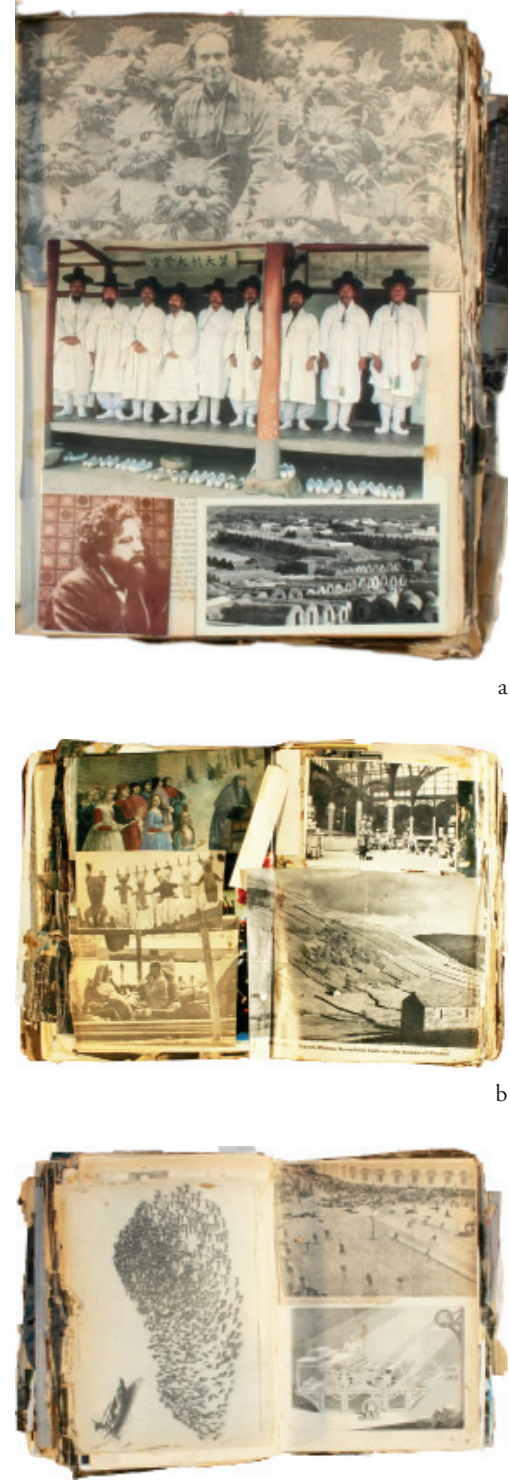

a. The BigScrapbook. p. 187. Conexiones de repetición.

b. The Big Scrapbook. p. 70. Seriación de elementos. En la parte derecha se muestra un recorte de fotografía de field walls de Yorkshire Dales.

c. The Big Scrapbook. p. 378. Formación de patrones. 


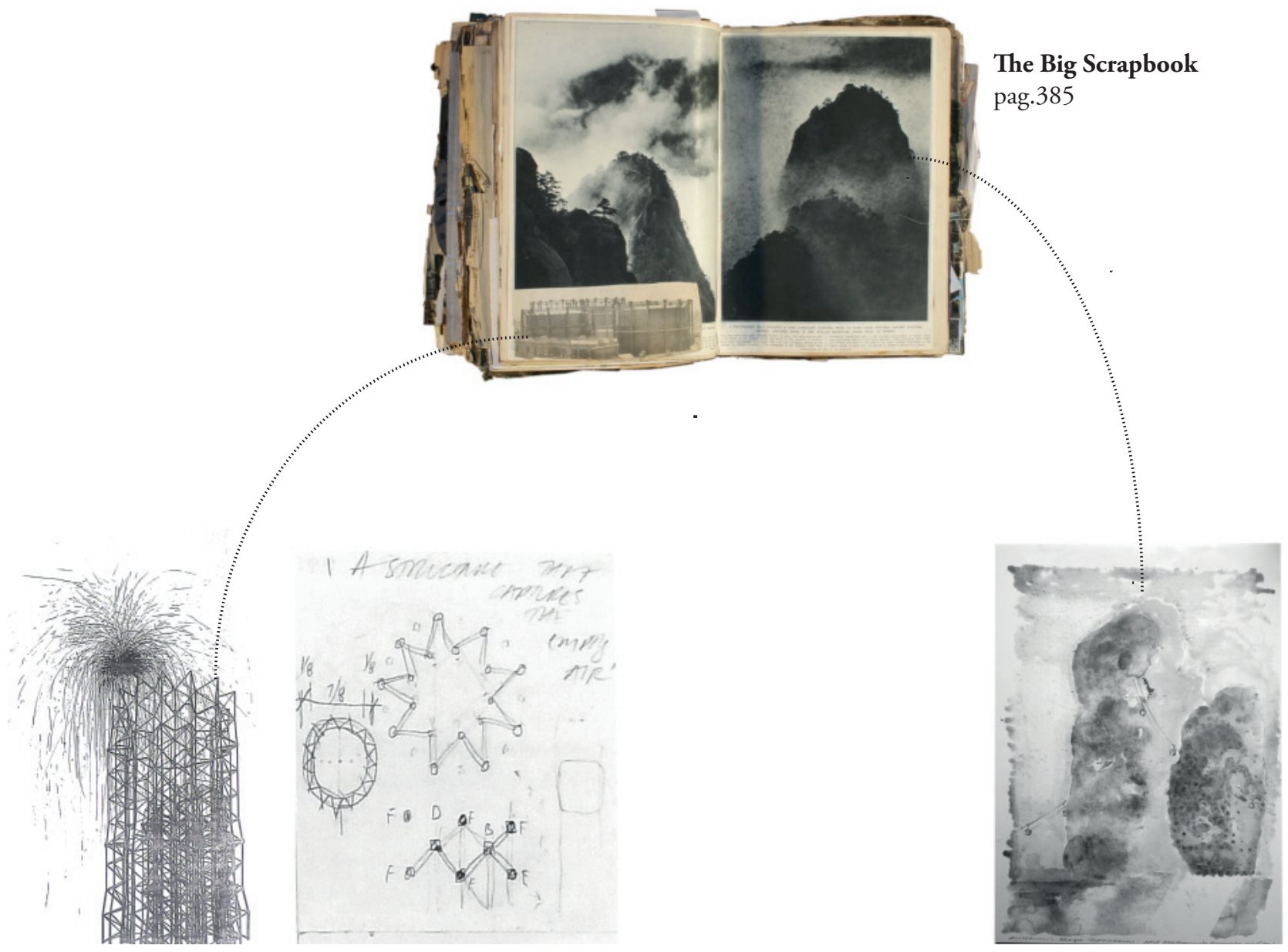

Imágenes yuxtapuestas

The Big Scrapbook p.385

Montaje del autor 
5. La idea de "enclave protegido"'11 se puede identificar en la imagen aérea de la Plaza de San Marcos de Venecia, así como en la planta en 'u' que aparece en la parte superior de esta página. El espacio envolvente que muestran estas imágenes también se reconoce en la huellas circulares de los earthworks, que generan contornos topográficos manipulando la sección del suelo.

Frente a esta acumulación de imágenes en una misma página, también encontramos la situación contraria. En el pliego 385, Alison Smithson introdujo tan solo tres imágenes: dos de ellas de gran tamaño, y la tercera, de menor dimensión, superpuesta a una de las anteriores en la parte inferior izquierda. Podemos interpretar esta yuxtaposición desde la relación el proyecto Melbourne Magic Mountains, ${ }^{92}$ una propuesta, realizada a finales de la década de 1970 que planteaba la creación de dos montańas artificiales. ${ }^{93}$ Para acometer el sistema estructural, Alison Smithson planteó la posibilidad de generar un esqueleto metálico de grandes dimensiones que posteriormente sería recubierto de vegetación. En los recortes introducidos en ese pliego del scrapbook, se reconocen las intenciones fundamentales del proyecto. Las acuarelas con las que Alison representó estas topografías son muy semejantes a las montículos que vemos en las dos imágenes que esta página; y la estructura tridimensional de soporte parece inspirarse en los depósitos metálicos que también observamos en otro de los "recortes". Este hecho, plantea la posibilidad de interpretar este documento como una posible herramienta proyectual que inicia procesos creativos y abre soluciones para los proyectos. ${ }^{94}$

\section{Imágenes yuxtapuestas}

The Big Scrapbook es un documento que alude a la personalidad de su creador. Los recortes que lo componen conforman una imagen articulada de fragmentos que construyen la identidad de los Smithson. Su descubrimiento constituye un hallazgo clave en esta investigación, no sólo por su intrínseco valor documental que aporta datos reveladores de los intereses y fuentes de inspiración de los Smithson, sino también, por la relación que establece esta técnica de montaje con los procesos de enraizamiento llevados a cabo mediante acciones de yuxtaposición.

En la arquitectura, la técnica del ensamblaje también adquiría un papel relevante, participando de un proceso consciente para encontrar

91.SMITHSON, Alison. Saint Jerome. The Desert-the Study. TECTA. Lauenförde, 1990.

92. Alison Smithson dice: "Melbourne's Magic Mountains are a kind of Henge, a continuation of a long tradition of ritual place of a great awe, capturing the empty air" The Charged Void, Urbanism, 307

93. Véase la explicación del proyecto en: VASSALLO, Javier. Las Montañas Mágicas de Melbourne. Un Paisajismo Emocional. Límite y Ocupación, Madrid: ETSAM/Mairea, 2010.

94. A pesar de la evidente conexión que establecen los recortes de esta página con el proyecto Melbourne Magic Mountains (1979-80), la posibilidad de interpretar The Big Scrapbook como un método proyectual será dificilmente demostrable en el resto del documento.
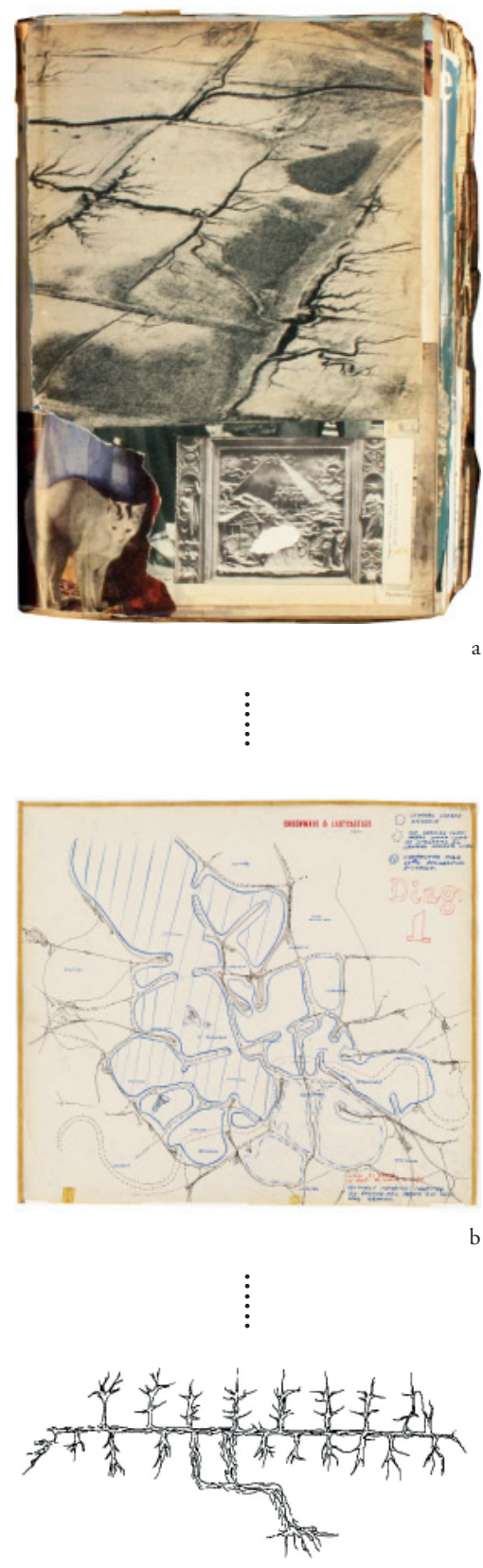

a. The Big Scrapbook. p. 244.

b. A\&PS. Greenways and Landcastles 1962: "New district formation suggested by existing rail system plus new road network' Greenways and Landcastles, London, 1962". Heuvel, Dirk van de, $A$ Brutalist Story, op.cit, p.386.

c. Bibliotheca Alexandrina. Ideogram of routes of readers on internal streets. Dibujo de Peter Smithson, 1989. 


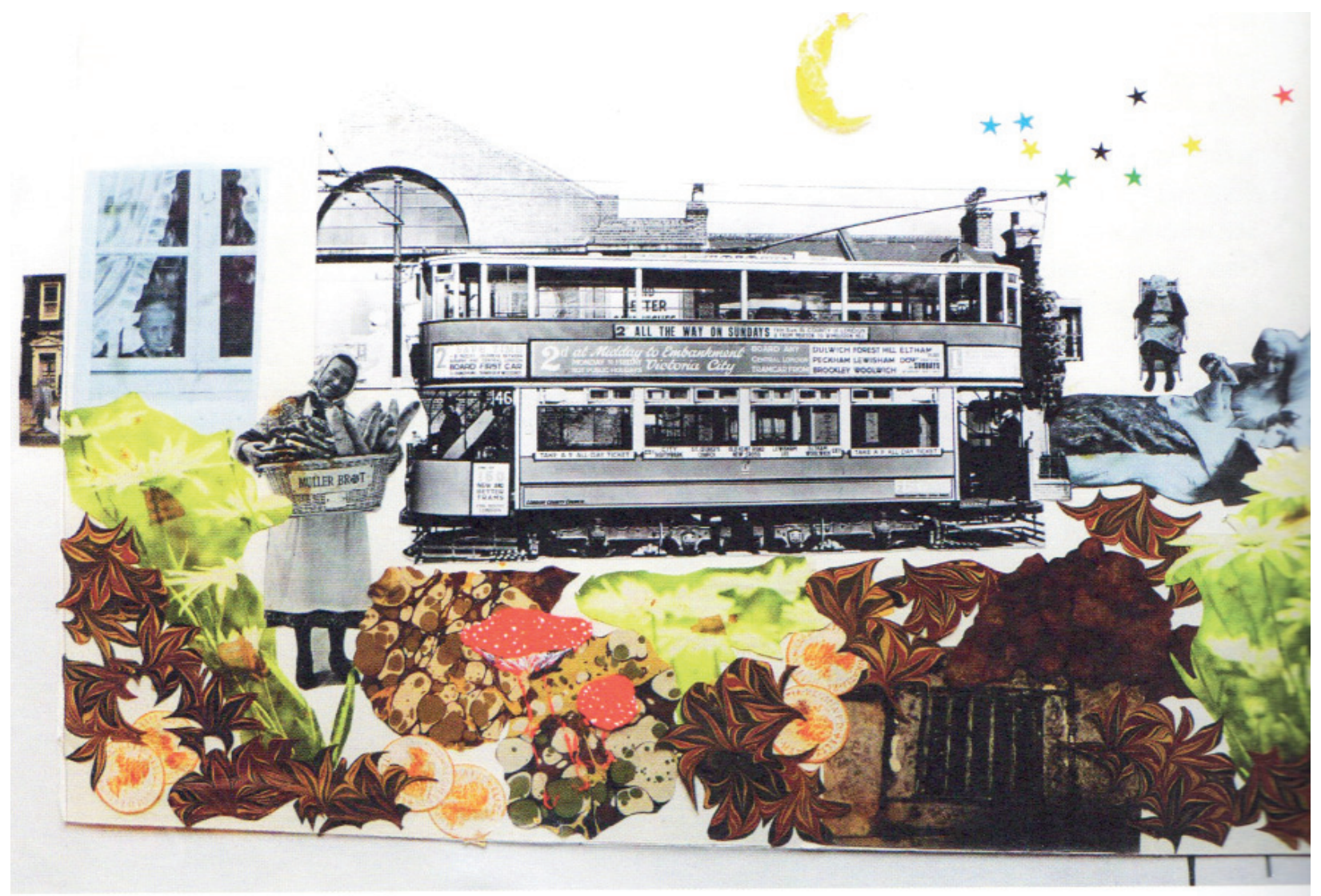

Alison Smithson's collages of Trams and Poppies

Smithson Family Collection

(Not Quite Architecture. C.Boyer) 
una arquitectura más impersonal, ${ }^{95}$ en la que, como sucedía en los collages y scrapbooks, el autor, más que un "artista", se mostraba como un "montador". ${ }^{6}$ En sus proyectos, los Smithson idearon ingeniosas combinaciones: yuxtaposiciones de diferentes elementos, sistemas, espacios o estratos que mantenían su propia individualidad dentro del orden superior del que formaban parte constituyente. ${ }^{97}$

El proyecto de la Casa Sugden contienen la esencia de estos procedimientos de montaje críticos con un orden establecido: ${ }^{98}$ la reunión en un mismo espacio de dos modelos aparentemente antagónicos - la tipología tradicional del hall inglésy la cocinaabierta americana - configura la planta baja dela vivienda. ${ }^{99} \mathrm{Y}$ en la Casa Bates, como explicaremos más adelante, la reconsideración creativa de una formación de tierra "encontrada" en el paisaje inglés -el earthwork de Castle Rising, en Norfolk- da lugar a una sorprendente yuxtaposición entre arquitectura y topografia.

David Dunster, señalaba que los proyectos de los Smithson poseían una particular lógica interna de configuración, donde las partes y el todo se encontraban íntimamente relacionadas, y al mismo tiempo, independientes, articulando entre ellas una fructífera conversación. ${ }^{100}$ Este singular 'orden' que dirigía las técnicas de montajes que produjeron también se está presente en las operaciones de yuxtaposición de sus estrategias de enraizamiento. En ellas, se puede apreciar la influencia del The Big Scrapbook: por un lado, observamos cómo, a modo de repertorio y repartidos a lo largo de todo este documento, se encuentran numerosos "recortes" de las referencias clave de las que se valieron los Smithson para producir sus ground-notations; por otro, reconocemos que la idea de recombinar y establecer nuevas relaciones entre fragmentos que origina esta práctica de montaje, también se encuentra latente y de manera análoga en las operaciones de yuxtaposición que permiten los procesos de enraizamiento de su arquitectura.

95. "Sólo un lenguaje arquitectónico vivo, fresco, altamente controlado y bastante impersonal puede profundizar en esa conexión básica [con sus habitantes]. SMITHSON, Alison and Peter. Cambiando el arte de habitar. op.cit. p.139

96. ELVIRA, Juan. «La naturaleza específica de las técnicas de montaje: del collage a la copia». BAU, 2000.

97. Como veremos en el análisis de The Big Scrapbook, cada uno de los fragmentos que lo componen se inserta en el conjunto sin perder su propia identidad, formando parte de un nuevo orden que surge por las conexiones entre sus componentes.

98. Como puntualiza Dirk van den Heuvel, la aplicación de un enfoque as found en la arquitectura debe de ser entendido, no en el sentido directo de una arquitectura automática, o surrealista, sino como un procedimiento crítico llevado a cabo con el objeto de distanciarse del encorsetamiento formal de los códigos modernos con los que los Smithson y toda una generación de jóvenes arquitectos se enfrentaron en la década de 1950. HEUVEL, Dirk van den. «As Found: The Metamorphosis of the Everyday. On the Work of Nigel Henderson, Eduardo Paolozzi, and Alison and Peter Smithson (1953-1956)». OASE, 2002.

99. HEUVEL Dirk van den, "Recogiendo, dando la vuelta y poniendo al lado de...", op. cit, p.29. 100.DUNSTER, David, Foreword, en: Alison and Peter Smithson. The Shift, Architectural Monographs, (David Dunster ed.), Vol. nr. 7. London: Academy Editions, 1982.
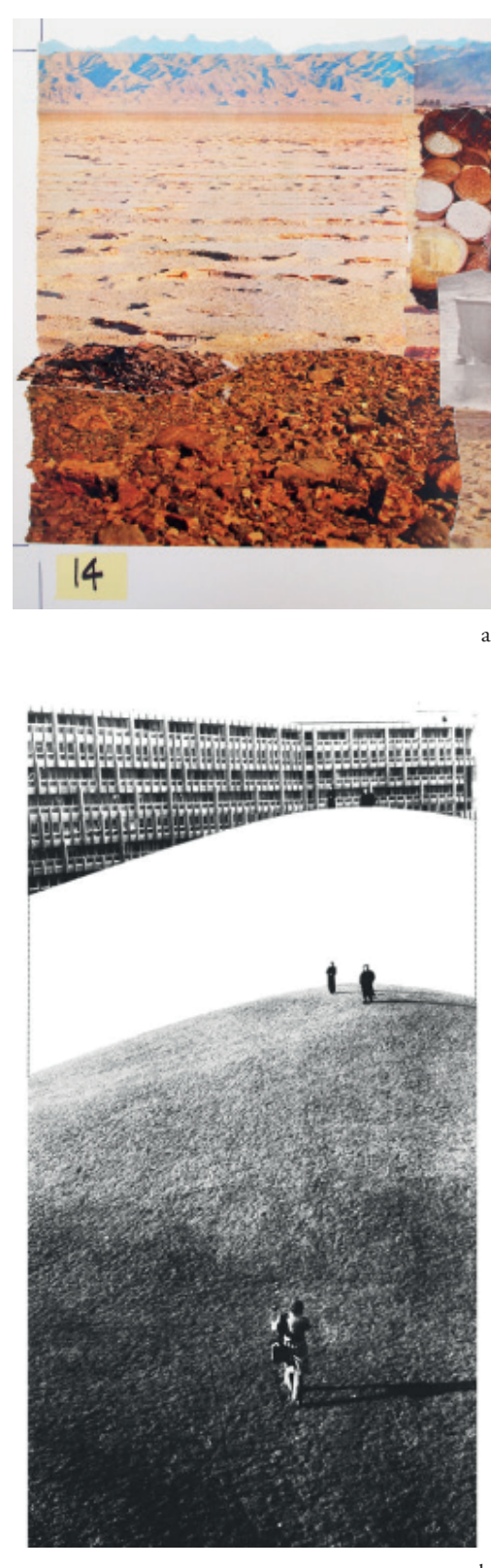

a. Collage de texturas de suelos .Alison Smithson . Smithson Family Collection.

b. Estrategias de enraizamiento mediante ground-notations. Montaje del autor. 


\section{Apropiaciones}

La interiorización del paisaje autóctono 